UNIVERSIDADE DE SÃO PAULO

INSTITUTO DE QUÍMICA

Programa de Pós-Graduação em Química

MÁRCIA DE MATHIAS RIZZO

\title{
CARACTERIZAÇÃo FÍSICO-QUÍMICA DE MATERIAIS DE ESCULTURAS DE CERA DO MUSEU ALPINO
}

Dissertação de Mestrado

Orientador: Prof. Dr. Jivaldo do Rosário Matos

São Paulo

Data do Depósito do Trabalho na SPG: 15/02/2008

Data do Depósito: quinze de fevereiro de dois mil e oito 


\section{MÁRCIA DE MATHIAS RIZZO}

\section{Caracterização físico-química de materiais de esculturas de cera do Museu Alpino}

Dissertação apresentada ao Instituto de Química da Universidade de São Paulo para obtenção do Título de Mestre em Química (Físico-Química) 
Márcia de Mathias Rizzo

Caracterização físico-química de materiais de esculturas de cera do Museu Alpino.

Dissertação apresentada ao Instituto de Química da Universidade de São Paulo para obtenção do Título de Mestre em Química (Físico-Química)

Aprovado em:

\section{Banca Examinadora}

Prof. Dr.

Instituição:

Assinatura:

Prof. Dr.

Instituição:

Assinatura:

Prof. Dr.

Instituição:

Assinatura: 
À minha família:

pais,

filhas,

irmãos e

companheiro. 


\section{AGRADECIMENTOS}

Agradeço à todas as pessoas que colaboraram direta ou indiretamente na realização desta pesquisa e dissertação de mestrado.

Agradeço em primeiro lugar aos meus pais, Sérgio e Linda, por toda a trajetória até aqui. Pela educação, formação, e, pelo apoio e incentivo constantes.

Às minhas queridas filhas, Gabriela e Rafaela pelo apoio incondicional, incentivo, ajuda, suporte, companhia em tantas horas de estudo e trabalho, e, principalmente pela compreensão com tantas ausências.

À Prof. Dr ${ }^{\text {a. }}$ Luci Diva Brocardo Machado pela enorme sensibilidade e interesse no andamento da pesquisa e por proporcionar o encontro com o Prof. Dr. Jivaldo do Rosário Matos, viabilizando assim a continuidade do trabalho.

Agradeço imensamente ao professor Dr. Jivaldo do Rosário Matos, por me acolher e orientar na realização deste trabalho, viabilizando-o. Agradeço por sua amizade, generosidade, paciência, disponibilidade e principalmente pelo seu exemplo.

Ao Prof. Dr. João Pedro Simon Farah pelo início deste trabalho e por todas as discussões interessantes sobre química.

À Prof ${ }^{\mathrm{a}}$. Dra ${ }^{\mathrm{a}}$. Lucildes Pita Mercuri pelo apoio e entusiasmo contagiante.

Ao Técnico de Laboratório Renato Vieira do Nascimento Junior por me ajudar na realização das medidas de termogravimetria e a todos os colegas do LATIG pelo companheirismo e amizade.

Ao Prof. Dr. Hernan Chaimovich Guralnik enquanto diretor do IQ/USP e à Prof. Dra ${ }^{\mathrm{a}}$. Maria Julia Manso Alves enquanto presidente da comissão de pós-graduação do IQ/USP por todo o empenho para sanar qualquer empecilho ou dificuldade burocrática que viesse a dificultar o bom andamento da pesquisa

Ao Prof. Dr. Paulo Roberto Pascholatti pela gentileza em se colocar à disposição no sentido de orientar na resolução das dificuldades burocráticas.

À secretária de pós-graduação Sra.Cibele Rosani Carlos e à toda a equipe da secretaria de pós-graduação por terem sempre me orientado da melhor forma possível em todos os procedimentos burocráticos.

Aos professores doutores Marcia Rizzutto e Nemitala Aded pela enorme gentileza na realização das medidas de PIXE no LAMFI (IF-USP), que darão continuidade a este trabalho, ao Prof. Dr. Manfredo Tabatinicks chefe do laboratório e a toda equipe do LAMFI.

À Dr $^{\text {a. }}$ Roseli Guennari do LACIFID (IF-USP) pela disponibilidade de medidas no IR. 
Ao Prof. Dr. Gustavo Micke e à doutoranda Ana Carolina de Oliveira Costa pelas análises realizadas na UFSC e pelos preciosos comentários e sugestões a respeito do trabalho.

Ao Prof. Dr. Maurício Batista por todas as discussões, comentários e sugestões fundamentais para a realização deste trabalho.

Ao Prof. Dr. Michel Loos por estar sempre disposto a esclarecer minhas dúvidas sobre física e química, e, por todas as discussões sobre o assunto.

Ao conservador Toby Raphael pelo envio de textos raros (esgotados) sobre cera.

Ao Dr. João Paulo Tardivo pelas fotografias das esculturas com endoscópio.

Ao Dr. Alberto Sabelian por me receber em seu consultório e pela generosidade com que compartilhou seus conhecimentos.

Ao Sr. Marco Miletic, proprietário do Museu de Cera Alpino, por emprestar as obras para a realização deste trabalho, contribuindo desta forma, com a pesquisa e conhecimento no universo de conservação e restauração dos bens culturais.

À Sra. Marilda Nakayama por intermediar a comunicação com Sr. Marco Miletic e por nos receber tão gentilmente no Museu de Cera Alpino.

Ao Prof. Armando Espinosa (in memorian) por ter contribuído de forma tão marcante na minha formação.

E finalmente ao Nestor, meu marido, amigo e companheiro de todas as horas que tanto ajudou neste trabalho.

Obrigada a todos! 


\section{SUMÁRIO}

PÁG.

RESUMO

ABSTRACT

ii

LISTA DE FIGURAS iii

LISTA DE TABELAS viii

LISTA DE ABREVIATURAS, SIGLAS E SÍMBOLOS ix

1. INTRODUÇÃO E OBJETIVOS 1

2. CONSIDERAÇõeS GERAIS 4

2.1. DEFINIÇÃO DE PATRIMÔNIO CULTURAL $\quad$.............................. 4

2.2. NATUREZA DO PATRIMÔNIO CULTURAL MATERIAL $\quad$....................... 4

2.3. DETERIORAÇÃO DO PATRIMÔNIO CULTURAL MATERIAL $\quad$................. 5

2.4. IMPORTÂNCIA DA PRESERVAÇÃO DO PATRIMÔNIO CULTURAL $\quad$ I............ 7

2.5. ESCULTURAS DE CERA $\quad$..................................................... 8

2.6. BREVE HISTÓRIA DOS MODELOS ANATÔMICOS DE CERA

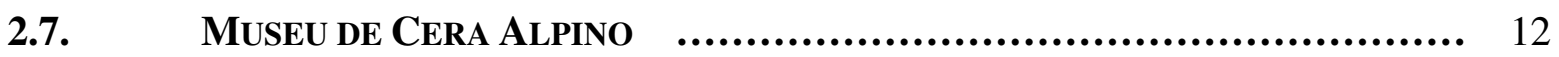

2.8. TÉCNICA DE CONFECÇão dAS PERSONAgens de CERA DOS MUSEUS "MADAME TuSSAUd" E "AlPinO" ..................................... 13

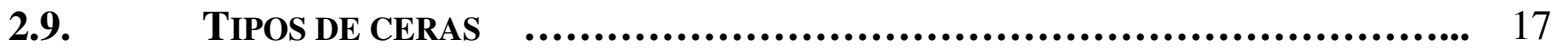

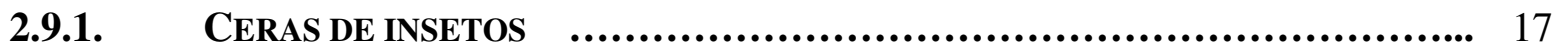

2.9.1.1. ClaSSIFICAÇÃO E ORGANIZAÇÃo SOCIAL DOS INSETOS PRODUTORES DE CERAS $\quad$.............................................................................. 17

2.9.1.2. CERA DE ABELHAS $\quad$...................................................... 17

2.9.1.2.1. SECREÇÃo dA CERA PELAS ABELHAS $\quad$................................... 18

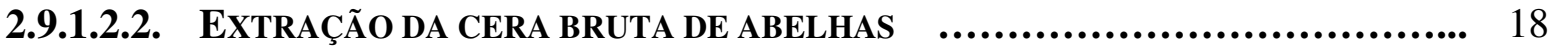

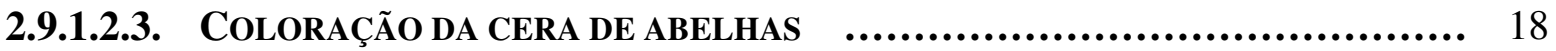

2.9.1.2.4. CllarifiCAÇÃO da CERA dE ABElHAS $\quad$................................. 18

2.9.1.2.5. COMPOSIÇÃO DA CERA DE ABELHAS $\quad$..................................... 19

2.9.2. CERAS DE PLANTAS $\quad$....................................................... 20

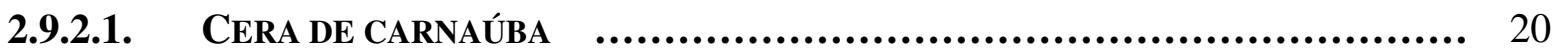


2.10.

RESINAS NATURAIS

2.10.1.

RESINA NATURAL DAMAR

2.11

TÉCNICAS ANALÍTICAS UTILIZADAS NESTE TRABALHO

2.11.1.

TÉCNICAS DE OBSERVAÇÃO E DOCUMENTAÇÃO

2.11.1.1.

OBSERVAÇÃO ORGANOLÉPTICA

2.11.1.2. FOTOGRAFIAS COM CÂMERA DIGITAL COM LUZ VISÍVEL

2.11.1.3. FOTOGRAFIAS COM CÂMERA DIGITAL COM RADIAÇÃO ULTRAVIOLETA (UV) 24

2.11.1.4. FOTOGRAFIAS SOB A LUPA BINOCULAR MICROSCÓPICA 25

2.11.2. ANÁLISES NÃo INVASIVAS OU NÃO DESTRUTIVAS DE SUPERFíCIE

2.11.2.1. MICROSCOPIA ELETRÔNICA DE VARREDURA COM ANALISADOR DE DISPERSÃO DE ENERGIA DE RAIOS X (MEV/EDS)

2.11.3. ANÁlISES COM RETIRADA DE AMOSTRAS (INVASIVAS OU DESTRUTIVAS $) \quad$................................................... 26

2.11.3.1. ESPECTROSCOPIA $\quad$ E............................................ 26

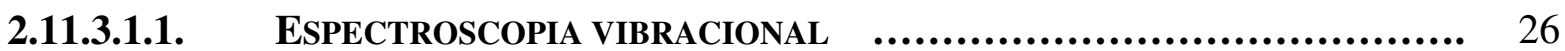

2.11.3.1.1.1. ESPECTROSCOPIA VIBRACIONAL DE ABSORÇÃo NO INFRAVERMELHO (IR )

2.11.3.1.1.2. ESPECTROSCOPIA DE INFRAVERMELHO POR TRANSFORMADA DE FOURIER $($ FTIR) $\quad$.............................................. 27

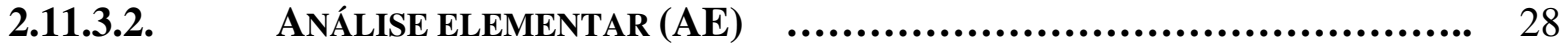

2.11.3.3. ANÁLISE TÉRMICA (TA) $\quad$........................................ 29

2.11.3.3.1. TERMOGRAVIMETRIA (TG) $\quad$..................................... 30

2.11.3.3.1.1. TERMOGRAVIMETRIA DERIVADA (DTG) $\quad$.......................... 31

2.11.3.3.2. CALORIMETRIA EXPLORATÓRIA DIFERENCIAL (DSC) ............... 32

3. MATERIAIS E MÉTODOS $\quad$.............................................. 33

3.1. MATERIAIS $\quad$..................................................... 33

3.1.1. MATÉRIAS PRIMAS $\quad$.............................................. 33

3.1.2. AMOSTRAS RETIRADAS DE OBRAS DE ARTE $\quad$........................ 33

3.1.3. RESUMO DOS MATERIAIS $\quad$............................................ 39 
3.2.1. CARACTERIZAÇÃo Físico-QuímiCA E ANALÍtiCa DaS MATÉrias PRIMAS E DAS AMOSTRAS RETIRADAS DAS OBRAS DE ARTE $\quad \ldots . . . . . . . .44$

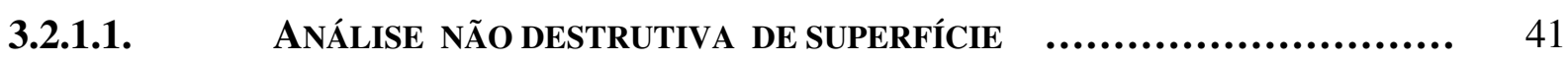

3.2.1.1.1. MICROSCOPIA ELETRÔNICA DE VARREDURA COM ANALISADOR DE DISPERSÃO DE ENERGIA DE RAIOS X (MEV/EDS) .................. 41

3.2.2. ANÁLISES COM RETIRADA DE AMOSTRA $\quad$........................... 42

3.2.2.1. ESTUDO TERMOANALÍTICO $\quad$...................................... 42

3.2.2.1.1 TERMOGRAVIMETRIA E TERMOGRAVIMETRIA DERIVADA (TG/DTG) 42

3.2.1.1.2. CALORIMETRIA EXPLORATÓRIA DIFERENCIAL ( DSC) _............... 43

3.2.2.2. ESPECTROSCOPIA DE ABSORÇÃO NA REGIÃO DO INFRAVERMELHO

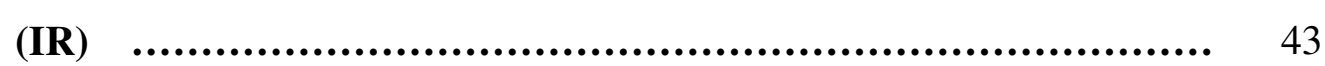

3.2.2.3. ANÁliSE ELEMENTAR (AE) $\quad$...................................... 43

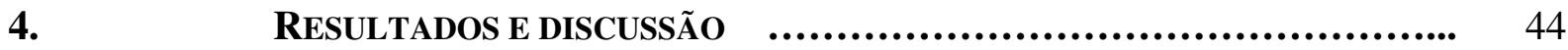

4.1. ASPECTOS GERAIS SOBRE AS AMOSTRAS $\quad$............................ 44

4.2. CARACTERIZAÇÃO DAS MATÉRIAIS PRIMAS $\quad$............................ 44

4.2.1. ANÁLISE TÉRMICA (TA) $\quad$....................................... 44

4.2.2. ESPECTROSCOPIA NO INFRAVERMELHO (IR) $\quad \ldots . . . . . . . . . . . . . . . . . . . .53$

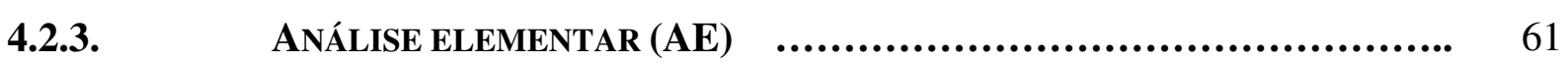

4.3. CARACTERIZAÇÃo daS AMOSTRAS RETIRAdAS DAS OBRAS DE ARTE 62

4.3.1. ANÁLISE TÉRMICA (TA) …........................................ 62

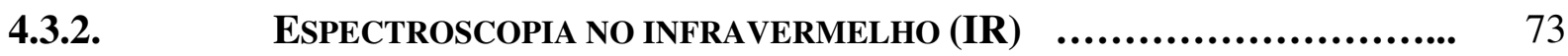

4.3.3. ANÁliSE ELEMENTAR (AE) $\quad$.................................... 91

4.3.4. MICROSCOPIA ELETRÔNICA DE VARREDURA COM ANALISADOR DE DISPERSÃO DE ENERGIA DE RAIOS X (MEV/EDS) ..................... 92

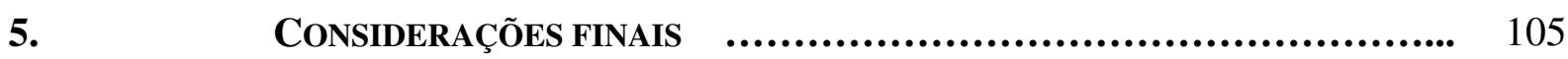

6. PERSPECTIVAS $\quad$.......................................................... 107

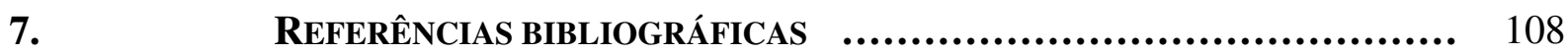


RESUMO

\section{Rizzo, M. M., Caracterização físico-química de materiais de esculturas de cera do Museu}

Alpino. 2008. 115p. Dissertação - Programa de Pós-Graduação em Química, Universidade de São Paulo, São Paulo.

As esculturas de cera do Museu Alpino, no Brasil, compostas por diversos materiais orgânicos e inorgânicos, apresentaram um tipo de degradação da superfície a qual foi investigada cientificamente através de metodologia diversificada baseada no uso de técnicas complementares, com cruzamento dos resultados. As matérias primas assim como os produtos de degradação foram caracterizadas físico-química e analiticamente. Foram empregadas as técnicas: análise térmica (termogravimetria, termogravimetria derivada e calorimetria exploratória diferencial); espectroscopia no infravermelho; análise elementar e microscopia eletrônica de varredura com analisador de dispersão de energia de raios X. A MEV/EDS foi utilizada para inspeção da micro morfologia da superfície e através dela foi possível identificar a presença de microorganismos que estavam causando a degradação físico-química pela forma como se fixaram na superfície através de suas hifas e por utilizarem os ácidos graxos presentes na cera como substrato metabólico. Os resultados de FTIR constataram a diminuição de ácidos graxos na superfície deteriorada em relação à superfície em bom estado. A TG/DTG e DSC permitiram avaliar o comportamento térmico das matérias primas e das amostras retiradas das obras de arte. Foi constatada a teoria da obra de arte como parte do ecossistema e a importância da utilização de políticas de preservação dos bens culturais por meio de ambientes controlados.

Palavras-chave: conservação, restauração, bens culturais, caracterização físico-química, degradação biológica. 


\begin{abstract}
Rizzo, M. M., Physical-chemical characterization of waxy sculptures materials from the Museum Alpino. 2008. 115p. Masters Thesis - Graduate Program in Chemistry, Universidade de São Paulo, São Paulo.
\end{abstract}

The waxy sculptures from Museum Alpino in Brazil, made of different organics and inorganics materials, presented a kind of surface degradation, which was scientifically investigated by multi-step methodology based on the use of complementary techniques with the interconnection of results. The raw materials as well as the degradation products were characterized physical-chemical and analytically. It was applied the following techniques: thermal analysis (thermogravimery, derivated thermogravimetry and differential scanning calorimetry); infrared spectroscopy; elemental analysis and scanning electronic microscopy with $\mathrm{X}$ ray energy dispersion system. The scanning electronic microscopy was used for the inspection of the micro morphology of the surface and after that it was possible to identify the presence of microorganisms which were causing the physical-chemical degradation analyzing the way they fixed their hyphae on the surface and the use of fat acids as metabolic substrate. Observing the FTIR results it was possible to notice the reduction of the fat acids on the deteriorated surface compared to the good surface. TG/DTG e DSC allowed to known the thermal behavior of the raw materials and the art works samples. It was possible to realize the theory of the work of art as part of the ecosystem and the importance of the cultural property's preservation policy by controlled ambient.

Key-words: conservation, restoration, cultural property, physical-chemical characterization, biological degradation. 


\section{LISTA DE FIGURAS}

PÁG.

Figura 1 Personagem Maria Bonita, antes de ser restaurada - Museu de Cera Alpino. As setas vermelhas indicam as áreas deterioradas.

Figura 2 Personagem Hermes da Fonseca, antes de ser restaurada - Museu de Cera Alpino. As setas vermelhas indicam as áreas deterioradas.

Figura 3 Personagem Maria Bonita, depois de ser restaurada - Museu de Cera Alpino.

Figura 4 Personagem Hermes da Fonseca, depois de ser restaurada - Museu de Cera Alpino.

Figura 5 Esquema representando a obra de arte como um ecossistema. Retirado do livro "Biology in the conservation of works of art" (CANEVA, NUGARI, SALVADORI, 1991).

Figura 6 Resquícios de um barco Viking do séc. IX em Oseberg - vista 1. .......... 9

Figura 7 Resquícios de um barco Viking do séc. IX em Oseberg - vista 2. $\quad$.......... 9

Figura 8 Molde de um coração em gesso.

Figura 9 Modelo de cera de um útero de mulher grávida com dilatação de colo.

Figura 10 Estudos para execução da escultura de cera "O Homem Esfolado". ..... 10

Figura 11 Escultura de cera “O Homem Esfolado" - séc. XVI. ............................. 10

Figura 12 Armação de metal que estrutura a escultura de argila de Liza Minnelli. 14

Figura 13 Escultura de argila da cantora Liza Minnelli. $\quad$........................................ 14

Figura 14 Escultura de cera sendo feita a partir do molde de gesso. $\quad$........................ 15

Figura 15 Acabamento colorido da cabeça de cera. ........................................... 15

Figura 16 Escultura de cera da cantora Liza Minnelli finalizada. $\quad$.......................... 16

Figura 17 Fluxograma ilustrativo das técnicas físico-químicas e analíticas utilizadas para caracterização de obras de arte. .................................... 23

Figura 18 Esquema de um espectrômetro de FTIR. .............................................. 27

Figura 19 Esquema do processo de determinação de carbono, hidrogênio e nitrogênio por análise elementar. ........................................................... 28

Figura 20 Esquema representativo de um analisador térmico atual. . ..................... 29

Figura 21 Cabeça quebrada da personagem Afonso Pena (AP). ........................... 34

Figura 22 Detalhe da superfície de um fragmento da cabeça de Afonso Pena (AP), mostrando a cera deteriorada (parte branca) e a cera em bom estado 
(parte mais escura). Vista frontal.

Figura 23 Detalhe da parte interna de um fragmento da cabeça Afonso Pena (AP), mostrando a cera mais dura usada no interior da cabeça. Vista posterior.

Figura 24 Detalhe da secção transversal de um fragmento da cabeça Afonso Pena (AP), mostrando as três camadas: superfície, miolo e interior. Vista lateral.

Figura 25 Detalhe da superfície de um fragmento da cabeça Afonso Pena (AP), mostrando a cera deteriorada (parte branca) e a cera em bom estado (parte colorida mais escura). Vista frontal.

Figura 26 Detalhe da parte interna de um fragmento da cabeça Afonso Pena (AP), mostrando a cera mais dura usada no interior da cabeça. Vista posterior.

Figura 27 Detalhe da secção transversal de um fragmento da cabeça Afonso Pena (AP), mostrando as três camadas: superfície, miolo e interior. Vista lateral.

Figura 28 Vista frontal da cabeça da personagem Lampião (LP).

Figura 29 Vista frontal superior da cabeça da personagem Lampião (LP).

Figura 30 Vista lateral direita da cabeça da personagem Lampião (LP).

Figura 31 Vista lateral esquerda da personagem Lampião (LP). A seta vermelha indica o local da amostragem da cera em bom estado da superfície.

Figura 32 Detalhe da cera deteriorada da cabeça da personagem Lampião (LP).

Figura 33 Detalhe da cera deteriorada da cabeça da personagem Lampião (LP).

Figura 34 Cabeça da personagem Lampião (LP) depois de restaurada. ................ 38

Figura 35 Esquema de corte estratigráfico das esculturas de cera. $\quad$.......................... 40

Figura 36 Sobreposição das curvas TG/DTG e DSC da amostra CRBRAB. $\quad$.......... 45

Figura 37 Sobreposição das curvas TG/DTG e DSC da amostra CRCLAB. .......... 46

Figura 38 Sobreposição das curvas TG/DTG das amostras de ceras de abelhas: (linhas vermelhas) clarificada e (linhas pretas) bruta. $\quad$.......................... 47

Figura 39 Sobreposição das curvas DSC das amostras de ceras de abelhas: (linhas vermelhas) clarificada e (linhas pretas) bruta. ...................................... 47

Figura 40 Sobreposição das curvas TG/DTG e DSC da amostra CRCNT1. .......... 48

Figura 41 Sobreposição das curvas TG/DTG e DSC da amostra CRCNT3. .......... 49

Figura 42 Sobreposição das curvas TG/DTG e DSC da amostra CRCNT4. $\quad$.......... 50

Figura 43 Sobreposição das curvas TG/DTG das amostras de cera de carnaúba: T1, 
T3 e T4.

Figura 44 Sobreposição das curvas DSC das amostras de cera de carnaúba: T1, T3 e T4.

Figura 45 Sobreposição das curvas TG/DTG e DSC da amostra de RSDM.

Figura 48 Sobreposição dos espectros no infravermelho das amostras CRBRAB e CRClAb.

Figura 49 Espectro de absorção na região do infravermelho da amostra CRCNT1. 56

Figura 50 Espectro de absorção no infravermelho da amostra CRCNT3. 57

Figura 51 Espectro de absorção no infravermelho da amostra CRCNT4.

Figura 52 Sobreposição dos espectros no infravermelho das amostras CRCNT1, CRCNT3 e CRCNT4.

Figura 53 Espectro de absorção no infravermelho da amostra RsDM.

Figura 54 Sobreposição das curvas TG/DTG e DSC da amostra AP_CRBESP.

Figura 55 Sobreposição das curvas DSC das amostra de CRCNT1, CRBRAB, RsDM e AP_CRBESP.

Figura 56 Sobreposição das curvas TG/DTG e DSC da amostra AP_CRDT.

Figura 57 Sobreposição das curvas DSC das amostras AP_CRBESP e AP_CRDT (no detalhe tem-se a sobreposição das curvas TG entre 30 e $240^{\circ} \mathrm{C}$ ). $\quad \ldots . \quad 65$

Figura 58 Sobreposição das curvas TG/DTG e DSC da amostra AP_CRML. 66

Figura 59 Sobreposição das curvas TG/DTG e DSC da amostra AP_CRIT.

Figura 60 Sobreposição das curvas TG/DTG e DSC da amostra LP_CRBESP. . .... 68

Figura 61 Sobreposição das curvas TG/DTG e DSC da amostra LP_CRDT. ......... 69

Figura 62 Sobreposição das curvas DSC das amostras LP_CRBESP e LP_CRDT. 70

Figura 63 Sobreposição das curvas TG/DTG das amostras LP_CRBESP e

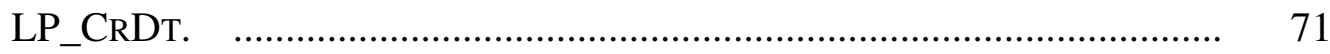

Figura 64 Sobreposição das curvas DSC das amostras AP_CRDT e LP_CRDT. $\quad \ldots \quad 72$

Figura 65 Espectro de absorção no infravermelho da amostra AP_CRBESP. $\quad$........ 73

Figura 66 Espectro de absorção no infravermelho da amostra AP_CRDT. $\quad$............ 74

Figura 67 Sobreposição dos espectros no infravermelho das amostras AP_CRBESP e AP_CRDT. ................................................... 75

Figura 68 Espectro de absorção no infravermelho da amostra AP_CRML. $\quad$........... 76 
Figura 69 Espectro de absorção no infravermelho da amostra AP_CRIT. $\quad$.............. 77

Figura 70 Espectro de absorção de infravermelho da amostra AP_CRDTRC. $\quad$....... 78

Figura 71 Sobreposição dos espectros no infravermelho das amostras AP_CRBESP, AP_CRML e AP_CRIT.

Figura 72 Sobreposição dos espectros no infravermelho das amostras AP_CRDT e AP_CRDTRC.

Figura 73 Espectro de absorção de infravermelho da amostra LP_CRBESP.

Figura 74 Espectro de absorção no infravermelho da amostra LP_CRDT.

Figura 75 Sobreposição dos espectros de absorção no infravermelho das amostras LP_CRBESP e LP_CRDT.

Figura 76 Espectro de absorção no infravermelho da amostra LP_CRML.

Figura 79 Sobreposição dos espectros de absorção no infravermelho das amostras LP_CRBESP, LP_CRML e LP_CRIT.

Figura 80 Sobreposição dos espectros no infravermelho das amostras LP_CRDT e LP_CRDTRC.

Figura 81 Sobreposição dos espectros no infravermelho das amostras AP_CRDT e LP_CRDT.

Figura 82 Fotografia com MEV/EDS da amostra AP_CRBESP, com aumento de 500 vezes.

Figura 83 Fotografia com MEV/EDS da amostra AP_CRBESP, com aumento de 2000 vezes.

Figura 84 Fotografia com MEV/EDS da amostra AP_CRBESP, com aumento de 2000 vezes, indicando uma região menor que engloba uma partícula chamada de região 1 .

Figura 85 Espectro de dispersão de energia de raios X da região ilustrada na Figura 84.

Figura 86 Detalhe ampliado do espectro de dispersão de energia de raios $\mathrm{X}$ da região ilustrado na Figura 85.

Figura 87 Espectro de dispersão de energia de raios $X$ da região 1 demarcada na Figura 84.

Figura 88 Detalhe ampliado do espectro de dispersão de energia de raios $\mathrm{X}$ da 
região 1 demarcada na Figura 84.

Figura 89 Fotografia com MEV/EDS da amostra AP_CRDT, com aumento de 2000 vezes.

Figura 90 Fotografia com MEV/EDS da amostra AP_CRML, com aumento de 500 vezes.

Figura 91 Fotografia com MEV/EDS da amostra AP_CRML, com aumento de 2000 vezes.

Figura 92 Fotografia com MEV/EDS da amostra AP_CRML, com aumento de .000 vezes.

Figura 93 Espectro de dispersão de energia de raios X da região ilustrada na Figura 92.

Figura 94 Fotografia com MEV/EDS da amostra AP_CRDT, com aumento de 2000 vezes, apontando as hifas e os esporos dos fungos.

Figura 95 Fotografia com MEV/EDS da amostra AP_CRDT, com aumento de 25000 vezes. Esporo.

Figura 96 Fotografia com MEV/EDS da amostra AP_CRDT, com aumento de 8000 vezes.

Figura 97 Fotografia com MEV/EDS da amostra AP_CRDT, com aumento de 60000 vezes. Esporo.

Figura 98 Espectro de dispersão de energia de raios X da região ilustrada na Figura 96.

Figura 99 Fotografia com MEV/EDS da amostra AP_CRDTRC, com aumento de 16000 vezes.

Figura 100 Fotografia com MEV/EDS da amostra AP_CRDTRC, com aumento de 8000 vezes.

Figura 101 Espectro de dispersão de energia de raios X da Figura 99.

Figura 102 Fotografia com MEV/EDS da amostra LP_CRDT, com aumento de 159 vezes. 


\section{LISTA DE TABELAS}

PÁG.

Tabela 1 Personagens do Museu de Cera Alpino.

Tabela 2 Composição média da cera de abelhas.

Tabela 3 Especificações físico-químicas e organolépticas da cera clarificada de abelhas.

Tabela 4 Especificações físico-químicas e organolépticas da cera de carnaúba tipo1.

Tabela 5 Cabeças de esculturas disponibilizadas pelo Museu de Cera Alpino. 33

Tabela 6 Relação do código, descrição e tipo das amostras analisadas.

Tabela 7 Resumo das técnicas empregadas no processo de caracterização das amostras de referência e das amostras retiradas de obras de arte.

Tabela $8 \quad$ Resultados de análise elementar das amostras das matérias primas. $\quad$.......... 61

Tabela $9 \quad$ Resultados de análise elementar das amostras retiradas de obras de arte. 91

Tabela 10 Porcentagem em massa dos elementos encontrados no espectro de área da Figura 85.

Tabela 11 Porcentagem em massa dos elementos encontrados no espectro de área da Figura 87.

Tabela 12 Porcentagem em massa dos elementos encontrados no espectro de área da partícula demarcada pela região vermelha na Figura 89.

Tabela 13 Porcentagem em massa dos elementos encontrados na região correspondente a Figura 92.

Tabela 14 Porcentagem em massa dos elementos encontrados na região correspondente a Figura 96.

Tabela 15 Porcentagem em massa dos elementos encontrados na região correspondente a Figura 99.

Tabela 16 Porcentagem em massa dos elementos encontrados na região 1 da Figura 102.

Tabela 17 Porcentagem em massa dos elementos encontrados na região 2 da Figura 102. 
LISTA DE ABREVIATURAS, SIGLAS E SÍMBOLOS

Personagens, AMOSTRAS E MATÉrias PRimas

AP - AFONSO PENA

LP - LAMPIÃO

$\mathrm{AB}-\mathrm{ABELHA}$

BE - BOM ESTADO

BR - BRUTA

CL-CLARIFICADA

CN-CARNAÚBA

$\mathrm{CR}-\mathrm{CERA}$

DM - DAMAR

DT - DETERIORADA

IT - INTERNA

ML - MIOLO

RC - RESTAURADA COM CALOR

RS - RESINA

SP - SUPERFÍCIE

T1 - TIPO 1

T2 - TIPO 2

T3 - TIPO 3

$\mathrm{T} 4-\mathrm{TIPO} 4$

\section{TÉCNICAS FÍSICO-QUíMICAS E ANALÍTICAS}

AE - ANALISE ELEMENTAR

GCMS - CROMATOGRAFIA GASOSA COM ESPECTROMETRIA DE MASSAS

DSC - CALORIMETRIA EXPLORATÓRIA DIFERENCIAL

DTG - TERMOGRAVIMETRIA DERIVADA

FTIR - INFRAVERMELHO COM TRANSFORAMADA DE FOURIER

IR - INFRAVERMELHO

MEV/EDS - MICROSCOPIA ELETRÔNICA DE VARREDURA COM ANALISADOR DE DISPERSÃO DE ENERGIA DE RAIOS $\mathrm{X}$

TA - ANÁLISE TÉRMICA 
TG - TERMOGRAVIMETRIA

UV - ULTRAVIOLETA

\section{INSTITUIÇÕES}

IF - INSTITUTO DE FÍSICA

IQ - INSTITUTO DE QUÍMICA

LACIFID - LABORATÓRIO DE CRISTAIS IÔNICOS, FILMES FINOS E DATAÇÃO

LAMFI - LABORATÓRIO DE MATERIAIS E FEIXES IÔNICOS

LATIG - LABORATÓRIO DE ANÁLISE TÉRMICA DR. IVO GIOLITO

UFSC - UNIVERSIDADE FEDERAL DE SANTA CATARINA

USP - UNIVERSIDADE DE SÃo PAULO

\section{ESPÉCIES QUÍMICAS}

Al - ALUMÍNIO

C - CARBONO

$\mathrm{C}_{5} \mathrm{H}_{4} \mathrm{~N}_{4} \mathrm{O}_{3}-$ URICITA

Ca-CÁLCIO

$\mathrm{Ca}\left(\mathrm{HCO}_{3}\right)_{2}-$ CARBONATO HIDROGENADO DE CÁlCIO

$\mathrm{Ca}\left(\mathrm{HSO}_{4}\right)_{2}-$ SULFATO HIDROGENADO DE CÁLCIO

$\mathrm{CaCO}_{3}-$ CARBONATO DE CÁlCIO

$\mathrm{CaSO}_{4}$ - SULFATO DE CÁLCIO

$\mathrm{CO}_{2}-$ DIÓXIDO DE CARBONO

$\mathrm{Fe}-$ FERRO

H - HIDROGÊNIO

$\mathrm{H}_{2} \mathrm{O}-$ ÁGUA

$\mathrm{H}_{2} \mathrm{~S}$ - SULFETO DE HIDROGÊNIO

$\mathrm{H}_{2} \mathrm{SO}_{4}$ - SULFATO DE HIDROGÊNIO (ÁCIDO SULFÚRICO)

$\mathrm{In}^{0}$ - ÍNDIO METÁLICO

K - POTÁSSIO

$\mathrm{KBr}$ - BROMETO DE POTÁSSIO

$\mathrm{Mg}$ - MAGNÉSIO

$\mathrm{N}$ - NITROGÊNIO 
$\mathrm{N}_{2}$ - NITROGÊNIO GASOSO

$\mathrm{Na}-$ SÓDIO

O - OXIGÊNIO

$\mathrm{O}_{2}$ - OXIGÊNIO GASOSO

$\mathrm{PbCO}_{3} \cdot \mathrm{Pb}(\mathrm{OH})_{2}-$ HIDROXI CARBONATO DE CHUMBO

$\mathrm{PbS}$ - SULFETO DE CHUMBO

$\mathrm{S}-$ ENXOFRE

$\mathrm{Si}$ - SILÍCIO

$\mathrm{SO}_{2}$ - DIÓXIDO DE ENXOFRE

$\mathrm{SO}_{3}-$ TRIÓXIDO DE ENXOFRE

Ti - TITÂNIO

$\mathrm{Zn}^{0}$ - ZINCO METÁLICO 


\section{INTRODUÇÃO E OBJETIVOS}

As obras de arte fazem parte do patrimônio cultural da humanidade e são constituídas por diversos tipos de materiais, dependendo da sua natureza: quadros, esculturas, etc. Estas estão sujeitas aos diferentes tipos de degradação: física, química e biológica.

Do ponto de vista físico-químico, elas próprias são complexos sistemas em cujas interfaces (internas e com o ar) ocorrem inúmeras reações químicas. As obras estão sujeitas às alterações do meio ambiente, como variações de umidade e temperatura, assim como à adsorção de poluentes sob sua superfície e, ainda, possíveis interações sólido-sólido entre as espécies que compõe a obra, além, é claro, de atos de vandalismo.

Do ponto de vista biológico, elas fazem parte do eco sistema e podem ser utilizadas como substrato por macro e microorganismos.

Existe um tipo de obra de arte a qual é chamada escultura de cera que reproduz, através de um molde, com uma mistura de ceras e resinas, corpos ou parte de corpos humanos. Este tipo de trabalho tem sido usado desde a antiguidade pela medicina, como um recurso com finalidade didática.

Desde o século XVIII esculturas de cera de personagens famosos da história da humanidade também começaram a ser feitas e exibidas em exposições itinerantes ou museus. O museu deste tipo mais conhecido é o Madame Tussaud, fundado pelos filhos da ceroplasta Marie Grosholtz em 1884, na Inglaterra.

No Brasil temos o Museu de Cera Alpino, em São Roque, São Paulo, que contém cinqüenta e quatro esculturas de personagens da história do Brasil. Neste museu, foi constatado certo tipo de degradação na superfície das esculturas de cera. Uma modificação na aparência da cera original, um tipo de alteração da consistência e cor, causando um efeito de flocos esbranquiçados (wax bloom), foi verificada em algumas partes do rosto como ilustram as Figuras 1 e 2 e em todo o couro cabeludo das peças. O procedimento utilizado para a reversão do processo foi a aplicação de calor local, sob a forma de ar quente no intervalo de temperatura de 60 à $65^{\circ} \mathrm{C}$ que recuperou a consistência e o aspecto original como pode ser visto nas Figuras 3 e 4. Foi levantada a hipótese de que a degradação ocorrida nas peças do Museu de Cera Alpino poderia ser devido ao ataque biológico e/ou quebra da emulsão.

O esbranquiçamento ao longo do tempo, ocorrendo principalmente nas regiões próximas a pêlos implantados em esculturas de cera, chamou a atenção de muitos pesquisadores e tem sido estudado de várias formas e por vários métodos. De um modo geral acredita-se que não haja degradação química da cera e dos pigmentos de acabamento. Bisson, já em 1940 
(CLYDESDALE, 1994), considerou que o efeito da temperatura pode alterar a plasticidade e "estrutura cristalina" de alguns componentes da cera de abelhas ocasionando o esbranquiçamento. Também são notórios os estudos de selos de documentos da realeza medieval inglesa (CASSAR et al., 1983) mostrando a grande estabilidade química e mesmo microbiológica da cera.

Sendo as ceras materiais complexos formados pela emulsão de muitos componentes, atribuiuse como causa deste fenômeno a "quebra" ou desestabilização desta emulsão ocasionada por migrações devido a gradientes de temperatura e/ou permeação de algum material do ambiente. Ainda os materiais usados na superfície das obras geralmente compõem-se de misturas de ceras, pigmentos, diversas cargas, etc., criando-se gradientes de concentração entre a superfície e o miolo, justificando estas migrações que ocasionariam o esbranquiçamento (CLYDESDALE, 1994). Entretanto não foram encontrados estudos na literatura que descrevam o processo de degradação com a caracterização físico-química e analítica do material gerado após degradação. Recentemente foram publicados alguns trabalhos referentes à caracterização das matérias primas envolvidas na confecção de esculturas de cera (REGERT et al., 2006).

No Brasil não há relatos de estudos desta natureza, também não foram encontrados estudos sobre biodeterioração de ceras em bens culturais. No livro "Biology in the conservation of works of art" (CANEVA, NUGARI, SALVADORI, 1991), é abordado o problema da madeira, papel, couro, têxteis e alguns aspectos sobre pinturas. Em vista disto, essa dissertação tem por objetivo investigar os processos de degradação na superfície das esculturas de cera, inseridas no nosso clima e sujeitas aos diversos tipos de degradação: física, química e biológica.

Foi também objetivo deste trabalho buscar a caracterização físico-química e analítica das matérias primas e de partes das esculturas em bom estado, deterioradas e restauradas. Foram empregadas as técnicas: análise térmica (termogravimetria, termogravimetria derivada e calorimetria exploratória diferencial); espectroscopia no infravermelho; análise elementar e microscopia eletrônica de varredura com analisador de dispersão de energia de raios X. 


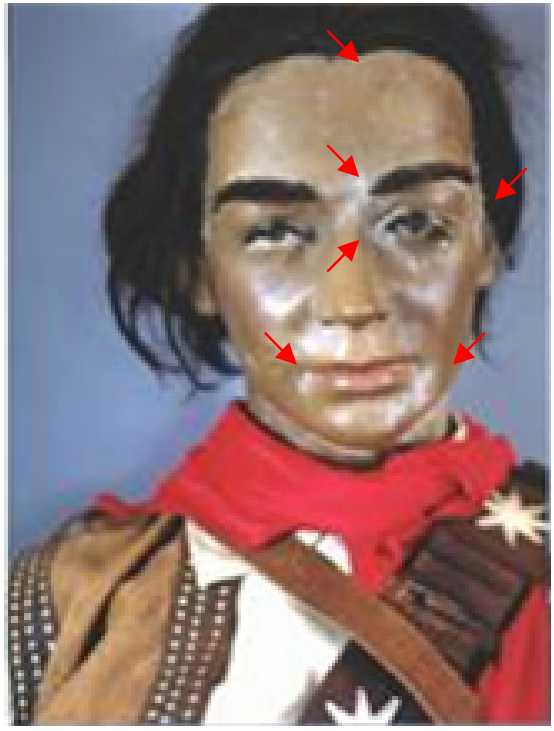

Figura 1 - Personagem Maria Bonita, antes de ser restaurada - Museu de Cera Alpino. As setas vermelhas indicam as áreas deterioradas.

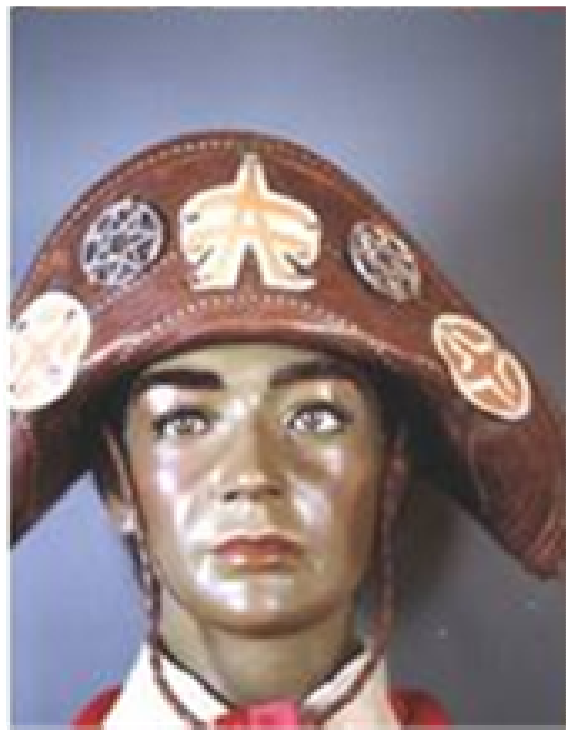

Figura 3 - Personagem Maria Bonita, depois de ser restaurada - Museu de Cera Alpino.

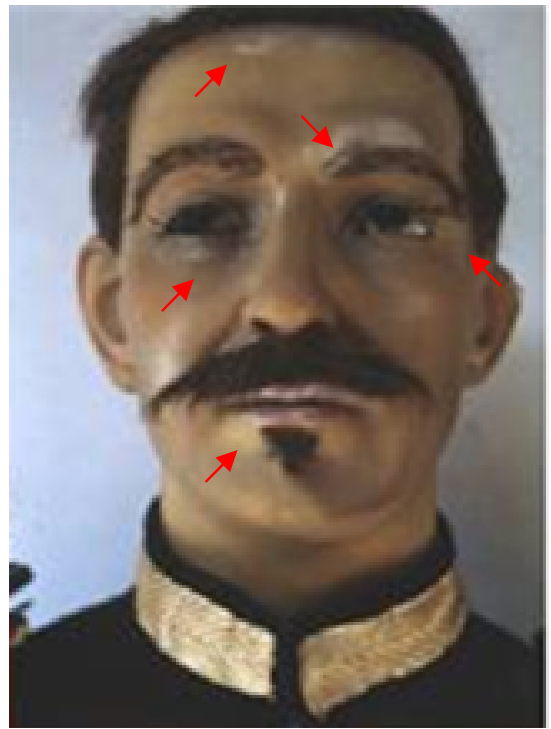

Figura 2 - Personagem Hermes da Fonseca, antes de ser restaurada Museu de Cera Alpino. As setas vermelhas indicam as áreas deterioradas.

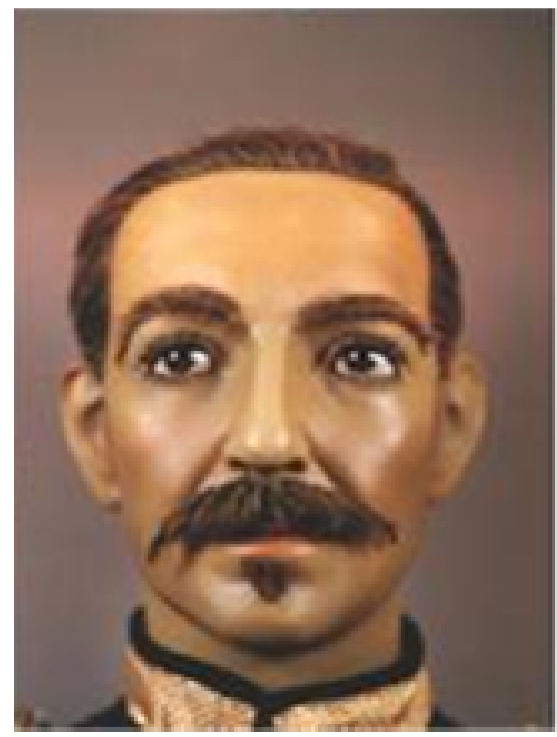

Figura 4 - Personagem Hermes da Fonseca, depois de ser restaurada Museu de Cera Alpino. 


\section{CONSIDERAÇões GERAIS}

Como este é um trabalho interdisciplinar e será lido por pessoas de diferentes áreas, o capítulo 2 tem a finalidade de apresentar dados e/ou informações adicionais com o intuito de enriquecer ou facilitar a leitura. Com o mesmo intuito o leitor encontrará algumas definições e/ou explicações entre parênteses ao lado de palavras ou termos específicos de áreas correlatas.

\subsection{DEFINIÇÃo DE PATRIMÔNIO CULTURAL}

Se definirmos "cultura" como tudo aquilo que o homem criou ou transformou, podemos chamar de "patrimônio cultural" o conjunto de todas as manifestações de expressões tangíveis e intangíveis do ser humano.

No âmbito das manifestações tangíveis temos o subconjunto representado pelo "patrimônio cultural material". Este nada mais é do que "matéria intencionalmente trabalhada" pelo homem (RIZZO, 2008).

\subsection{NATUREZA DO PATRIMÔNIO CULTURAL MATERIAL}

Como expressão material da atividade humana, os bens culturais podem ser de qualquer espécie. Desde que o homo habilis há cerca de dois milhões de anos atrás, começou a pegar elementos da natureza e trabalhá-los para conferir-lhes outra forma, como a pedra lascada, até os dias de hoje com a utilização de materiais sintéticos para fabricação de utensílios ou objetos de arte; todo e qualquer tipo de matéria intencionalmente trabalhada é considerado bem cultural material ou tangível. Fósseis e restos mortais de seres vivos também são documentos históricos e evidentemente devem ser conservados, mas não são considerados patrimônio cultural, pois não são produtos da transformação humana intencional.

Entretanto, durante a história da humanidade desde o homo habilis até os nossos dias, alguns materiais foram preferidos a outros em determinadas formas de expressão, períodos ou regiões geográficas. No universo da arte, por exemplo, as obras foram se modificando através dos tempos, tanto do ponto de vista material e tecnológico como do ponto de vista estético. A forma de expressão artística varia no tempo e no espaço e está subordinada à cultura, ao conhecimento, à tecnologia e aos materiais disponíveis na época (RIZZO, 2008). 


\subsection{DETERIORAÇÃO DO PATRIMÔNIO CULTURAL MATERIAL}

O patrimônio cultural material está sujeito às degradações físicas, químicas e biológicas. Os bens culturais são sensíveis às alterações do meio ambiente. Com as variações de umidade relativa e temperatura, a estrutura da obra pode dilatar e contrair, como por exemplo, no caso de uma pintura sobre madeira. As fibras da madeira absorvem e liberam a umidade do ar, movimentando-se e causando danos à camada pictórica, como craquelamento, descolamento do suporte e até perda (THOMSON, G., 1986).

A superfície da obra reage principalmente com o oxigênio do ar, mas também com outras substâncias presentes na atmosfera, como por exemplo, o sulfeto de hidrogênio. Numa pintura a óleo sobre tela feita antes do século XIX, o artista certamente utilizou "branco de chumbo" que é hidróxi carbonato de chumbo $\left(\mathrm{PbCO}_{3} \cdot \mathrm{Pb}(\mathrm{OH})_{2}\right)$, pois os outros brancos normalmente utilizados, branco de zinco (óxido de zinco) e de titânio (dióxido de titânio), só apareceram em 1834 e 1918, respectivamente. Se não estiver isolada do ar, com um verniz de proteção, a pintura que contiver este pigmento reagirá com o sulfeto de hidrogênio proveniente da decomposição de plantas e animais, resultando em sulfeto de chumbo, que apresenta uma cor cinza escuro, quase preto, modificando a obra (WEAVER, 1987). A Equação de Reação 1 ilustra a reação química que ocorre.

$$
\mathrm{PbCO}_{3} \cdot \mathrm{Pb}(\mathrm{OH})_{2}+2 \mathrm{H}_{2} \mathrm{~S} \rightarrow 2 \mathrm{PbS}+\mathrm{CO}_{2}+3 \mathrm{H}_{2} \mathrm{O}
$$

As obras que se encontram ao ar livre estão sujeitas às intempéries, à poluição e seus subprodutos. Por exemplo: o dióxido de enxofre liberado na queima dos combustíveis pelos carros e fábricas reage com o oxigênio do ar formando trióxido de enxofre (Equação de Reação 2), que por sua vez reage com a água da chuva originando a chuva ácida, que neste caso é ácido sulfúrico diluído (Equação de Reação 3). A chuva ácida ao cair sobre esculturas de mármore compostas basicamente por carbonato de cálcio, pode reagir parcialmente formando os hidrogenossais (Equação de Reação 4), que são solúveis, ou ainda pode transformar completamente o carbonato de cálcio em sulfato (Equação de Reação 5). O $\mathrm{CaSO}_{4}$ é parcialmente solúvel em água e é arrastado lentamente pela ação mecânica da própria chuva.

$$
\begin{aligned}
& \mathrm{SO}_{2}+1 / 2 \mathrm{O}_{2} \rightarrow \mathrm{SO}_{3} \\
& \mathrm{SO}_{3}+\mathrm{H}_{2} \mathrm{O} \rightarrow \mathrm{H}_{2} \mathrm{SO}_{4} \\
& 2 \mathrm{H}_{2} \mathrm{SO}_{4}+2 \mathrm{CaCO}_{3} \rightarrow \mathrm{Ca}\left(\mathrm{HSO}_{4}\right)_{2}+\mathrm{Ca}\left(\mathrm{HCO}_{3}\right)_{2} \\
& \mathrm{H}_{2} \mathrm{SO}_{4}+\mathrm{CaCO}_{3} \rightarrow \mathrm{CaSO}_{4}+\mathrm{CO}_{2}+\mathrm{H}_{2} \mathrm{O}
\end{aligned}
$$


Existem também os processos de biodeterioração. A análise das relações entre uma obra de arte e seu meio ambiente é baseada num enfoque ecológico do sistema, ou ecossistema. A Figura 5 ilustra um esquema representando a obra de arte como um ecossistema (CANEVA, NUGARI, SALVADORI, 1991).

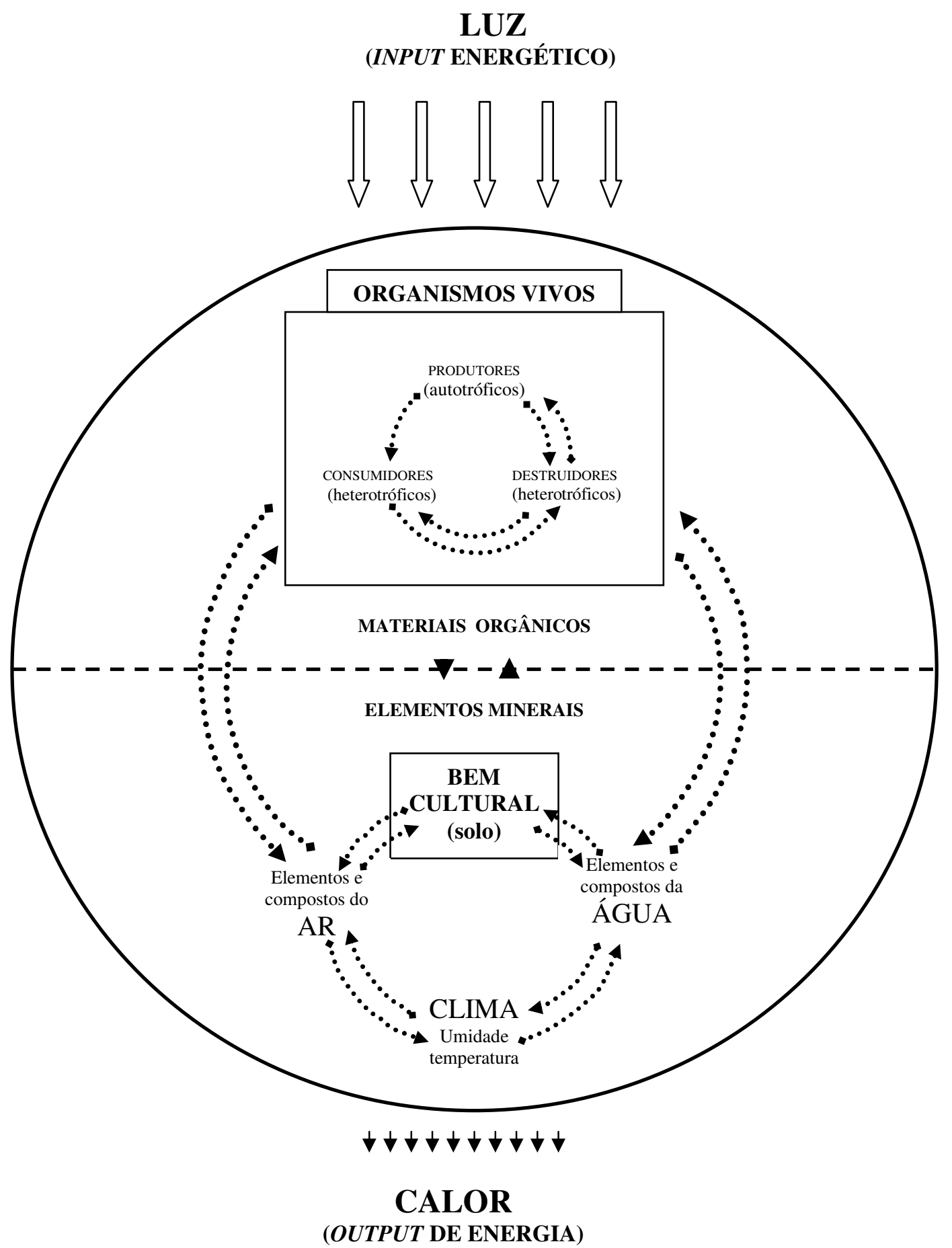

Figura 5 - Esquema representando a obra de arte como um ecossistema. Adaptado do livro "Biology in the conservation of works of art" (CANEVA, NUGARI, SALVADORI, 1991). 
O bem cultural (ou objeto a ser conservado) representa o "solo", isto é: o material que está no ciclo bio-geo-químico, exposto aos fatores ambientais e potencialmente transformado pelas populações biológicas. Populações biológicas (organismos e microorganismos) são consideradas potencialmente agentes deteriorantes (biodeteriogenes).

Num bem cultural material é possível encontrar uma ou mais regiões que apresentam regularidade nas condições ambientais e nas populações animais e vegetais (biótopos), e, associações de populações de espécies diferentes que nele habitam (biocenoses).

De acordo com a cadeia alimentar, os organismos presentes num bem cultural, podem ser produtores (autótrofos), e destruidores ou consumidores (heterótrofos).

Os produtores não utilizam a matéria da obra diretamente, mas podem danificá-la devido a produtos de seu metabolismo ou mecanicamente por penetração (CANEVA, NUGARI, SALVADORI, 1991). Por exemplo, o material proveniente da excreção de aves (pombos) que causa danos em monumentos de pedra. A uricita $\left(\mathrm{C}_{5} \mathrm{H}_{4} \mathrm{~N}_{4} \mathrm{O}_{3}\right)$ é uma substância insolúvel, originada a partir da evolução dos excrementos dos pombos (AIRES-BARROS, 1991).

Os destruidores utilizam matéria orgânica para sua nutrição, modificando severamente o substrato por quebra ou oxidação. A maioria das bactérias, fungos ou insetos ligados à biodeterioração são destruidores. Por exemplo, o ataque de térmitas em obras de arte que contém madeira.

Os consumidores são o grupo menos preocupante para a conservação e restauração de bens culturais porque eles utilizam matéria viva de outros micro ou macro organismos. Eles não atacam o substrato, mas podem estar presentes nos materiais como predadores de outras comunidades biológicas.

Do ponto de vista de energia, a cadeia alimentar, da qual as obras de arte fazem parte, dá origem a uma pirâmide ecológica, em cada estágio há uma dispersão de energia seguida da lei termodinâmica de aumento de entropia (CANEVA, NUGARI, SALVADORI, 1991).

Por esta razão a conservação de materiais (ou de bens culturais) por um tempo infinito é impossível, porque a matéria tende a se reverter para o seu estado original, para uma estrutura mais simples e mais estável (CANEVA, NUGARI, SALVADORI, 1991).

\subsection{IMPORTÂNCIA DA PRESERVAÇÃO DO PATRIMÔNIO CULTURAL}

O patrimônio cultural material - matéria intencionalmente trabalhada pelo homem - é no mínimo um documento histórico de uma época, podendo ser ainda, no caso de obras de arte, o representante único de uma expressão artística. A importância de preservá-lo, portanto, é 
evidente: como documento histórico ele carrega informações sobre a trajetória do homem, seus hábitos, suas crenças, seus medos, a forma de interação com os outros e com a natureza; sua forma de subsistência e organização social, as rotas de comércio, etc. Conhecendo o passado, podemos compreender o presente e até inferir sobre o futuro (RIZZO, 2008).

A preservação ou conservação e restauração de bens culturais é uma atividade multi e interdisciplinar, se situa numa interface que não apenas tange, mas intercepta universos de outras atividades correlatas (RIZZO, 2005).

O patrimônio cultural material é constituído por matéria, portanto, para preservá-lo é preciso conhecê-lo a nível atômico e molecular. É preciso conhecer a fundo as espécies com que ele foi feito e como elas se comportam - isto é: como reagem umas em relação às outras, através do tempo, com o meio ambiente, etc., em outras palavras, seus mecanismos de reação. É preciso conhecer ainda os produtos e os meios de que se dispõe para atuar interferindo nestes processos, seja prevenindo, retardando ou restaurando os processos de deterioração.

O estudo da degradação de materiais constitutivos de obras de arte tem recebido muita atenção do ponto de vista científico no último século. Do ponto de vista químico e físicoquímico trata-se de um sistema complexo, em cujas interfaces ocorrem modificações contínuas ao longo do tempo. Muitos estudos têm promovido o envelhecimento artificial e acelerado destes materiais constitutivos, no intuito de assim inferir sobre o envelhecimento e conservação de obras de arte. Este enfoque, entretanto, utiliza os materiais isoladamente, perdendo então informação crucial advinda do contexto, dos efeitos na própria obra.

Dentre os materiais mais estudados podemos citar os vernizes, que por recobrirem a obra apresentam efeitos diretos na sua visualização, pois ao envelhecerem se modificam, podendo amarelecer e interferir na leitura da obra, obscurecendo-a, além de tornarem-se quebradiços e cada vez menos solúveis (DOELEN, 2002); e os ligantes ou aglutinantes para as tintas, cujos efeitos sobre as cores são diretos.

\subsection{ESCULTURAS DE CERA}

As ceras têm sido utilizadas na manufatura de objetos e obras de arte há séculos. Vestígios de cera de abelhas foram encontrados nas tumbas egípcias, e, nas máscaras funerárias e nos potes de cozinha do Império Romano (KIMPE \& WAELKENS, 2002), por exemplo, assim como num barco Viking do séc. IX, achado em Oseberg - Noruega (SEBELIEN, 1913). As Figuras 6 e 7 mostram duas vistas diferentes do barco Viking achado em Oseberg. 


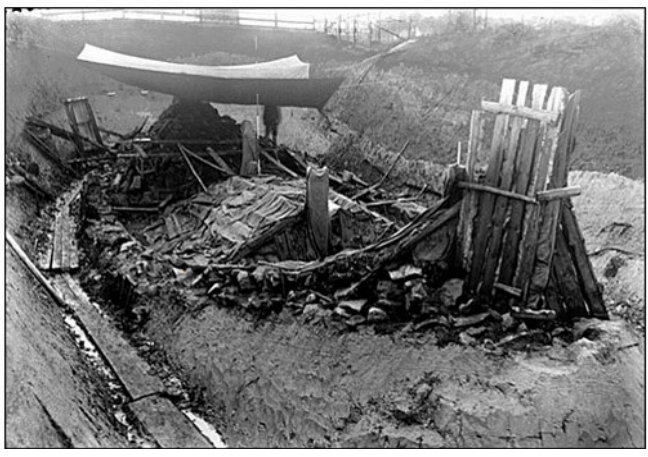

Figura 6 - Resquícios de um barco Viking do séc. IX em Oseberg - vista 1.

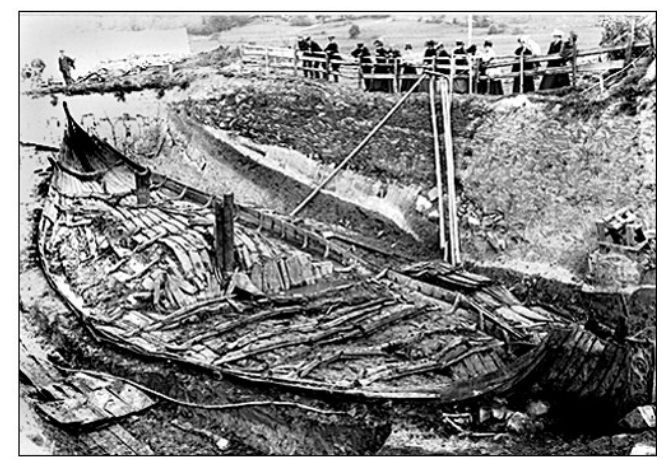

Figura 7 - Resquícios de um barco Viking do séc. IX em Oseberg - vista 2.

Na Europa na Idade Média produziu-se um grande número de oferendas ou estátuas de santos e presépios em cera (POGGESI, 2006). No Brasil, a partir de meados do séc. XX, a cera de abelhas substituiu em grande parte a madeira na manufatura das peças de devoção conhecidas como ex-votos. A cera de abelhas foi muito utilizada também na conservação e restauração de obras de arte durante séculos, até as últimas décadas, portanto, podemos encontrar numa obra, ceras que são parte estrutural do trabalho, como na técnica de pintura encáustica ou em esculturas e/ou ceras adicionadas posteriormente com a finalidade de conservação e/ou restauração.

Ceras de diversas procedências, misturadas ou não, tiveram um papel muito importante na história da medicina desde o séc. XVII, até recentemente no séc. XX, sendo utilizadas na confecção de modelos anatômicos destinados à pesquisa e estudo, feitos a partir de moldes de gesso tirados diretamente de cadáveres (KAUFMANN, 1988). A Figura 8 ilustra o molde de um coração sendo tirado em gesso e a Figura 9 ilustra um útero de mulher grávida com dilatação de colo.

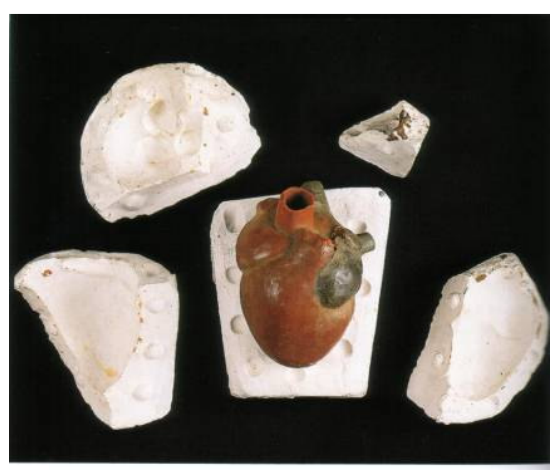

Figura 8 - Molde de um coração em gesso.

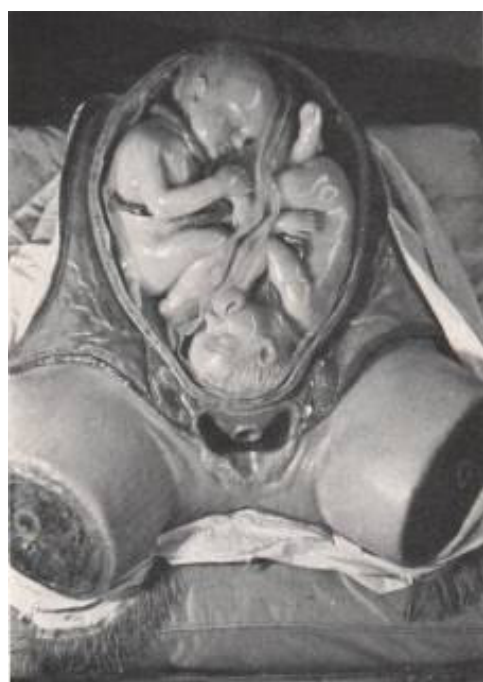

Figura 9 - Modelo de cera de um útero de mulher grávida com dilatação de colo. 


\subsection{BREVE HISTÓRIA DOS MODELOS ANATÔMICOS DE CERA}

A primeira representação anatômica do corpo humano conhecida é "O Homem Esfolado", sendo assim chamada porque mostra o corpo sem pele. É uma delicadíssima escultura em cera vermelha, medindo 61 centímetros. Ela foi produzida em 1600 por Lodovico Cardi (1559 1613) conhecido como "Il Cigoli". O artista "treinou" na Escola Florentina de Bronzino e logo desenvolveu uma paixão pela disciplina de anatomia artística. Dissecou inúmeros cadáveres no Hospital Santa Maria Nova em Florença. "O Homem Esfolado" demonstra todo o conhecimento sobre anatomia adquirido pelo artista. A Figura 10 mostra os estudos feitos no papel para execução da escultura, enquanto que a Figura 11 ilustra a própria escultura "O Homem Esfolado". A escultura pode ser vista no Museu Nacional de Bargello (Florença Itália) (POGGESI, 2006).

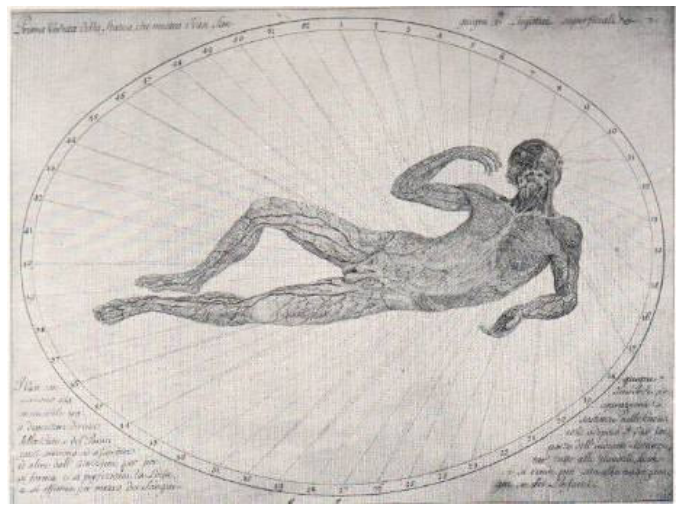

Figura 10 - Estudos para execução da escultura de cera "O Homem Esfolado".

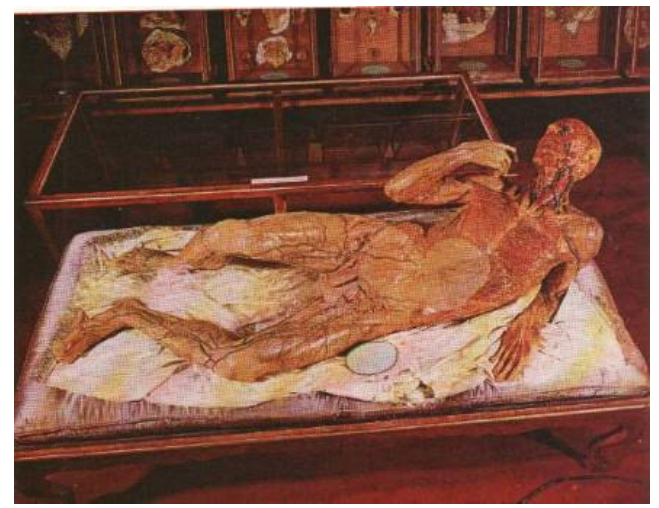

Figura 11 - Escultura de cera "O Homem Esfolado" - séc. XVI.

Cerca de um século depois, outro grande artista, o siciliano Gaetano Zumbo (1656-1701), que estudou anatomia em Bolonha, se dedicou a fazer esculturas policromadas em cera. $\mathrm{O}$ primeiro modelo de cera considerado policromado representando a anatomia humana é uma cabeça de homem, apesar da escultura "O Homem Esfolado" já apresentar diferentes tons de amarelo, vermelho e roxo. A escultura da cabeça de homem se encontra no Museu "La Specola" em Florença.

Entretanto, o apogeu das esculturas anatômicas de cera só aconteceu no século XVIII, quando se fez premente o ensino de médicos, cirurgiões e obstetras. Os modelos de cera eram muito úteis para ensinar aos jovens estudantes anatomia, fisiologia, cirurgia, zoologia, etc., pois ajudavam a memorizar partes do corpo humano e a aparência de algumas doenças. No Brasil 
temos o museu de doenças ocupacionais, da FUNDACENTRO, o qual está fechado, aguardando por restauração.

Uma escola com reconhecidos escultores de cera começou a se formar em Bolonha no início do séc. XVIII, estes artesãos são responsáveis por inspirar os artistas florentinos do Museu de la Specola (Museu do Observatório). Nos documentos do Museu de la Specola consta que eram necessários aproximadamente 200 cadáveres para a execução de uma única figura. Este número extraordinariamente elevado se deve ao fato de, na época não existirem ainda produtos para conservar os cadáveres ou a possibilidade de congelar. (POGGESI, 2006).

O pintor, escultor e arquiteto bolonhês Ercolli Lelli (1702-1766), decidiu usar modelos de cera policromados para ensinar anatomia aos estudantes sem dissecação de cadáveres. Ele fazia suas demonstrações anatômicas modelando trapos e estopa embebidos em cera e terebintina ao redor de esqueletos humanos. Em 1742 Lelli foi encarregado pelo papa Lambertini de produzir a coleção de modelos de cera do laboratório de anatomia da Universidade de Bolonha. Lelli foi assistido pelo artista, escultor e anatomista Giovanni Manzolini (1700-1755), o qual trabalhava juntamente com sua esposa Anna Morandi (17161774). Quando Giovanni morreu, Anna continuou a produzir os modelos de cera, e ficou famosa na Europa, sendo provavelmente a única mulher envolvida com este trabalho naquela época. Ela inclusive lecionou anatomia humana na Universidade de Bolonha.

A escola de modelos anatômicos de Florença é uma derivação direta da escola bolonhesa que nasceu da dedicação do cirurgião Giuseppe Galletti, professor de obstetrícia no Hospital de Santa Maria Nova. (AZZAROLI, 1975).

Galletti foi para Bolonha para ver o trabalho de Lelli e dos Manzolinis, observando também os modelos obstétricos feitos por Giovanni Antonio Galli (1708-1782). Ficou tão fascinado com a beleza das peças de cera que decidiu montar uma coleção de modelos de cera obstétricos assim que retornasse a Florença. O modelador Giuseppe Ferrini criou uma série de modelos. Em 1771 quando o Museu de História Natural "La Especola" foi fundado, Ferrini começou a trabalhar sob orientação de Felice Fontana, fundador do famoso atelier de modelagem anatômica em cera (Modelos de Cera Cagliari) e empresário de Clemente Susini (AZZAROLI, 1975). Vários outros museus na Itália e no resto do mundo possuem coleções de modelos de cera. Atualmente os museus italianos com coleções de cera são: os de Florença, Bolonha, Caligari, Pavia, Pisa, Modena e Trapani. Em outros lugares do mundo encontramos os museus de cera: Museu Acadêmico Militar de Saúde Josephinum em Viena, Museu Britânico de Londres, Museu Semmelweis em Budapeste, Museu do Departamento Anatômico da Universidade de Leyden na Holanda. 
Como uma derivação desta técnica, outros museus de cera trataram de imortalizar personagens famosos, fazendo réplicas de suas fisionomias. O mais conhecido é o "Museu Madame Tussaud", originariamente de Londres, mas hoje com filiais em Paris, Nova York, Hong Kong, Lãs Vegas, Amsterdã e em breve em Hollywood.

No Brasil temos o Museu de Cera Alpino, situado no Km 58 da rodovia Raposo Tavares, no interior do Hotel Alpino. Atualmente este museu está fechado e suas obras guardadas num depósito sem controle ambiental, no mesmo local.

\subsection{Museu de Cera Alpino}

O Museu de Cera Alpino foi idealizado por Glória Tavares Bahia, quando em 1952 numa visita a Europa conheceu o Museu Madame Tussaud. Trouxe de Londres o escultor Manoel Garcia e o ceroplasta Francisco Pastor, aos quais se juntaram Juan Scotto e Carlos Rangel. Durante dez anos a partir de 1954 foram feitas cinqüenta e quatro peças. As obras em questão são esculturas mistas, representando personagens da história do Brasil. De um modo geral, o corpo e os membros inferiores são feitos de papelão com resina acrílica; na região do pescoço há uma pequena plataforma de madeira com um pino, também de madeira onde é encaixada a cabeça; os membros superiores são feitos de madeira torneada, com articulações nos ombros e cotovelos com pinos de ferro; as mãos e os pés são feitos de resina pintada ou de cera, conforme o caso; e o rosto - parte de destaque da escultura - é feito de cera sobre um suporte de madeira circular com um furo no centro que dá sustentação ao pescoço, recoberto com uma fina camada de cera-resina translúcida e colorida a qual é responsável pela sensação de vida da peça, os olhos são de vidro e o cabelo é humano. Depois de prontas, estas peças são vestidas a caráter.

Devido à grande variedade e fragilidade de materiais que compõe estas obras, a preservação e conservação das mesmas exigem, além do domínio de diferentes técnicas, atenção e cuidados especiais. A Tabela 1 lista as personagens do Museu de Cera Alpino 
Tabela 1 - Personagens do Museu de Cera Alpino.

\begin{tabular}{|c|c|c|}
\hline \multicolumn{3}{|c|}{ PERSONAGENS } \\
\hline Hermes da Fonseca & Cláudio Manoel & Tiradentes \\
\hline Ana Néri & Marechal Deodoro & Raposo Tavares \\
\hline Lampião & Barão do Rio Branco. & Marechal Rondon \\
\hline Rui Barbosa & Duque de Caxias & Juscelino Kubitschek \\
\hline Anita Garibaldi & Bartholomeu Bueno & Borba Gato \\
\hline Padre José Anchieta & Padre Manoel da Nóbrega & Pedro Álvares Cabral \\
\hline Índio Tibiriçá & Índio Caramuru & Rodrigues Alves \\
\hline Delfim Moreira & Castro Alves & Getúlio Vargas \\
\hline Prudente de Moraes & Fernão Dias & Cangaceiro Ângelo \\
\hline Osvaldo Cruz & Almirante Barroso & Floriano Peixoto \\
\hline Almirante Tamandaré & Cangaceiro Mergulhão & D. Pedro I \\
\hline Visconde de Mauá & D. Pedro II & D. João VI \\
\hline Dragão I - A. Bernardes & Dragão II - Wenceslau Braz & Maria Leopoldina \\
\hline Marquesa de Santos & Carlota Joaquina & Maria Bonita \\
\hline Campos Salles & Tomás Antonio Gonzaga & José Bonifácio \\
\hline Cangaceiro Elítiuco & Regente Feijó & Epitácio Pessoa \\
\hline
\end{tabular}

Imperatriz Teresa Cristina Maria de Bourbon

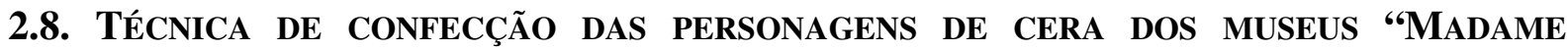 TUSSAUD" E "AlPINO"}

Os artistas do Museu de Cera Alpino não documentaram seu trabalho, portanto as informações que se tem são provenientes de investigações, incluindo todos os dados obtidos através do processo de restauração das obras e desta dissertação. Como eles são oriundos do Museu Madame Tussaud, acredita-se que tenham utilizado a mesma técnica aprendida na Europa, talvez com alguma adaptação devido às possíveis dificuldades de aquisição de material, financeiras, etc.

As técnicas de confecção de esculturas de cera do Museu Madame Tussaud, e conseqüentemente do Museu de Cera Alpino, não sofreram alterações nos últimos 200 anos. 
O primeiro passo para a confecção de uma escultura de uma personagem famosa é coletar as informações preliminares: imagens (fotografias, etc.) e artigos ou biografia. Depois é preciso decidir em que parte da exposição a obra ficará, com que pose e qual será sua interação com as outras esculturas.

A primeira parte da escultura a ser feita é uma armação precária sobre a qual será moldado o corpo. Esta armação é feita geralmente de metal. A Figura 12 ilustra uma armação feita no Museu Madame Tussaud para a escultura da cantora Liza Minnelli. Sobre esta armação o artista esculpe a imagem em argila, como mostra a Figura 13 (MURRELL, 1971).

Quando a escultura de argila está terminada, é feito um molde da cabeça e algumas vezes também do pescoço e do dorso, caso estes eventualmente não forem ficar cobertos por roupas. O molde da cabeça geralmente é feito em aproximadamente doze partes separadas, para evitar retração na hora de desmoldar, o que não representa grande problema devido ao processo de contração da cera ao solidificar. Dentro do molde fechado da cabeça, é derramada cera-resina fundida. Quando uma espessura suficiente de cera-resina (cerca de 1,25 cm) solidificou-se, o restante de cera-resina ainda fundida que está no centro é vertida para fora. Algumas vezes o corpo também é feito de cera-resina, como ilustra a Figura 14 (MURRELL, 1971).

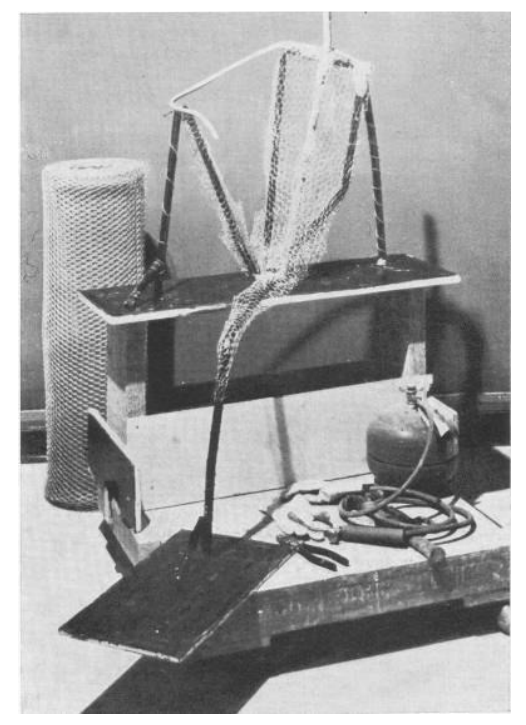

Figura 12 - Armação de metal que estrutura a escultura de argila de Liza Minnelli.

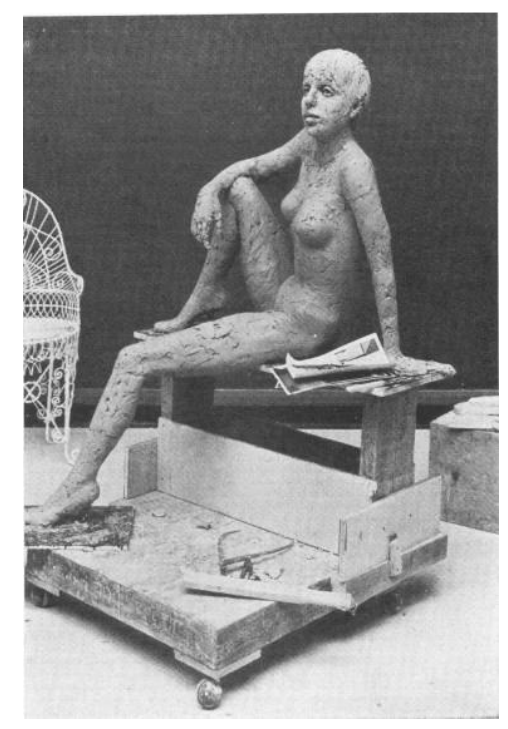

Figura 13 - Escultura de argila da cantora Liza Minnelli. 
Cera-resina, como o próprio nome diz, é uma mistura de diferentes tipos de cera com uma ou mais resinas naturais, os materiais são misturados em pedaços e fundidos. Cada um deles contribui com uma ou mais propriedades na mistura. A composição desta mistura é de grande importância para aparência e estabilidade da obra de arte final, e são utilizadas ceras e resinas com diferentes pontos de fusão e diferenças de plasticidade ou rigidez, obtendo-se pontos de fusão e durezas adequados ao produto final.

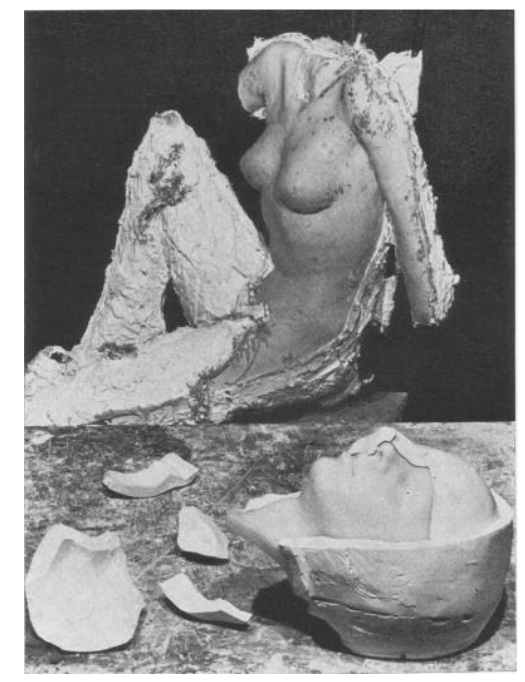

Figura 14 - Escultura de cera sendo feita a partir do molde de gesso.

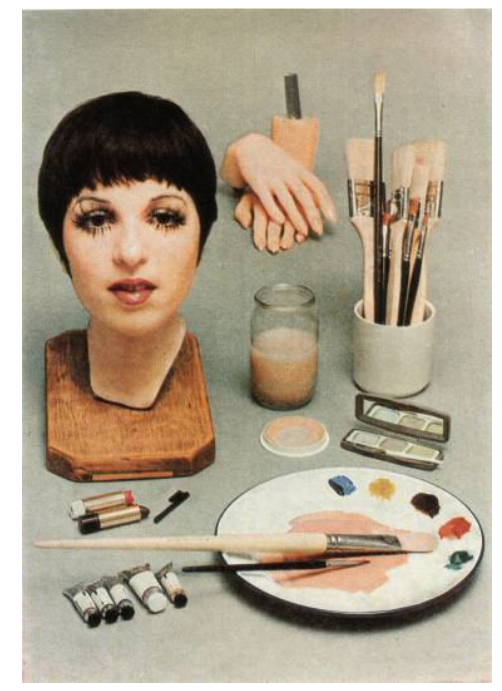

Figura 15 - Acabamento colorido da cabeça de cera.

A receita de mistura de cera-resina apropriada para esta etapa dada pelo Museu Madame Tussaud nos anos 70, era de três partes de cera clarificada de abelhas, para uma parte de cera japonesa (cera de origem vegetal, equivalente a nossa cera de carnaúba), com um pouco de cera bruta, a qual era usada por dois motivos: primeiro porque diminuía a retração e segundo porque atribuía uma coloração especial à mistura, e, uma pequena quantidade de resina natural damar. Maior coloração era adquirida com a adição de pigmentos para cera na mistura. Antes de 1969, tinta á óleo era usada na mistura, mas ela tinha a desvantagem de se separar facilmente.

O próximo estágio é a fixação dos olhos. Os olhos são de vidro, muitas vezes pintados à mão especialmente. Pequenas órbitas moldadas a partir de gesso incorporado anteriormente no molde são alargadas com uma ferramenta aquecida, e os olhos são então fixados pelo lado de dentro da cabeça pelo artista. 
Em seguida, o cabelo, que é humano, na cor e textura correta para a personagem é implantado no "couro cabeludo" de cera, o qual é aquecido com uma lâmpada. Os cílios podem ser pintados, ou são usados cílios postiços ou implantados da mesma forma que os cabelos ( até 1939, pêlo de camelo era usado neste processo); os outros pêlos do rosto, como sobrancelhas, barbas e bigodes são implantados da mesma forma que os cabelos.

A última etapa antes de a escultura ser vestida é a pintura do rosto ou maquiagem. Várias técnicas podem ser utilizadas na pintura direta das esculturas de cera. A mais comumente usada é um misto de aquarela com maquiagem, como ilustra a Figura 15 numa escultura sendo confeccionada no museu Madame Tussaud. Outra possibilidade é o uso da própria cera dissolvida e/ou diluída como veículo da tinta (AZZAROLI, 1975). No Museu de Cera Alpino parece que foi utilizada esta última técnica, porém não temos dados documentais que elucidem este processo.

A escultura é então ornamentada, vestida a caráter, e inserida num cenário, como ilustra a Figura 16 (MURRELL, 1971).

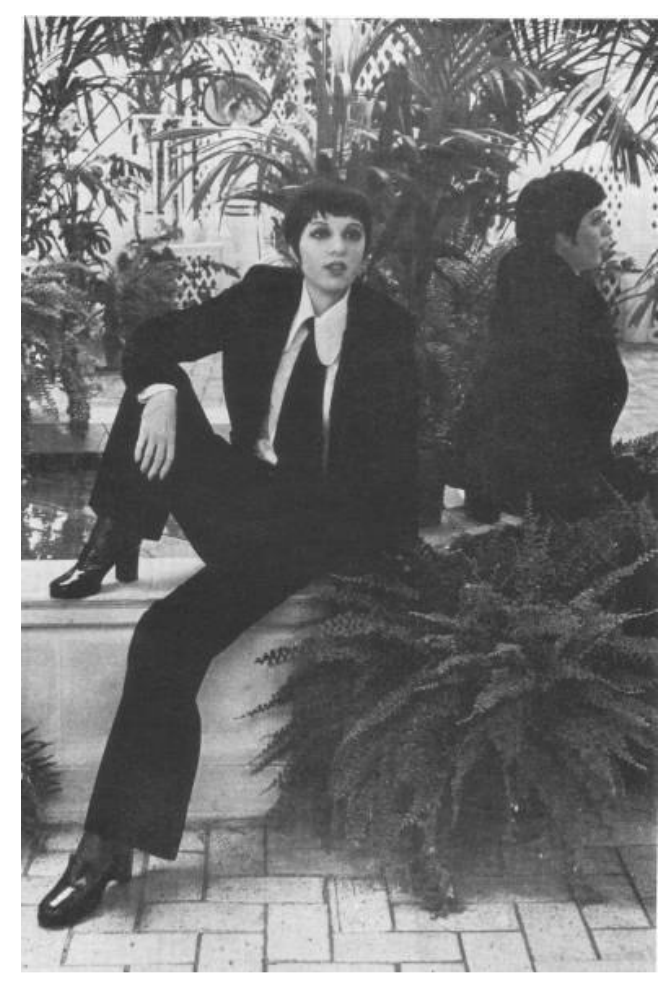

Figura 16 - Escultura de cera da cantora Liza Minnelli finalizada. 


\subsection{TIPOS DE CERAS}

Existem vários tipos de cera: a cera de origem animal, vegetal e mineral. As ceras de origem animal são provenientes de alguns animais terrestres, alguns animais aquáticos e dos insetos, as ceras de origem vegetal, vem das folhas de algumas plantas e a cera de origem mineral é proveniente da destilação fracionada do petróleo.

Nas esculturas de cera são utilizadas apenas: cera bruta de abelhas, cera clarificada de abelhas e cera de carnaúba.

\subsubsection{CERAS DE INSETOS}

\subsubsection{CLASSIFICAÇÃO E ORGANIZAÇÃO SOCIAL DOS INSETOS PRODUTORES DE CERAS}

Os dois principais grupos de insetos produtores de ceras são: (1) o Apidae, do qual as abelhas são os principais membros; e (2) o Coccidae, ao qual pertence o Coccus ceriferus, que produz cera chinesa.

Dentro da ordem Apidae, existem três gêneros: (a) o gênero Appis que tem a maior ordem social, produzindo importantes colméias; (b) Melipoma, Trigona e Tetrasoma de abelhas menores; (c) Bombus, conhecido como "mamangaba" ou "abelhão" que não é tão abundante como as outras abelhas (WARTH, 1947).

\subsubsection{CERA DE ABELhaS}

O gênero Apis ocupa o papel mais importante economicamente no comércio de ceras de abelhas. Dentro do gênero Apis temos varias espécies: a abelha gigante Apis dorsata; a média Apis indica, ambas da Ásia; Apis florea, a minúscula abelha do oeste da Índia e por último a domesticada abelha do mel Apis mellifica. A abelha do mel foi originalmente chamada de Apis mellifera, por Linnaeus em 1758, embora ele tenha mudado o nome mais tarde para Apis mellifica para denotar colméia especificamente. A Apis mellifica produz colméias de cera pura conhecida comercialmente como "cera genuína de abelhas".

Existem muitas raças de A. mellifera, praticamente tantas quantas são os paises em que ela foi domesticada - por todo o mundo. As ceras obtidas dessas diversas raças diferem muito pouco em suas características físicas ou constantes químicas (WARTH, 1947). 


\subsection{SECREÇÃO DA CERA PELAS ABELHAS}

As escamas de cera são secretadas por oito glândulas localizadas na parte inferior do abdome da abelha operária. Logo que é secretada, a cera, que é derivada do sangue da abelha por ação celular é líquida. A secreção rapidamente endurece (cristaliza) como uma pérola mais ou menos transparente como mica. Em geral a forma do cristal muda dependendo de alguns parâmetros físicos como temperatura, pressão e tempo de resfriamento. A escama de cera é removida do abdome pela pata traseira do inseto e recebida pela mandíbula de outra operária onde ela é mastigada com secreção antes de ser colocada como um biscoito na célula da colméia. A colméia é construída num modelo hexagonal, o qual garante resistência estrutural e o máximo de otimização do espaço. Numa colméia natural existem 825 células por decímetro cúbico (WATH, 1947; GUERINO, 2003).

\subsection{EXTRAÇÃO DA CERA BRUTA DE ABELHAS}

A cera de abelhas, normalmente é retirada dos favos das molduras no apiário sendo fundida em água quente ou no sol.

\subsection{COLORAÇÃo dA CERA DE ABELHAS}

Logo que é excretada a cera de abelhas é branca, mas rapidamente muda de cor. Um dos principais motivos é a presença de pólen, o qual também é liberado pela abelha no estado sólido ou líquido. Diferentes tipos de pólen conferem diferentes tonalidades às ceras, por exemplo: o girassol (Helianthus bolanderi) origina um laranja amarelado brilhante, o dentede-leão (Taraxacum officiale), um amarelo brilhante, o trevo branco (Trifolium repens), apenas um traço de amarelo, enquanto que o pólen da alfafa, linho e azevinho, entre outros, não dão coloração nenhuma (VANSELL \& BISSON, 1940).

\subsection{ClarifiCAÇÃo da CERA dE ABELHAS}

Muitos métodos foram desenvolvidos para refinar e clarificar a cera de abelhas. O mais usado é um no qual a cera é fundida com ácido sulfúrico diluído a 5\%. A adição de peróxido de hidrogênio ao ácido sulfúrico aumenta a eficácia do método. Outro método funde a cera diretamente com uma solução alcalina para extrair as impurezas solúveis em álcalis, em 
seguida a resfria e separa da solução e funde novamente com uma segunda solução aquosa de sal e hipoclorito (BISSON, 1936).

\subsection{COMPOSIÇÃO DA CERA DE ABELHAS}

As ceras de abelhas são obtidas pelo homem através dos favos construídos pelas abelhas. Elas apresentam uma complexa composição de mais de 300 substâncias, número variável dependendo da origem. Trata-se de uma mistura de hidrocarbonetos, mono, di, tri e poliésteres, álcoois e ácidos livres além de uma infinidade de outras substâncias em pequena quantidade. Um trabalho publicado utilizando a técnica de cromatografia gasosa com espectrometria de massas (GCMS) apresenta um panorama desta composição para algumas ceras de abelhas européias (TULLOCH, 1980). A Tabela 2 mostra este panorama.

Tabela 2 - Composição média da cera de abelhas.

\begin{tabular}{l|c}
\hline ESPÉCIES & TEOR (\%) \\
\hline Hidrocarbonetos & $14 \%$ \\
\hline Monoésteres & $35 \%$ \\
\hline Diésteres & $14 \%$ \\
\hline Triésteres & $3 \%$ \\
\hline Hidroxi monoésteres & $4 \%$ \\
\hline Hidroxi poliésteres & $8 \%$ \\
\hline Ésteres ácidos & $1 \%$ \\
\hline Poliésteres ácidos & $2 \%$ \\
\hline Ácidos livres & $12 \%$ \\
\hline Álcoois livres & $1 \%$ \\
\hline Não identificados & $6 \%$ \\
\hline & \\
\hline TOTAL HIDROCARBONETOS & $14 \%$ \\
\hline TOTAL ÉSTERES & $67 \%$ \\
\hline TOTAL ÁCIDOS & $12 \%$ \\
\hline TOTAL ALCóOIS & $1 \%$ \\
\hline OUTROS & $6 \%$ \\
\hline
\end{tabular}

Nos dois últimos séculos a composição da cera de abelhas foi objeto de discussão e foi revisada repetidas vezes com o desenvolvimento de novas técnicas de caracterização, mas foi somente depois de 1960, com os procedimentos cromatográficos que foi possível determinar sua composição detalhada. Para relacionar a composição da cera com suas propriedades era necessário primeiro separar a cera não hidrolisada em diferentes classes de componentes e depois analisar os produtos de hidrólise dessas frações. Foi através deste procedimento que 
muitos componentes das ceras de abelhas foram identificados nos últimos anos (TULLOCH, 1980).

Quando usada em conjunto com ceras duras, a cera de abelhas contribui para a plasticidade e flexibilidade. A presença de cera de abelhas numa mistura de ceras e resinas contribui para um leve encolhimento na moldagem. Quimicamente a cera de abelhas estabiliza a cor da mistura pela presença dos ácidos cerótico e melíssico livres contidos na cera. É compatível com todas as ceras animais e vegetais, uma grande variedade de resinas naturais e sintéticas, ácidos graxos, glicerídeos e hidrocarbonetos (em certas proporções).

A Tabela 3 lista as especificações físico-químicas e organolépticas da cera clarificada de abelhas, as quais são de extrema importância na confecção das esculturas de cera (OLIVEIRA, 2002).

Tabela 3 - Especificações físico-químicas e organolépticas da cera clarificada de abelhas.

\begin{tabular}{c|c}
\hline PARÂMETRO & ESPECIFICAÇÕES \\
\hline Aparência & Barra \\
\hline Cor & Amarelado \\
\hline Odor & Característico \\
\hline Faixa de Fusão, ${ }^{\circ} \mathrm{C}$ & Max. $65^{\circ} \mathrm{C}$ \\
\hline Índice de Acidez, $\mathrm{mgKOH} / \mathrm{g}_{\text {amostra }}$ & $17,0-24,0$ \\
\hline
\end{tabular}

\subsubsection{CERAS DE PLANTAS}

A parede externa da epiderme de uma folha de planta adulta é recoberta por uma substância cerosa altamente impermeável à água: a cutícula.

As ceras de plantas podem ser agrupadas da seguinte maneira: (1) ceras de palmeiras; (2) ceras de ervas; (3) ceras de gramas; (4) ceras de folhas largas; (5) ceras de folhas estreitas.

\subsubsection{CERA DE CARNAÚBA}

A cera de carnaúba é obtida das folhas de uma palmeira americana designada Copernicia (ou Copernica) cerifera, assim chamada em homenagem a Copérnico. Acredita-se que o nome carnaúba tenha vindo de uma distorção da palavra carnaíba do Tupi, composto de caraná ou carandá que significa escamoso e iba que significa palmeira ou árvore (WARTH, 1947). 
Apresenta-se amorfa, dura, de alto ponto de fusão, firme e lustrosa. Possui odor agradável e quebra com uma fratura limpa. A adição da cera de carnaúba à mistura de outras ceras proporciona aumento do ponto de fusão, dureza, rigidez, brilho e diminui a pegajosidade, plasticidade e cristalização, além disso, proporciona propriedades de contração no processo de moldagem. Quando utilizada em alta quantidade pode proporcionar uma textura granular à formulação.

Existem quatro tipos de cera de carnaúba. A diferença química entre elas se deve a forma de extração e industrialização. A cera de carnaúba tipo 1 (CRCNT1) é obtida do pó do "olho" das carnaubeiras e sua cor é amarelo-ouro. Ela é refinada, clareada, se apresenta em escamas e geralmente é usada em indústrias farmacêuticas, cosméticas, alimentícias e em emulsões.

As ceras tipo 2, tipo 3 e tipo 4 são obtidas do pó da palha das carnaubeiras e todas se apresentam sob forma de escamas. A cera de carnaúba tipo 2 (CRCNT2) é amarelo-laranja, ela é refinada e clareada e geralmente é utilizada em tintas de impressoras e códigos de barras. A cera de carnaúba tipo 3 (CRCNT3) é marrom escuro. Ela é filtrada e geralmente é usada em tintas, vernizes e cera para polimentos. A cera de carnaúba tipo 4 ( $\mathrm{CRCNT} 4)$ é preta. Ela é centrifugada e normalmente é utilizada para a fabricação de papel carbono. O Brasil é o principal produtor de cera de carnaúba no mundo e atualmente toda sua produção de CRCNT2 é destinada à exportação. Os artistas, na maioria das vezes, preferem a $\mathrm{CRCNT1}$ por ser mais pura.

A Tabela 4 lista as especificações físico-químicas e organolépticas da cera de carnaúba tipo 1, as quais são de extrema importância na confecção das esculturas de cera (OLIVEIRA, 2002).

Tabela 4 - Especificações físico-químicas e organolépticas da cera de carnaúba tipo1.

\begin{tabular}{c|c}
\hline PARÂMETROS & ESPECIFICAÇõES \\
\hline Aparência & Escama \\
\hline Cor & Amarelo Ouro \\
\hline Odor & Característico \\
\hline Faixa de Fusão, ${ }^{\circ} \mathrm{C}$ & $81-86$ \\
\hline Índice de Saponificação, $\mathrm{mgKOH} / \mathrm{g}_{\text {amostra }}$ & $68,0-88,0$ \\
\hline Índice de Acidez, $\mathrm{mgKOH} / \mathrm{g}_{\text {amostra }}$ & $2,0-6,0$ \\
\hline
\end{tabular}

\subsection{RESINAS NATURAIS}

Existem diversos tipos de resinas naturais usadas em obras de arte como veículos nas tintas, incorporadas em misturas para conferir certas propriedades e principalmente como camada de 
proteção ou verniz. Estas resinas são provenientes de excreções ou secreções de plantas, são exemplos delas: damar, mastique, copal, colofonia, etc. A mais utilizada é a resina damar, a qual está presente nas esculturas de cera.

\subsubsection{RESINA NATURAL DAMAR}

A resina damar é classificada como um triterpenóide, o que significa que ela consiste de compostos isoprenóides cíclicos com 30 átomos de carbono. Ela é proveniente das árvores Dipterocarpaceae. Esta resina é utilizada desde o século IX como verniz em pinturas de cavalete (DOELEN, 2002). Ela é aplicada de forma líquida, dissolvida e depois da evaporação do solvente forma um filme protetor sobre a pintura. Este filme confere propriedades especiais à obra: superfície uniforme, saturação das cores, brilho e sensação de profundidade. Porém ele é altamente oxidável e muda de cor com o passar dos anos, modificando (escurecendo) a camada pictórica (FELLER, 1985). Por este motivo, as resinas naturais, têm sido substituídas pelas sintéticas na formulação dos vernizes para obras de arte, pois as últimas não reagem com o oxigênio.

\subsection{TÉCNICAS ANALÍTICAS UTILIZADAS NESTE TRABALHO}

Geralmente na caracterização físico-química e analítica de obras de arte as seguintes técnicas físico-químicas e analíticas, Figura 17, podem ser utilizadas, conforme o tipo de obra e o propósito da caracterização (FERRETI, 1993): 


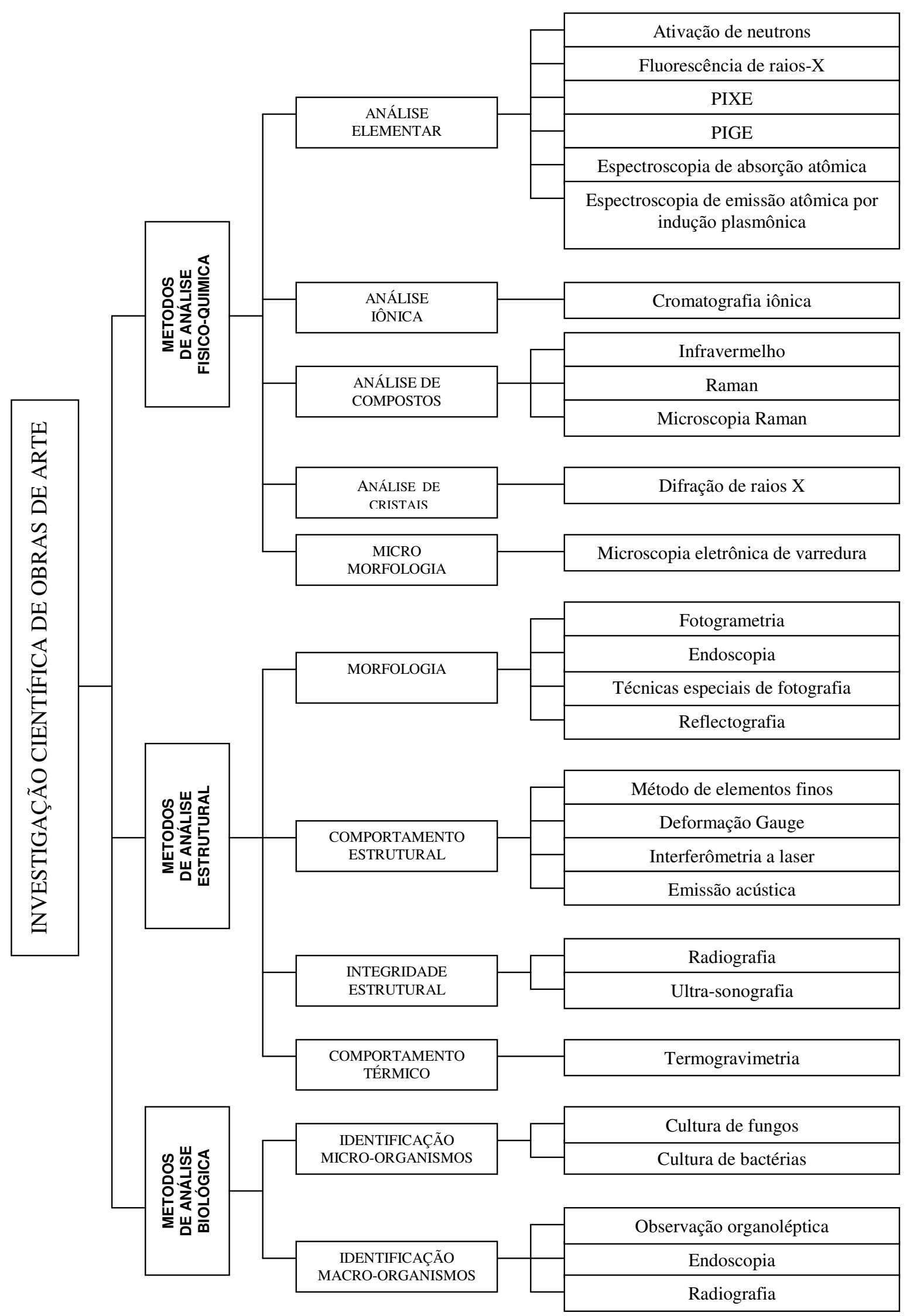

Figura 17 - Fluxograma ilustrativo das técnicas físico-químicas e analíticas utilizadas para caracterização de obras de arte. Adaptado do livro "Scientific investigation of works of art". 
Das técnicas listadas no fluxograma da Figura 17 aquelas utilizadas no presente trabalho serão brevemente descritas nos itens seguintes.

\subsubsection{TÉCNICAS DE OBSERVAÇÃO E DOCUMENTAÇÃO}

\subsubsection{OBSERVAÇÃo ORGANOLÉPTICA}

A observação organoléptica utiliza os nossos sentidos. No caso de obras de arte a visão, o olfato e algumas vezes o tato são utilizados para reconhecimento da obra e suas possíveis alterações. O conhecimento profundo das obras de arte é imprescindível neste tipo de observação analítica. Um restaurador experiente pode identificar pequenas alterações numa obra ou ainda adulterações e falsificações. Esta é a etapa fundamental, a partir da qual a análise científica se faz necessária.

\subsubsection{FOTOGRAFIAS COM CÂMERA DIGITAL COM LUZ VISÍVEL}

A fotografia com luz visível é utilizada como documentação da obra, antes, durante e depois dos procedimentos de restauro e/ou análise. Geralmente são utilizadas duas lâmpadas alógenas de 1000 Watts cada uma, $220 \mathrm{~V}$, suportadas por tripés sendo que muitas vezes um difusor é colocado na frente para evitar reflexos na fotografia. Antes de se iniciarem as fotos, é realizado um "balanço de branco" com a luz que será usada para garantir a reprodutibilidade da cor e a fotografia é tirada com uma fita de referência de cor.

\subsubsection{FOTOGRAFIAS COM CÂMERA DIGITAL COM RADIAÇÃO ULTRAVIOLETA (UV)}

A fotografia com radiação ultravioleta (UV) permite visualizar alguns tipos de fungos e antigas intervenções de restauro ou alterações propositais feitas na peça. Materiais de natureza e épocas diferentes absorvem a radiação UV e re-emitem luz visível com comprimentos de onda diferentes. Este recurso, portanto, é bastante utilizado como etapa preliminar na análise de obras de arte (RIZZO, 2005). 


\subsubsection{FOTOGRAFIAS SOB A LUPA BINOCULAR MICROSCÓPICA}

A fotografia sob a lupa binocular microscópica permite visualizar melhor a superfície da obra, possibilitando uma melhor escolha das áreas a serem analisadas com as diferentes técnicas disponíveis.

\subsubsection{ANÁlISES NÃo INVASIVAS OU NÃO DESTRUTIVAS DE SUPERFíCIE}

\subsubsection{MICROSCOPIA ELETRÔNICA DE VARREDURA COM ANALISADOR DE DISPERSÃO DE ENERGIA DE RAIOS X (MEV-EDS)}

A microscopia eletrônica de varredura (MEV) permite observar a superfície analisada com aumentos de até 300000 vezes. As imagens fornecidas pelo MEV possuem um caráter virtual, pois o que é visualizado no monitor do aparelho é a transcodificação da energia emitida pelos elétrons, diferente das imagens formadas no nosso cérebro devido à radiação eletromagnética captada pelos sensores de nossos olhos.

A imagem eletrônica de varredura é formada pela incidência de um feixe de elétrons na amostra, sob condições de vácuo. A incidência do feixe de elétrons na amostra promove a emissão de elétrons secundários, retroespalhados, auger e absorvidos, assim como de raios X característicos e de catodo luminescência (REED, 1996).

Ao MEV pode ser acoplado um analisador de dispersão de energia de raios X (EDS - Energy Dispersive System), o qual possibilita a determinação da composição qualitativa e semiquantitativa das amostras, a partir da emissão de raios X característicos. O limite de detecção é da ordem de $1 \%$, mas pode variar de acordo com as especificações utilizadas durante a análise, como o tempo de contagem, por exemplo. Uma das desvantagens do sistema EDS é a limitação da análise pelo $\mathrm{Z}$ médio da região ionizada, pois apenas os elementos com $\mathrm{Z}$ superior a 4 são detectados e quantificados por esta técnica.

Uma das vantagens da utilização do MEV/EDS é a rapidez e facilidade na preparação das amostras, que depende do objetivo da pesquisa.

As amostras não condutoras de corrente elétrica para serem analisadas por MEV/EDS devem ser previamente metalizadas. A metalização consiste na precipitação, à vácuo, de uma película micrométrica de material condutor (por exemplo: ouro ou carbono) sobre a superfície da amostra, possibilitando a condução da corrente elétrica (DUARTE et al., 2003). 
Esta técnica está sendo considerada como não destrutiva neste trabalho, pois na maioria dos casos foi possível utilizar fragmentos inteiros da cabeça da personagem Afonso Pena, sem qualquer preparação preliminar para observação e caracterização.

É uma técnica muito útil na caracterização de obras de arte, mesmo quando é necessária a remoção de amostras, pois ela permite literalmente ver a micro estrutura da obra, além de permitir a análise elementar de áreas ou pontos específicos (partículas) delimitados na superfície visualizada. Neste trabalho foi de extrema importância no entendimento do processo de degradação.

\subsubsection{ANÁLISES COM RETIRADA DE AMOSTRAS (INVASIVAS OU DESTRUTIVAS)}

\subsubsection{ESPECTROSCOPIA}

A espectroscopia é o estudo da interação da radiação eletromagnética com a matéria. Essa interação se dá em três processos distintos: absorção, emissão e espalhamento de radiação. As diferentes técnicas espectroscópicas têm sido cada vez mais utilizadas em conservação e restauração de bens culturais, pois sozinhas ou aliadas a outras técnicas elas permitem a identificação dos materiais constitutivos da obra e dos possíveis subprodutos de sua degradação (CASTRO et al., 2005; HOOYDONK, 2000; VANDENABEELE et al., 2000).

\subsection{ESPECTROSCOPIA VIBRACIONAL}

A espectroscopia vibracional engloba basicamente duas técnicas: a absorção no infravermelho e o espalhamento Raman. As duas técnicas baseiam-se em princípios físicos distintos, mas que propiciam resultados complementares no que diz respeito às freqüências fundamentais das vibrações normais moleculares. A espectroscopia vibracional é uma ferramenta poderosa para a identificação, a determinação de grupos funcionais e os estudos de conformação e estruturas de moléculas (KAWANO, 2007).

\subsection{ESPECTROSCOPIA VIBRACIONAL DE ABSORÇÃO NO INFRAVERMELHO (IR)}

A espectroscopia de absorção no infravermelho pode ser dividida em três regiões distintas: (a) 10 a $400 \mathrm{~cm}^{-1}$, IR longínquo (FIR); (b) 400 a $4000 \mathrm{~cm}^{-1}$, IR médio (MIR); (c) 4000 a 12820 $\mathrm{cm}^{-1}$, IR próximo (NIR). 
A maior parte dos estudos em IR referem-se à região média (MIR) onde se localizam as freqüências de modos vibracionais fundamentais $(\mathrm{v}=0 \rightarrow \mathrm{v}=1 ; \Delta \mathrm{v}=1)$, conhecida como região da impressão digital do espectro IR.

O MIR é uma ferramenta poderosa para caracterizar os constituintes do material analisado, pois os diferentes grupos químicos orgânicos apresentam transições específicas.

Absorções vibracionais no infravermelho próximo também são utilizadas. Estas correspondem às transições vibracionais entre o nível de energia fundamental e os níveis de energia de ordem superior $(\mathrm{v}=2,3,4, \ldots$.$) (KAWANO, 2007).$

\subsection{ESPECTROSCOPIA DE INFRAVERMELHO POR TRANSFORMADA DE FOURIER (FTIR)}

O espectrômetro de FTIR é constituído por uma fonte de radiação, um interferômetro, compartimento da amostra, e um detector de radiação infravermelho. O espectrômetro de FTIR utiliza o interferômetro de Michelson como principio de funcionamento. Os elementos de um espectrômetro de FTIR variam de acordo com as regiões do infravermelho em estudo. O interferômetro de Michelson é constituído por um divisor de feixe (beam splitter), um espelho fixo e um espelho móvel. A configuração ótica do interferômetro varia de acordo com o fabricante do aparelho, mas seu funcionamento e princípios envolvidos são similares (KAWANO, 2007). A Figura 18 mostra o esquema de um espectrômetro de FTIR.

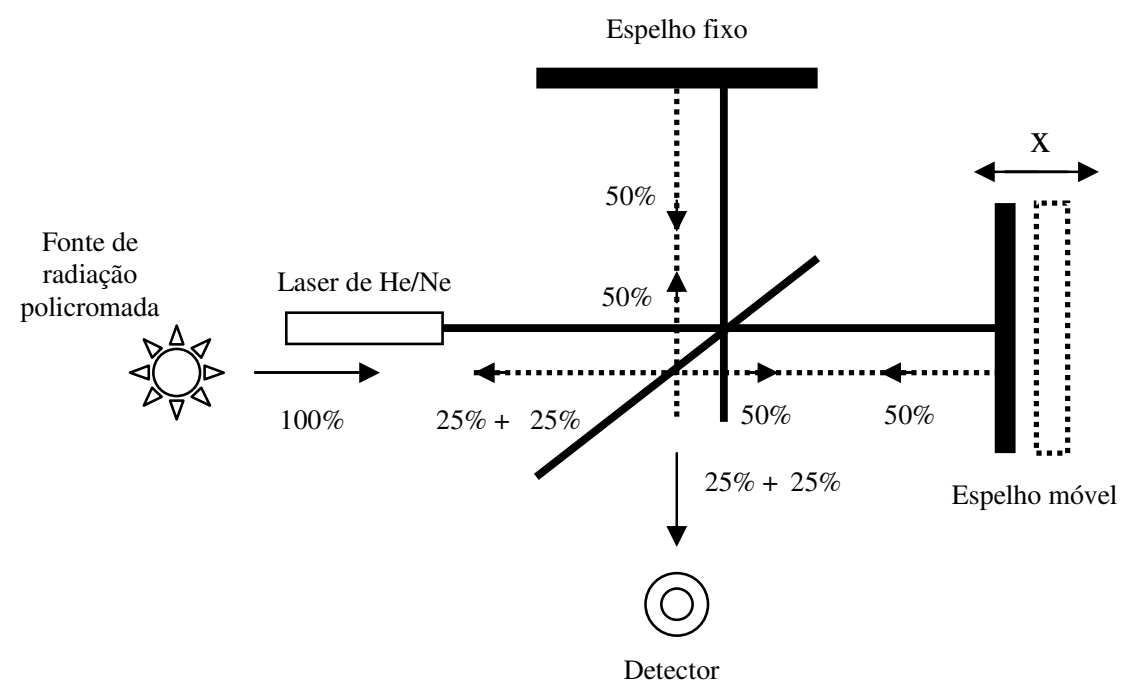

Figura 18 - Esquema de um espectrômetro de FTIR. 
A espectroscopia no infravermelho é uma das técnicas de caracterização mais utilizadas em conservação e restauração de bens culturais, pois ela permite a identificação dos materiais poliméricos (adesivos, ligantes, vernizes, etc.) e também de alguns pigmentos. Há alguns anos, bancos de dados de materiais utilizados em obras de arte, têm sido elaborados. Um dos trabalhos mais importantes sobre o uso da espectroscopia de infravermelho para caracterização de obras de arte é da cientista Michelle Derrick (DERRICK, 1999).

\subsubsection{ANÁLISE ELEMENTAR (AE)}

Análise elementar é a técnica instrumental utilizada na determinação dos teores de carbono, hidrogênio e nitrogênio num dado material. O ensaio é executado colocando-se a amostra numa cápsula de estanho que é introduzida num tubo de combustão, como mostra a Figura 19, na temperatura de $925^{\circ} \mathrm{C}$, sob atmosfera de $\mathrm{O}_{2}$ (PERKIN ELMER CORPORATION, 1988). Durante a combustão forma-se uma mistura de voláteis constituídos por $\mathrm{CO}_{2}, \mathrm{H}_{2} \mathrm{O}$, e óxido de nitrogênio $\left(\mathrm{N}_{2} \mathrm{O}_{\mathrm{x}}\right)$, que é arrastada por uma vazão contínua de He para um tubo de quartzo preenchido com cobre, cuja função é de reduzir os $\mathrm{N}_{2} \mathrm{O}_{\mathrm{x}}$ para $\mathrm{N}_{2}$. O tubo de combustão contém sais de prata, vanádio e tungstênio, que têm a finalidade de reter as outras substâncias formadas durante a queima (decomposição térmica) (MIYANO, 1996).

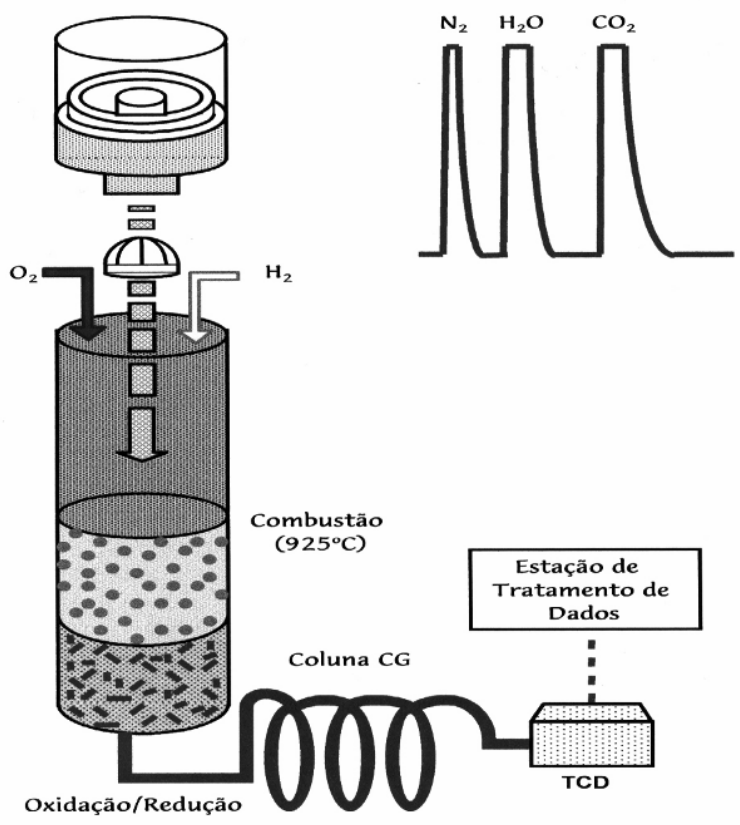

Figura 19 - Esquema do processo de determinação de carbono, hidrogênio e nitrogênio por análise elementar. 
A mistura de voláteis passa por uma coluna cromatográfica empacotada com sílica e os constituintes são separados por ordem de polaridade: $\mathrm{N}_{2}<\mathrm{CO}_{2}<\mathrm{H}_{2} \mathrm{O}$, os quais são detectados por um detector de condutividade térmica.

A análise elementar complementa outras técnicas analíticas e permite fazer comparações entre as proporções de carbono, hidrogênio e nitrogênio de diferentes amostras, possibilitando a compreensão da natureza dos materiais ou de seus mecanismos de reação.

\subsubsection{ANÁLISE TÉRMICA (TA)}

A análise térmica é um conjunto de técnicas pelas quais uma propriedade física de uma substância (e/ou de seus produtos de reação) é medida em função da temperatura e/ou tempo, enquanto a substância é submetida a uma programação controlada de temperatura (IONASHIRO \& GIOLITO, 1980; WENDLANDT, 1986; HAINES, 1995). Existem vários métodos de análise termoanalítica, porém todos os instrumentos têm características em comum. De maneira geral o que os diferencia é o tipo de transdutor empregado na sua construção, o qual tem a função de converter as propriedades físicas avaliadas em sinais elétricos. A Figura 20 mostra um esquema representativo de um analisador térmico atual.

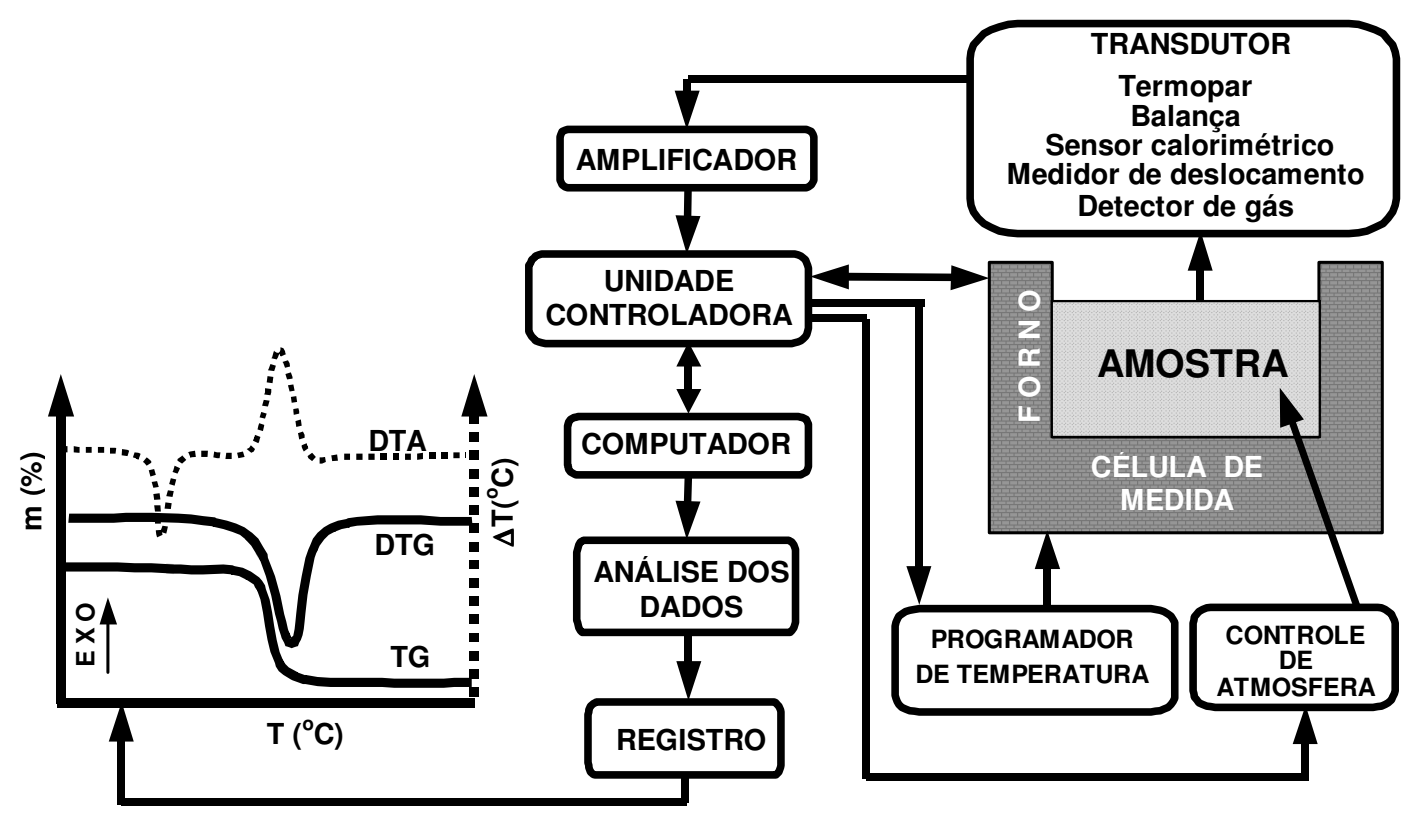

Figura 20 - Esquema representativo de um analisador térmico atual. 
Um analisador térmico é constituído por um forno (célula de medida) onde a temperatura da amostra é modificada para mais ou para menos a uma taxa controlada sob atmosfera previamente estabelecida. As mudanças das propriedades da amostra são monitoradas por um transdutor seletivo que pode ser constituído por: a) termopares; b) balança; c) sensor calorimétrico; d) medidor de deslocamento; e) detector de gás. O transdutor gera um sinal elétrico que é amplificado e transmitido para a unidade controladora, mantendo a comunicação permanente com a célula de medida. Esta unidade, além de receber os dados da célula de medidas, transfere as informações necessárias para colocar o equipamento em operação de acordo com os parâmetros previamente estabelecidos. A unidade controladora é interfaceada por um microcomputador que controla a operação, a aquisição e análise de dados e o registro da curva termoanalítica gerada ( MATOS, 2004).

Destas técnicas, as mais amplamente difundidas e utilizadas são a termogravimetria/termogravimetria derivada (TG/DTG), a análise térmica diferencial (DTA) e a calorimetria exploratória diferencial (DSC).

\subsection{TERMOGRAVIMETRIA (TG)}

A termogravimetria é uma técnica de análise térmica onde a variação da massa da amostra é determinada em função da temperatura e/ou tempo, enquanto a amostra é submetida a uma programação controlada de temperatura. A termogravimetria nos dá informações sobre as alterações que o aquecimento pode provocar na massa das substâncias, permitindo estabelecer a faixa de temperatura que elas adquirem composição química fixa, definida e constante, a temperatura em que começam a se decompor, acompanhar o andamento de reações de desidratação, oxidação, combustão, decomposição, etc.. Em relação a obras de arte essa técnica pode fornecer informações de extrema importância, pois permite avaliar a estabilidade térmica das matérias primas empregadas na confecção da peça e o teor de umidade após certo período de exposição. Ainda é possível desenvolver o estudo da cinética de decomposição térmica dos materiais das diversas camadas da obra visando obter informações quanto às condições ambientais para a sua conservação. Também, pode-se investigar amostras de obras de arte antigas, com o intuito de caracterização dos materiais empregados pelo artista e avaliação do seu estado de conservação. Três tipos de TG são normalmente usados: a) TG isotérmica - massa registrada em função do tempo à temperatura constante; b) TG quaseisotérmica - amostra é aquecida à uma razão de aquecimento linear enquanto não ocorre alteração de massa, a partir do momento em que a balança detecta a variação de massa a 
temperatura é mantida constante até se obter um novo patamar, característico de massa constante para a amostra, e assim sucessivamente; c) TG dinâmica ou convencional - amostra é aquecida ou resfriada num ambiente cuja temperatura varia de maneira pré-determinada, de preferência à razão de aquecimento ou resfriamento linear (WENDLANDT, 1986).

No método termogravimétrico convencional ou dinâmico, são registradas curvas de massa da amostra (M) em função da temperatura $(\mathrm{T})$ ou do tempo (t), conforme a Equação 6.

$$
M=f(T \text { ou } t)
$$

Essas curvas são denominadas curvas termogravimétricas ou, simplesmente curvas TG.

\subsection{TERMOGRAVIMETRIA DERIVADA (DTG)}

Na termogravimetria derivada (DTG), as curvas são registradas a partir das curvas de TG e correspondem à derivada primeira da variação de massa em relação ao tempo $(\mathrm{dm} / \mathrm{dt})$, que é registrada em função da temperatura ou do tempo, isto é conforme a equação de reação 7; ou à derivada primeira da variação da massa em relação à temperatura $(\mathrm{dm} / \mathrm{dT})$ que é registrada em função da temperatura ou do tempo, conforme a equação de reação 8 .

$$
\begin{aligned}
\mathrm{dm} / \mathrm{dt} & =\mathrm{f}(\mathrm{T} \text { ou } \mathrm{t}) \\
\mathrm{dm} / \mathrm{dT} & =\mathrm{f}(\mathrm{T} \text { ou } \mathrm{t})
\end{aligned}
$$

A curva DTG simplesmente apresenta os dados da curva TG de forma diferente, mais facilmente visualizável. A curva DTG permite a pronta determinação da temperatura em que a taxa de variação da massa é máxima $\left(\mathrm{T}_{\text {pico }}\right)$ e fornece informações adicionais para $\mathrm{T}_{\text {onset }}$ (início extrapolado do evento térmico) e $\mathrm{T}_{\text {endset }}$ (final extrapolado do evento térmico). $\mathrm{A}$ área de pico sob a curva DTG é diretamente proporcional à variação de massa. A altura do pico da curva DTG a qualquer temperatura fornece a razão de variação de massa naquela temperatura. Esses valores podem ser usados para obter informações cinéticas, visto que as equações podem ser escritas conforme a equação de reação 9 (WENDLANDT, 1986).

$$
-\mathrm{dm} / \mathrm{dt}=\mathrm{A} \mathrm{e} \mathrm{e}^{(-\mathrm{E} / \mathrm{RT})} \mathrm{f}(\mathrm{m})
$$

Onde A é o fator pré-exponencial, E é a energia de ativação e R é a constante da lei dos gases. 


\subsection{CALORIMETRIA EXPLORATÓRIA DIFERENCIAL (DSC)}

Existem dois tipos de DSC: DSC de fluxo de calor e DSC de compensação de potência; as quais se diferenciam devido à configuração do equipamento.

A DSC de fluxo de calor é uma técnica derivada da DTA. A propriedade física medida também é a diferença de temperatura entre a amostra $(A)$ e a referência $(R)\left(\Delta T=T_{A}-T_{R}\right)$, enquanto ambos são submetidos à uma programação rigorosamente controlada de temperatura. A amostra e referência são colocadas em cápsulas idênticas, posicionadas sobre um disco termoelétrico e aquecidas por uma única fonte de calor. O calor é transferido para as cápsulas de amostra e referência por meio do disco, com o fluxo de calor entre ambas as cápsulas sendo controlado por meio de termopares conectados ao disco, uma vez que $\Delta \mathrm{T}$, em um dado momento, é proporcional à variação de entalpia, à capacidade calorífica e à resistência térmica total do fluxo calórico (MACHADO \& MATOS 2004).

O DSC de compensação de potencia é um calorímetro que mede diretamente a energia envolvida nos eventos térmicos. A amostra e a referência são aquecidas ou resfriadas em fornos separados idênticos ambos em condições isotérmicas. Se a amostra sofre alteração de temperatura devido à um evento endotérmico ou exotérmico, os termopares detectam a diferença de temperatura entre ela e a referência, e o equipamento automaticamente modifica a potência de entrada de um dos fornos de modo a igualar a temperatura de ambos. A diferença entre o calor fornecido à amostra e à referência $(\mathrm{dH} / \mathrm{dt})$ é registrada em função da temperatura (T) ou do tempo (t) (McNAUGHTIN \& MORTIMER, 1975).

As técnicas termoanalíticas nos dão informações de extrema importância a respeito do comportamento térmico das amostras de obras de arte, contribuindo para o conhecimento de sua composição e mecanismos de reação (BURMESTER, 1992; ODLYHA, 2000; RIZZO et al., 2002). 


\section{MATERIAIS E MÉTODOS}

\subsection{MATERIAIS}

\subsubsection{MATÉRIAS PRIMAS}

Com a finalidade de caracterização dos materiais e comparação dos resultados, foram analisadas amostras das matérias primas utilizadas na confecção das obras de arte, segundo os procedimentos descritos na literatura, comumente chamados de "receitas" pelos artistas.

Os seguintes materiais foram adquiridos no Palácio da Cera, aonde normalmente os artistas e restauradores costumam comprar: (a) cera bruta de abelhas (CRBRAB); (b) cera clarificada de abelhas (CRCLAB); (c) cera de carnaúba T1, T3 e T4 (CRCN T1, T3 E T4); resina natural damar (RSDM). Como já foi mencionado anteriormente toda a produção de cera de carnaúba tipo 2 do Brasil é destinada à exportação.

\subsubsection{AMOSTRAS RETIRADAS DE OBRAS DE ARTE}

Foram estudadas amostras retiradas das personagens de cera do Museu de Cera Alpino, antes e depois de serem restauradas. Oito cabeças de esculturas, listadas na Tabela 5, foram disponibilizadas pelo museu para realização deste trabalho. Dessas, duas foram selecionadas e estudadas: Afonso Pena (AP - cabeça quebrada) e Lampião (LP - cabeça inteira).

Tabela 5 - Cabeças de esculturas disponibilizadas pelo Museu de Cera Alpino.

\begin{tabular}{l|l}
\hline CABEÇA DE ESCULTURA & CABEÇA DE ESCULTURA \\
\hline 1 - Nilo Peçanha & $2-$ General Osório \\
\hline $3-$ Afonso Pena & $4-$ Alvarenga Peixoto \\
\hline $5-$ Manoel da Nóbrega & $6-$ D. Pedro II \\
\hline 7 - Lampião & $8-$ Campos Salles \\
\hline
\end{tabular}

Por se tratarem de obras de arte, a retirada de amostras é muito limitada. A escolha destas duas personagens foi baseada nos seguintes critérios: a cabeça da personagem Lampião foi a 
que sofreu maior dano, a parte deteriorada não se limitou a superfície, chegando a se aprofundar cerca de $0,5 \mathrm{~cm}$; e a cabeça da personagem Afonso Pena está quebrada, com partes faltantes e o museu não tem a intenção de restaurá-la, facilitando a retirada de amostras de lugares não visíveis.

As Figuras 21 a 34 são ilustrações dessas cabeças de esculturas ou partes delas.

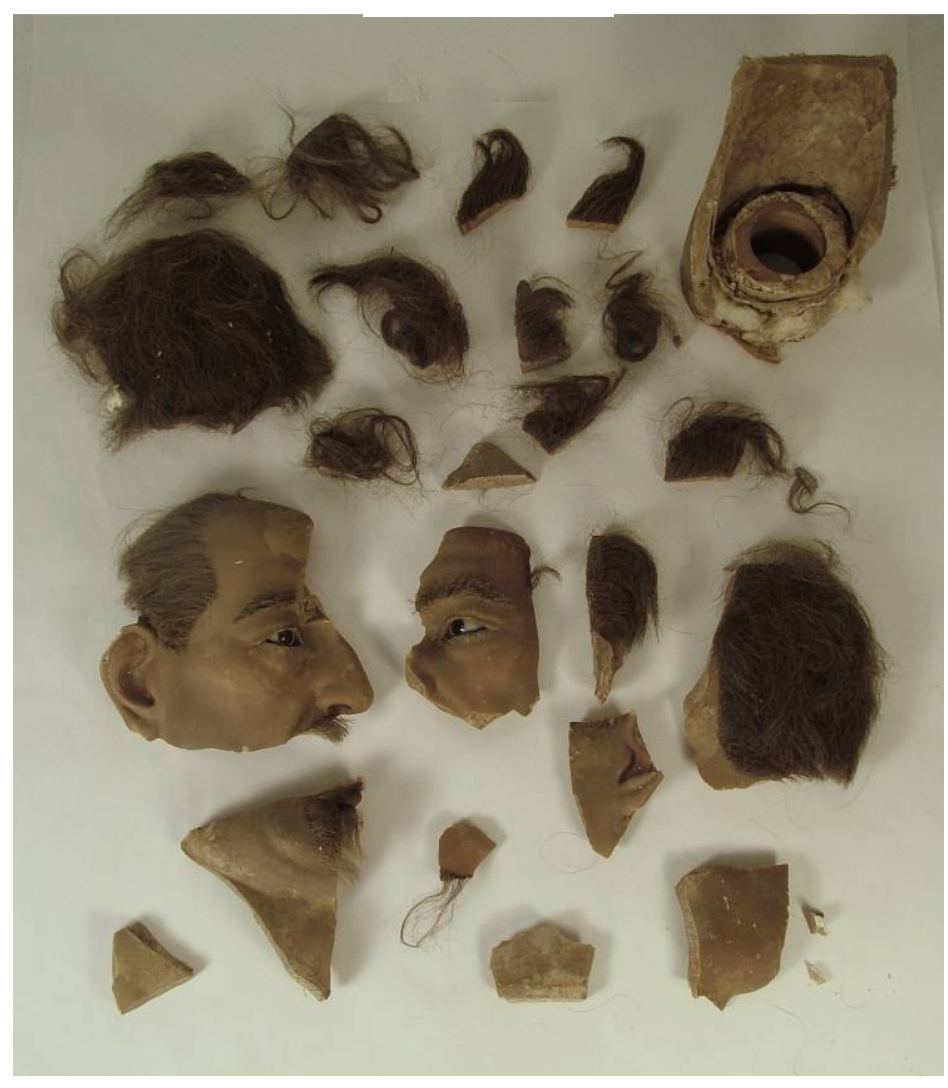

Figura 21 - Cabeça quebrada da personagem Afonso Pena (AP).

Da personagem apresentada na Figura 21 os fragmentos ou amostras ilustradas nas Figuras 22 a 27 foram estudados: 


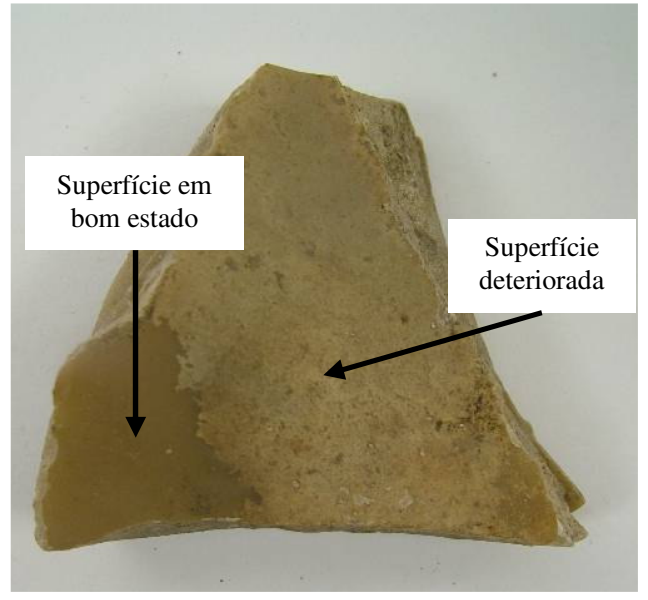

Figura 22 - Detalhe da superfície de um fragmento da cabeça de Afonso Pena (AP), mostrando a cera deteriorada (parte branca) e a cera em bom estado (parte mais escura). Vista frontal.

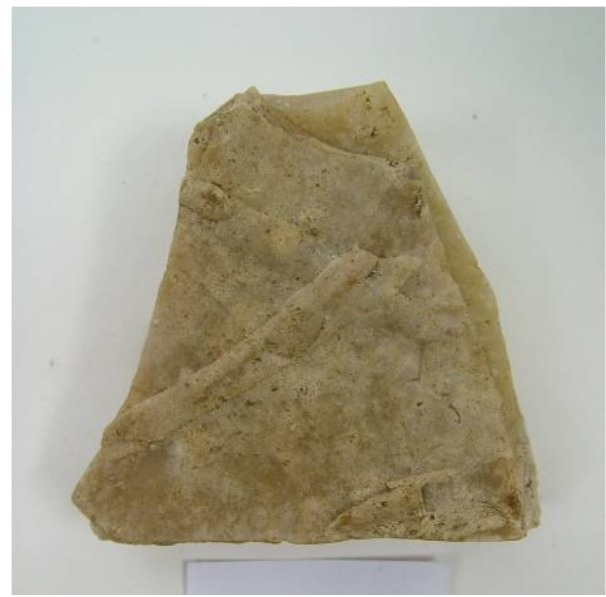

Figura 23 - Detalhe da parte interna de um fragmento da cabeça de Afonso Pena (AP), mostrando a cera mais dura usada no interior da cabeça. Vista posterior.

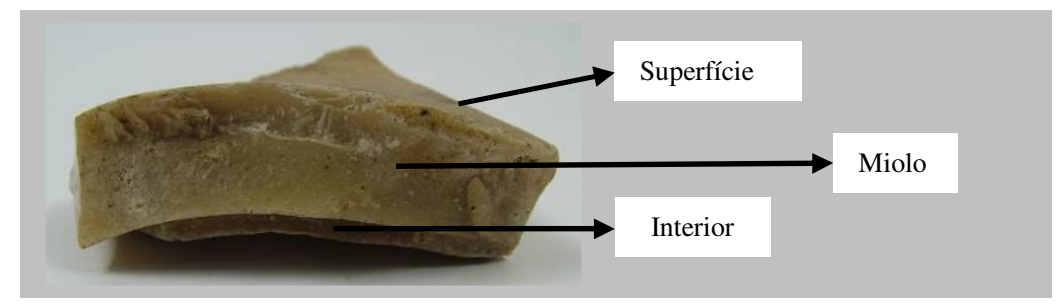

Figura 24 - Detalhe da secção transversal de um fragmento da cabeça de Afonso Pena (AP), mostrando as três camadas: superfície, miolo e interior. Vista lateral. 


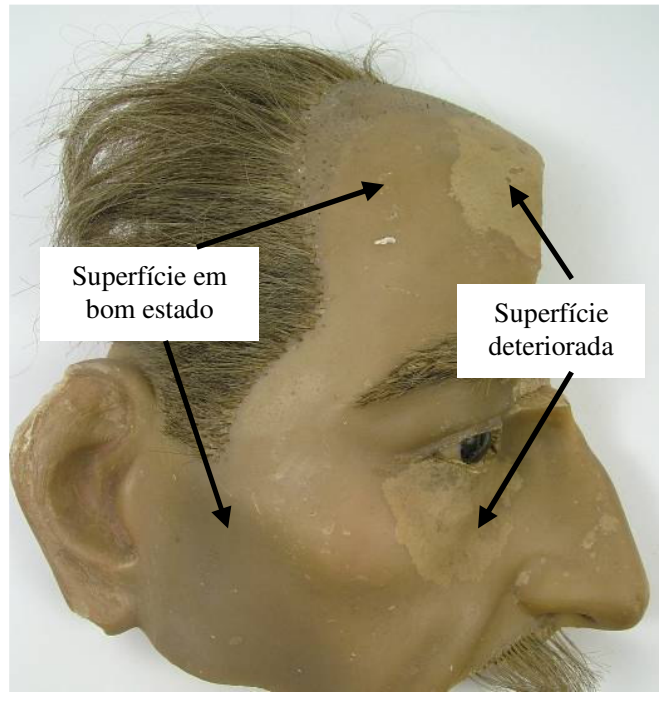

Figura 25 - Detalhe da superfície de um fragmento da cabeça de Afonso Pena (AP), mostrando a cera deteriorada (partes brancas) e a cera em bom estado (partes coloridas mais escuras). Vista frontal.

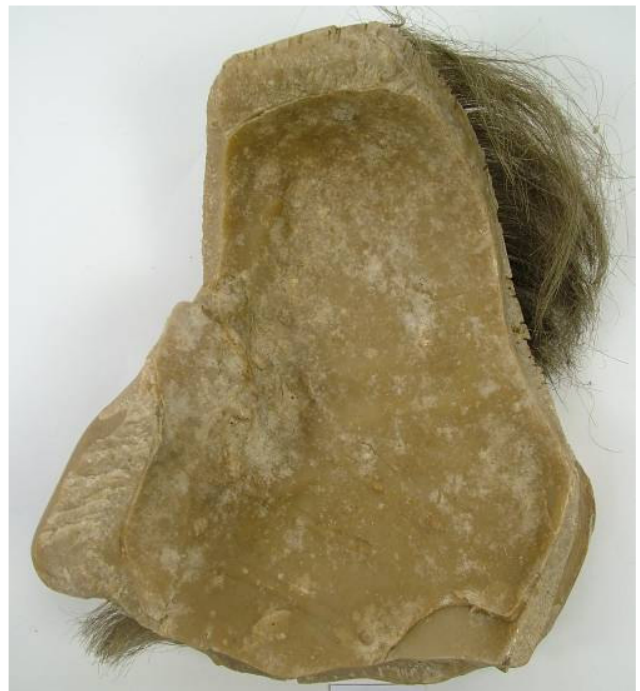

Figura 26 - Detalhe da parte interna de um fragmento da cabeça de Afonso Pena (AP), mostrando a cera mais dura usada no interior da cabeça. Vista posterior.

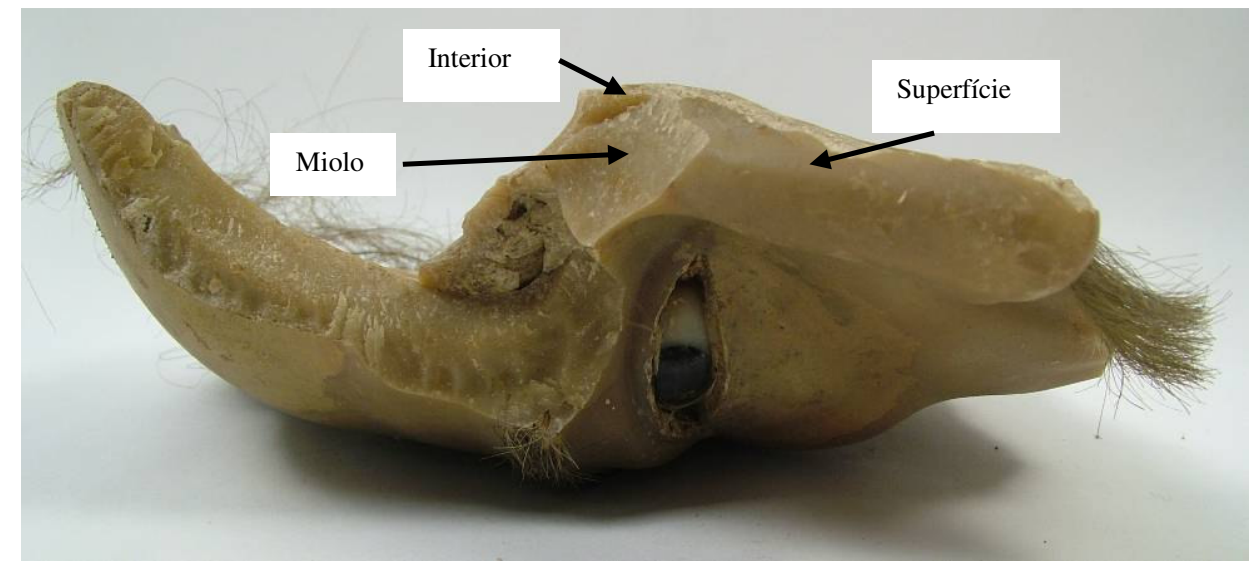

Figura 27 - Detalhe da secção transversal de um fragmento da cabeça da personagem Afonso Pena (AP), mostrando as três camadas: superfície, miolo e interior. Vista lateral. 


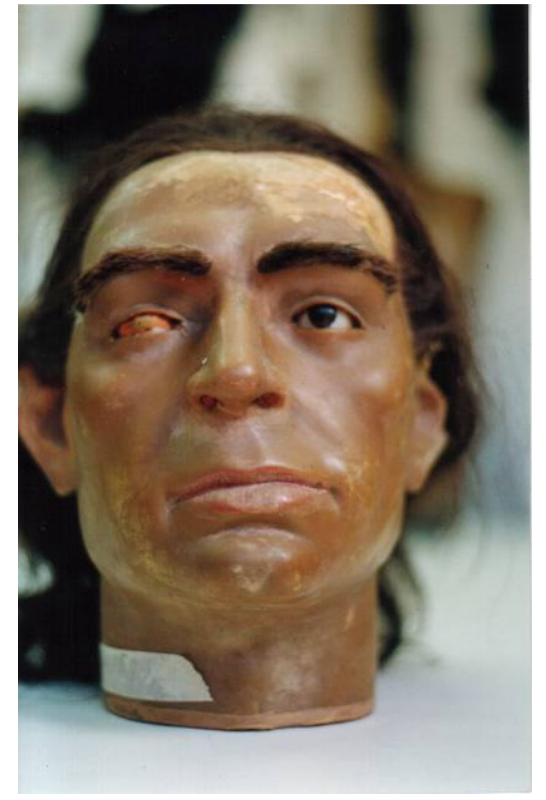

Figura 28 - Vista frontal da personagem Lampião (LP).

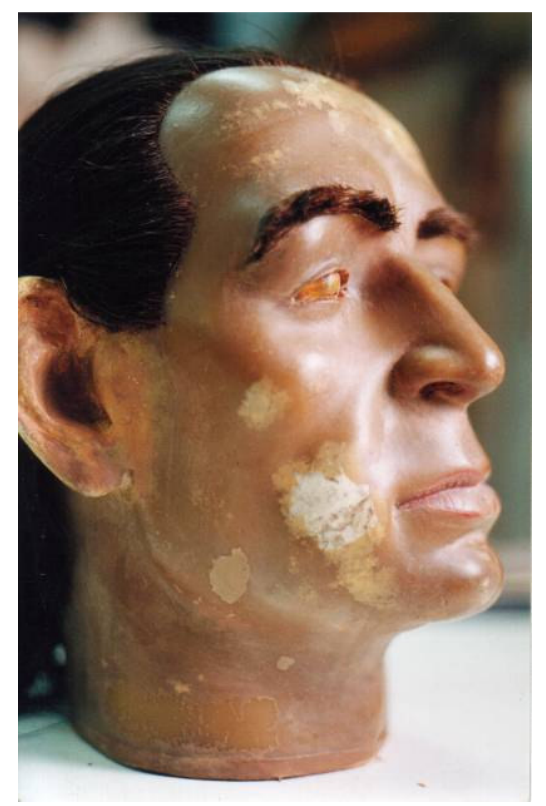

Figura 30 - Vista lateral direita da personagem Lampião (LP).

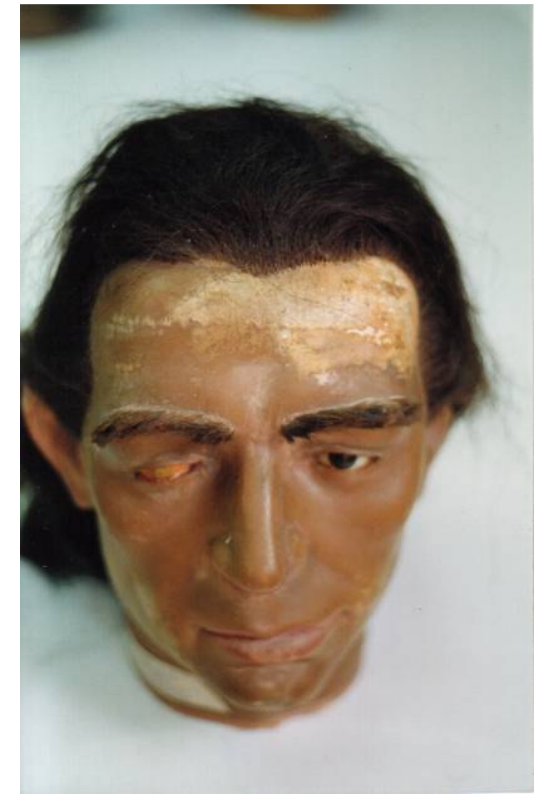

Figura 29 - Vista frontal superior da personagem Lampião (LP).

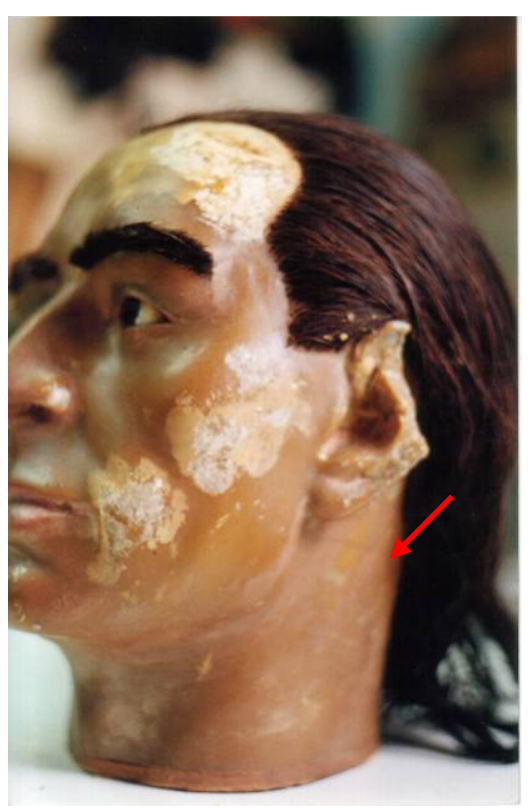

Figura 31 - Vista lateral esquerda da personagem Lampião (LP). A seta vermelha indica o local da amostragem da cera em bom estado da superfície. 
Da personagem apresentada nas Figuras 28 a 31 as amostras de cera deteriorada (Figuras 32 e 33) e cera deteriorada restaurada com calor (Figura 34) indicadas pelas setas foram retiradas para estudos.

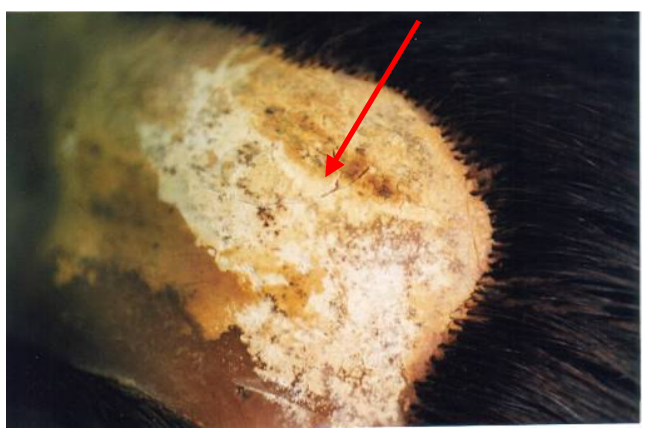

Figura 32 - Detalhe da cera deteriorada da cabeça da personagem Lampião (LP).

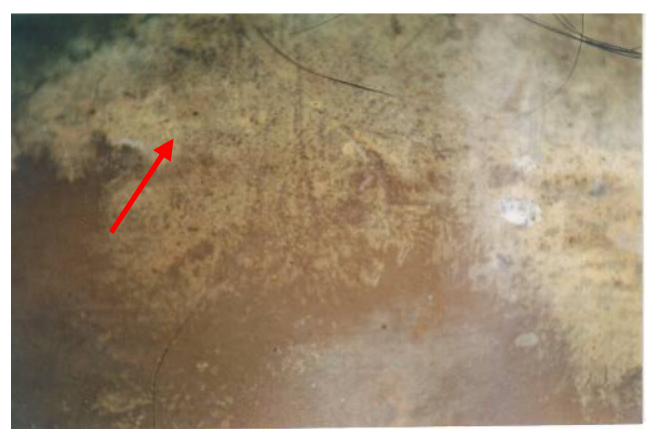

Figura 33 - Detalhe da cera deteriorada da cabeça da personagem Lampião (LP).

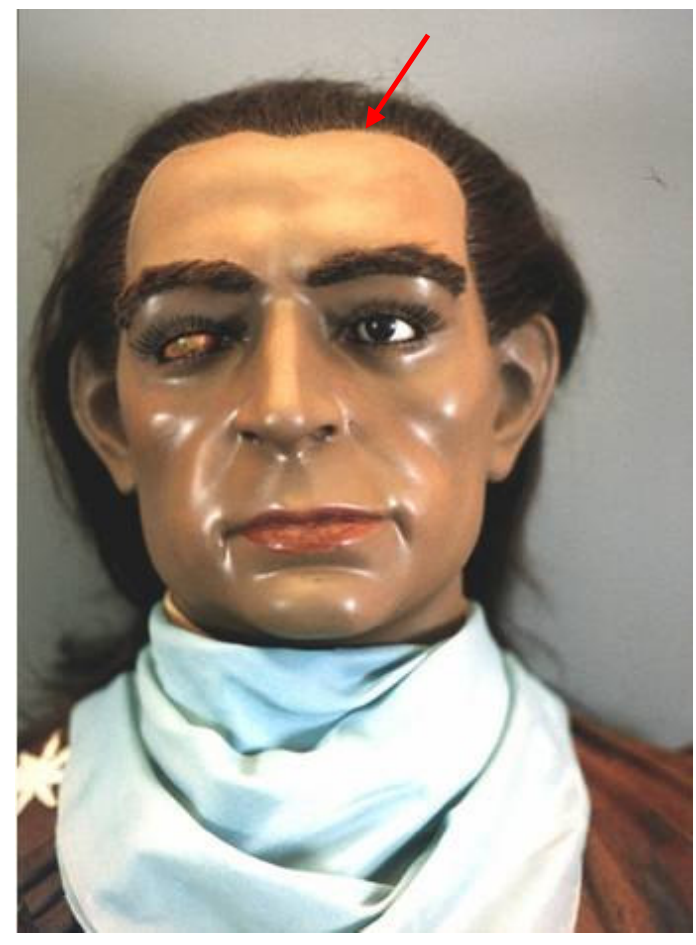

Figura 34 - Cabeça da personagem Lampião (LP) depois de restaurada. 


\subsubsection{RESUMO DOS MATERIAIS}

A Tabela 6 resume os materiais utilizados, relacionando o código, a descrição e o tipo de amostra.

Tabela 6 - Relação do código, descrição e tipo das amostras analisadas.

\begin{tabular}{l|l|l}
\hline \multicolumn{1}{c|}{ CÓDIGO DA AMOSTRA } & DESCRIÇÃo & TIPO \\
\hline CRBRAB & AMOSTRAS DE REFERÊNCIA & \\
\hline CRCLAB & Cera bruta de abelhas & Referência \\
\hline CRCNT1 & Cera clarificada de abelhas & Referência \\
\hline CRCNT3 & Cera de carnaúba tipo 1 & Referência \\
\hline CRCNT4 & Cera de carnaúba tipo 3 & Referência \\
\hline RSDM & Cera de carnaúba tipo 4 & Referência \\
\hline & Resina damar & Referência \\
\hline AP & AMOSTRAS DE OBRAS & \\
\hline LP & $\begin{array}{l}\text { Amostras retiradas da cabeça da personagem } \\
\text { Afonso Pena }\end{array}$ & Obra de arte \\
\hline & $\begin{array}{l}\text { Amostras retiradas da cabeça da personagem } \\
\text { Lampião }\end{array}$ & Obra de arte \\
\hline
\end{tabular}

Obs.: Os códigos que simbolizam o lugar de proveniência e o estado das amostras, por ex: AP_CRBESP (Afonso Pena_cera em bom estado da superfície) estão relacionados na Lista de abreviaturas, siglas e símbolos no início do trabalho.

\subsection{MÉTODOS DE ANÁLISE}

Muitos métodos analíticos têm sido utilizados nos últimos anos com o intuito de determinar a composição das ceras de abelhas (JIMÉNEZ et al., 2005; JIMÉNEZ et al., 2006; KAMEDA, 2004; VOORHEES, BEVERLY \& KAY, 1995). Alguns deles são muito eficientes como os métodos cromatográficos, porém, no processo de preparação das amostras, devido à baixa volatilidade de seus componentes o primeiro passo é a hidrólise dos ésteres, seguido da derivatização. Com estes procedimentos, informações sobre as alterações ocorridas no processo de degradação podem ser perdidas. Neste trabalho, portanto, foram preferidos os tipos de análise para caracterização das obras de arte e de seus produtos de degradação, onde não é necessária a modificação da amostra devido à processos de preparação.

É necessário salientar que a expressão "análise não destrutiva” tem significado diferente para os químicos e para os restauradores. Para os químicos "análise não destrutiva" é aquela que não destrói a amostra enquanto que para os restauradores é aquela que não destrói a obra, ou seja, não é invasiva, pois nenhuma amostra é retirada. 
Foi utilizada uma metodologia analítica diversificada, baseada no uso de técnicas complementares (RIZZO, 2005; REGERT et al., 2006).

As cabeças de cera das personagens do Museu Alpino são constituídas por três camadas: a interior de material mais duro com cerca de $2 \mathrm{~mm}$ de espessura, sobre esta camada existe uma outra a qual chamamos de miolo, de material mais macio com cerca de 1,25 cm de espessura e por último a camada externa, ou da superfície, colorida e translúcida, que tem alguns microns de espessura. A Figura 35 esquematiza esta estratigrafia e as Figuras 24 e 27 ilustram a vista lateral das personagens AP e LP respectivamente.

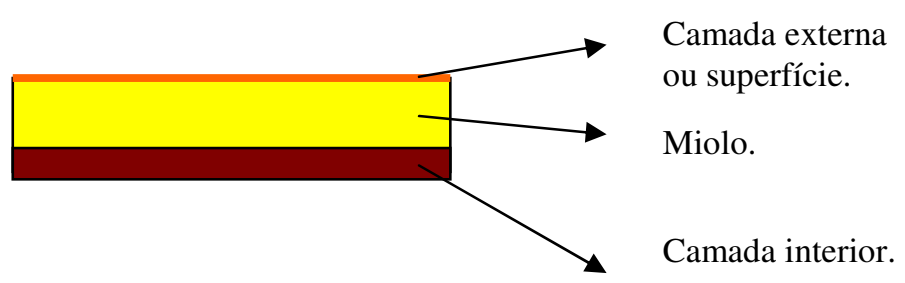

Figura 35 - Esquema de corte estratigráfico das esculturas de cera.

Antes de iniciar as análises foram utilizadas diferentes técnicas de observação e documentação através de aquisição de imagens em todas as amostras de obras de arte: observação organoléptica, fotografias com câmera digital, com luz visível e com radiação ultravioleta. Foram obtidas também fotografias sob a lupa binocular microscópica, com o intuito de documentação e determinação dos melhores pontos e/ou áreas para serem analisados pelas diferentes técnicas. Todas as situações de interesse foram analisadas: as três camadas da obra (superfície, miolo e interior), sendo que na superfície foram comparadas a parte íntegra e parte deteriorada.

Inicialmente foram realizadas as análises com técnicas não invasivas e/ou não destrutivas em seguida foram realizadas as análises com retirada de amostras das obras ou fragmentos de obras.

A Tabela 7 mostra todas as técnicas empregadas no processo de caracterização das amostras de referência e das amostras de material em bom estado, bem como do material modificado retiradas das obras de arte; e também, as técnicas de análise térmica utilizadas para o estudo termoanalítico. 
Tabela 7 - Resumo das técnicas empregadas no processo de caracterização das amostras de referência e das amostras retiradas de obras de arte.

\begin{tabular}{l|c|c|c|c|c|c}
\hline $\begin{array}{c}\text { MATERIA } \\
\text { PRIMA }\end{array}$ & TG & DTG & DSC & MEV & FTIR & AE \\
\hline CRBRAB & $\mathbf{X}$ & $\mathbf{X}$ & $\mathbf{X}$ & & $\mathbf{X}$ & $\mathbf{X}$ \\
\hline CRCLAB & $\mathbf{X}$ & $\mathbf{X}$ & $\mathbf{X}$ & & $\mathbf{X}$ & $\mathbf{X}$ \\
\hline CRCN-T1 & $\mathbf{X}$ & $\mathbf{X}$ & $\mathbf{X}$ & & $\mathbf{X}$ & $\mathbf{X}$ \\
\hline CRCN-T3 & $\mathbf{X}$ & $\mathbf{X}$ & $\mathbf{X}$ & & $\mathbf{X}$ & $\mathbf{X}$ \\
\hline CRCN-T4 & $\mathbf{X}$ & $\mathbf{X}$ & $\mathbf{X}$ & & $\mathbf{X}$ & $\mathbf{X}$ \\
\hline RsDM & $\mathbf{X}$ & $\mathbf{X}$ & $\mathbf{X}$ & & $\mathbf{X}$ & $\mathbf{X}$ \\
\hline $\begin{array}{c}\text { AMOSTRAS } \\
\text { DE OBRAS }\end{array}$ & & & & & & \\
\hline LP_CRDT & $\mathbf{X}$ & $\mathbf{X}$ & $\mathbf{X}$ & $\mathbf{X}$ & $\mathbf{X}$ & $\mathbf{X}$ \\
\hline LP_CRBESP & $\mathbf{X}$ & $\mathbf{X}$ & $\mathbf{X}$ & & $\mathbf{X}$ & $\mathbf{X}$ \\
\hline LP_CRDTRC & & & & & $\mathbf{X}$ & $\mathbf{X}$ \\
\hline LP_CRML & & & & & $\mathbf{X}$ & $\mathbf{X}$ \\
\hline LP_CRIT & & & & & $\mathbf{X}$ & $\mathbf{X}$ \\
\hline AP_CRDT & $\mathbf{X}$ & $\mathbf{X}$ & $\mathbf{X}$ & $\mathbf{X}$ & $\mathbf{X}$ & $\mathbf{X}$ \\
\hline AP_CRBESP & $\mathbf{X}$ & $\mathbf{X}$ & $\mathbf{X}$ & $\mathbf{X}$ & $\mathbf{X}$ & $\mathbf{X}$ \\
\hline AP_CRDTRC & & & & $\mathbf{X}$ & $\mathbf{X}$ & $\mathbf{X}$ \\
\hline AP_CRML & $\mathbf{X}$ & $\mathbf{X}$ & $\mathbf{X}$ & $\mathbf{X}$ & $\mathbf{X}$ & $\mathbf{X}$ \\
\hline AP_CRIT & $\mathbf{X}$ & $\mathbf{X}$ & $\mathbf{X}$ & & $\mathbf{X}$ & $\mathbf{X}$ \\
\hline
\end{tabular}

\subsubsection{CaracterizaÇÃo físico-Química e analítica das matérias primas e daS AMOSTRAS RETIRADAS DAS OBRAS DE ARTE}

\subsubsection{ANÁliSE NÃO DESTRUTIVA DE SUPERFíCIE}

Em amostras retiradas de obras de arte, que passarão por mais de um tipo de análise, sempre que possível começa-se pelas não invasivas e/ou não destrutivas.

\subsection{MICROSCOPIA ELETRÔNICA DE VARREDURA COM ANALISADOR DE DISPERSÃO DE ENERGIA DE RAIOS X ( MEV/EDS)}

As amostras AP_CRBESP, AP_CRDT, AP_CRDTRC e AP_CRML foram observadas no microscópio eletrônico MEV- Microscope Electron Varredure Quanta 600 da FEI acoplado a um EDS - Energy Dispersion System da marca Inca Oxford, na empresa Mahle, em São Paulo; e as amostras AP_CRDT e LP_CRDT foram observadas e analisadas por um 
equipamento semelhante da marca Phillips, modelo XL 30 na Universidade Federal de Santa Catarina (UFSC).

Pôde-se desta forma avaliar a morfologia das amostras, assim como obter-se a composição elementar das mesmas (para elementos com $\mathrm{Z}>4$ ).

\subsubsection{ANÁLISES COM RETIRADA DE AMOSTRA}

\subsubsection{ESTUDO TERMOANALÍTICO}

As amostras de referência CRBrAb, CrClAb, CrCnT1, CrCnT3, CrCnT4 e RsDm adquiridas no comércio local e as amostras AP_CrBESP, AP_CRDT, AP_CrML, AP_CRIT, LP_CRDT e LP_CRDTRC das personagens do Museu de Cera Alpino foram avaliadas termoanaliticamente por termogravimetria/termogravimetria derivada (TG/DTG) e calorimetria exploratória diferencial (DSC) no Laboratório de Análise Térmica Dr. Ivo Giolito (LATIG) no Instituto de Química da Universidade de São Paulo (IQ/USP).

\subsection{TERMOGRAVIMETRIA E TERMOGRAVIMETRIA DERIVADA (TG/DTG)}

Os ensaios de TG/DTG foram empregados para avaliar o comportamento térmico de todas as amostras utilizadas no estudo termoanalítico. Esses ensaios foram executados empregando a termobalança, modelo TGA-51, da marca Shimadzu, que permite uma detecção de variação de massa de $\pm 1 \mu$ g. Essa termobalança pode operar com capacidade máxima de cerca de 2000 $\mathrm{mg}$ e o forno permite fazer aquecimentos desde a temperatura ambiente até $1500^{\circ} \mathrm{C}$.

As curvas TG/DTG foram obtidas na faixa de temperatura de 25 a $900^{\circ} \mathrm{C}$, sob atmosfera dinâmica de ar $\left(50 \mathrm{~mL} \mathrm{~min}{ }^{-1}\right)$, razão de aquecimento de $10^{\circ} \mathrm{C} \mathrm{min}^{-1}$, utilizando cadinho de platina contendo massa de amostra em torno de $15 \mathrm{mg}$. Antes dos ensaios verificou-se a calibração da instrumentação empregando-se uma amostra padrão de oxalato de cálcio monoidratado conforme norma ASTM (E1582 - 04). Periodicamente era executado, nas mesmas condições experimentais, um ensaio com cadinho vazio para obtenção da curva em branco. Essa curva em branco foi empregada para subtração de linha base, visto que nesse sistema ocorre um aparente ganho de massa durante o aquecimento. 


\subsection{CALORIMETRIA EXPLORATÓRIA DIFERENCIAL (DSC)}

As medidas de DSC permitiram avaliar o comportamento térmico de todas as amostras utilizadas no estudo termoanalítico a partir da temperatura ambiente até $725^{\circ} \mathrm{C}$. As curvas DSC foram obtidas mediante o emprego de uma célula calorimétrica, modelo DSC-50, da marca Shimadzu, sob atmosfera dinâmica de $\mathrm{N}_{2}\left(50 \mathrm{~mL} \mathrm{~min}^{-1}\right)$ e razão de aquecimento de $10^{\circ} \mathrm{C} \min ^{-1}$, no intervalo de temperatura entre 25 e $500^{\circ} \mathrm{C}$, em cápsulas de $\mathrm{Al}$ parcialmente fechadas e massas de amostra em torno de $2 \mathrm{mg}$.

Antes dos ensaios foram obtidas curvas em branco para avaliar a linha base do sistema. A célula DSC foi calibrada (antes dos experimentos) e verificada a sua calibração (depois dos experimentos), empregando as substâncias padrão $\operatorname{In}^{0}\left(\mathrm{~T}_{\text {fusão }}=156,6^{\circ} \mathrm{C} ; \Delta \mathrm{H}_{\text {fusão }}=28,7 \mathrm{~J} \cdot \mathrm{g}^{-1}\right) \mathrm{e}$ $\mathrm{Zn}^{0}\left(\mathrm{~T}_{\text {fusão }}=419,5^{\circ} \mathrm{C}\right)$ metálicos com pureza de $99,99 \%$.

Todos os resultados de TG/DTG e DSC foram tratados empregando o software TA-60 que faz parte da instrumentação.

\subsubsection{ESPECTROSCOPIA DE ABSORÇÃO NA REGIÃO DO INFRAVERMELHO (IR)}

Os espectros de absorção na região do infravermelho de todas as amostras de referência e de obras de arte foram obtidos em equipamento da marca Bomem modelo MB102, na região de 4000 a $400 \mathrm{~cm}^{-1}$ e registrados como transmitância vs número de ondas. As amostras foram trituradas, dispersas em $\mathrm{KBr}$, prensadas para a formação de pastilhas e adaptadas ao porta amostra para registro dos espectros. Os ensaios foram realizados nos Laboratórios da Central Analítica do Instituto de Química da USP.

\subsubsection{ANÁLISE ELEMENTAR (AE)}

Os teores de carbono, hidrogênio e nitrogênio de todas as amostras de referência e de obras de arte foram determinados no Laboratório da Central Analítica do IQ-USP, utilizando o equipamento Elemental Analyser 2400 CHN (PERKIN ELMER CORPORATION, 1988). O equipamento foi calibrado com o composto acetanilida e a precisão das determinações é de $0,3 \%$. 


\section{RESUlTADOS E DisCUSSÃO}

\subsection{ASPECTOS GERAIS SOBRE AS AMOSTRAS}

Nos itens 3.1.1. e 3.1.2. foram mencionados os critérios adotados para a seleção das amostras de matérias primas e esculturas empregadas no estudo de caracterização por variadas técnicas físico-químicas e analíticas.

Todas as matérias primas, exceto os pigmentos, que potencialmente tivessem sido utilizadas na confecção das obras de arte do Museu de Cera Alpino, foram estudadas com a intenção de comparação de dados com as amostras retiradas das obras de arte. São elas: cera bruta de abelhas, cera clarificada de abelhas, cera de carnaúba tipos 1, 3 e 4, e, resina damar.

Apesar da grande quantidade de esculturas que compõe o acervo do Museu de Cera Alpino, quase todas com problemas de deterioração da superfície da cera, a disponibilidade de material para estudo é muito pequena, por se tratarem de obras de arte. Das oito esculturas disponibilizadas dentre as cinqüenta e quatro existentes, apenas duas foram destinadas à pesquisa. Da escultura de Afonso Pena, que se encontrava quebrada e incompleta, pôde-se coletar maior quantidade de material da superfície (em bom estado e deteriorada), material do miolo e da parte interna (Figuras 22, 24 e 26). Da escultura de Lampião, que se encontrava inteira pôde-se retirar apenas uma pequena quantidade de material da superfície (em bom estado e deteriorada), Figuras 31 e 32, material do miolo e da parte interna, e, também, restaurado com calor (Figura 34). Apenas para relembrar todas as amostras foram codificadas conforme a lista de abreviaturas, siglas e símbolos.

\subsection{CARACTERIZAÇÃo dAS MATÉrias PRIMAS}

\subsubsection{ANÁLISE TÉRMICA (TA)}

A Figura 36 ilustra as curvas TG/DTG e DSC da amostra de cera bruta de abelhas. As curvas TG/DTG evidenciam que a amostra é estável termicamente até cerca de $215^{\circ} \mathrm{C}$ e se decompõe em duas etapas principais, entre 215 e $620^{\circ} \mathrm{C}$. A primeira ocorre rapidamente no intervalo de 215 a $428^{\circ} \mathrm{C}$, com acentuada perda de massa $\left(\Delta \mathrm{m}_{1}=85,21 \%\right.$ e $\left.\mathrm{T}_{\text {pico DTG }}=326^{\circ} \mathrm{C}\right)$. A segunda etapa ocorre de forma mais lenta entre 428 e $620^{\circ} \mathrm{C}\left(\Delta \mathrm{m}_{2}=13,92 \%\right)$ e é devido ao término da decomposição térmica e eliminação de material carbonáceo formado na etapa anterior. A curva DTG mostra que esta última etapa pode ser subdividida em dois eventos distintos $\left(\mathrm{T}_{\text {picos }}\right.$ 
DTG em 470 e $566^{\circ} \mathrm{C}$ ). Na temperatura de $620^{\circ} \mathrm{C}$ a perda de massa é praticamente completa, resta aproximadamente $1 \%$ de material inorgânico.

A curva DSC mostra eventos endotérmicos entre 30 e $75^{\circ} \mathrm{C}(\Delta \mathrm{H}=196 \mathrm{~J} / \mathrm{g})$, com $\mathrm{T}_{\text {pico DSC }}$ principal em $57,8^{\circ} \mathrm{C}$, devido a fusão do material, visto que na mesma faixa de temperatura as curvas TG/DTG não evidenciam perda de massa. A ampliação da faixa de fusão, ilustrada como detalhe no interior da figura, evidencia que há diferentes espécies fundindo no mesmo intervalo de temperatura, o que é característico para esse tipo de material. Após fusão, a curva DSC evidencia que inicialmente o processo de decomposição térmica da amostra é endotérmico, o que pode ser observado pela variação de linha base nesse sentido, porém acima de $260^{\circ} \mathrm{C}$ é exotérmico $\left(\mathrm{T}_{\text {pico DSC }}=436^{\circ} \mathrm{C}\right)$.

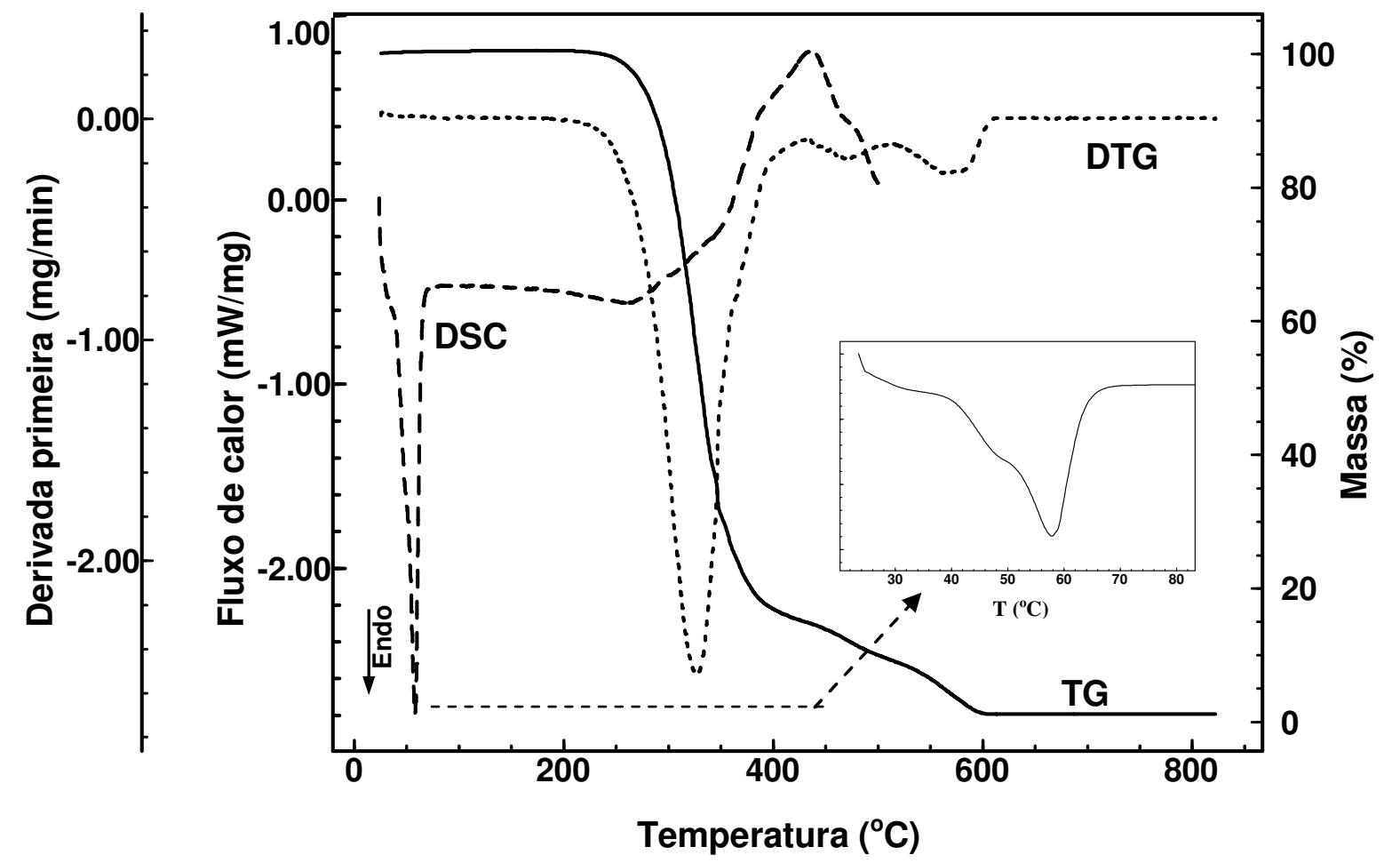

Figura 36 - Sobreposição das curvas TG/DTG e DSC da amostra CRBRAB.

A Figura 37 ilustra as curvas TG/DTG e DSC da amostra de cera clarificada de abelhas. As curvas TG/DTG evidenciam que a amostra é estável termicamente até cerca de $210^{\circ} \mathrm{C}$ e se decompõe em duas etapas principais, entre 210 e $600^{\circ} \mathrm{C}$. A primeira ocorre rapidamente entre 210 a $425^{\circ} \mathrm{C}$, com acentuada perda de massa $\left(\Delta \mathrm{m}_{1}=88,56 \%\right.$ e $\left.\mathrm{T}_{\text {pico DTG }}=319^{\circ} \mathrm{C}\right)$. A segunda 
etapa ocorre de forma mais lenta entre 425 e $600^{\circ} \mathrm{C}\left(\Delta \mathrm{m}_{2}=10,13 \%\right.$ e $\left.\mathrm{T}_{\text {pico DTG }}=556^{\circ} \mathrm{C}\right)$ e é devido ao término da decomposição térmica e eliminação de material carbonáceo formado na etapa anterior. $\mathrm{Na}$ temperatura de $600^{\circ} \mathrm{C}$ a perda de massa é praticamente completa, resta aproximadamente $1 \%$ de material inorgânico.

A curva DSC mostra eventos endotérmicos entre 30 e $75^{\circ} \mathrm{C}(\Delta \mathrm{H}=202 \mathrm{~J} / \mathrm{g})$, com $\mathrm{T}_{\text {pico DSC }}$ principal em $57,9^{\circ} \mathrm{C}$, devido a fusão do material, visto que na mesma faixa de temperatura as curvas TG/DTG não evidenciam perda de massa. A ampliação da faixa de fusão, ilustrada como detalhe no interior da figura, evidencia que há diferentes espécies fundindo no mesmo intervalo de temperatura, o que é característico para esse tipo de material. Após fusão, a curva DSC evidencia que inicialmente o processo de decomposição térmica da amostra é endotérmico, o que pode ser observado pela variação de linha base nesse sentido. Acima de $260^{\circ} \mathrm{C}$ o processo é exotérmico, como pode ser visto pelos eventos com $\mathrm{T}_{\text {picos DSC }}$ em 370 e $430^{\circ} \mathrm{C}$.

A comparação entre as curvas TG/DTG (Figura 38) e DSC (Figura 39) de ambas as ceras de abelhas (bruta e clarificada) não permite a diferenciação entre elas, porém pode-se observar a partir das curvas TG/DTG, que a decomposição térmica da amostra da cera clarificada de abelhas ocorre em temperaturas menores.

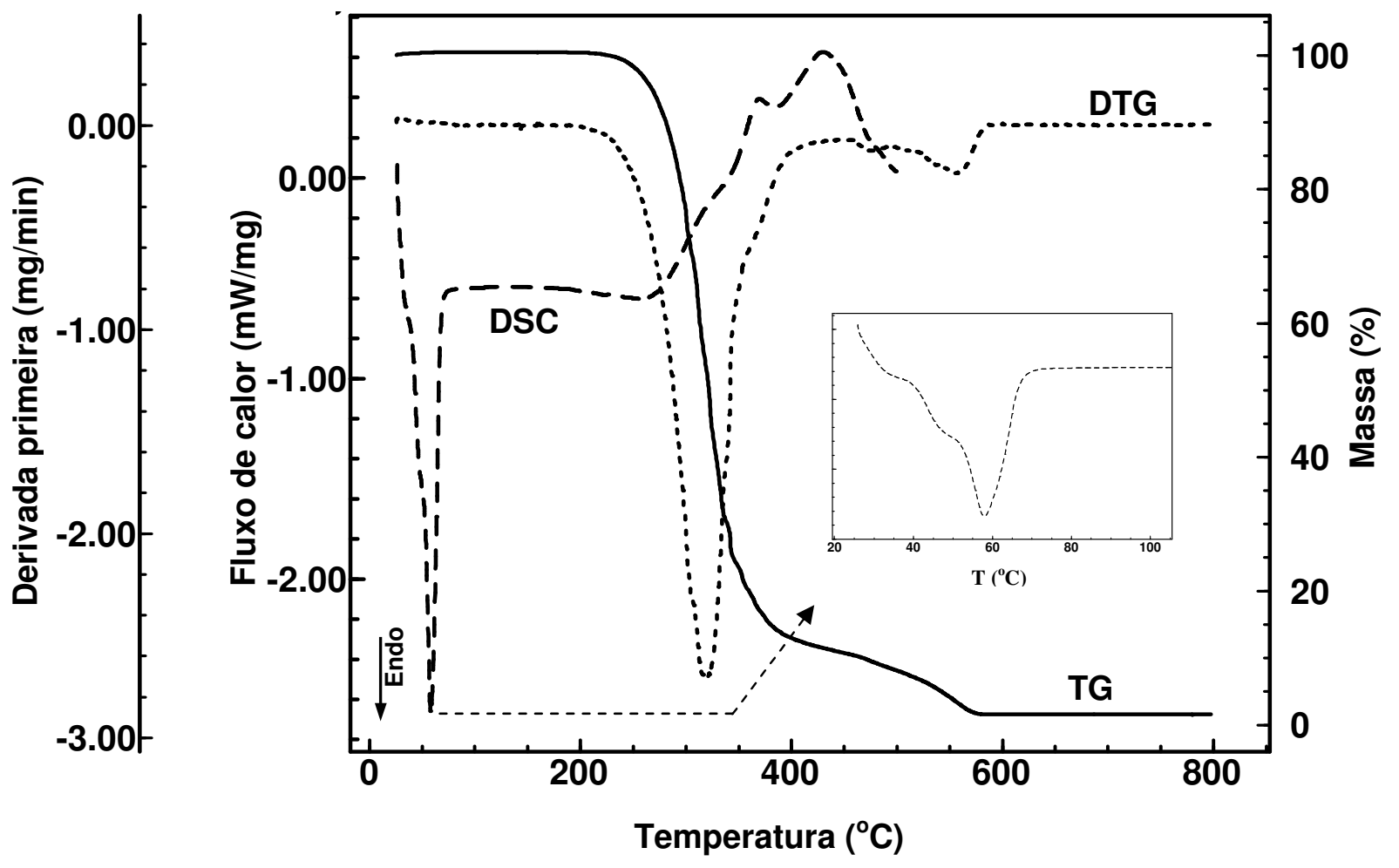

Figura 37 - Sobreposição das curvas TG/DTG e DSC da amostra CRCLAB. 


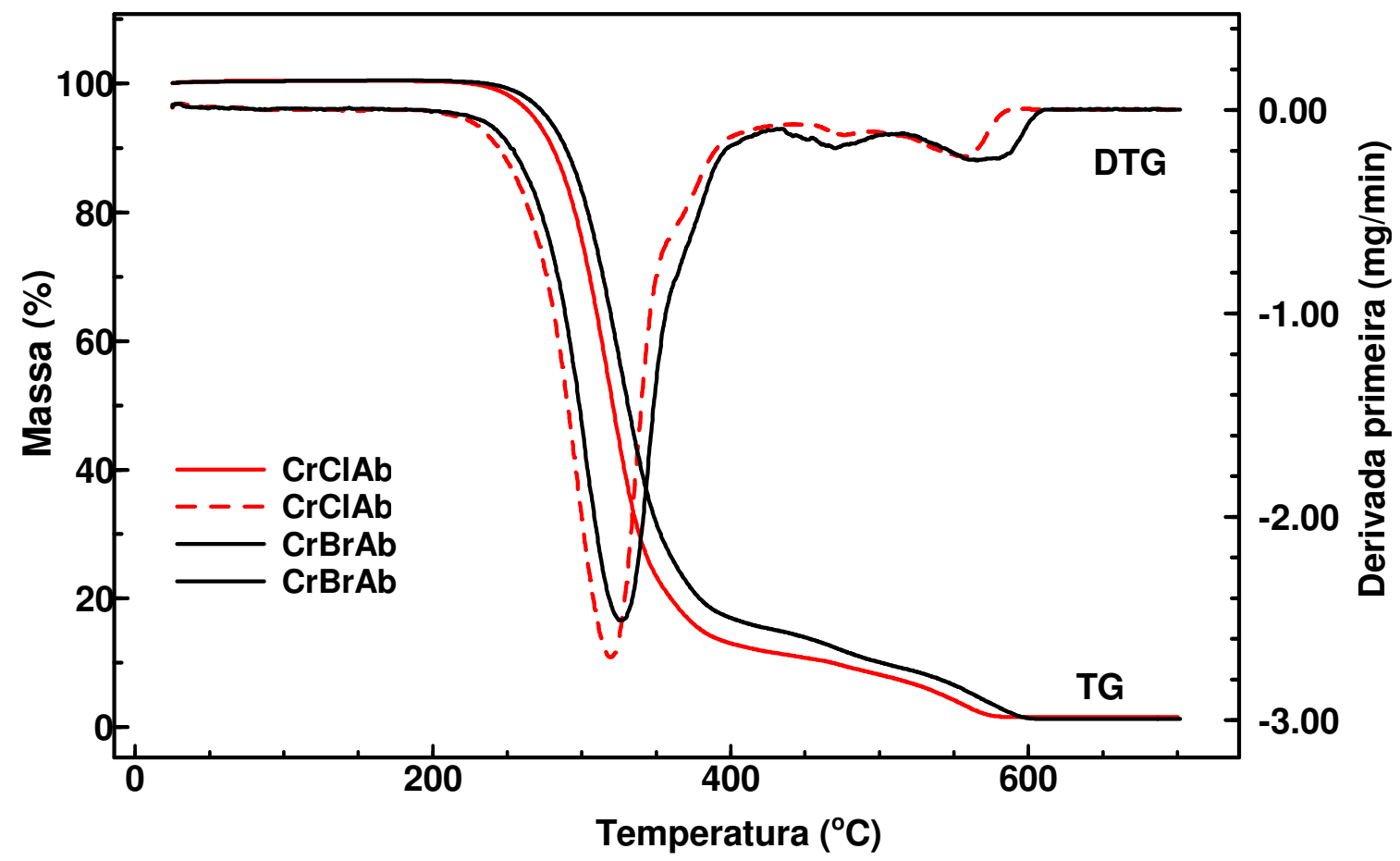

Figura 38 - Sobreposição das curvas TG/DTG das amostras de ceras de abelhas: (linhas vermelhas) clarificada e (linhas pretas) bruta.

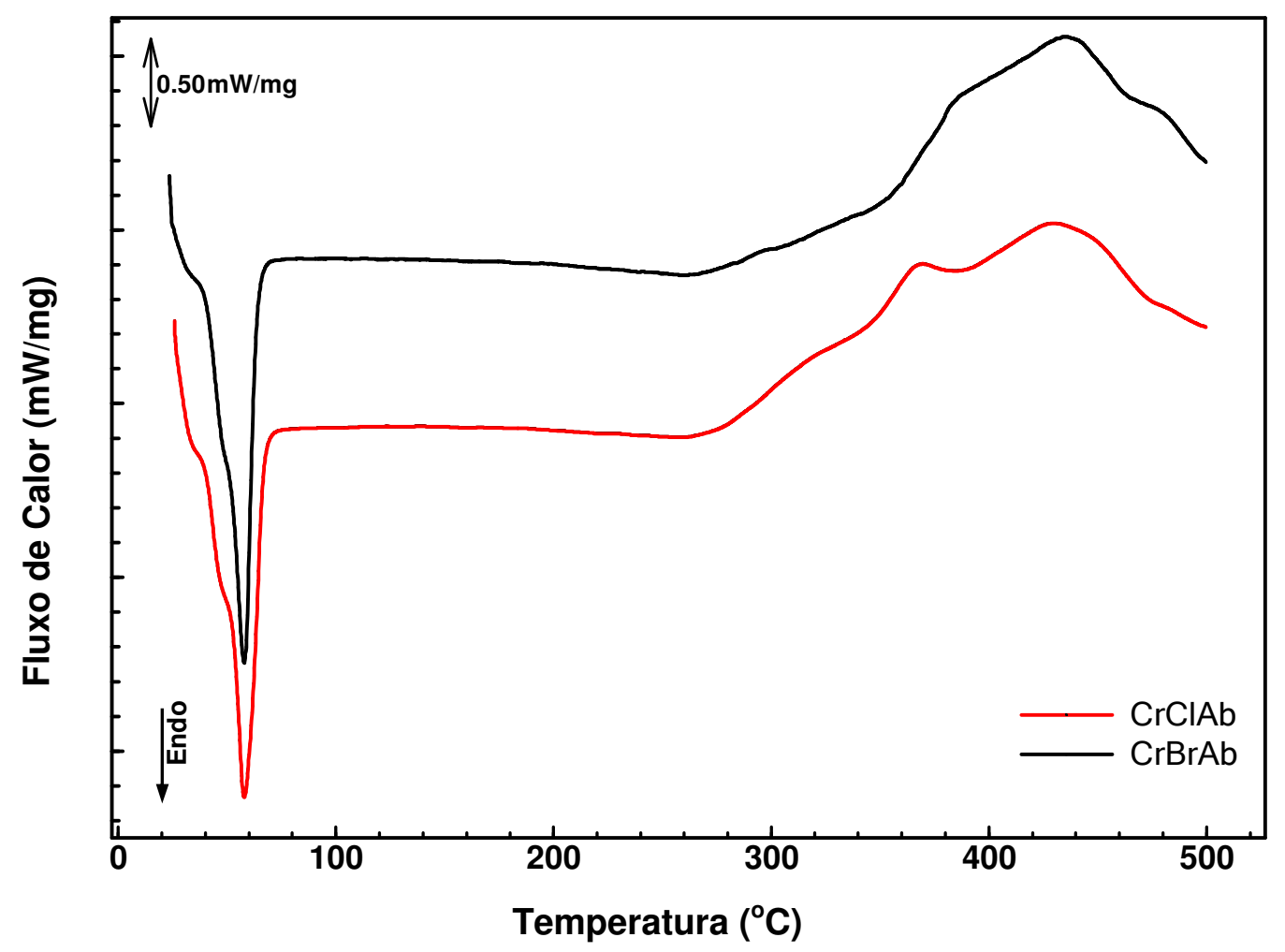

Figura 39 - Sobreposição das curvas DSC das amostras de ceras de abelhas: (linhas vermelhas) clarificada e (linhas pretas) bruta. 
A Figura 40 ilustra as curvas TG/DTG e DSC da amostra de cera de carnaúba tipo 1. As curvas TG/DTG evidenciam que a amostra é estável termicamente até cerca de $210^{\circ} \mathrm{C}$ e se decompõe em duas etapas principais, entre 210 e $620^{\circ} \mathrm{C}$. A primeira ocorre rapidamente entre 210 e $400^{\circ} \mathrm{C}$, com acentuada perda de massa $\left(\Delta \mathrm{m}_{1}=85,82 \%\right.$ e $\left.\mathrm{T}_{\text {pico DTG }}=329^{\circ} \mathrm{C}\right)$. A segunda etapa ocorre de forma mais lenta entre 405 e $620^{\circ} \mathrm{C}\left(\Delta \mathrm{m}_{2}=13,11 \%\right.$ e $\left.\mathrm{T}_{\text {pico DTG }}=555^{\circ} \mathrm{C}\right)$ e é devido ao término da decomposição térmica e eliminação de material carbonáceo formado na etapa anterior. $\mathrm{Na}$ temperatura de $620^{\circ} \mathrm{C}$ a perda de massa é praticamente completa, resta aproximadamente $1 \%$ de material inorgânico.

A curva DSC mostra eventos endotérmicos entre 30 e $93^{\circ} \mathrm{C}(\Delta \mathrm{H}=198 \mathrm{~J} / \mathrm{g})$, com $\mathrm{T}_{\text {pico DSC }}$ principal em $61,9^{\circ} \mathrm{C}$, devido a fusão do material, visto que na mesma faixa de temperatura as curvas TG/DTG não evidenciam perda de massa. A ampliação da faixa de fusão, ilustrada como detalhe no interior da figura, mostra também na curva DSC um pico em $49,5^{\circ} \mathrm{C}$ e um ombro em $80^{\circ} \mathrm{C}$, evidenciando que há diferentes espécies fundindo no mesmo intervalo de temperatura, o que é característico para esse tipo de material. Após fusão, a curva DSC evidencia que inicialmente o processo de decomposição térmica da amostra é endotérmico, o que pode ser observado por um pico em $261^{\circ} \mathrm{C}$. Acima de $290^{\circ} \mathrm{C}$ o processo é complexo e exotérmico como pode ser visto na curva pelo ombro em $308^{\circ} \mathrm{C}$ e $\mathrm{T}_{\text {picos DSC }}$ em 365 e $425^{\circ} \mathrm{C}$.

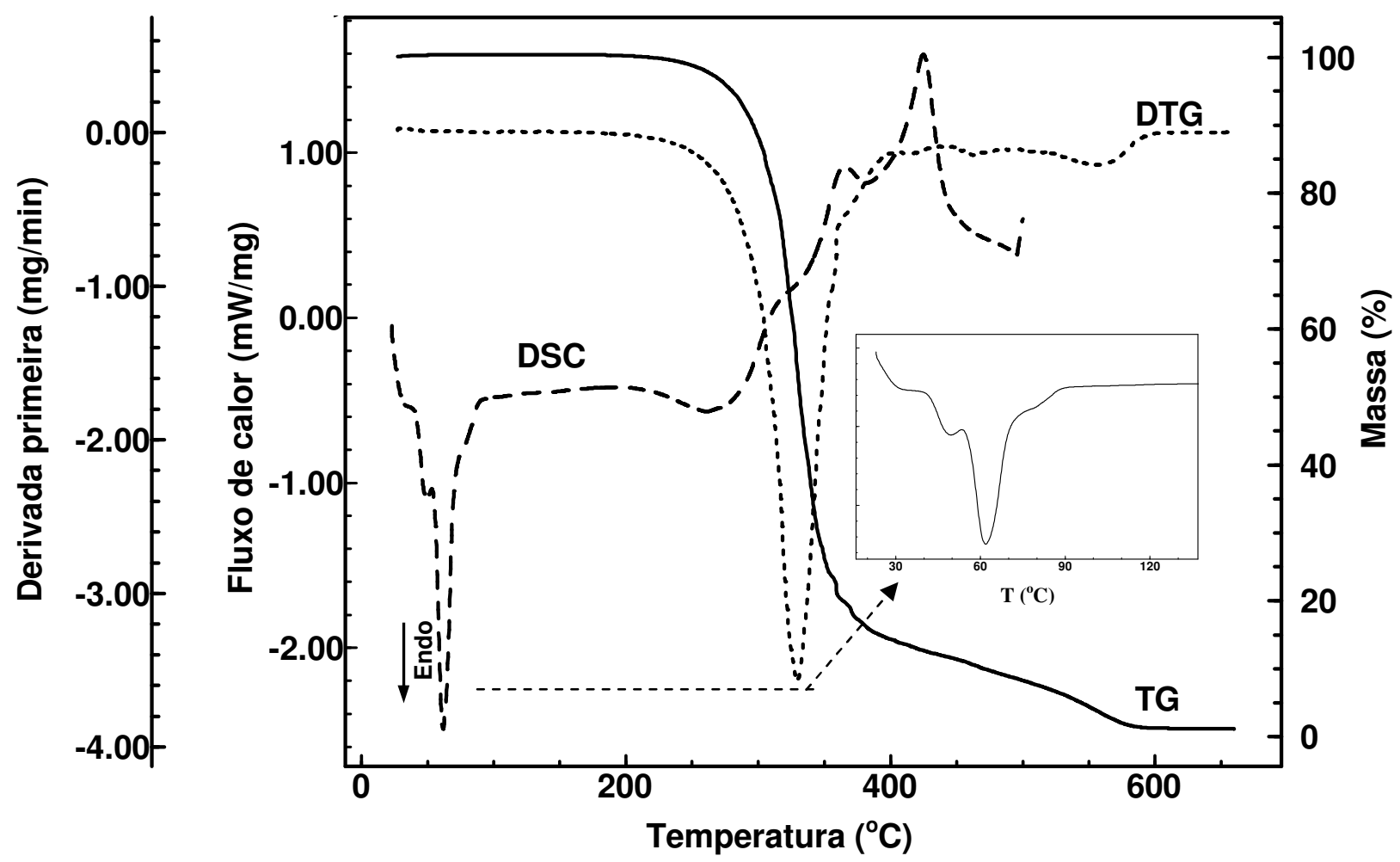

Figura 40 - Sobreposição das curvas TG/DTG e DSC da amostra CRCNT1. 
A Figura 41 ilustra as curvas TG/DTG e DSC da amostra de cera de carnaúba tipo 3. As curvas TG/DTG evidenciam que a amostra é estável termicamente até cerca de $215^{\circ} \mathrm{C}$ e se decompõe em três etapas distintas, entre 215 e $600^{\circ} \mathrm{C}$. A primeira ocorre rapidamente entre 215 e $393^{\circ} \mathrm{C}$, com acentuada perda de massa $\left(\Delta \mathrm{m}_{1}=72,94 \%\right.$ e $\left.\mathrm{T}_{\text {pico DTG }}=333^{\circ} \mathrm{C}\right)$. A segunda e terceira etapas ocorrem de forma mais lenta entre 393 e $600^{\circ} \mathrm{C}$ com $\Delta \mathrm{m}_{2}=15,70 \%\left(\mathrm{~T}_{\text {pico DTG }}\right.$ $=473)$ e $\Delta \mathrm{m}_{3}=11,03 \%\left(\mathrm{~T}_{\text {pico DTG }}=532^{\circ} \mathrm{C}\right)$ e são devidas ao término da decomposição térmica e eliminação de material carbonáceo formado na etapa anterior. $\mathrm{Na}$ temperatura de $600^{\circ} \mathrm{C} \mathrm{a}$ perda de massa é praticamente completa, restam aproximadamente $0,5 \%$ de material inorgânico.

A curva DSC mostra eventos endotérmicos entre 28 e $92^{\circ} \mathrm{C}(\Delta \mathrm{H}=240 \mathrm{~J} / \mathrm{g})$ e $\mathrm{T}_{\text {pico }}$ DSC principal em $60,9^{\circ} \mathrm{C}$, devido a fusão do material, visto que na mesma faixa de temperatura as curvas TG/DTG não evidenciam perda de massa. A ampliação da faixa de fusão, ilustrada como detalhe no interior da figura, mostra também na curva DSC um pico e dois ombros, um antes e outro depois do pico principal, em 27,3 e $88,1^{\circ} \mathrm{C}$ respectivamente, evidenciando que há diferentes espécies fundindo no mesmo intervalo de temperatura, o que é característico para esse tipo de material. Após fusão, a curva DSC evidencia que inicialmente o processo de decomposição térmica da amostra é endotérmico, o que pode ser observado pelo desvio da linha base para baixo. Acima de $290^{\circ} \mathrm{C}$ o processo é exotérmico como pode ser visto na curva, com $\mathrm{T}_{\text {pico DSC }} \mathrm{em} 443^{\circ} \mathrm{C}$.

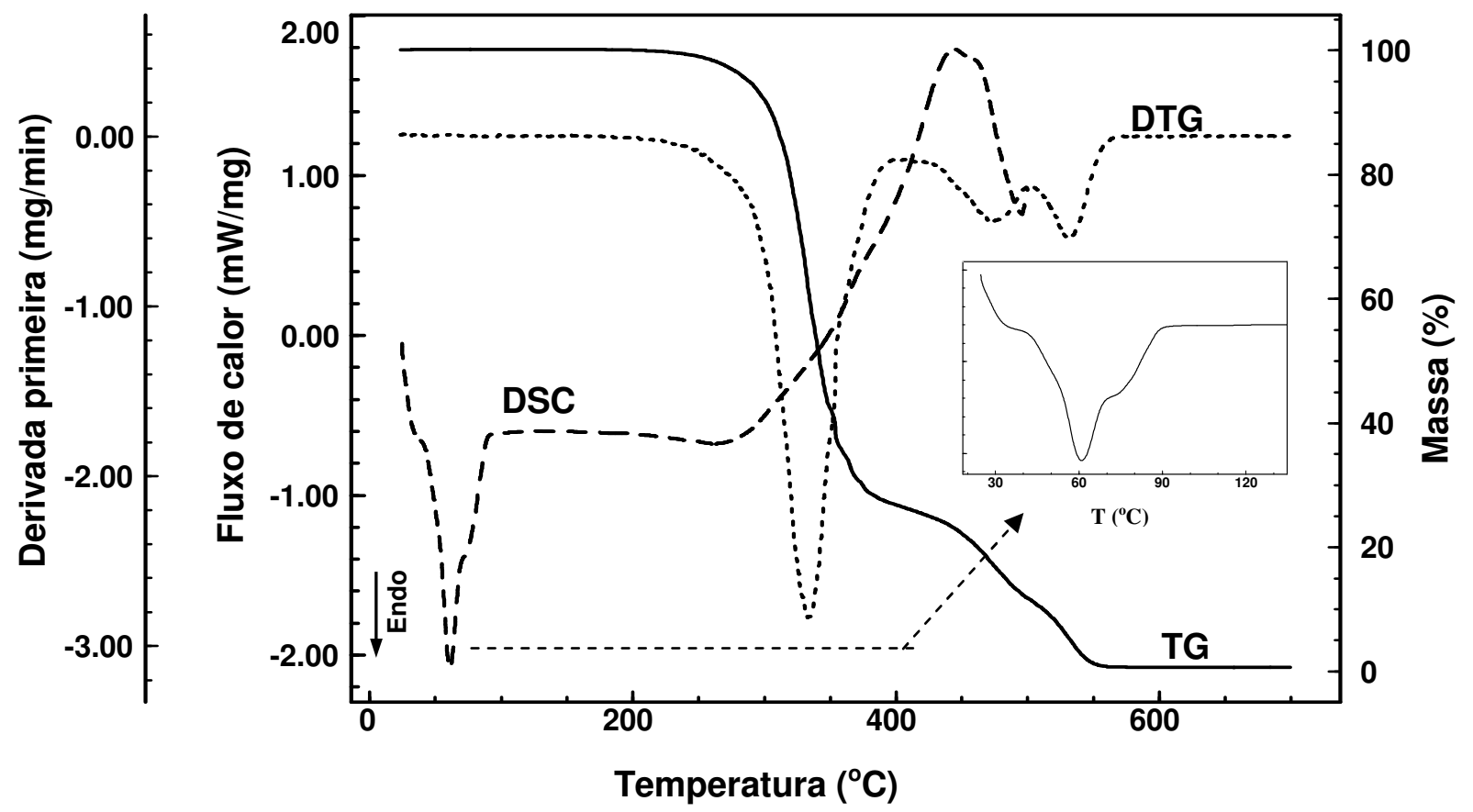

Figura 41 - Sobreposição das curvas TG/DTG e DSC da amostra CRCNT3. 
A Figura 42 ilustra as curvas TG/DTG e DSC da amostra de cera de carnaúba tipo 4. As curvas TG/DTG evidenciam que a amostra é estável termicamente até cerca de $189^{\circ} \mathrm{C}$ e se decompõe em duas etapas principais, entre 189 e $554^{\circ} \mathrm{C}$. A primeira ocorre rapidamente entre 229 e $420^{\circ} \mathrm{C}$, com acentuada perda de massa $\left(\Delta \mathrm{m}_{1}=83.36 \%\right.$ e $\left.\mathrm{T}_{\text {pico DTG }}=326^{\circ} \mathrm{C}\right)$. A segunda etapa ocorre de forma mais lenta entre 463 e $569^{\circ} \mathrm{C}\left(\Delta \mathrm{m}_{2}=15,8 \%\right.$ e $\left.\mathrm{T}_{\text {pico DTG }}=531^{\circ} \mathrm{C}\right)$ e é devido ao término da decomposição térmica e eliminação de material carbonáceo formado na etapa anterior. $\mathrm{Na}$ temperatura de $581^{\circ} \mathrm{C}$ a perda de massa é praticamente completa, restam aproximadamente $0,8 \%$ de material inorgânico.

A curva DSC mostra eventos endotérmicos entre 22 e $92^{\circ} \mathrm{C}(\Delta \mathrm{H}=316 \mathrm{~J} / \mathrm{g})$ e $\mathrm{T}_{\text {pico }}$ DSC principal em $60,6^{\circ} \mathrm{C}$, devido a fusão do material, visto que na mesma faixa de temperatura as curvas TG/DTG não evidenciam perda de massa. A ampliação da faixa de fusão, ilustrada como detalhe no interior da figura, mostra também na curva DSC um ombro em $47,5^{\circ} \mathrm{C}$ e outros dois picos em 52,9 e $80,9^{\circ} \mathrm{C}$, evidenciando que há diferentes espécies fundindo no mesmo intervalo de temperatura, o que é característico para esse tipo de material. Após fusão, a curva DSC evidencia que inicialmente o processo de decomposição térmica da amostra é endotérmico, o que pode ser observado pelo pico em $262,9^{\circ} \mathrm{C}$. Acima de $290^{\circ} \mathrm{C}$ o processo é exotérmico como pode ser visto na curva, com $\mathrm{T}_{\text {pico DSC }}$ principal em $438,1^{\circ} \mathrm{C}$.

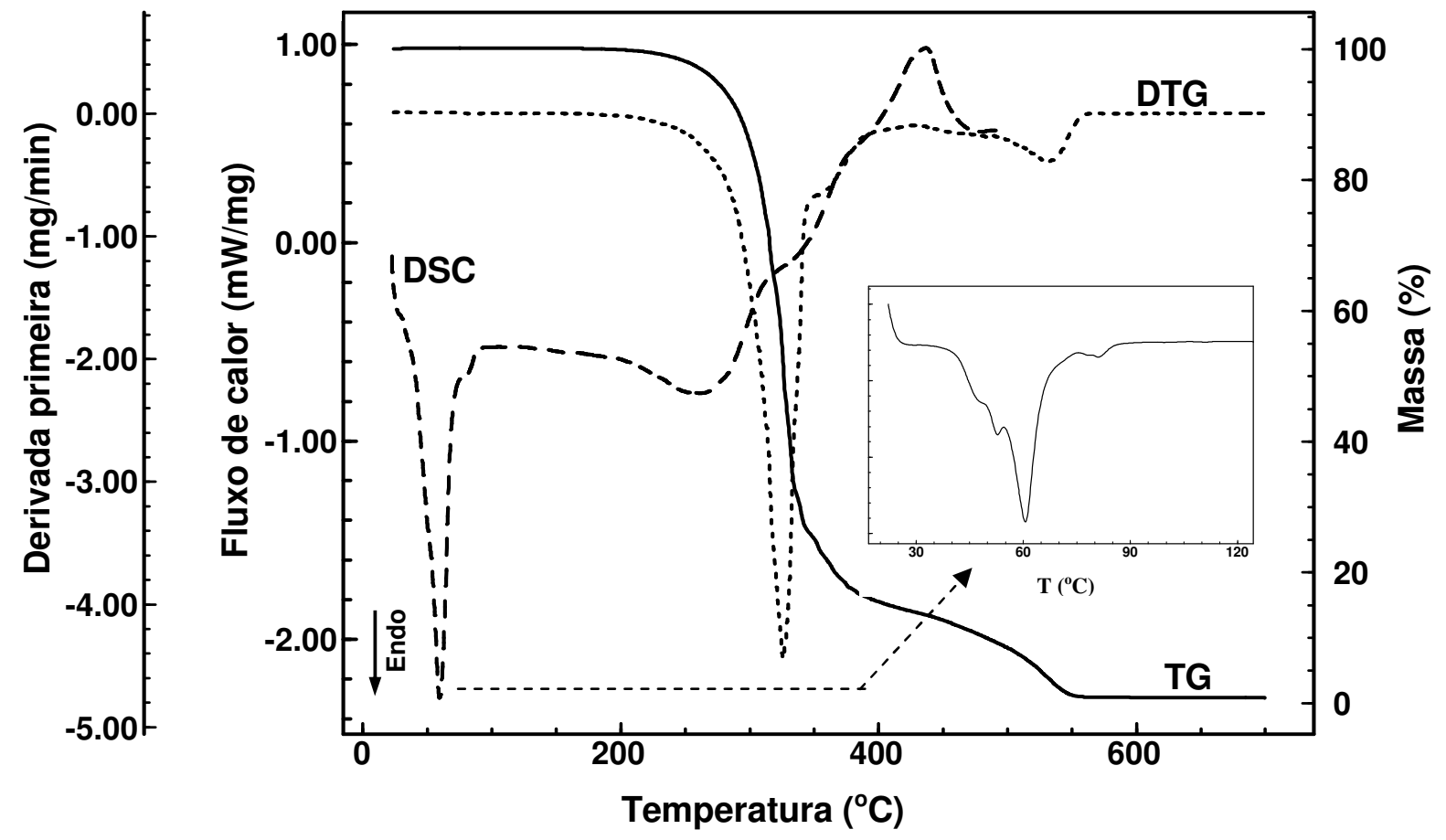

Figura 42 - Sobreposição das curvas TG/DTG e DSC da amostra CRCNT4. 
A comparação entre as curvas TG/DTG (Figura 43) e DSC (Figura 44) dos três tipos de amostras de ceras de carnaúba permite claramente diferenciar a amostra T3 das outras duas quanto à estabilidade térmica. Essa amostra é a mais estável e apresentou uma menor perda de massa na primeira etapa de decomposição. As amostras T1 e T4 apresentaram estabilidade térmica semelhante, porém o valor da entalpia total de fusão da amostra T4 é praticamente $30 \%$ maior para $\mathrm{T} 4$ em relação a $\mathrm{T} 1$.

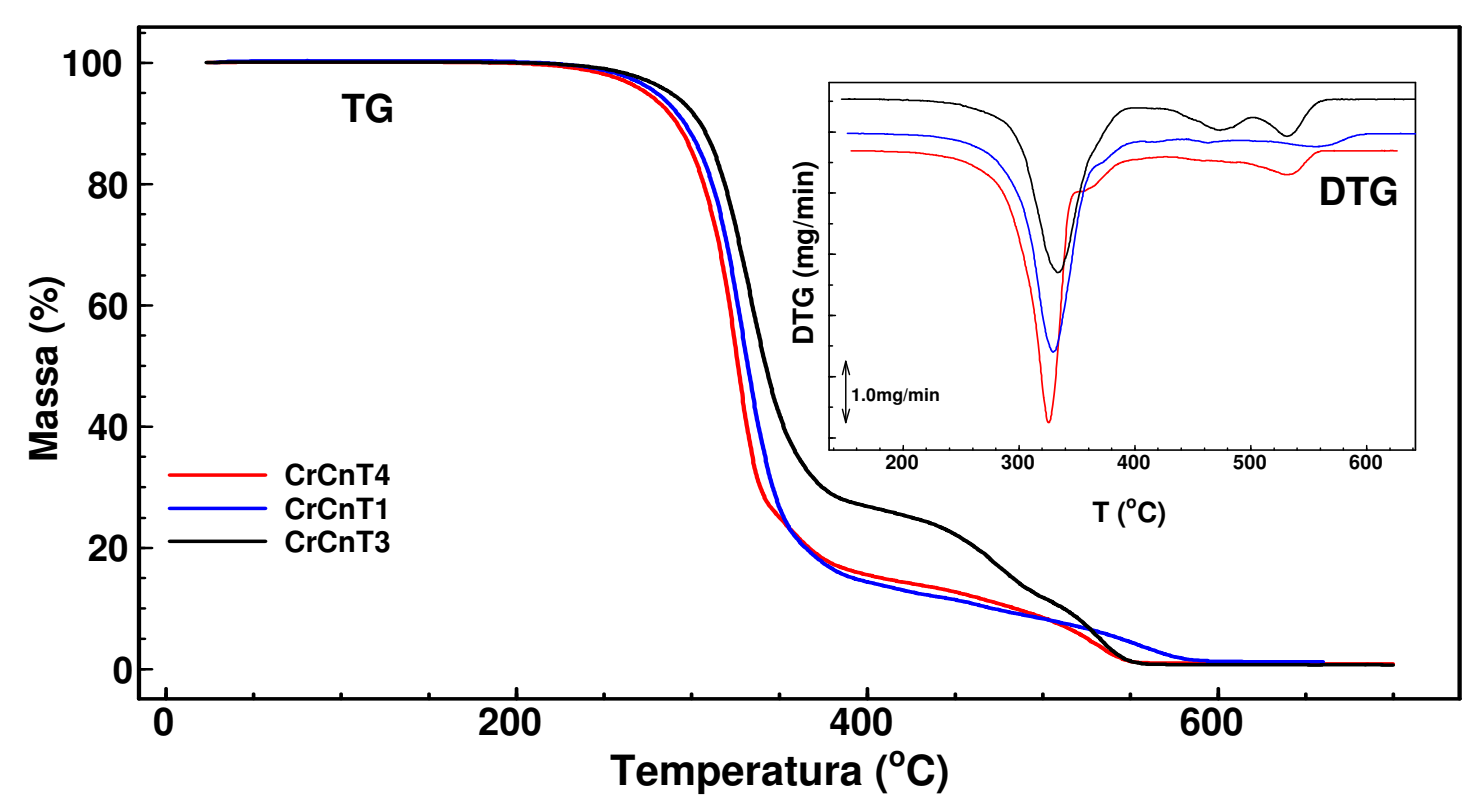

Figura 43 - Sobreposição das curvas TG/DTG das amostras de cera de carnaúba: T1, T3 e T4.

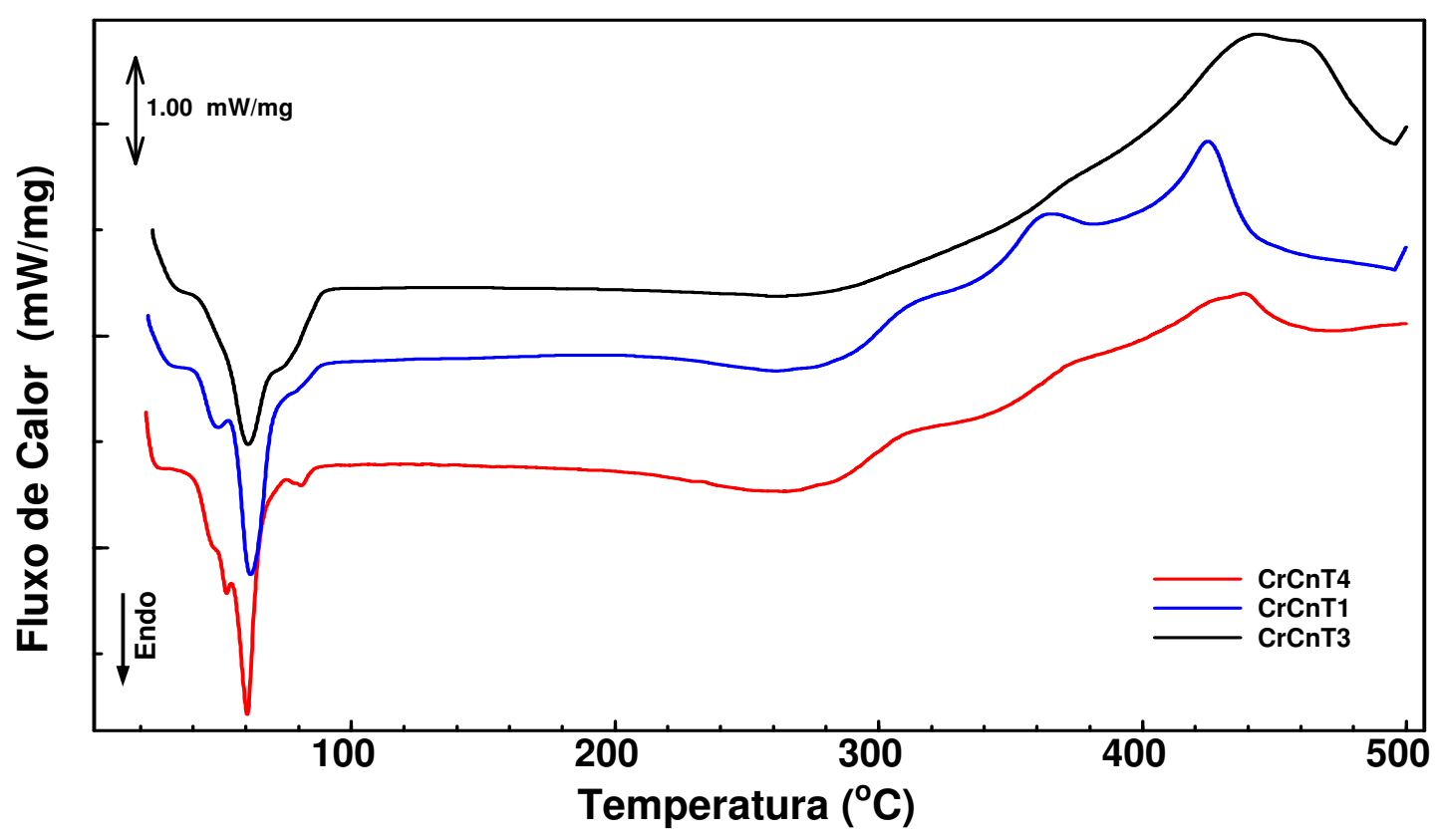

Figura 44 - Sobreposição das curvas DSC das amostras de cera de carnaúba: T1, T3 e T4. 
A Figura 45 ilustra as curvas TG/DTG e DSC da amostra de resina damar. As curvas TG/DTG evidenciam que a amostra perde $0,77 \%$ da massa inicial entre 25 e $130^{\circ} \mathrm{C}$, possivelmente devido à eliminação de água de umidade ou algum volátil mais leve presente na resina. Mantém-se estável termicamente até cerca de $150^{\circ} \mathrm{C}$. Entre 150 e $630^{\circ} \mathrm{C}$ ocorrem três perdas de massa distintas devido à decomposição térmica, $\Delta \mathrm{m}_{1}=64,71 \% \quad\left(130 \mathrm{a} 430^{\circ} \mathrm{C} \mathrm{e}\right.$ $\left.\mathrm{T}_{\text {pico DTG }}=394^{\circ} \mathrm{C}\right), \Delta \mathrm{m}_{2}=13,27 \%\left(430 \mathrm{a} 495^{\circ} \mathrm{C}\right.$ e $\left.\mathrm{T}_{\text {pico DTG }}=469^{\circ} \mathrm{C}\right)$ e $\Delta \mathrm{m}_{3}=19,34 \% \quad(495 \mathrm{a}$ $630^{\circ} \mathrm{C}$ e $\mathrm{T}_{\text {pico }}$ DTG $=570^{\circ} \mathrm{C}$ ). Na temperatura de $630^{\circ} \mathrm{C}$ a perda de massa é praticamente completa, restam aproximadamente $1,87 \%$ de material inorgânico.

A curva DSC evidencia, inicialmente, variação de linha base no sentido endotérmico, que caracteriza a eliminação de água ou outra espécie volátil presente. No processo de aquecimento, essa amostra não passa por processo de fusão, sofre direta decomposição térmica. Pode-se observar um evento altamente exotérmico entre 310 e $497^{\circ} \mathrm{C}\left(\mathrm{T}_{\text {pico }} \mathrm{DSC}=\right.$ $415,7^{\circ} \mathrm{C}$ e $\Delta \mathrm{H}=1.150 \mathrm{~J} / \mathrm{g}$ ), que caracteriza um processo de decomposição térmica muito favorável, visto que na mesma faixa de temperatura as curvas TG/DTG evidenciam uma acentuada perda de massa. Esse comportamento térmico indica que a resina natural damar pode sofrer oxidação nas condições ambiente num tempo não muito longo, deixando a obra de arte escurecida, conforme mencionado por Gisela A. van der Doelen em "Molecular studies of fresh and aged triterpenoid varnishes" (DOELEN, 2002), porém sem se referir a dados de análise térmica.

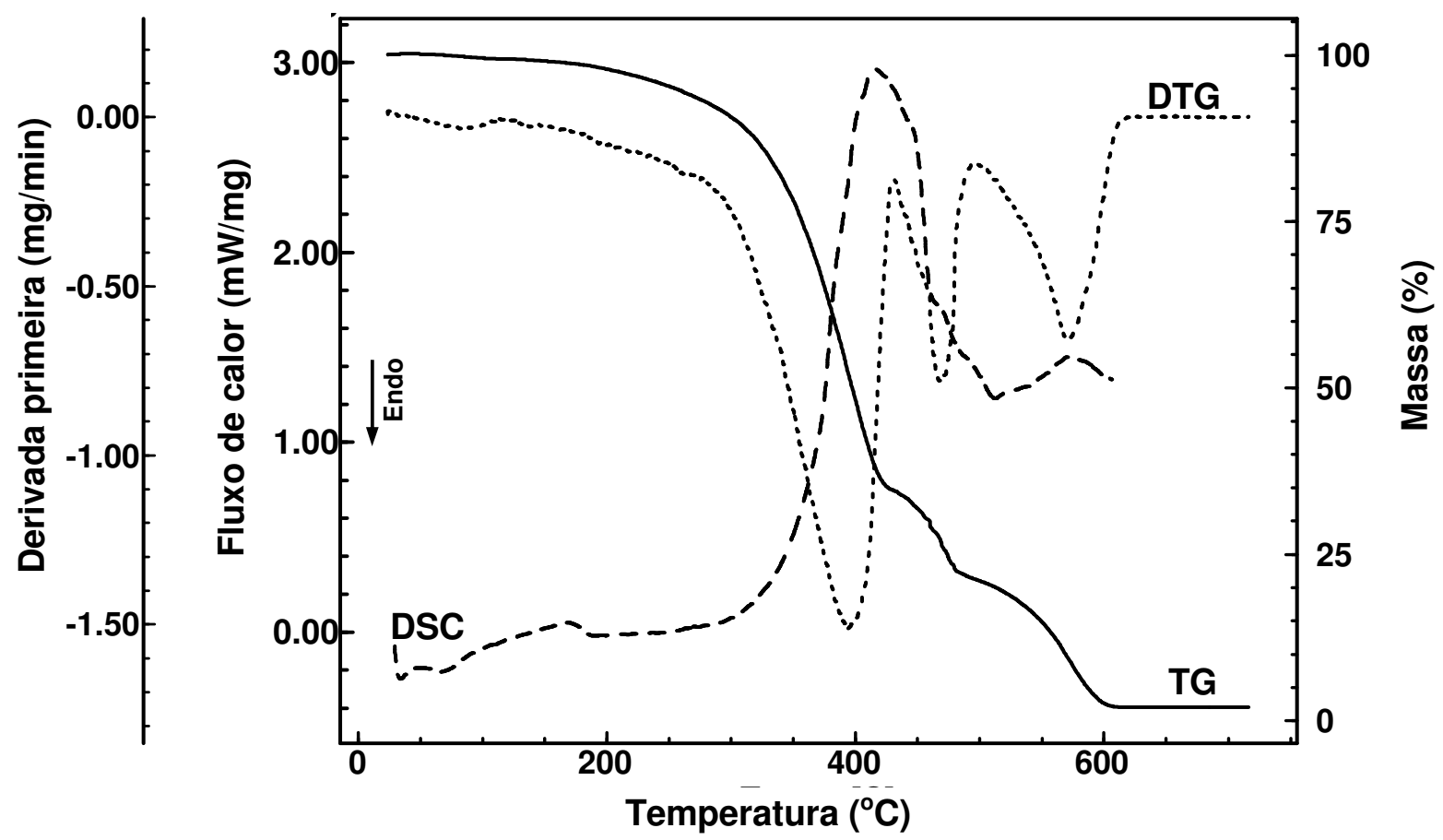

Figura 45 - Sobreposição das curvas TG/DTG e DSC da amostra de RSDM. 


\subsubsection{ESPECTROSCOPIA NO INFRAVERMELHO (IR)}

A Figura 46 apresenta o espectro no infravermelho da amostra de cera bruta de abelhas. $\mathrm{O}$ espectro mostra as bandas de absorção características da cera bruta de abelhas em: 3606 e $3456 \mathrm{~cm}^{-1}$ (estiramento da ligação O-H); 2955, 2917 e $2849 \mathrm{~cm}^{-1}$ (estiramento da ligação $\mathrm{C}-\mathrm{H}$ ); 1736 e $1714 \mathrm{~cm}^{-1}$ (estiramento da ligação $\mathrm{C}=\mathrm{O}$ ); 1468 e $1415 \mathrm{~cm}^{-1}$ (dobramento da ligação C-H); $1173 \mathrm{~cm}^{-1}$ (estiramento da ligação C-O) e 724 e $720 \mathrm{~cm}^{-1}$ (torção da ligação C-H).

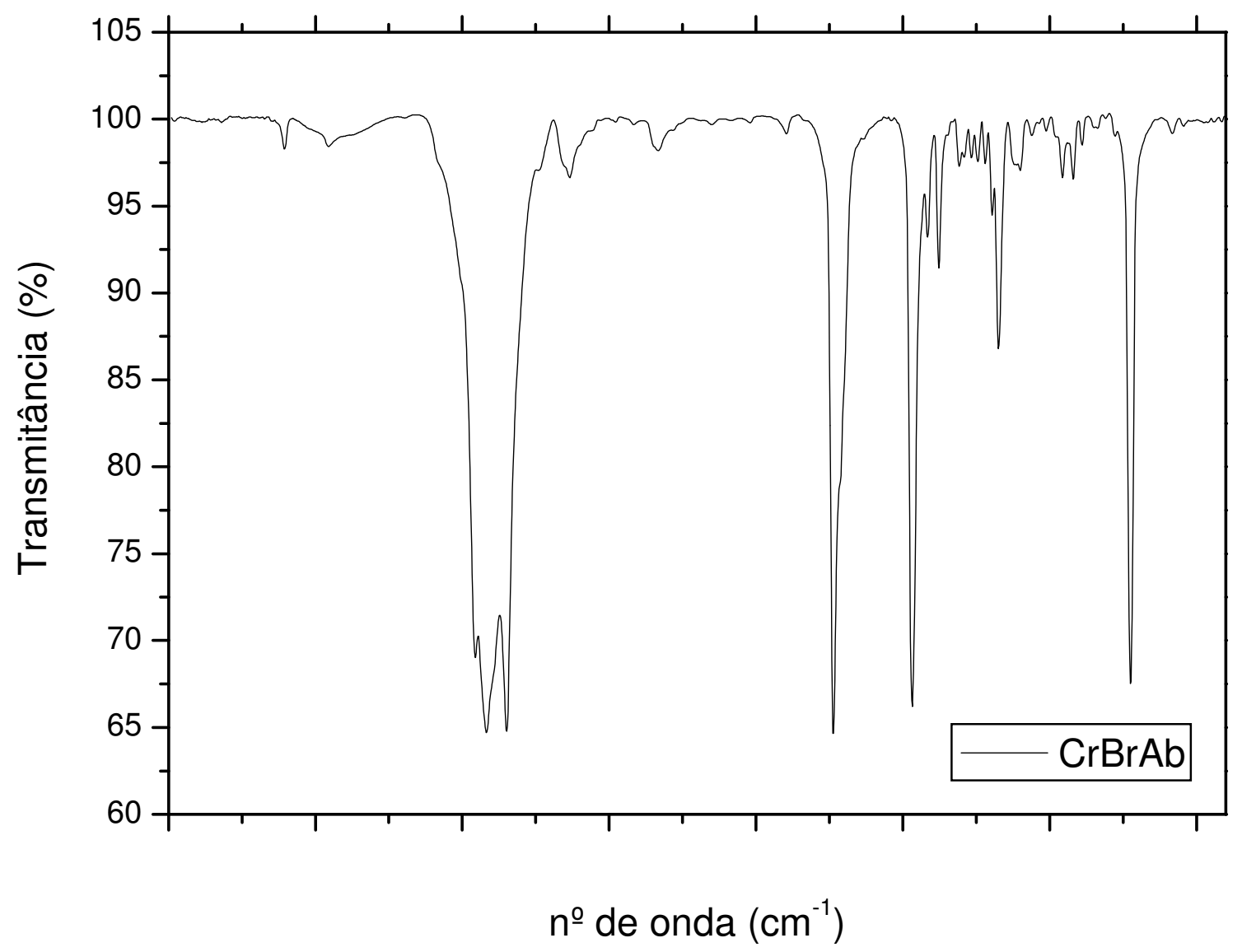

Figura 46 - Espectro de absorção na região do infravermelho da amostra CRBRAB. 
A Figura 47 apresenta o espectro no infravermelho da amostra de cera clarificada de abelhas. O espectro mostra as bandas de absorção características da cera clarificada de abelhas em: $3605 \mathrm{~cm}^{-1}$ (estiramento da ligação $\mathrm{O}-\mathrm{H}$ ); 2955, 2917 e $2849 \mathrm{~cm}^{-1}$ (estiramento da ligação $\mathrm{C}-\mathrm{H}$ ); 1736-1715 $\mathrm{cm}^{-1}$ (estiramento da ligação $\mathrm{C}=\mathrm{O}$ ); 1472 e $1463 \mathrm{~cm}^{-1}$ (dobramento da ligação C-H); 1377 e $1308 \mathrm{~cm}^{-1}$ (estiramento da ligação C-O) e 729 e $719 \mathrm{~cm}^{-1}$ (torção da ligação C-H).

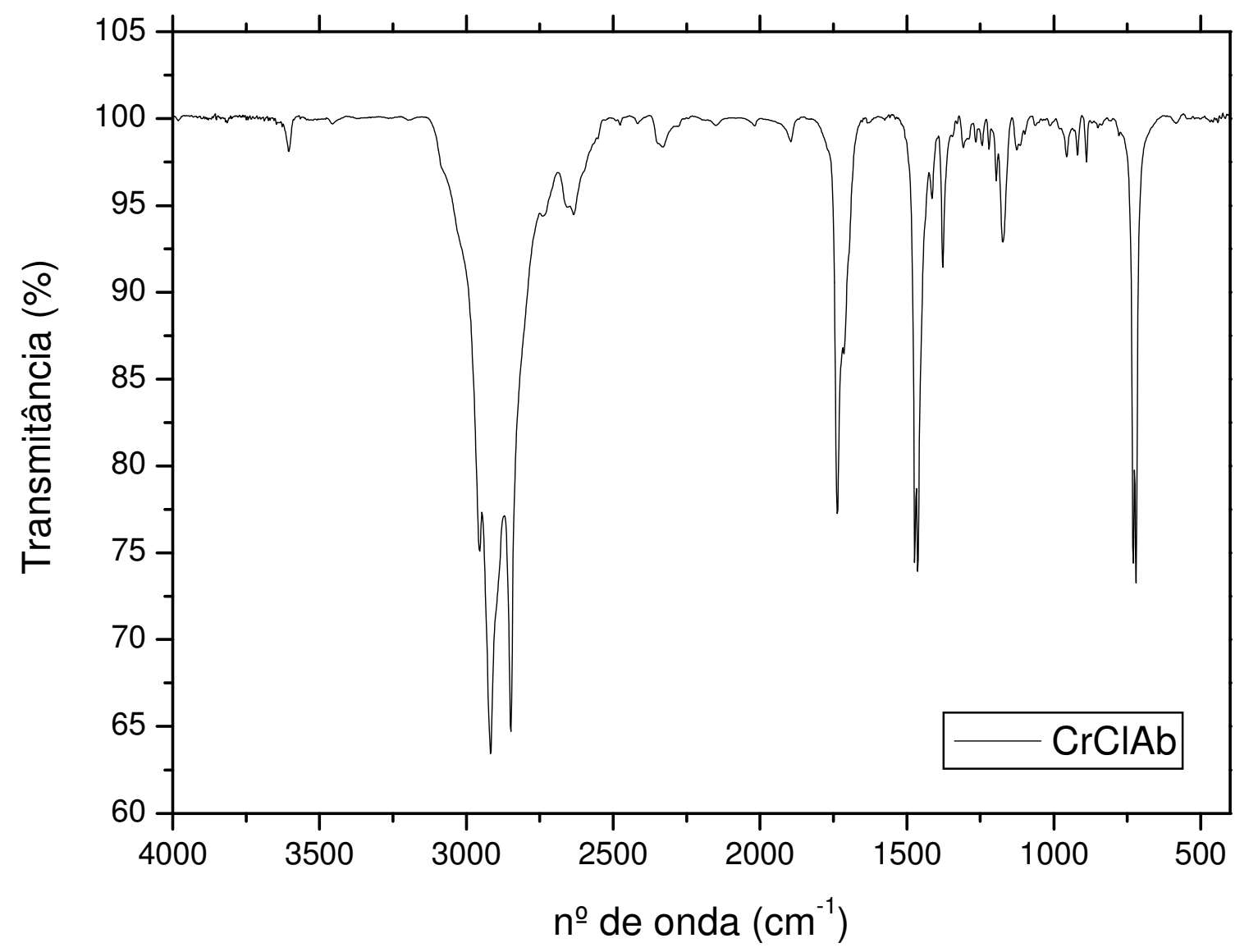

Figura 47 - Espectro de absorção na região do infravermelho da amostra CRCLAB. 
A Figura 48 apresenta a sobreposição dos espectros no infravermelho das amostras das ceras bruta e clarificada de abelhas. Os espectros são muito similares, porém, naquele correspondente a cera bruta de abelhas pode-se observar uma banda de absorção de baixa intensidade na região entre 3600 e $3250 \mathrm{~cm}^{-1}$. Essa banda de absorção pode ser devido a alguma impureza que é eliminada quando do processo de clarificação da cera. Apesar disso não é possível distingui-las com precisão por esta técnica.

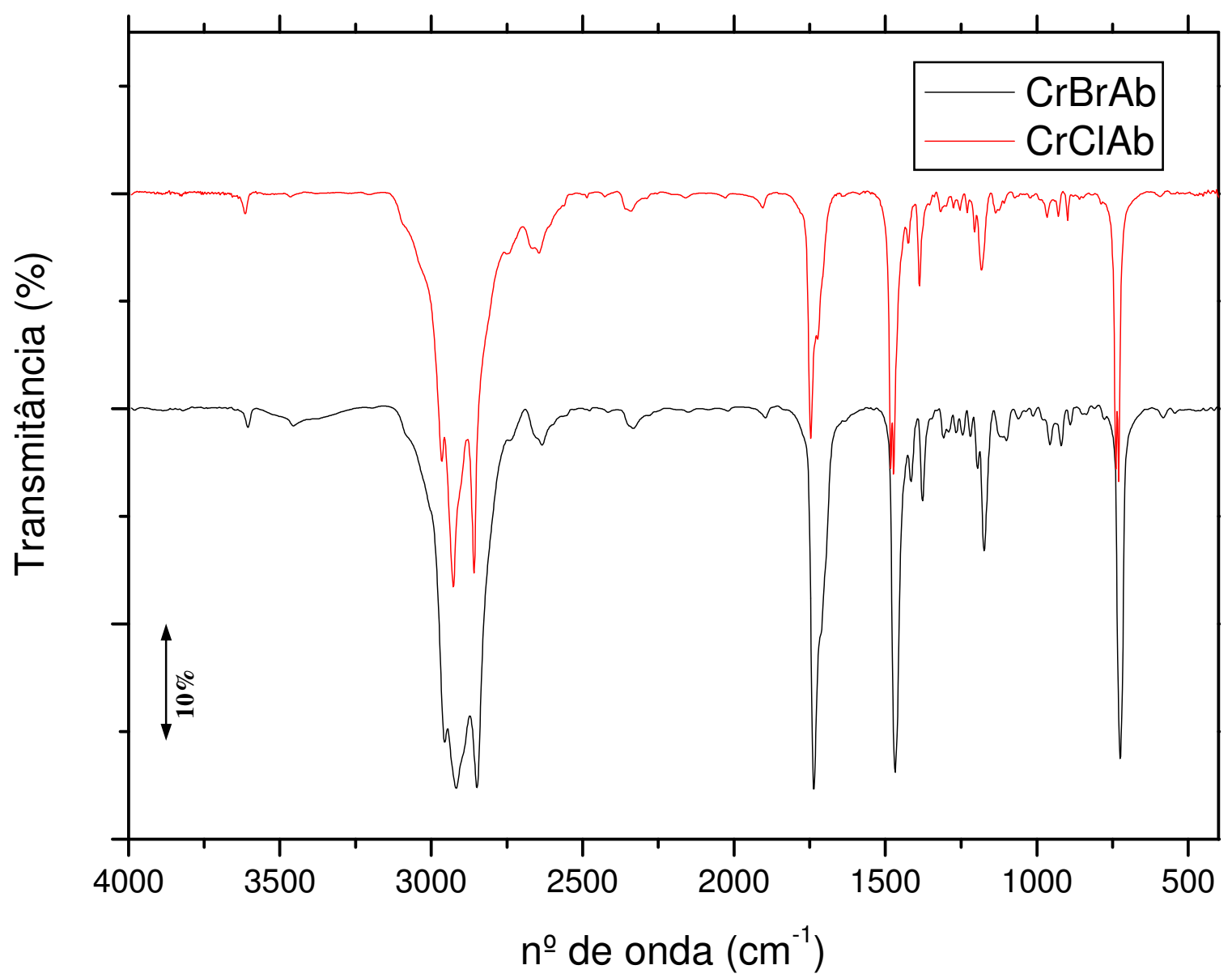

Figura 48 - Sobreposição dos espectros no infravermelho das amostras CRBRAB e CRCLAB. 
A Figura 49 apresenta o espectro no infravermelho da amostra de cera de carnaúba tipo 1. O espectro mostra as bandas de absorção características da cera de carnaúba tipo 1 em: 2956, 2918 e $2848 \mathrm{~cm}^{-1}$ (estiramento da ligação $\mathrm{C}-\mathrm{H}$ ); $1736 \mathrm{~cm}^{-1}$ (estiramento da ligação $\mathrm{C}=\mathrm{O}$ ); $1467,1377 \mathrm{~cm}^{-1}$ (dobramento da ligação C-H); $1168 \mathrm{~cm}^{-1}$ (estiramento da ligação C-O) e 723 $\mathrm{cm}^{-1}$ (torção da ligação C-H).

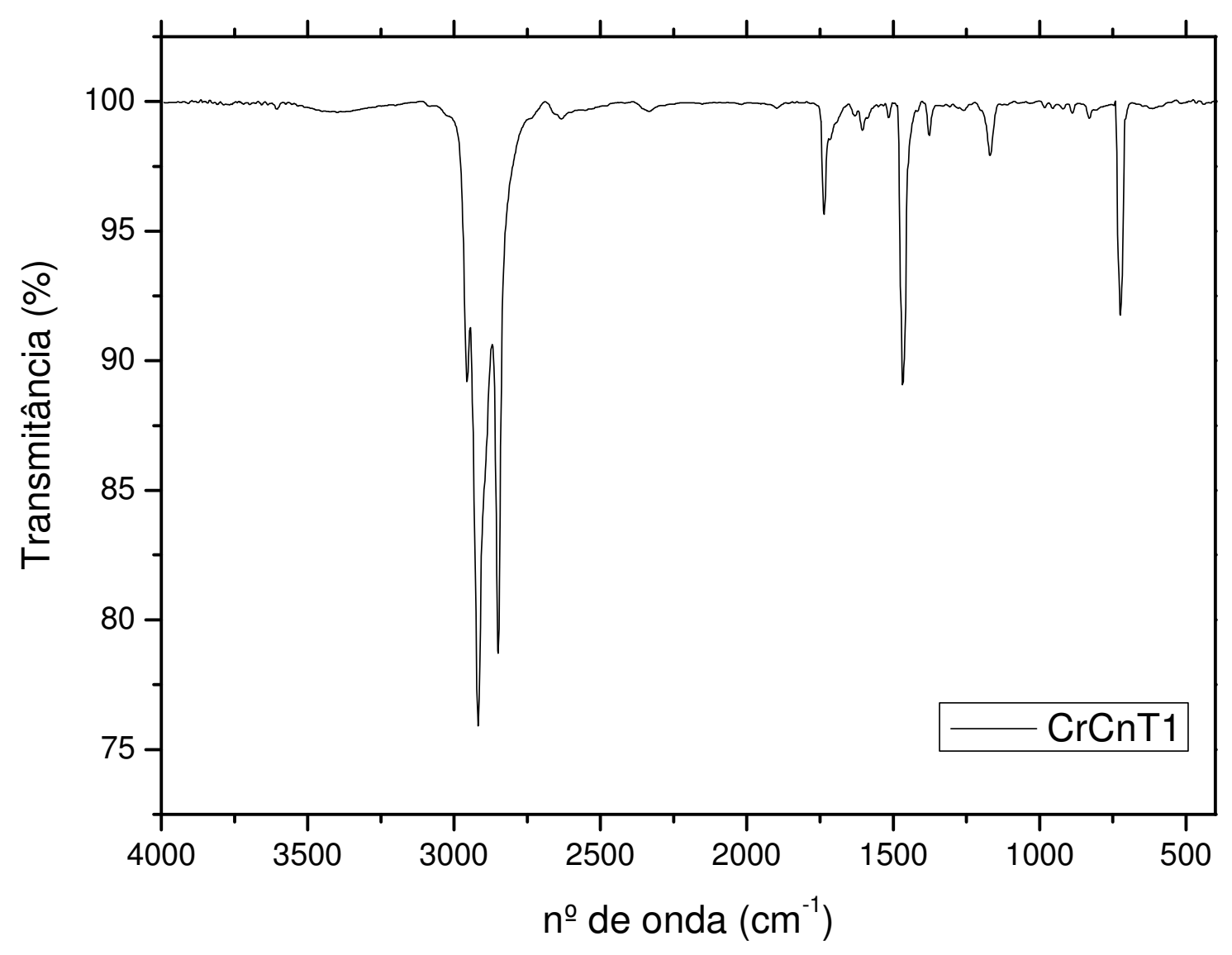

Figura 49 - Espectro de absorção na região do infravermelho da amostra CRCNT1. 
A Figura 50 apresenta o espectro no infravermelho da amostra de cera de carnaúba tipo 3. O espectro mostra as bandas de absorção características da cera de carnaúba tipo 3 em: 3453 $\mathrm{cm}^{-1}$ (estiramento da ligação O-H); 2955, 2917 e $2849 \mathrm{~cm}^{-1}$ (estiramento da ligação C-H); $1736 \mathrm{~cm}^{-1}$ (estiramento da ligação $\mathrm{C}=\mathrm{O}$ ); $1467 \mathrm{e} 1416 \mathrm{~cm}^{-1}$ (dobramento da ligação $\mathrm{C}-\mathrm{H}$ ); $1170 \mathrm{~cm}^{-1}$ (estiramento da ligação C-O) e 730 e $724 \mathrm{~cm}^{-1}$ (torção da ligação C-H).

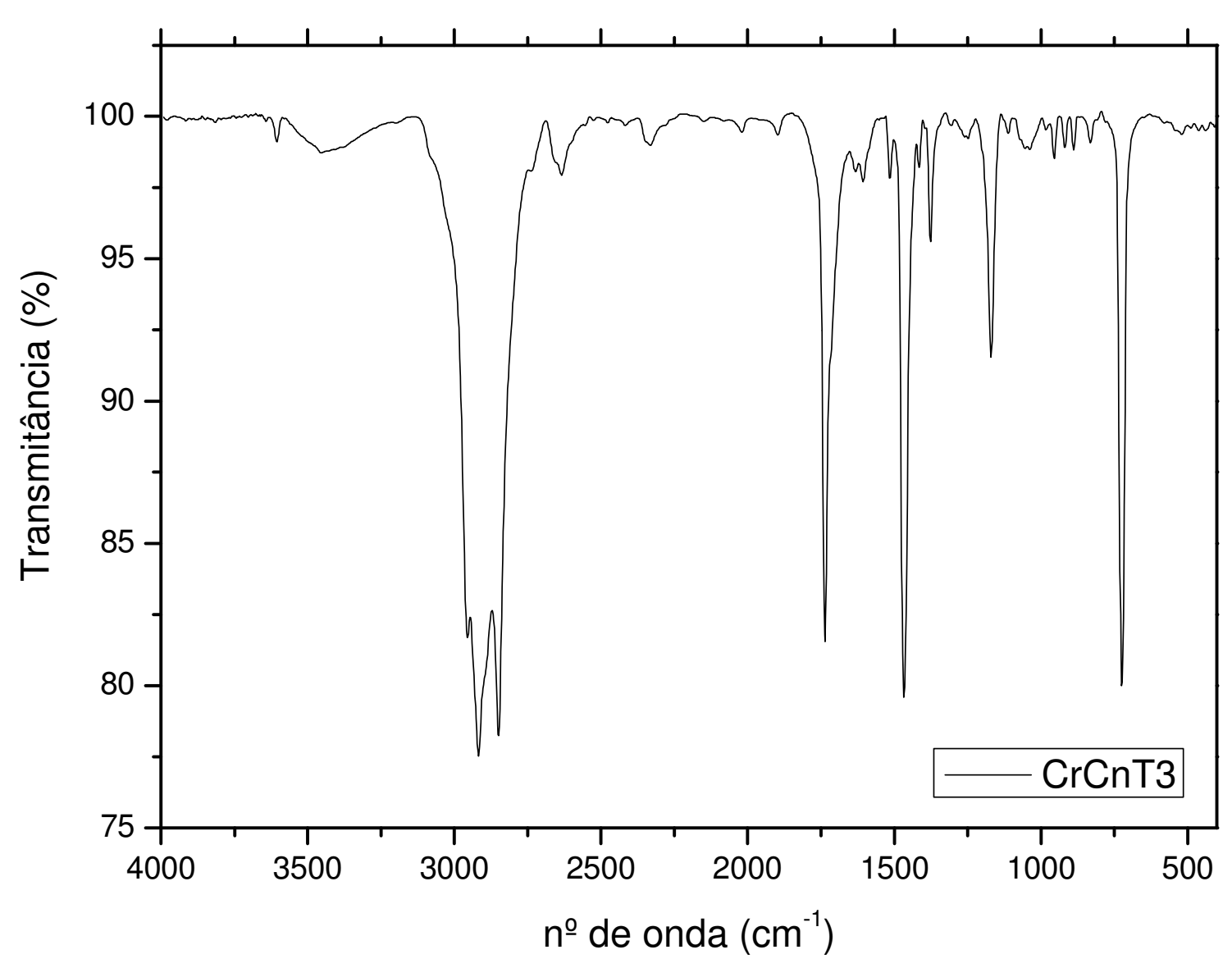

Figura 50 - Espectro de absorção no infravermelho da amostra CRCNT3. 
A Figura 51 apresenta o espectro no infravermelho da amostra de cera de carnaúba tipo 4. O espectro mostra as bandas de absorção características da cera de carnaúba tipo 4 em: 2959, 2917 e $2849 \mathrm{~cm}^{-1}$ (estiramento da ligação C-H); 1739 e $1707 \mathrm{~cm}^{-1}$ (estiramento da ligação $\mathrm{C}=\mathrm{O}$ ); 1467 e $1377 \mathrm{~cm}^{-1}$ (dobramento da ligação $\mathrm{C}-\mathrm{H}$ ); 1172 e $1101 \mathrm{~cm}^{-1}$ (estiramento da ligação C-O) e $723 \mathrm{~cm}^{-1}$ (torção da ligação C-H).

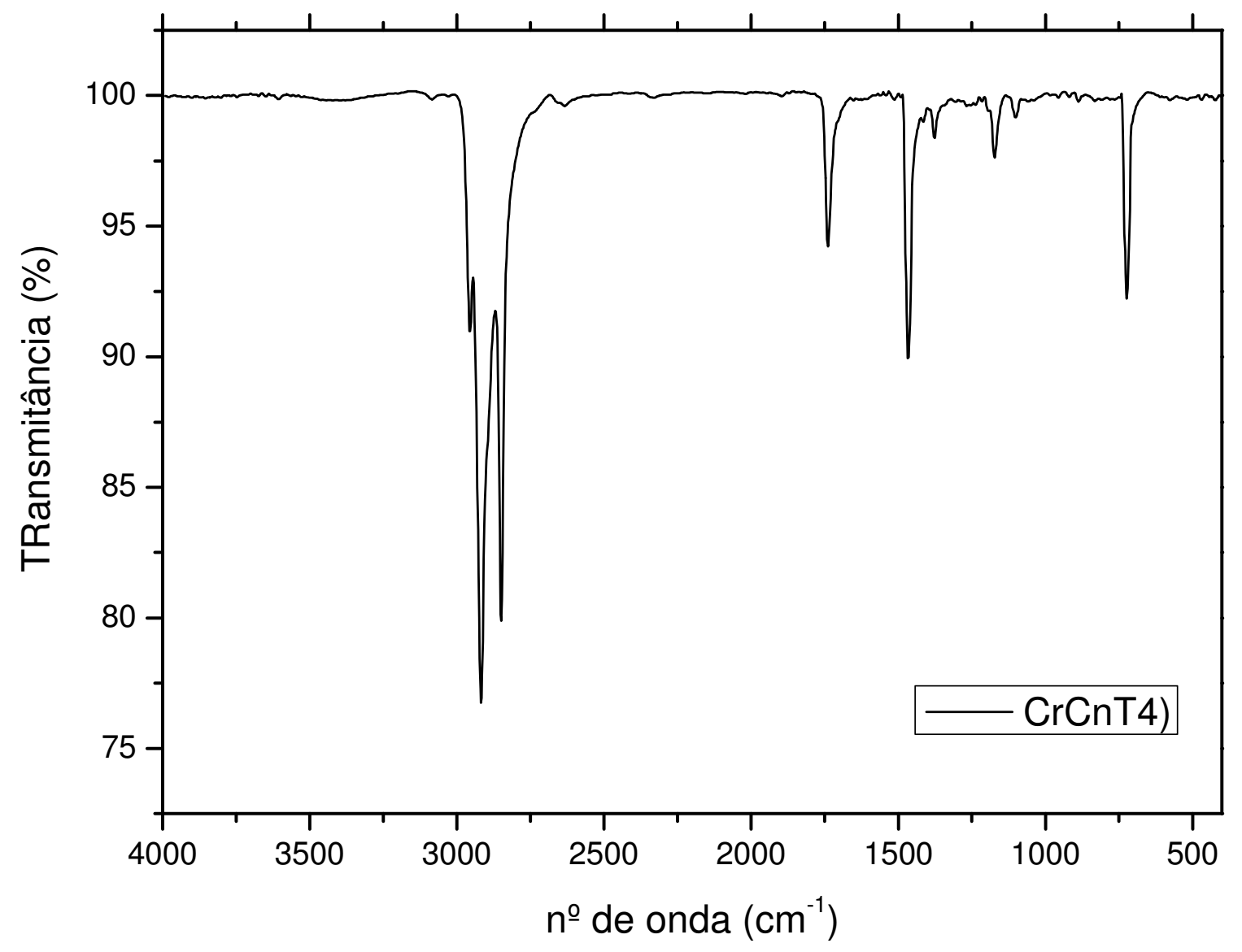

Figura 51 - Espectro de absorção no infravermelho da amostra CRCNT4. 
A Figura 52 apresenta a sobreposição dos espectros no infravermelho das amostras de cera de carnaúba tipo 1, tipo 3 e tipo 4 . Os espectros são similares, uma vez que todas as amostras retratam grupos químicos iguais. Porém pode-se observar naquele da amostra da cera T3 uma banda de absorção na região entre 3600 e $3250 \mathrm{~cm}^{-1}$ com maior intensidade em relação às outras duas. Também, observa-se no espectro da amostra de cera T3 o aparecimento de bandas na região de 1100 a $700 \mathrm{~cm}^{-1}$ que não são vistas nos espectros das amostras de carnaúba T1 e T4. Essas diferenças podem estar relacionadas às formas de obtenção e industrialização da cera (descrito no item 2.9.2.1., § 2). A partir da termogravimetria foi possível caracterizar que a amostra de cera T3 apresentou uma estabilidade térmica maior.

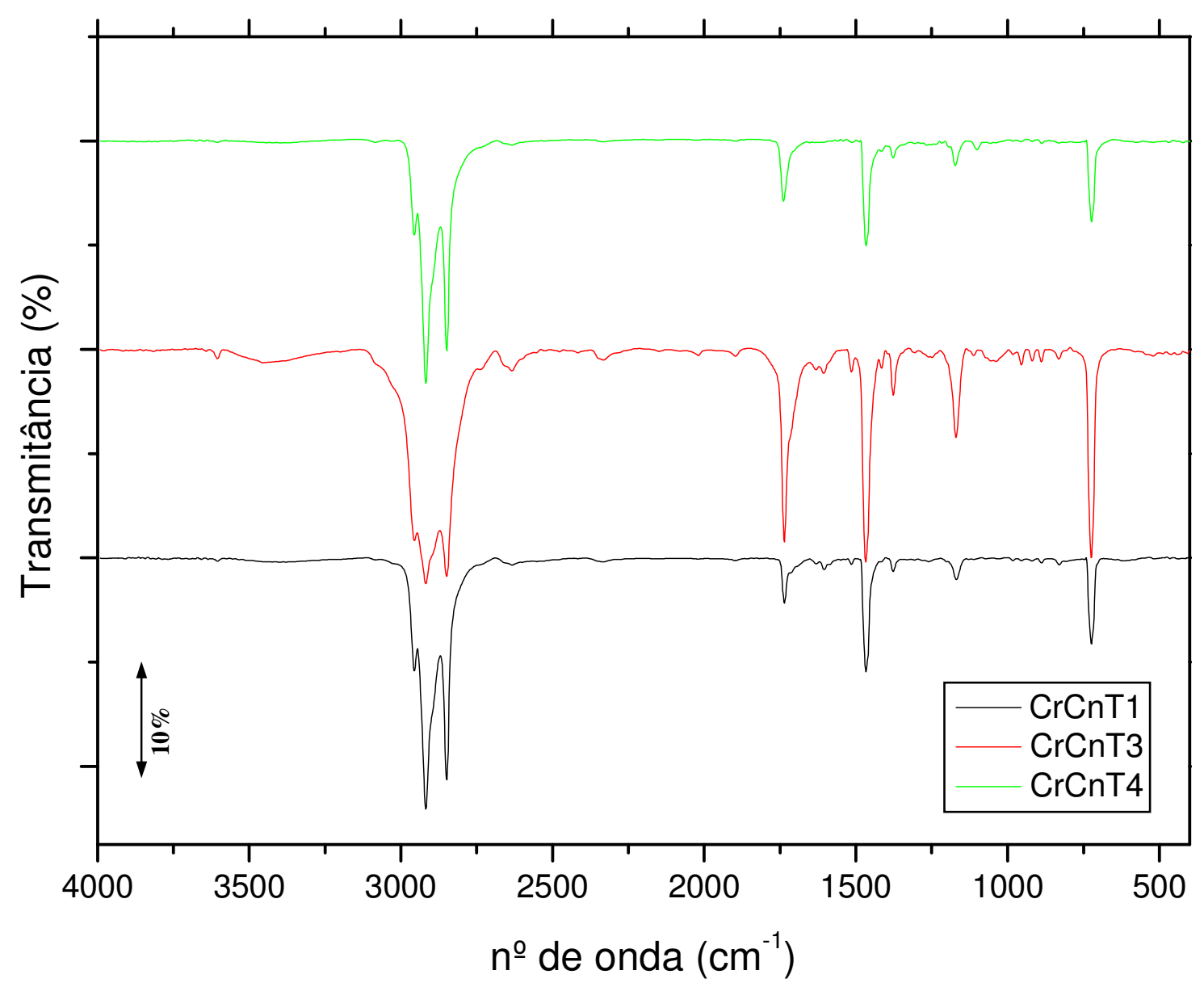

Figura 52 - Sobreposição dos espectros no infravermelho das amostras CRCNT1, CRCNT3 e CRCNT4. 
A Figura 53 apresenta o espectro no infravermelho da amostra de resina damar. O espectro mostra as bandas de absorção características da resina damar em: $3436 \mathrm{~cm}^{-1}$ (estiramento da ligação O-H); 2948 e $2872 \mathrm{~cm}^{-1}$ (estiramento da ligação C-H); $1706 \mathrm{~cm}^{-1}$ (estiramento da ligação $\mathrm{C}=\mathrm{O}$ ); $1650 \mathrm{~cm}^{-1}$ (estiramento da ligação C-C); 1457 e $1382 \mathrm{~cm}^{-1}$ (dobramento da ligação C-H) e 1246, 1160, 1077 e 1029 cm$^{-1}$ (estiramento da ligação C-O).

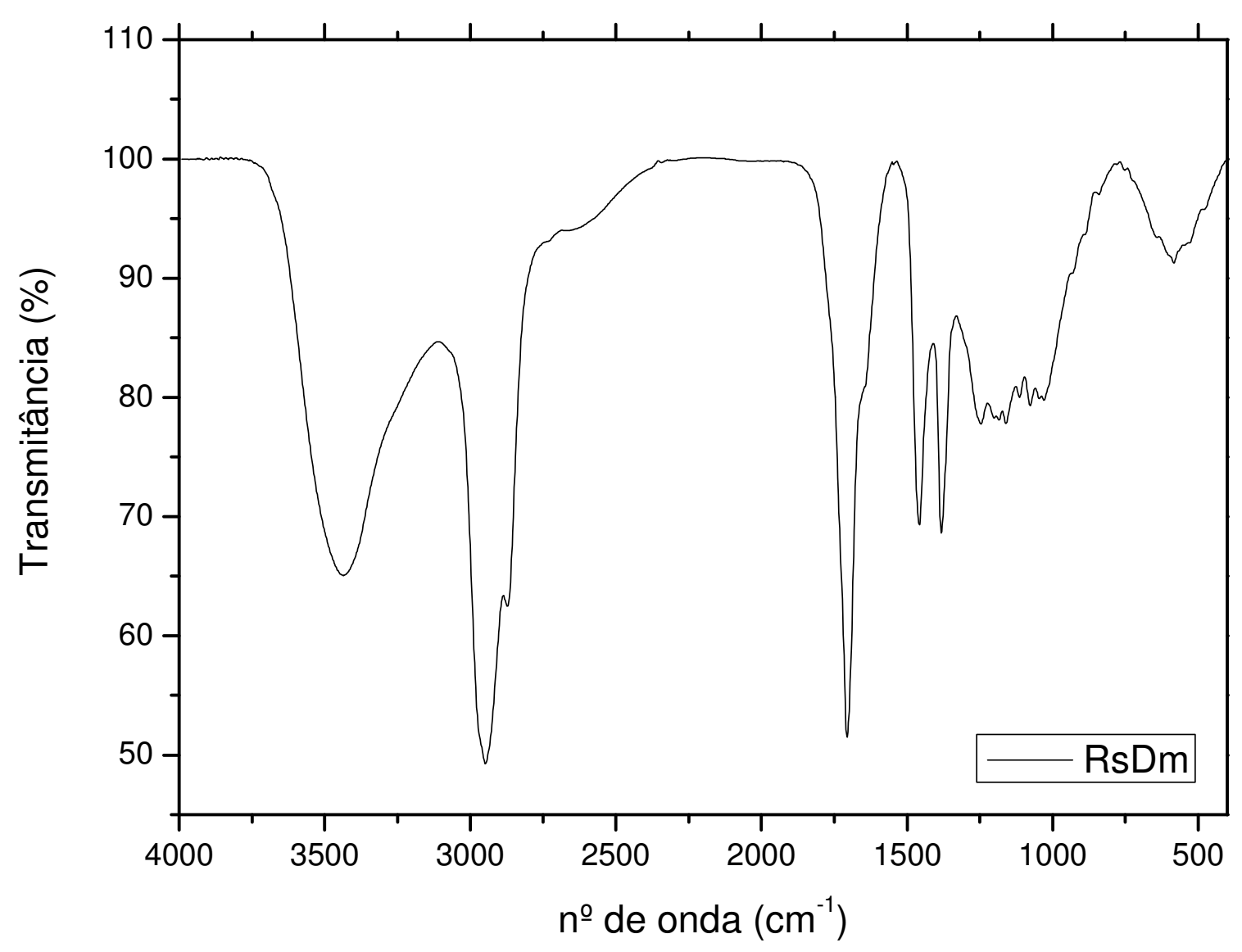

Figura 53 - Espectro de absorção no infravermelho da amostra RsDM. 


\subsubsection{ANÁLISE ELEMENTAR (AE)}

A Tabela 8 lista as porcentagens em massa de carbono, hidrogênio e nitrogênio obtidas por análise elementar das matérias primas: cera bruta de abelhas, cera clarificada de abelhas, cera de carnaúba tipo 1, tipo 3, tipo 4 e resina damar. De maneira geral as ceras de abelha ou carnaúba são compostas principalmente de ésteres, álcoois e ácidos graxos de alto peso molecular o que conduz a elevados teores de carbono. As diferenças observadas nos resultados de análise elementar entre as amostras de um mesmo tipo de cera estão relacionadas ao processo de obtenção e/ou processos de industrialização. Essas diferenças também influenciaram nos resultados de caracterização obtidos por outras técnicas. Por outro lado, a utilização de um tipo ou outro de cera depende do artista, e, principalmente, da característica da obra de arte que se deseja confeccionar.

Tabela 8 - Resultados de análise elementar das amostras das matérias primas.

\begin{tabular}{c|c|c|c}
\hline AMOSTRA & $\% \mathrm{C}$ & $\% \mathrm{H}$ & $\% \mathrm{~N}$ \\
\hline CRBRAB & 81,90 & 13,56 & 1,71 \\
\hline CRCLAB & 84,05 & 13,96 & 0,86 \\
\hline CRCNT1 & 84,06 & 13,98 & 1,45 \\
\hline CRCNT3 & 82,77 & 13,50 & 1,68 \\
\hline CRCNT4 & 83,32 & 13,56 & 0,79 \\
\hline RSDM & 76,97 & 9,88 & 1,05 \\
\hline
\end{tabular}

Os resultados de análise elementar indicaram que a amostra de cera bruta apresenta um percentual de carbono menor e de nitrogênio maior em relação à clarificada. Na sobreposição dos espectros no infravermelho dessas duas ceras (Figura 48) pôde-se observar uma banda de absorção de baixa intensidade na região entre 3600 e $3250 \mathrm{~cm}^{-1}$. Atribui-se à esta banda alguma impureza que é eliminada no processo de clarificação da cera. Essa impureza possivelmente apresenta grupos $\mathrm{N}-\mathrm{H}$ ou $\mathrm{O}-\mathrm{H}$.

Os resultados de análise elementar também evidenciaram diferenças nos teores de $\mathrm{C}$ e $\mathrm{N}$ entre os diferentes tipos de ceras de carnaúba, T1, T3 e T4. Observou-se também diferença na sobreposição dos espectros no infravermelho destas ceras (Figura 52) e na análise térmica (Figuras 43 e 44). 


\subsection{CARACTERIZAÇÃo DAS AMOSTRAS RETIRADAS DAS OBRAS DE ARTE}

\subsubsection{ANÁLISE TÉRMICA (TA)}

A Figura 54 ilustra as curvas TG/DTG e DSC da amostra de cera da superfície em bom estado retirada da cabeça da personagem Afonso Pena (AP_CRBESP). As curvas TG/DTG evidenciaram que a amostra é termicamente estável até cerca de $150^{\circ} \mathrm{C}$. Entre 150 e $578^{\circ} \mathrm{C}$ ocorrem três perdas de massa distintas devido à decomposição térmica da amostra, $\Delta \mathrm{m}_{1}=$ $47,42 \%\left(150\right.$ a $319^{\circ} \mathrm{C}$ e $\left.\mathrm{T}_{\text {pico DTG }}=270^{\circ} \mathrm{C}\right), \Delta \mathrm{m}_{2}=28,94 \%\left(319 \mathrm{a} 440^{\circ} \mathrm{C}\right.$ e $\left.\mathrm{T}_{\text {pico DTG }}=380^{\circ} \mathrm{C}\right)$ e $\Delta \mathrm{m}_{3}=10,29 \%\left(440\right.$ a $600^{\circ} \mathrm{C}$ e $\left.\mathrm{T}_{\text {pico DTG }}=500^{\circ} \mathrm{C}\right)$. As curvas TG/DTG evidenciaram que na temperatura de $600^{\circ} \mathrm{C}$ o teor de material inorgânico é de $13,34 \%$, que pode ser atribuído aos resíduos inorgânicos dos pigmentos e/ou cargas empregados.

A curva DSC mostra um evento endotérmico entre 30 e $70^{\circ} \mathrm{C}\left(\mathrm{T}_{\text {pico DSC }}=51,6^{\circ} \mathrm{C}\right.$ e $\Delta \mathrm{H}=130$ $\mathrm{J} / \mathrm{g}$ ), devido a fusão do material, visto que na mesma faixa de temperatura as curvas TG/DTG não evidenciam perda de massa. Esse evento endotérmico corresponde à fusão da mistura das ceras, porém não permite afirmar quais são os componentes presentes ou qual conduziu a uma diminuição no ponto de fusão da mistura das ceras. Observou-se também um estreitamento no intervalo de fusão e uma maior simetria no pico que indica esse processo térmico. A curva DSC evidencia que o processo de decomposição térmica da amostra, acima de $158^{\circ} \mathrm{C}$, é exotérmico e ocorre em duas etapas distintas $\left(\mathrm{T}_{\text {pico1 DSC }}=200^{\circ} \mathrm{C}\right.$ e $\Delta \mathrm{H}_{1}=-141 \mathrm{~J} / \mathrm{g} ; \mathrm{T}_{\text {pico2 DSC }}=$ $417,4^{\circ} \mathrm{C}$ ) e concordantes com as etapas de perda de massa observadas nas curvas TG/DTG. A Figura 55 ilustra a sobreposição das curvas DSC das amostras CRCNT1, CRBRAB, RsDM e AP_CRBESP e permite uma melhor comparação do comportamento térmico dos componentes isoladamente e na mistura após confecção da escultura. A maior simetria do pico de fusão pode estar relacionada à mistura das ceras. Por outro lado, o aparecimento do evento exotérmico durante a decomposição térmica da amostra AP_CRBESP , diferentemente do que ocorre para as espécies isoladas, pode indicar que ocorre uma interação química entre elas durante o processo térmico. 


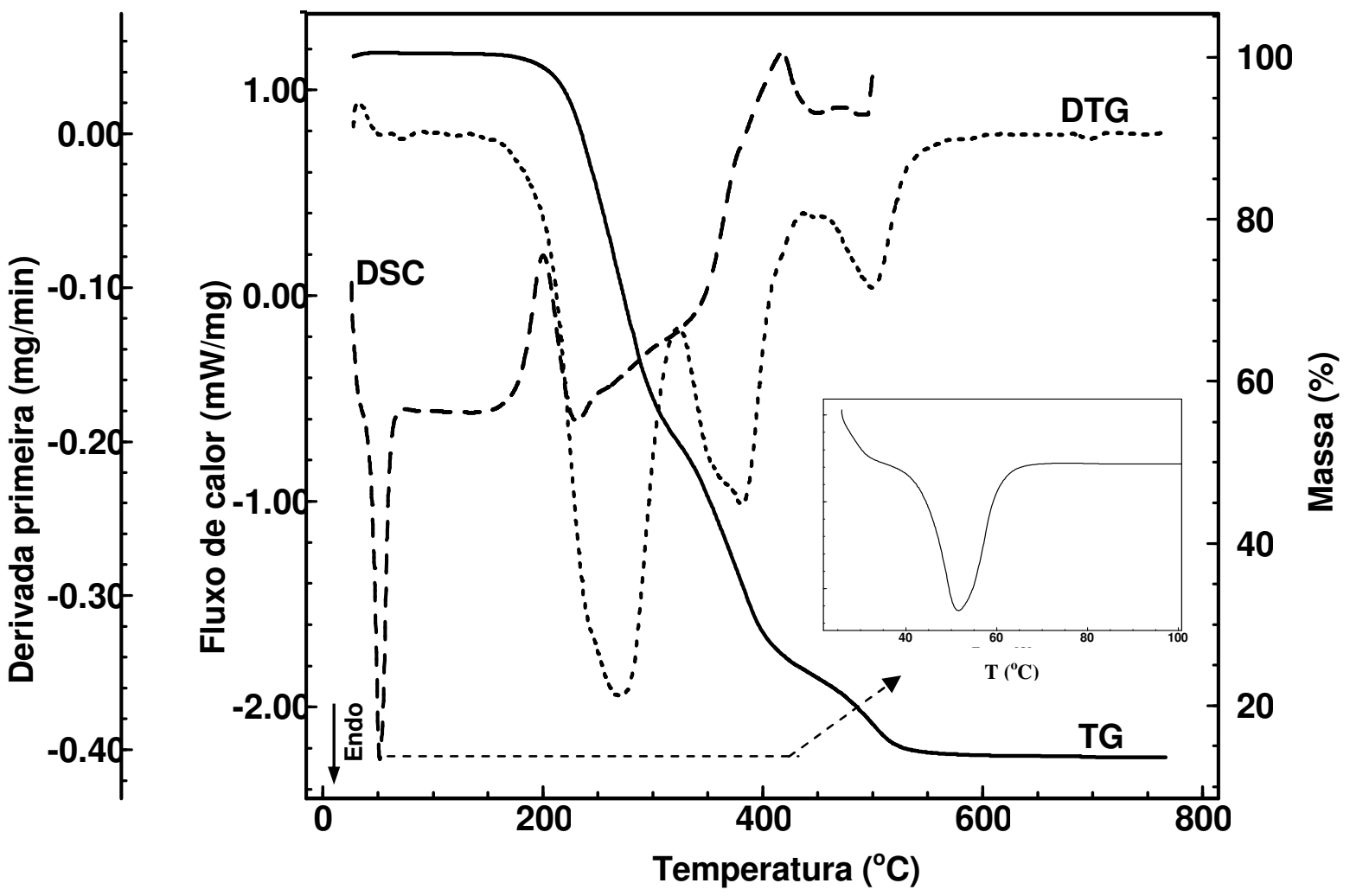

Figura 54 - Sobreposição das curvas TG/DTG e DSC da amostra AP_CRBESP.

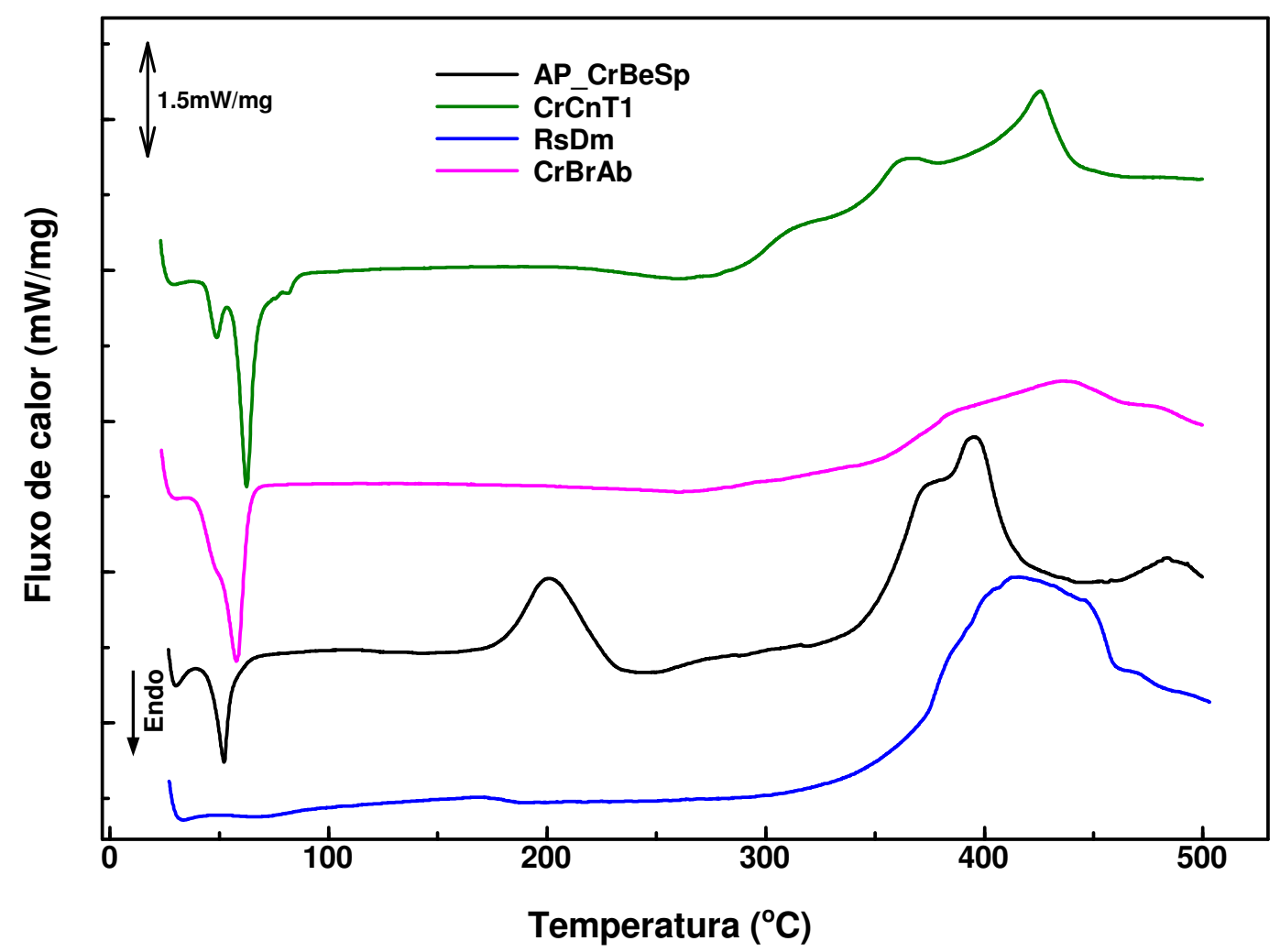

Figura 55 - Sobreposição das curvas DSC das amostra de CRCNT1, CRBRAB, RSDM e AP_CRBESP . 
A Figura 56 ilustra as curvas TG/DTG e DSC da amostra de cera deteriorada retirada da cabeça da personagem Afonso Pena (AP_CRDT). As curvas TG/DTG evidenciam uma pequena perda de massa $\left(\Delta \mathrm{m}_{1}=0,78 \%\right)$ entre 25 e $100^{\circ} \mathrm{C}$ que é devida à eliminação de água de umidade e/ou alguma outra substância ainda não identificada. É estável termicamente até $150^{\circ} \mathrm{C}$. Entre 150 e $600^{\circ} \mathrm{C}$ ocorrem quatro perdas de massa devido à decomposição térmica da amostra, $\Delta \mathrm{m}_{2}=38,71 \% \quad\left(150\right.$ a $\left.313^{\circ} \mathrm{C}\right), \Delta \mathrm{m}_{3}=11,41 \% \quad\left(313\right.$ a $\left.353^{\circ} \mathrm{C}\right), \Delta \mathrm{m}_{4}=22,23 \%$ (353 a $\left.437^{\circ} \mathrm{C}\right)$ e $\Delta \mathrm{m}_{5}=14,92 \% \quad\left(437\right.$ a $\left.630^{\circ} \mathrm{C}\right)$. As curvas TG/DTG evidenciaram que na temperatura de $630^{\circ} \mathrm{C}$ o teor de material inorgânico é de $12,15 \%$, que pode ser atribuído aos resíduos inorgânicos dos pigmentos empregados, conforme já relatado para a amostra AP_CRBESP.

A curva DSC mostra um evento endotérmico entre 27 e $73^{\circ} \mathrm{C}\left(\mathrm{T}_{\text {picol DSC }}=52,2^{\circ} \mathrm{C}\right.$ e $\Delta \mathrm{H}_{1}=107$ $\mathrm{J} / \mathrm{g}$ ), devido a fusão do material e eliminação de água de umidade, visto que na mesma faixa de temperatura as curvas TG/DTG evidenciaram uma pequena perda de massa. Semelhante ao ocorrido para a amostra não deteriorada, observou-se um estreitamento no intervalo de fusão e uma maior simetria no pico que indica esse processo térmico. Comparando-se os valores de $\Delta \mathrm{H}_{\text {fusão, }}$ aquele da amostra deteriorada é cerca de $20 \%$ menor, essa diminuição pode estar associada à deterioração parcial das ceras e eliminação de água de umidade. A curva DSC evidencia que o processo de decomposição térmica da amostra, acima de $150^{\circ} \mathrm{C}$, é exotérmico, ocorrendo em duas etapas $\left(\mathrm{T}_{\text {pico2 }} \mathrm{DSC}=237^{\circ} \mathrm{C}\right.$ e $\Delta \mathrm{H}_{2}=-161 \mathrm{~J} / \mathrm{g} ; \mathrm{T}_{\text {pico3 }}$ DSC $=$ $\left.422^{\circ} \mathrm{C}\right)$.

A Figura 57 ilustra a sobreposição das curvas DSC das amostras AP_CRBESP e AP_CRDT e no detalhe a ampliação das curvas TG das amostras até a temperatura de $240^{\circ} \mathrm{C}$. Essas ilustrações permitem visualizar melhor a similaridade e as pequenas diferenças no comportamento térmico das amostras. No detalhe pode-se verificar, claramente, a pequena perda de massa que ocorreu na amostra deteriorada. Por outro lado, apesar do evento exotérmico relacionado à decomposição térmica ter ocorrido para ambas as amostras, o valor de $\Delta \mathrm{H}$ é cerca de $15 \%$ maior para aquela que apresenta o material deteriorado. 


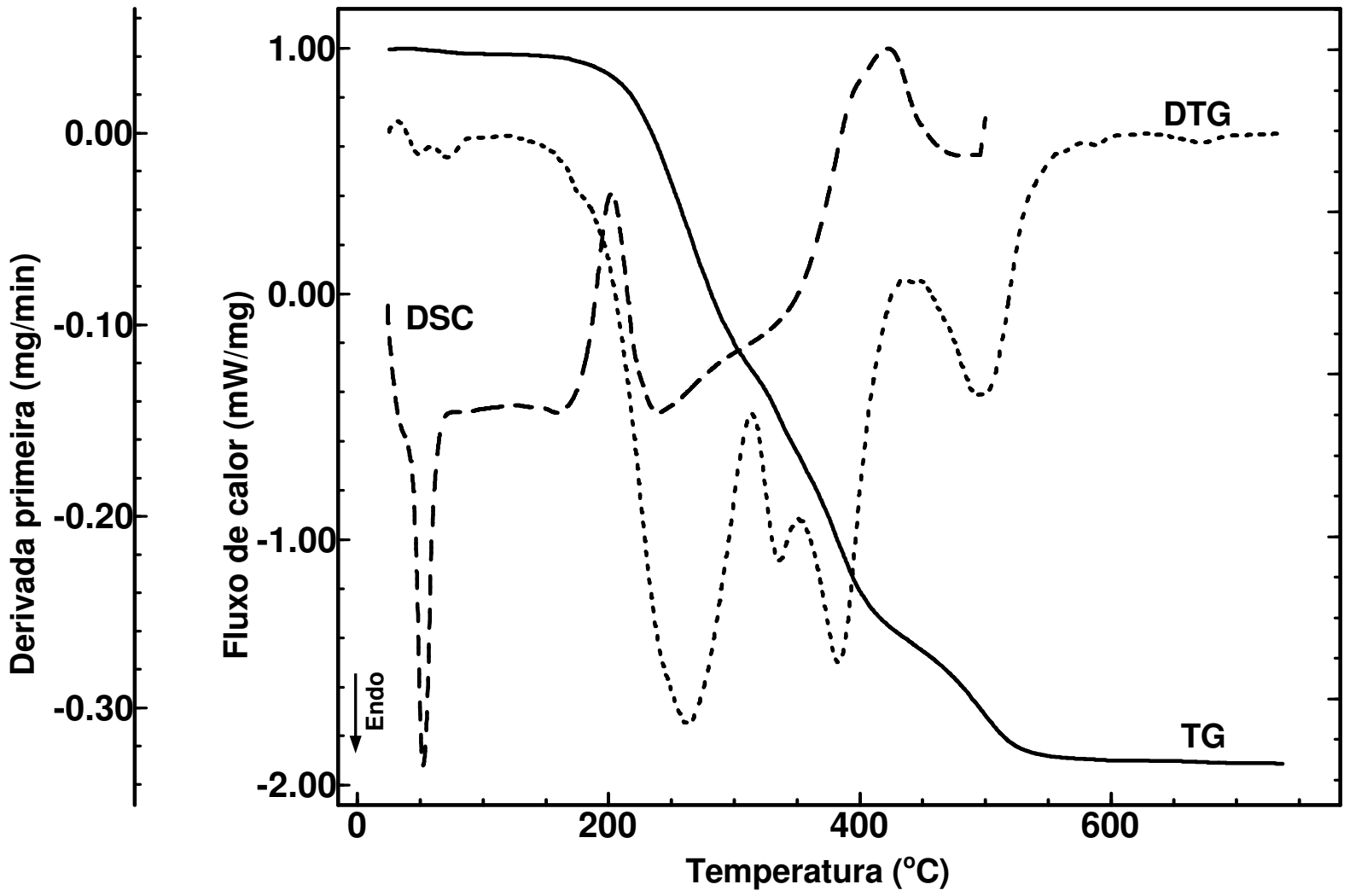

Figura 56 - Sobreposição das curvas TG/DTG e DSC da amostra AP_CRDT.

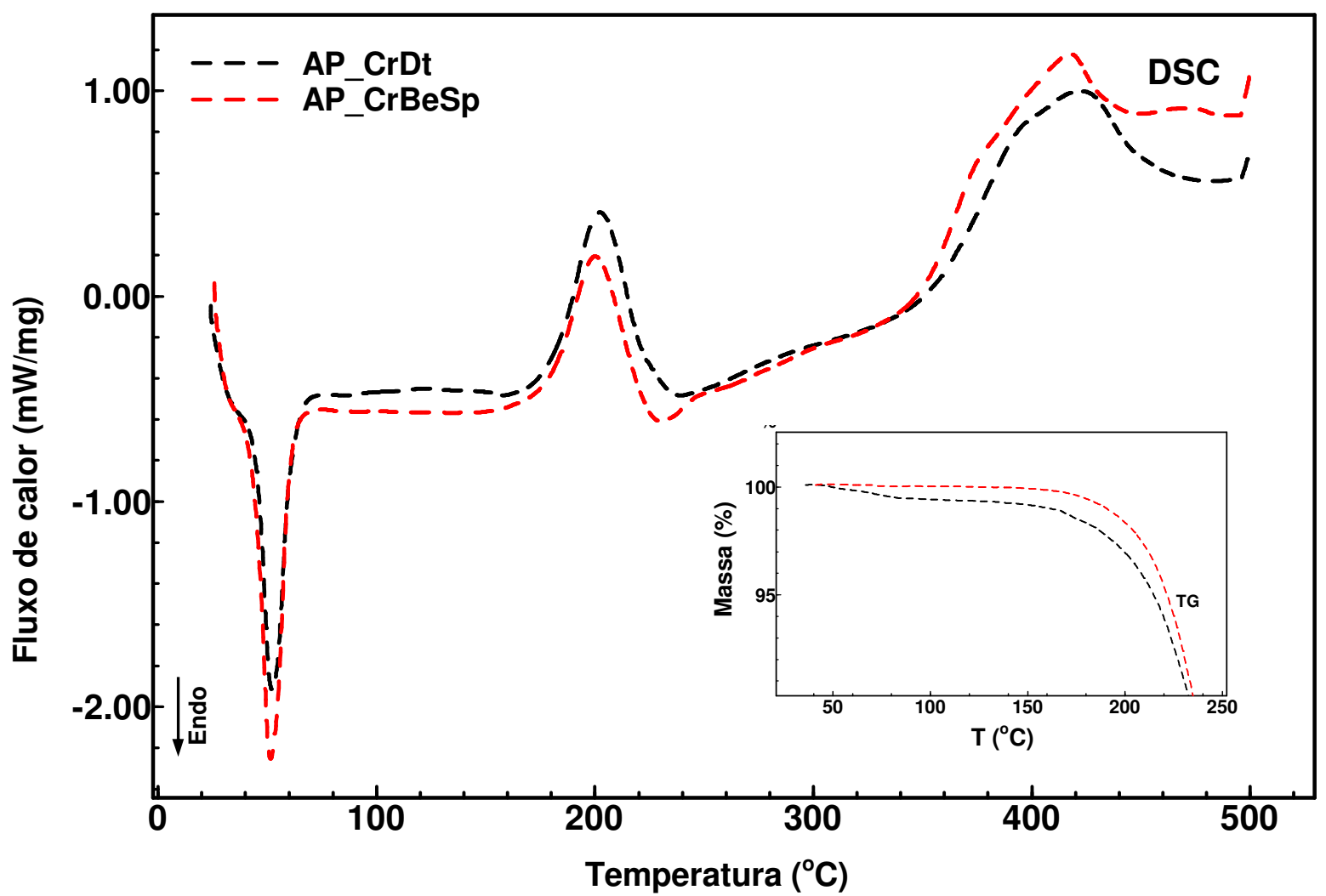

Figura 57 - Sobreposição das curvas DSC das amostras AP_CRBESP e AP_CRDT (no detalhe temse a sobreposição das curvas TG entre 30 e $240^{\circ} \mathrm{C}$ ). 
A Figura 58 ilustra as curvas TG/DTG e DSC da amostra de cera do miolo retirada da cabeça da personagem Afonso Pena (AP_CRML). As curvas TG/DTG evidenciam que a amostra é estável termicamente até $142^{\circ} \mathrm{C}$. Entre 142 e $556^{\circ} \mathrm{C}$ ocorrem quatro perdas de massa devido à decomposição térmica da amostra, $\Delta \mathrm{m}_{1}=75,12 \% \quad\left(171\right.$ a $\left.379^{\circ} \mathrm{C}\right), \Delta \mathrm{m}_{2}=4,31 \% \quad(379$ a $\left.419^{\circ} \mathrm{C}\right), \Delta \mathrm{m}_{3}=11,73 \% \quad\left(419\right.$ a $\left.492^{\circ} \mathrm{C}\right)$ e $\Delta \mathrm{m}_{4}=7,82 \% \quad\left(492\right.$ a $\left.556^{\circ} \mathrm{C}\right)$. As curvas TG/DTG evidenciaram que na temperatura de $556^{\circ} \mathrm{C}$ praticamente não há material inorgânico $(0,78 \%)$, o que é razoável posto que nesta camada deve haver somente cera de abelhas. A curva DSC mostra um evento endotérmico entre 29 e $67^{\circ} \mathrm{C}\left(\mathrm{T}_{\text {picol } \mathrm{DSC}}=51,2^{\circ} \mathrm{C}\right.$ e $\left.\Delta \mathrm{H}_{1}=192 \mathrm{~J} / \mathrm{g}\right)$, devido a fusão do material, visto que na mesma faixa de temperatura as curvas TG/DTG não evidenciaram perda de massa. Observou-se um estreitamento no intervalo de fusão e uma maior simetria no pico que indica esse processo térmico. A curva DSC evidencia que o processo de decomposição térmica da amostra, acima de $264^{\circ} \mathrm{C}$, é exotérmico, aparecem dois ombros $\left(\mathrm{T}_{\text {pico2 DSC }}=380^{\circ} \mathrm{C}\right.$ e $\left.\mathrm{T}_{\text {pico3 DSC }}=411^{\circ} \mathrm{C}\right)$.

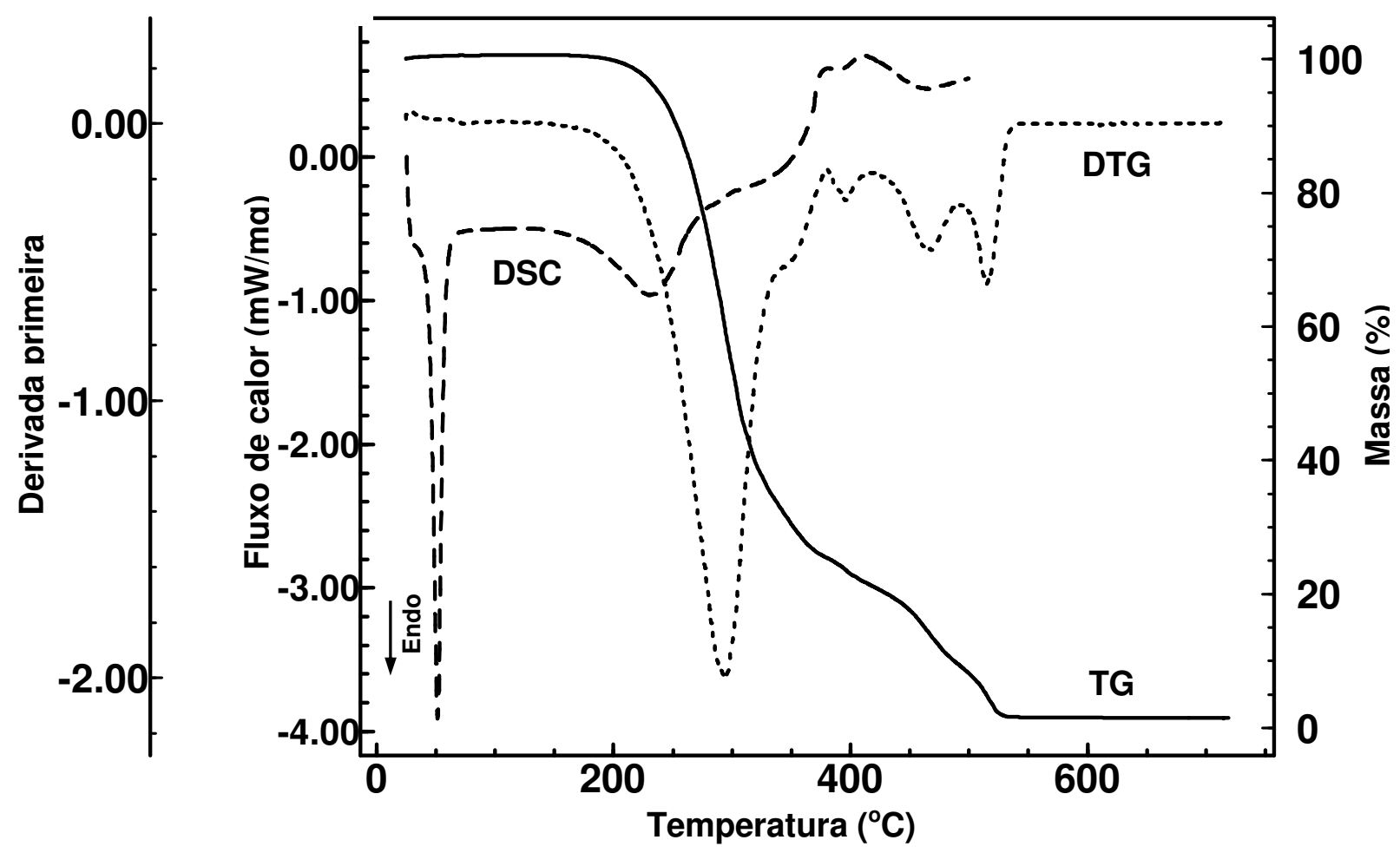

Figura 58 - Sobreposição das curvas TG/DTG e DSC da amostra. 
A Figura 59 ilustra as curvas TG/DTG e DSC da amostra de cera interna retirada da cabeça da personagem Afonso Pena (AP_CRIT). As curvas TG/DTG evidenciam que a amostra é estável termicamente até $150^{\circ} \mathrm{C}$. Entre 150 e $559^{\circ} \mathrm{C}$ ocorrem três perdas de massa devido à decomposição térmica da amostra, $\Delta \mathrm{m}_{1}=77,21 \% \quad\left(170\right.$ a $\left.407^{\circ} \mathrm{C}\right), \Delta \mathrm{m}_{2}=10,42 \% \quad(407$ a $\left.485^{\circ} \mathrm{C}\right)$ e $\Delta \mathrm{m}_{3}=10,54 \%\left(485\right.$ a $\left.559^{\circ} \mathrm{C}\right)$. As curvas TG/DTG evidenciaram que na temperatura de $559^{\circ} \mathrm{C}$ praticamente não há material inorgânico $(1,59 \%)$, o que é razoável posto que nesta camada deve haver somente cera de carnaúba ou uma mistura de cera de abelhas com cera de carnaúba. A curva DSC mostra um evento endotérmico entre 31 e $69^{\circ} \mathrm{C}\left(\mathrm{T}_{\text {pico1 DSC }}=51,3^{\circ} \mathrm{C}\right.$ e $\Delta \mathrm{H}_{1}=174 \mathrm{~J} / \mathrm{g}$ ), devido a fusão do material, visto que na mesma faixa de temperatura as curvas TG/DTG não evidenciaram perda de massa. Observou-se um estreitamento no intervalo de fusão e uma maior simetria no pico que indica esse processo térmico. A curva DSC evidencia que o processo de decomposição térmica da amostra, acima de $243^{\circ} \mathrm{C}$, é exotérmico, ocorrendo em uma etapa com dois ombros $\left(\mathrm{T}_{\text {pico2 }}\right.$ DSC $=379^{\circ} \mathrm{C}$ e $\mathrm{T}_{\text {pico3 }}$ DSC $=$ $\left.408^{\circ} \mathrm{C}\right)$.

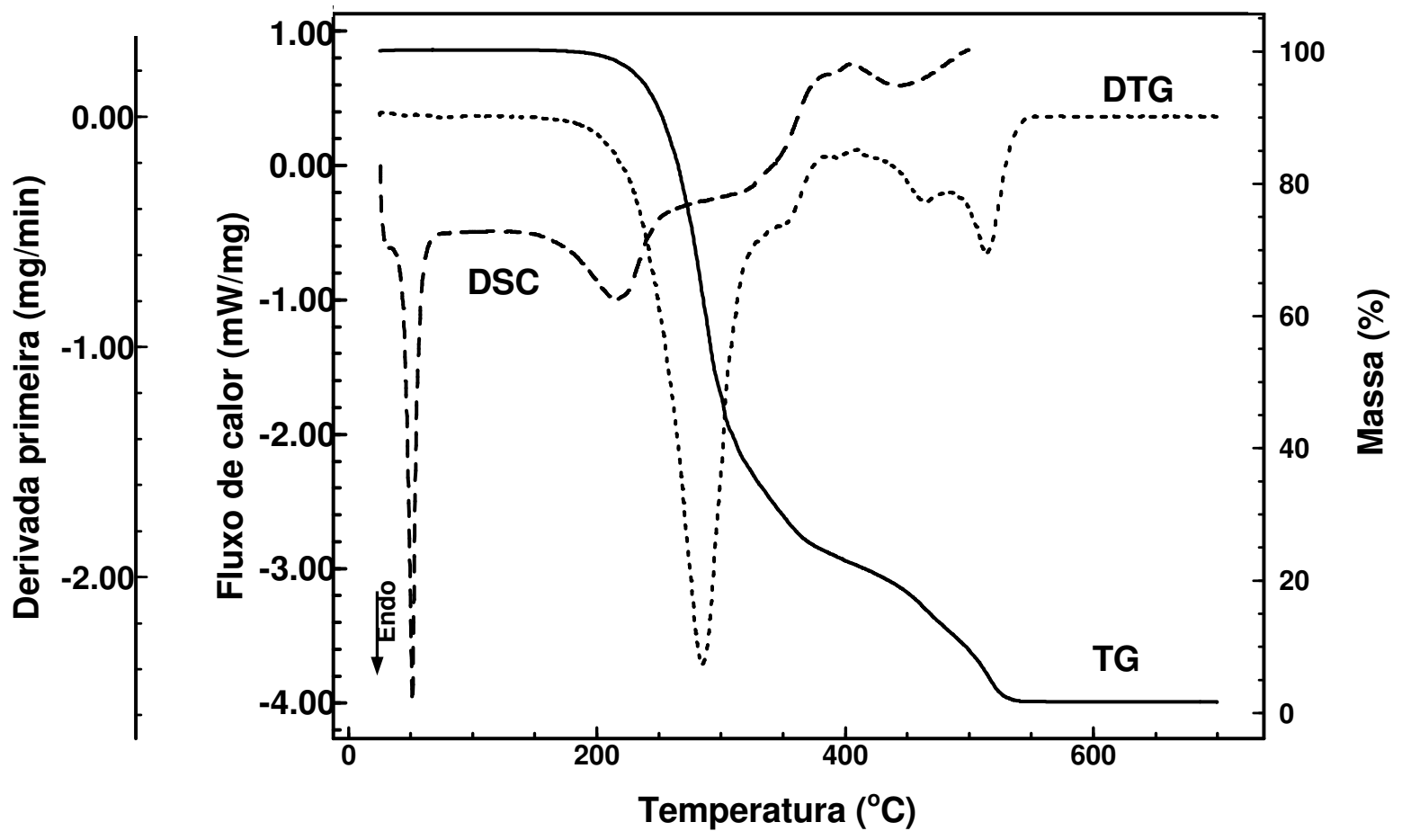

Figura 59 - Sobreposição das curvas TG/DTG e DSC da amostra AP_CRIT. 
A Figura 60 ilustra as curvas TG/DTG e DSC da amostra de cera em bom estado retirada da cabeça da personagem Lampião (LP_CRBESP). As curvas TG/DTG evidenciam uma pequena perda de massa $\left(\Delta \mathrm{m}_{1}=1,69 \%\right)$ entre 20 e $128^{\circ} \mathrm{C}$ que é devida à eliminação de água de umidade e/ou eliminação de algum outro material ainda não identificado. É estável termicamente até $150^{\circ} \mathrm{C}$. Entre 150 e $567^{\circ} \mathrm{C}$ ocorrem três perdas de massa devido à decomposição térmica da amostra, $\Delta \mathrm{m}_{2}=28,61 \% \quad\left(128\right.$ a $\left.295^{\circ} \mathrm{C}\right), \Delta \mathrm{m}_{3}=33,73 \% \quad(295$ a $\left.435^{\circ} \mathrm{C}\right)$ e $\Delta \mathrm{m}_{4}=8,44 \% \quad\left(435\right.$ a $\left.567^{\circ} \mathrm{C}\right)$. As curvas TG/DTG evidenciaram que na temperatura de $567^{\circ} \mathrm{C}$ o teor de material inorgânico é de $27,26 \%$, que pode ser atribuído aos resíduos inorgânicos dos pigmentos empregados, semelhantemente à amostra AP_CRBESP.

A curva DSC mostra um evento endotérmico entre 25 e $70^{\circ} \mathrm{C}\left(\mathrm{T}_{\text {picol }} \mathrm{DSC}=52,2^{\circ} \mathrm{C}\right.$ e $\Delta \mathrm{H}_{1}=77$ $\mathrm{J} / \mathrm{g}$ ), devido a fusão do material e eliminação de água de umidade, visto que na mesma faixa de temperatura as curvas TG/DTG evidenciaram uma pequena perda de massa. Observou-se um estreitamento no intervalo de fusão e uma maior simetria no pico que indica esse processo térmico. A curva DSC evidencia que o processo de decomposição térmica da amostra, acima de $142^{\circ} \mathrm{C}$, é exotérmico, ocorrendo em duas etapas $\left(\mathrm{T}_{\text {pico2 }} \mathrm{DSC}=97,5^{\circ} \mathrm{C}\right.$ e $\Delta \mathrm{H}_{2}=-193 \mathrm{~J} / \mathrm{g}$; $\left.\mathrm{T}_{\text {pico3 DSC }}=385^{\circ} \mathrm{C}\right)$.

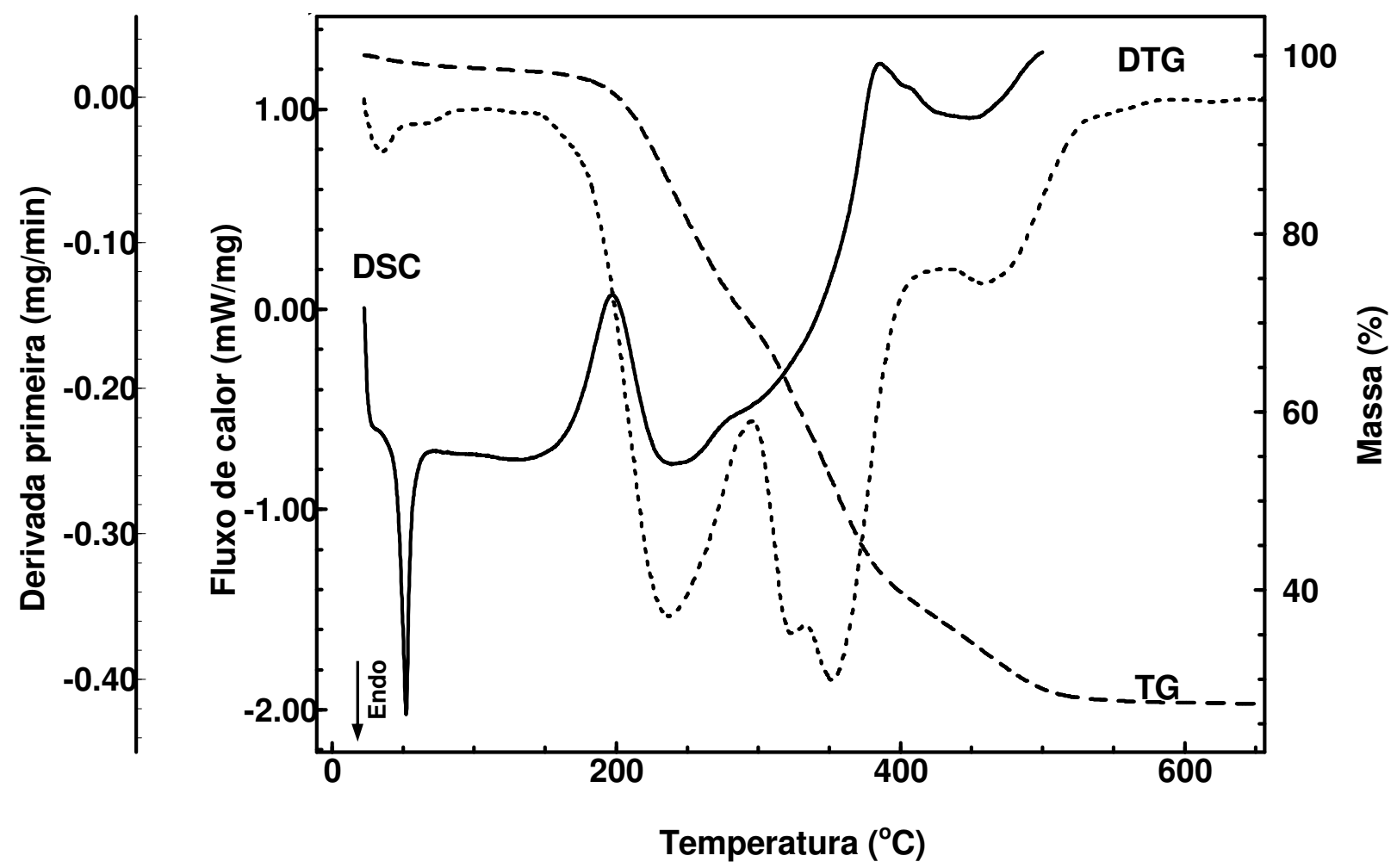

Figura 60 - Sobreposição das curvas TG/DTG e DSC da amostra LP_CRBESP. 
A Figura 61 ilustra as curvas TG/DTG e DSC da amostra de cera deteriorada retirada da cabeça da personagem Lampião (LP_CRDT). As curvas TG/DTG evidenciam que a amostra é estável termicamente até cerca de $177^{\circ} \mathrm{C}$. Entre 177 e $599^{\circ} \mathrm{C}$ ocorrem três perdas de massa principais devido à decomposição térmica da amostra, $\Delta \mathrm{m}_{1}=69,43 \% \quad\left(177 \mathrm{a} 406^{\circ} \mathrm{C}\right), \Delta \mathrm{m}_{2}=$ $19,45 \% \quad\left(406\right.$ a $\left.521^{\circ} \mathrm{C}\right)$ e $\Delta \mathrm{m}_{3}=8,03 \% \quad\left(521\right.$ a $\left.600^{\circ} \mathrm{C}\right)$. A curva DSC mostra um evento endotérmico entre 39 e $84^{\circ} \mathrm{C}\left(\mathrm{T}_{\text {pico DSC }}=51,9^{\circ} \mathrm{C}\right.$ e $\left.\Delta \mathrm{H}=135 \mathrm{~J} / \mathrm{g}\right)$, devido a fusão do material, visto que na mesma faixa de temperatura as curvas TG/DTG não evidenciam perda de massa. A curva DSC evidencia que o processo de decomposição térmica da amostra inicialmente é endotérmico, o que pode ser constatado pelo desvio da linha base neste sentido e acima de $220^{\circ} \mathrm{C}$ é exotérmico.

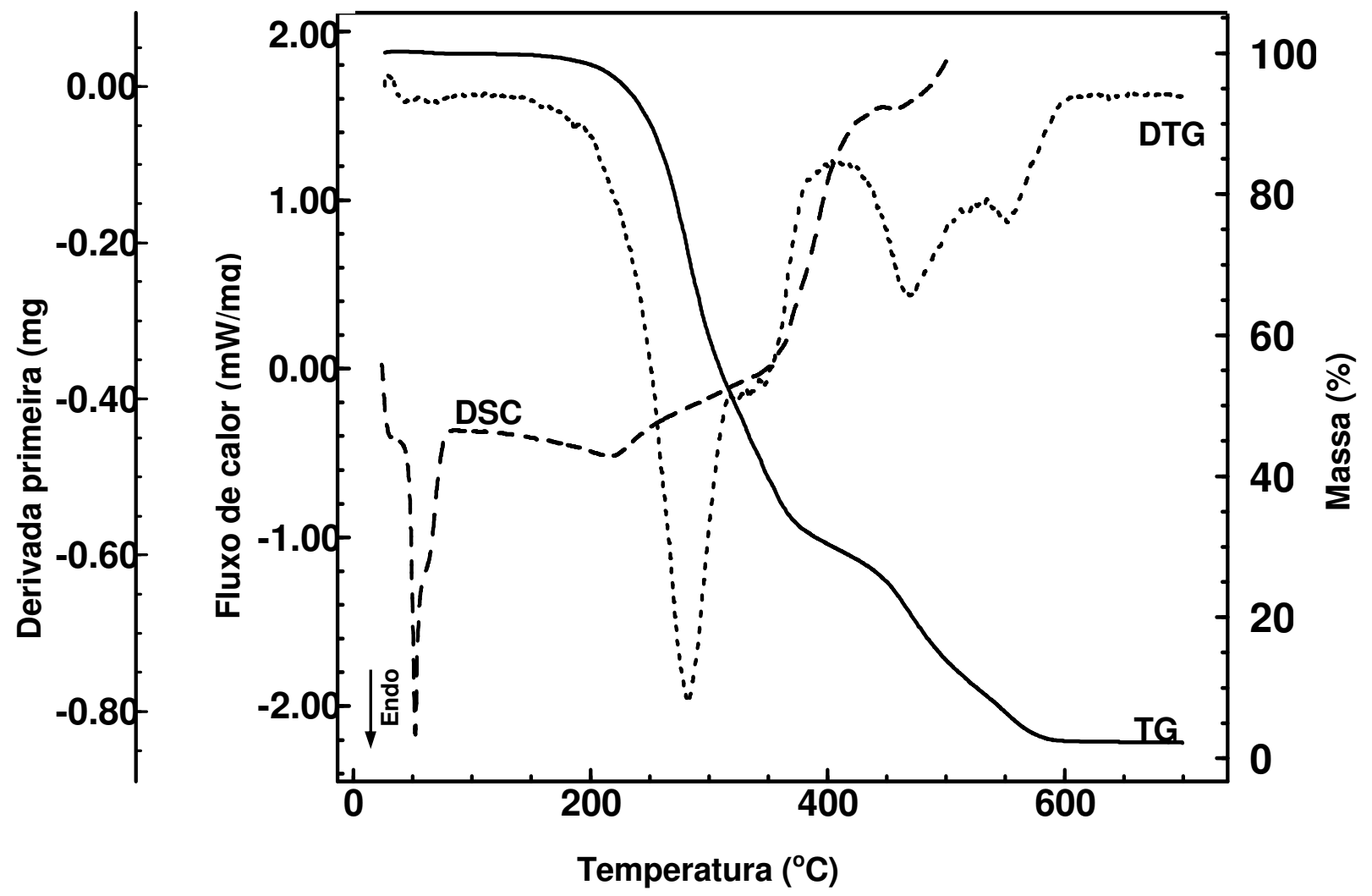

Figura 61 - Sobreposição das curvas TG/DTG e DSC da amostra LP_CRDT. 
A Figura 62 ilustra a sobreposição das curvas DSC das amostras LP_CRBESP e LP_CRDT e no detalhe a ampliação da sobreposição das faixas de fusão. Essas ilustrações permitem visualizar melhor a similaridade e as diferenças no comportamento térmico das amostras.

As amostras da superfície (em bom estado e deteriorada) retiradas da personagem Lampião apresentam um comportamento térmico um pouco diferente do observado nas amostras equivalentes da personagem Afonso Pena. Enquanto na personagem AP o material deteriorado apresentava um valor de $\Delta \mathrm{H}_{\text {fusão }}$ menor que o da cera em bom estado, na personagem LP esta relação se inverte. No processo de decomposição térmica também o comportamento é diferente entre as amostras equivalentes das duas personagens. Enquanto a amostra LP_CRBESP apresenta um evento exotérmico, a amostra LP_CRDT apresenta um pequeno evento endotérmico no mesmo intervalo de temperatuta.

A ampliação da faixa de fusão, ilustrada como detalhe no interior da figura, mostra que também o tamanho e o formato dos picos de fusão são diferentes. O pico da amostra LP_CRBESP é menor que o da amostra LP_CRDT e é simétrico. O pico da amostra LP_CRDT é assimétrico e apresenta um ombro, evidenciando que há diferentes espécies fundindo no mesmo intervalo de temperatura.

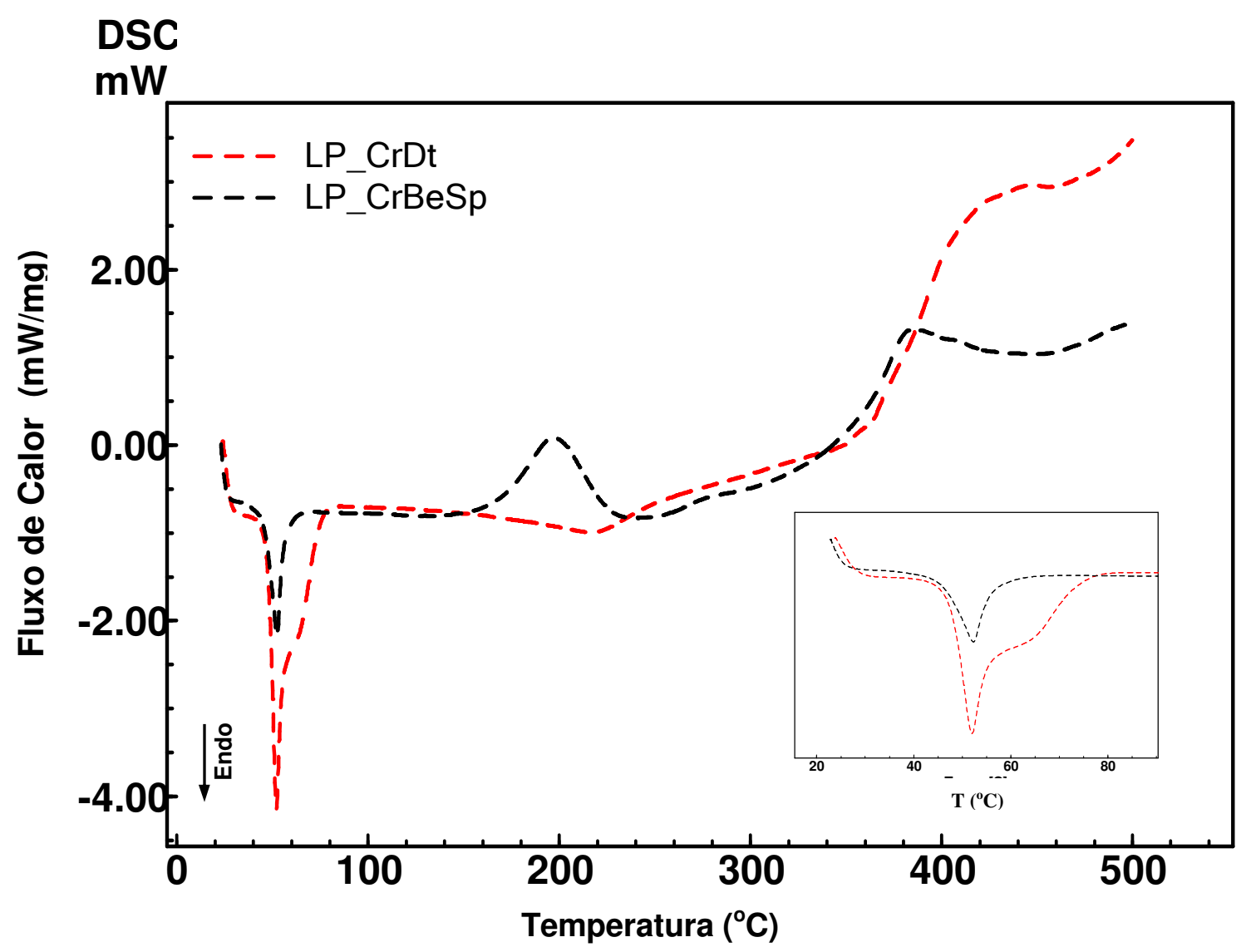

Figura 62 - Sobreposição das curvas DSC das amostras LP_CRBESP e LP_CRDT. 
A Figura 63 ilustra a sobreposição das curvas TG/DTG das amostras LP_CRBESP e LP_CRDT. Essas ilustrações permitem visualizar melhor a similaridade e as pequenas diferenças no comportamento térmico das amostras. Pode-se verificar, claramente, a pequena perda de massa que ocorreu na amostra em bom estado. Na comparação entre as curvas TG/DTG das amostras em bom estado e deteriorada da personagem AP ilustrada no detalhe da Figura 57, ao contrário da personagem Lampião, nota-se que a amostra deteriorada inicialmente perde mais massa que a outra, mas acima de $281^{\circ} \mathrm{C}$ esta relação se inverte. A amostra de cera em bom estado apresenta um resíduo de material inorgânico 14 vezes maior que a amostra de cera deteriorada $\left(\Delta \mathrm{m}_{\text {total LP_CRBESP }}=72,07 \%\right.$ e $\left(\Delta \mathrm{m}_{\text {total LP_CRDT }}=97,98 \%\right)$. Este resultado é coerente, pois no caso da personagem Lampião o processo de deterioração se alastrou nas camadas internas chegando a $0,5 \mathrm{~cm}$ de profundidade, ou seja: ultrapassando a camada da superfície onde se encontram os pigmentos e avançando na camada do miolo, que é somente de material orgânico (Figura 32). A coleta da amostra avançou na camada imediatamente abaixo - miolo. Houve uma perda mecânica da matéria.

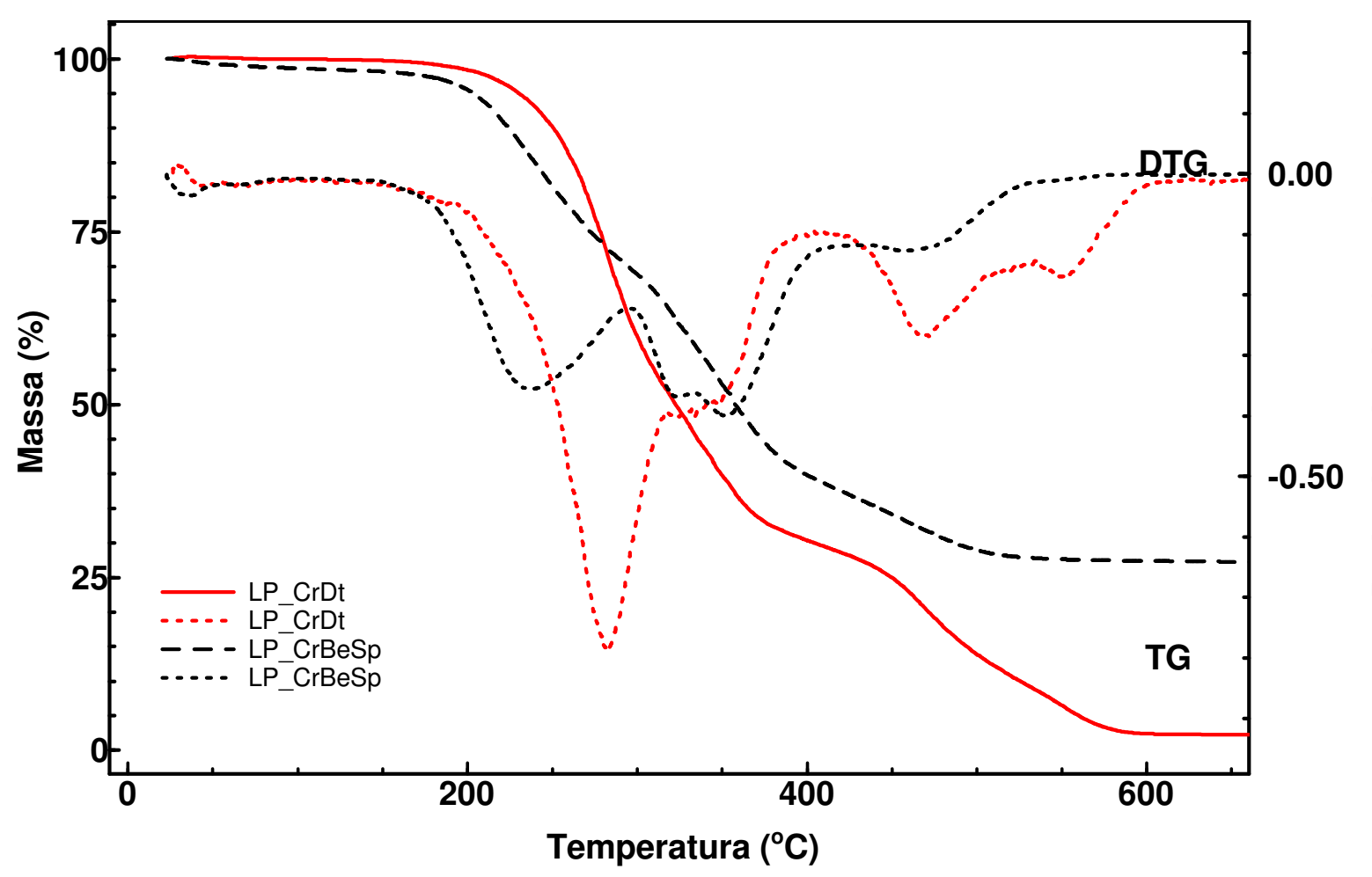

Figura 63 - Sobreposição das curvas TG/DTG das amostras LP_CRBESP e LP_CRDT. 
A Figura 64 ilustra a sobreposição das curvas DSC das amostras AP_CRDT e LP_CRDT e no detalhe a ampliação da sobreposição das faixas de fusão. Essas ilustrações permitem visualizar melhor a similaridade e as diferenças no comportamento térmico das amostras.

A ampliação da faixa de fusão, ilustrada como detalhe no interior da figura, mostra que o tamanho e o formato dos picos de fusão são diferentes. O pico da amostra AP_CRDT é menor e mais largo na extremidade que o da amostra LP_CRDT e é simétrico. O pico da amostra LP_CRDT é assimétrico e apresenta um ombro evidenciando que há diferentes espécies fundindo no mesmo intervalo de temperatura.

O valor de $\Delta \mathrm{H}_{\text {fusão }}$ é $30 \%$ menor para a amostra AP_CRDT do que para a amostra LP_CRDT . Entretanto, a maior diferença que se nota é a sobreposição do evento exotérmico da amostra AP_CRDT no mesmo intervalo de temperatura do evento endotérmico da amostra LP_CRDT, ambos no processo de decomposição térmica.

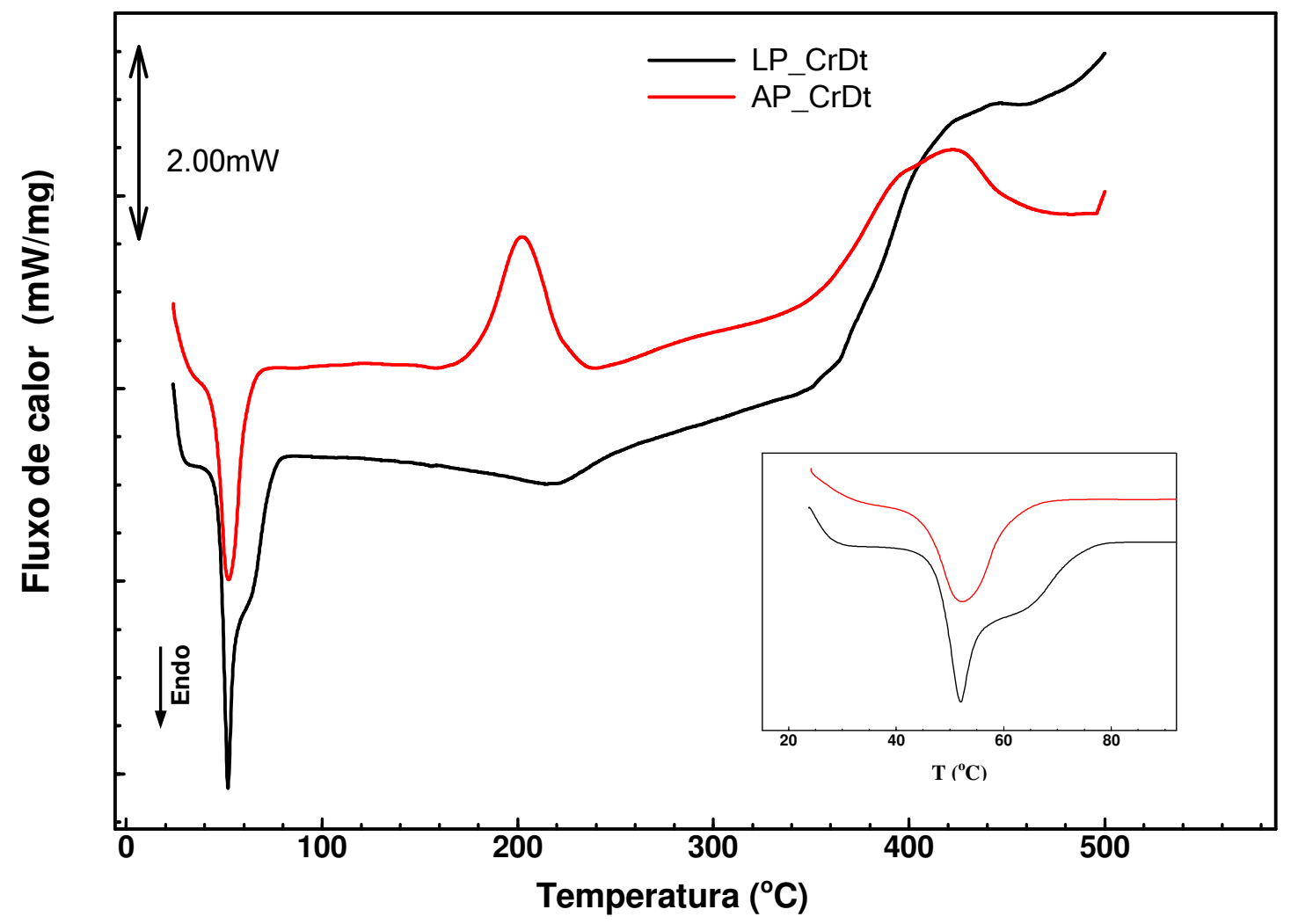

Figura 64 - Sobreposição das curvas DSC das amostras AP_CRDT e LP_CRDT. 


\subsubsection{ESPECTROSCOPIA NO INFRAVERMELHO (IR)}

Foram realizadas diversas medidas de IR de cada tipo de amostra e pôde-se verificar a reprodutibilidade nos resultados. Em vista disso foram selecionados apenas os espectros que estavam em formato digital para serem apresentados neste trabalho.

A Figura 65 apresenta o espectro no infravermelho da amostra de cera da superfície em bom estado da personagem Afonso Pena (AP_CRBESP). O espectro é característico da cera de abelhas (bruta ou clarificada) possivelmente com adição de resina damar. Observa-se uma banda de absorção de baixa intensidade em $3677 \mathrm{~cm}^{-1}$ e uma banda de absorção larga em $3435 \mathrm{~cm}^{-1}$ (ambas referentes ao estiramento da ligação $\mathrm{O}-\mathrm{H}$ ). Também são observadas absorções em: a) 2919 e 2850 cm$^{-1}$ (estiramento da ligação C-H); b) 1734 e 1708 cm$^{-1}$ (estiramento da ligação $\mathrm{C}=\mathrm{O}$ ); c) $1646 \mathrm{~cm}^{-1}$ (dobramento da ligação $\mathrm{O}-\mathrm{H}$ ); d) 1467, 1432, 1412 e $1377 \mathrm{~cm}^{-1}$ (dobramento da ligação C-H); e) 1285, 1170, 1122, 1015 e $841 \mathrm{~cm}^{-1}$ (estiramento da ligação C-O) e f) $724 \mathrm{~cm}^{-1}$ (torção da ligação C-H).

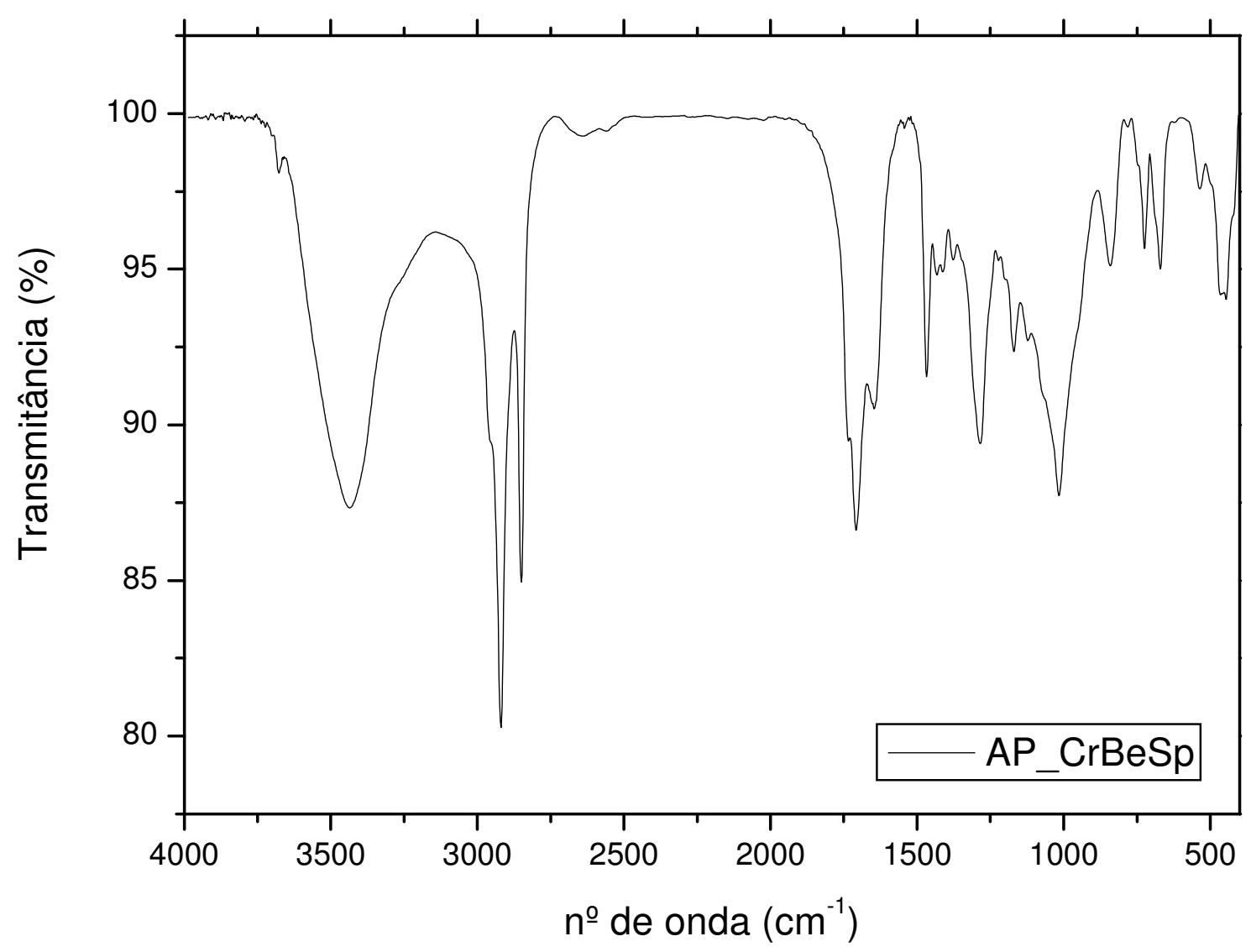

Figura 65 - Espectro de absorção no infravermelho da amostra AP_CRBESP. 
A Figura 66 apresenta o espectro no infravermelho da amostra de cera deteriorada da personagem Afonso Pena (AP_CRDT). O espectro mostra um aumento na intensidade da banda de absorção na região entre 3600 e $3200 \mathrm{~cm}^{-1}\left(3438 \mathrm{~cm}^{-1}\right)$ que corresponde ao estiramento da ligação $\mathrm{O}-\mathrm{H}$, mas também pode ser devido ao estiramento da ligação $\mathrm{N}-\mathrm{H}$. Relativamente, mostra uma diminuição na intensidade das bandas correspondentes ao estiramento da ligação C-H, 2921 e $2853 \mathrm{~cm}^{-1}$. Em $1734 \mathrm{~cm}^{-1}$ tem-se a absorção referente à carbonila do éster (estiramento da ligação $\mathrm{C}=\mathrm{O}$, linha pontilhada), que também diminui de intensidade, enquanto aquele referente à carbonila do ácido (estiramento da ligação $\mathrm{C}=\mathrm{O}$ ) na região de $1708 \mathrm{~cm}^{-1}$ não é visível. Também, são observadas as absorções em: a) $1646 \mathrm{~cm}^{-1}$ (dobramento da ligação O-H); b) $1465 \mathrm{~cm}^{-1}$ (dobramento da ligação C-H); c) 1282, 1017 e $837 \mathrm{~cm}^{-1}$ (estiramento da ligação C-O) e d) $747 \mathrm{~cm}^{-1}$ (torção da ligação C-H).

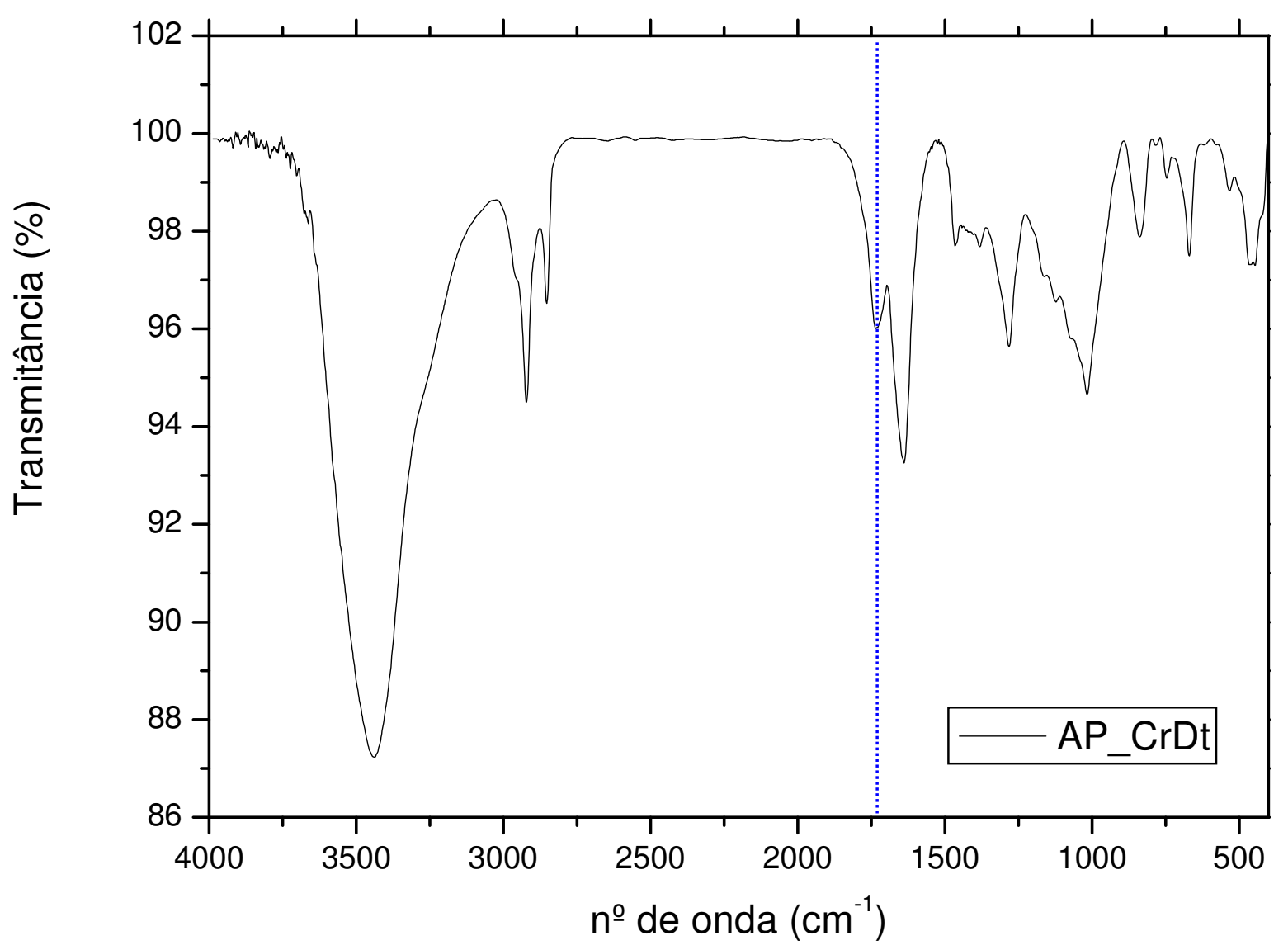

Figura 66 - Espectro de absorção no infravermelho da amostra AP_CRDT. 
A Figura 67 apresenta a sobreposição dos espectros no infravermelho das amostras de cera em bom estado da superfície e cera deteriorada da personagem Afonso Pena. As principais diferenças entre os dois espectros são as intensidades relativas das bandas de absorção referentes à vibração do grupo carbonila do ácido (intervalo de 1630 a $1710 \mathrm{~cm}^{-1}$ ) e do éster (intervalo de $1730 \mathrm{~cm}^{-1}$ ). Na cera em bom estado as bandas de absorção referente à carbonila do ácido aparecem em 1646 e $1708 \mathrm{~cm}^{-1}$ e aquela referente à carbonila do éster aparece como um ombro em $1734 \mathrm{~cm}^{-1}$. Com a deterioração ocorre o desaparecimento da banda de absorção em $1708 \mathrm{~cm}^{-1}$ e o aumento da intensidade da banda em $1734 \mathrm{~cm}^{-1}$ da carbonila do éster. Este resultado indica haver maior quantidade de ácido antes da deterioração.

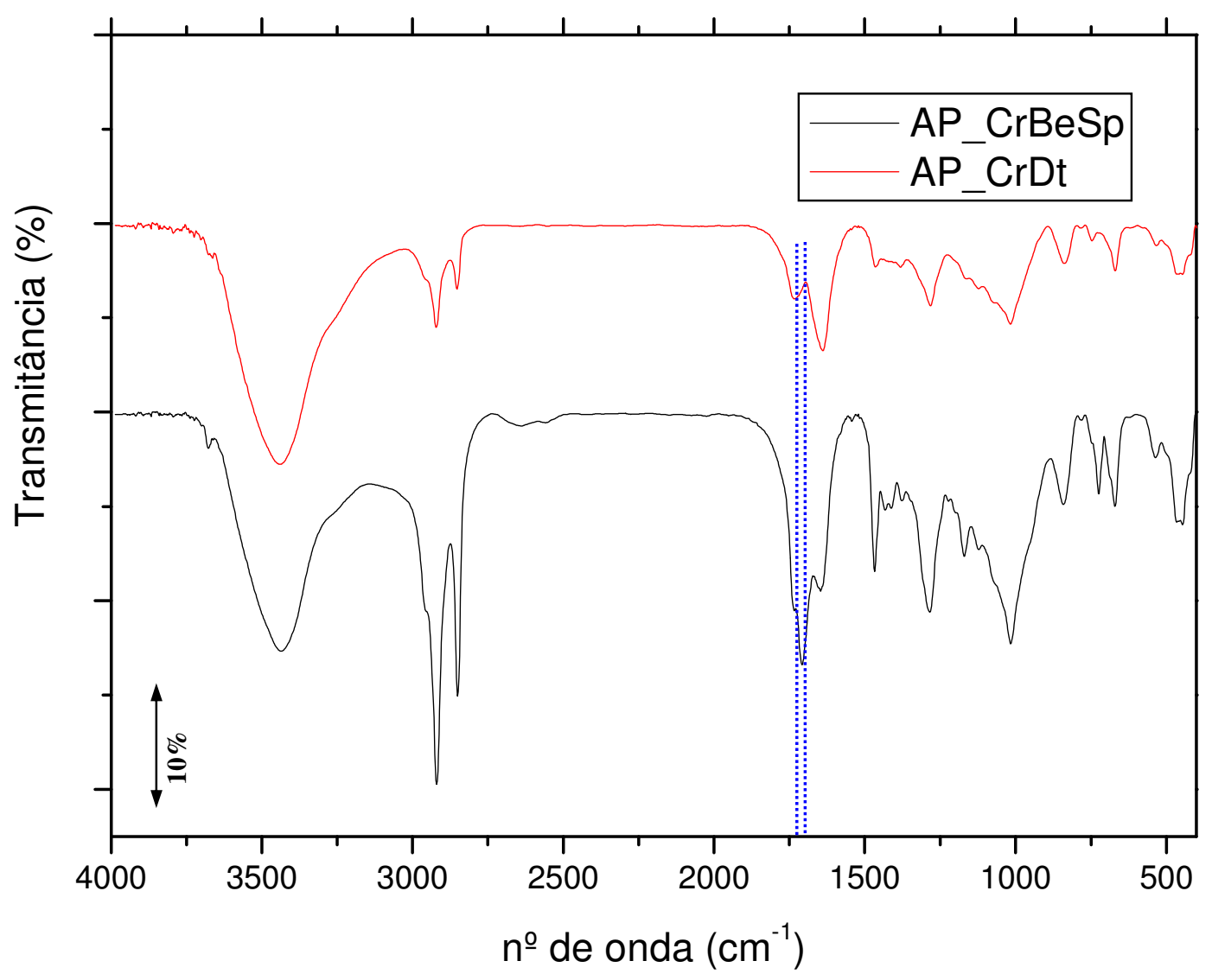

Figura 67 - Sobreposição dos espectros no infravermelho das amostras AP_CRBESP e AP_CRDT. 
A Figura 68 apresenta o espectro no infravermelho da amostra de cera do miolo da personagem Afonso Pena (AP_CRML).Esse espectro é característico daquele da cera de abelhas (bruta ou clarificada), com as bandas de absorção em: a) $3425 \mathrm{~cm}^{-1}$ (estiramento da ligação O-H); b) 2918 e 2849 cm$^{-1}$ (estiramento da ligação C-H); c) 1736 e 1704 cm$^{-1}$ (estiramento da ligação C=O); d) 1468 e $1433 \mathrm{~cm}^{-1}$ (dobramento da ligação C-H); e) 1296 $\mathrm{cm}^{-1}$ (estiramento da ligação C-O) e f) $723 \mathrm{~cm}^{-1}$ (torção da ligação C-H). Este resultado indica que o processo de deterioração é superficial e não afeta a parte do miolo da escultura de Afonso Pena.

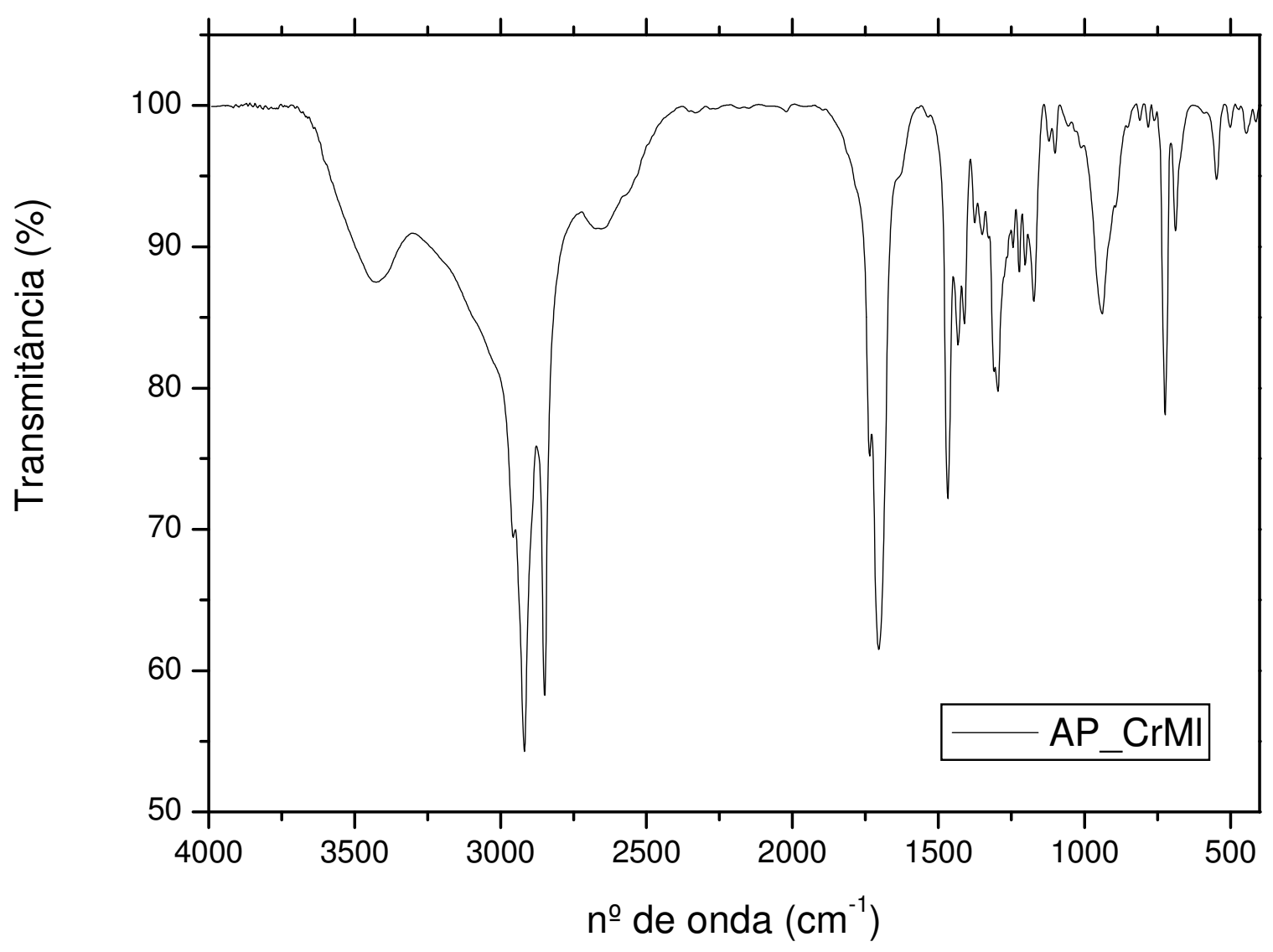

Figura 68 - Espectro de absorção no infravermelho da amostra AP_CRML. 
O mesmo foi observado na cera da parte interna da escultura da personagem Afonso Pena (AP_CRIT), cujo espectro no infravermelho é apresentado na Figura 69. O espectro é característico da cera de abelhas (bruta ou clarificada), com as bandas de absorção em: a) $3429 \mathrm{~cm}^{-1}$ (estiramento da ligação O-H); 2919 e $2849 \mathrm{~cm}^{-1}$ (estiramento da ligação C-H); b) 1736 e $1705 \mathrm{~cm}^{-1}$ (estiramento da ligação C=O); c) 1468 e $1433 \mathrm{~cm}^{-1}$ (dobramento da ligação C-H); d) $1296 \mathrm{~cm}^{-1}$ (estiramento da ligação C-O) e e) $724 \mathrm{~cm}^{-1}$ (torção da ligação C-H).

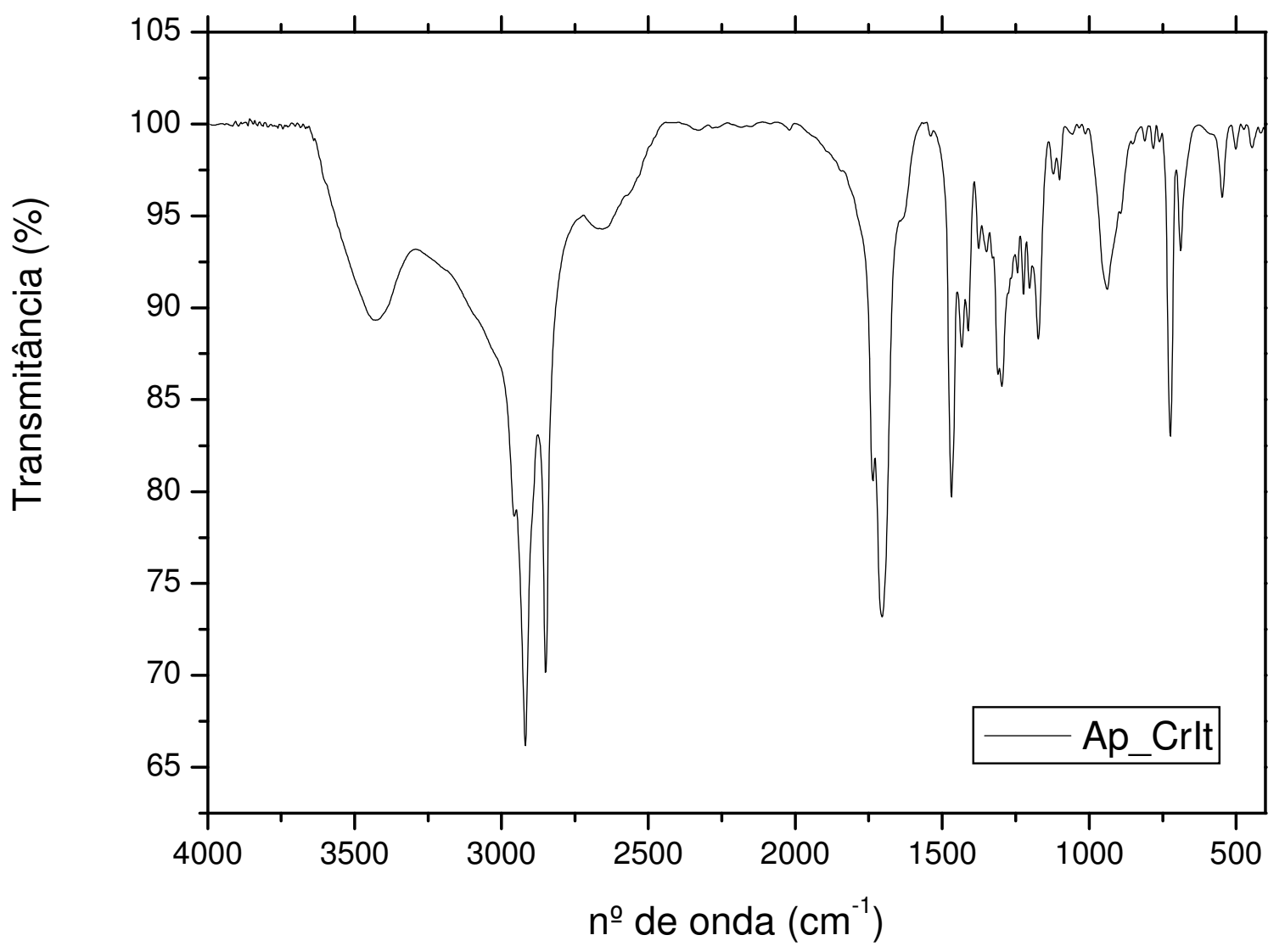

Figura 69 - Espectro de absorção no infravermelho da amostra AP_CRIT. 
A Figura 70 apresenta o espectro no infravermelho da amostra de cera deteriorada da personagem Afonso Pena restaurada com calor (AP_CRDTRC). O espectro é característico da cera de abelhas (bruta ou clarificada), com as bandas de absorção em: $3436 \mathrm{~cm}^{-1}$ (estiramento da ligação O-H); 2919 e 2850 cm$^{-1}$ (estiramento da ligação C-H); 1736 e 1710 cm$^{-1}$ (estiramento da ligação $\mathrm{C}=\mathrm{O}$ ); $1467 \mathrm{~cm}^{-1}$ (dobramento da ligação $\mathrm{C}-\mathrm{H}$ ); 1282, 1171, 1016 e $939 \mathrm{~cm}^{-1}$ (estiramento da ligação C-O) e 724 e $699 \mathrm{~cm}^{-1}$ (torção da ligação C-H).

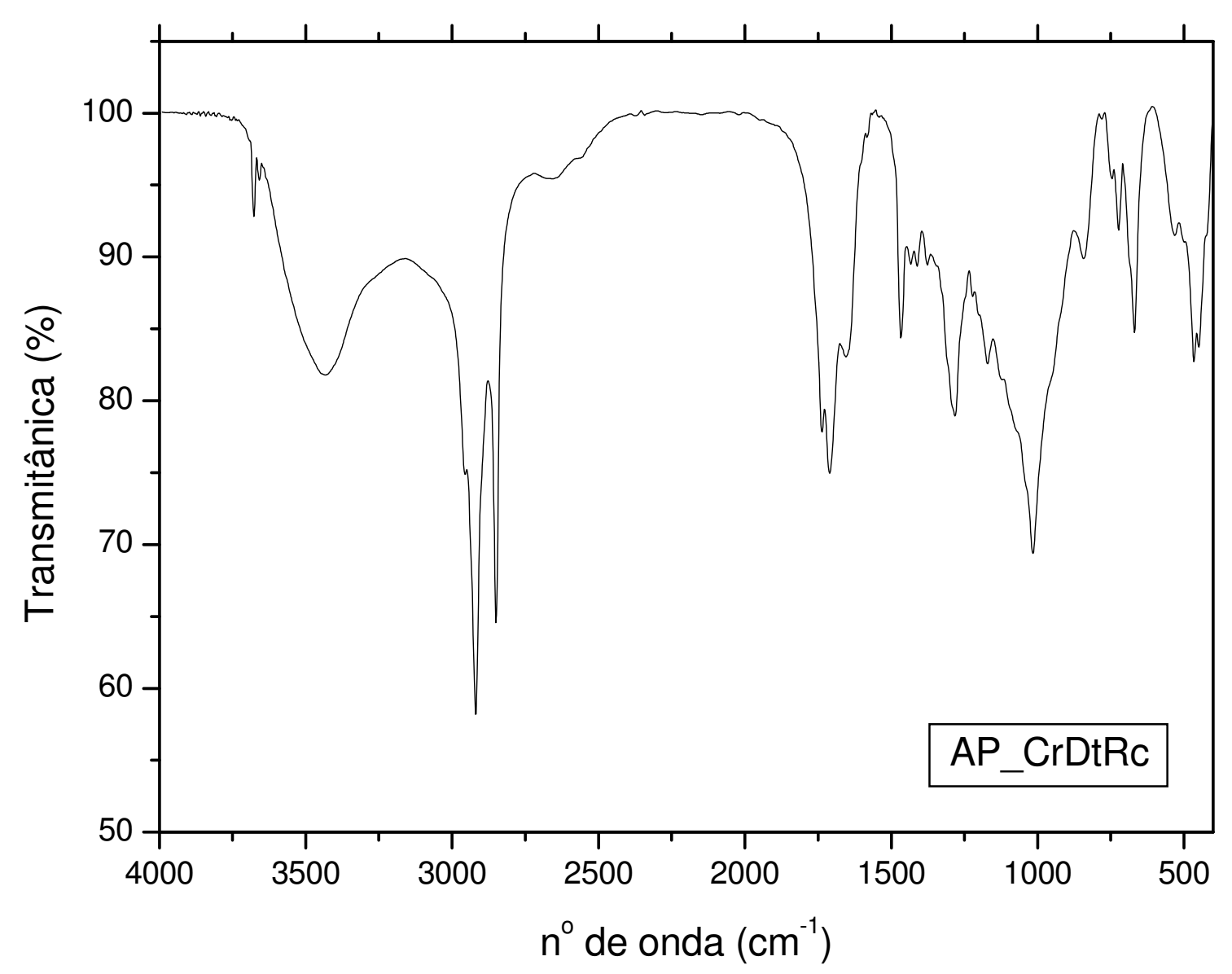

Figura 70 - Espectro de absorção de infravermelho da amostra AP_CRDTRC. 
Os espectros no infravermelho das três amostras de cera não deteriorada da personagem AP, podem ser melhor comparados e visualizadas na sobreposição apresentada na Figura 71. Não é possível distinguir entre as camadas com esta técnica.

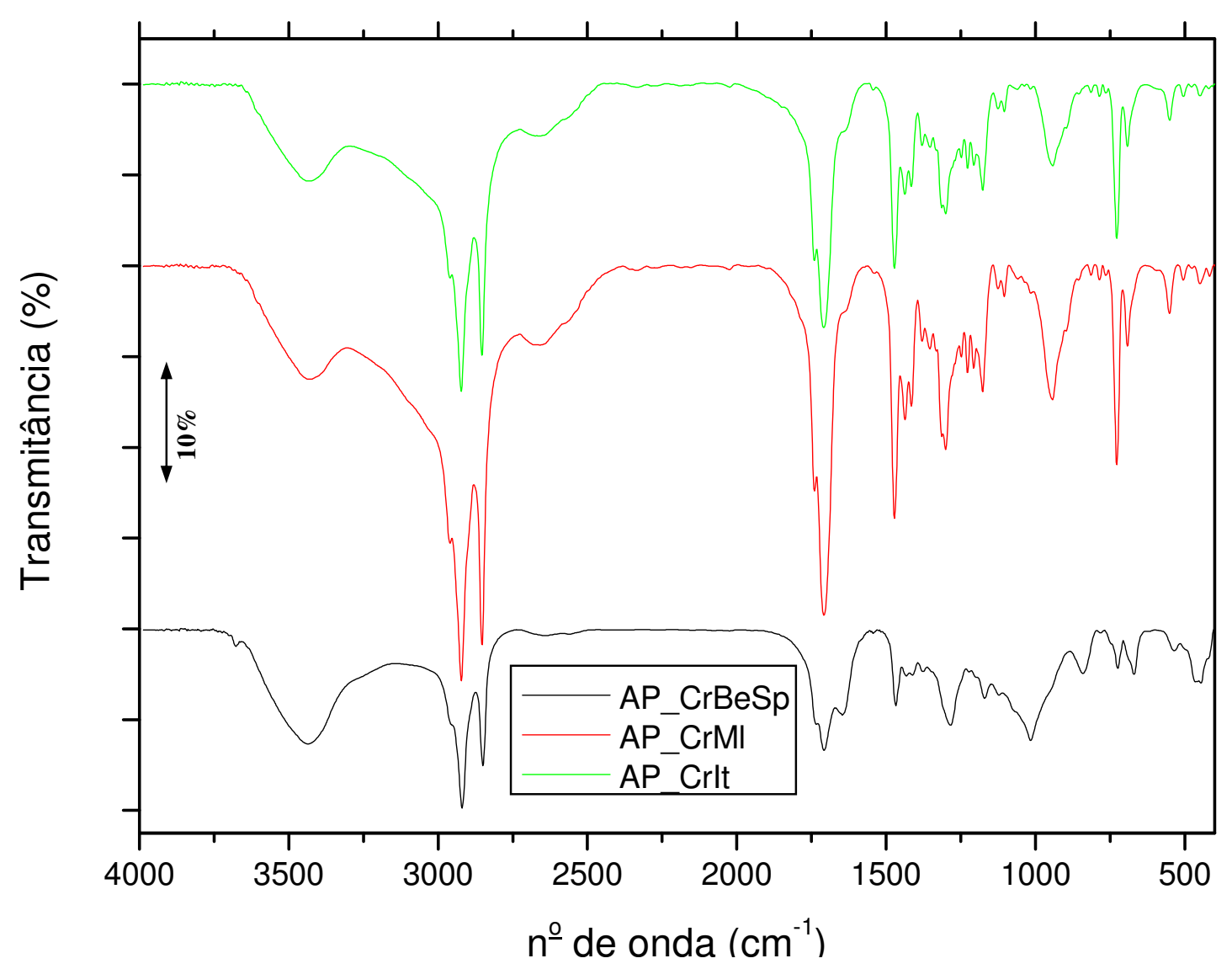

Figura 71 - Sobreposição dos espectros no infravermelho das amostras AP_CRBESP, AP_CRML e AP_CRIT. 
A Figura 72 apresenta a sobreposição dos espectros no infravermelho das amostras de cera deteriorada e cera deteriorada restaurada com calor da personagem Afonso Pena. Na amostra de cera deteriorada não é possível visualizar a banda de absorção na região de $1710 \mathrm{~cm}^{-1}$ referente a carbonila do ácido, como já foi dito anteriormente. Na amostra de cera deteriorada restaurada com calor verifica-se uma relação entre as intensidades das bandas de absorção das carbonilas do éster e do ácido semelhante aquela da cera em bom estado. Possivelmente no tratamento térmico ocorre uma homogeneização da cera aproximando-se novamente da proporção ácido/éster da cera original em bom estado.

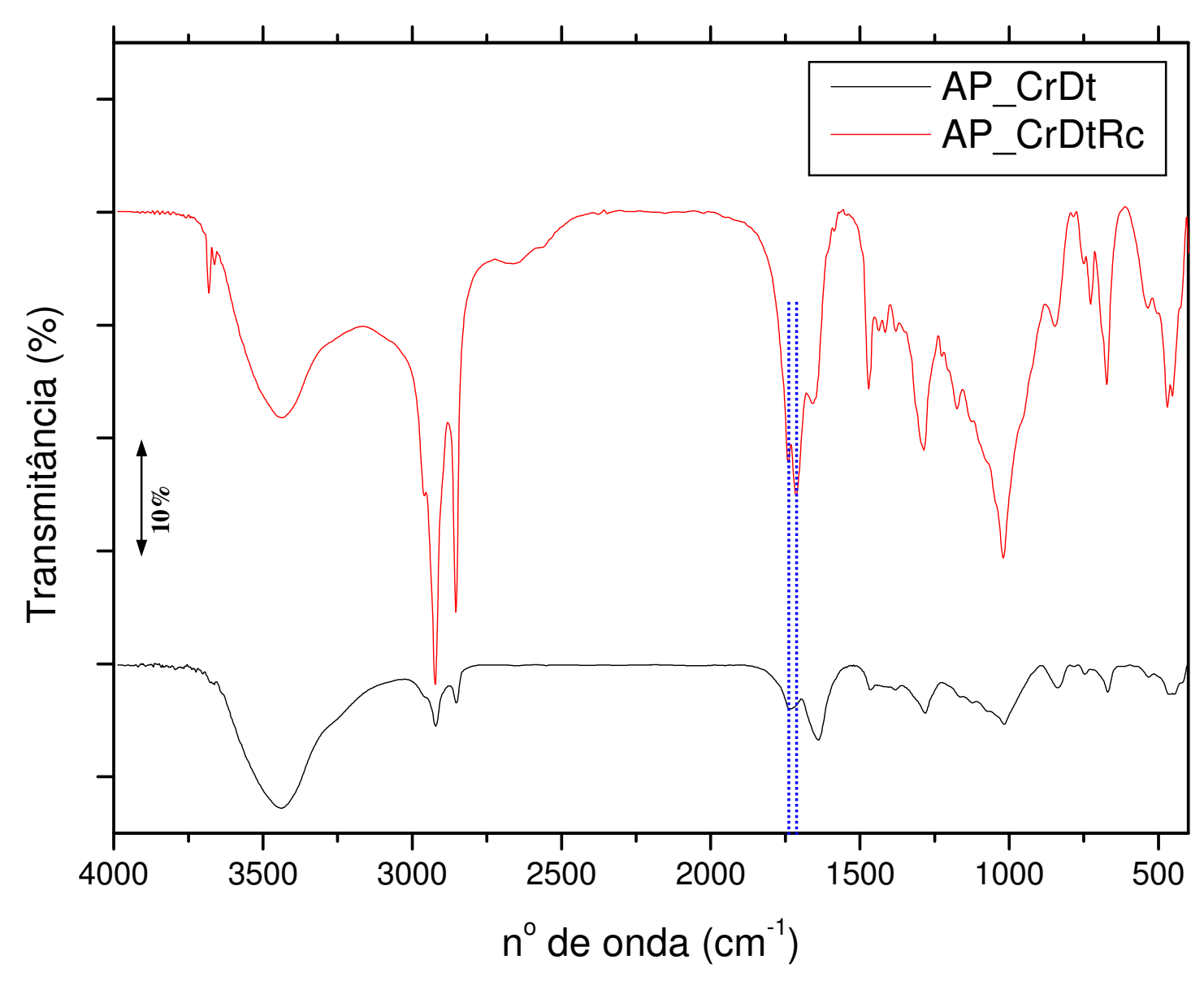

Figura 72 - Sobreposição dos espectros no infravermelho das amostras AP_CRDT e AP_CRDTRC. 
A Figura 73 apresenta o espectro no infravermelho da amostra de cera da superfície em bom estado da personagem Lampião (LP_CRBESP). O espectro é característico da cera de abelhas (bruta ou clarificada) com adição de resina damar, com as bandas de absorção em: $3431 \mathrm{~cm}^{-1}$ (estiramento da ligação O-H); 2918 e 2849 cm$^{-1}$ (estiramento da ligação C-H); 1736 e 1708 $\mathrm{cm}^{-1}$ (estiramento da ligação $\mathrm{C}=\mathrm{O}$ ); 1467 e $1433 \mathrm{~cm}^{-1}$ (dobramento da ligação C-H); 1294, 1171 e $1015 \mathrm{~cm}^{-1}$ (estiramento da ligação C-O) e $724 \mathrm{~cm}^{-1}$ (torção da ligação C-H).

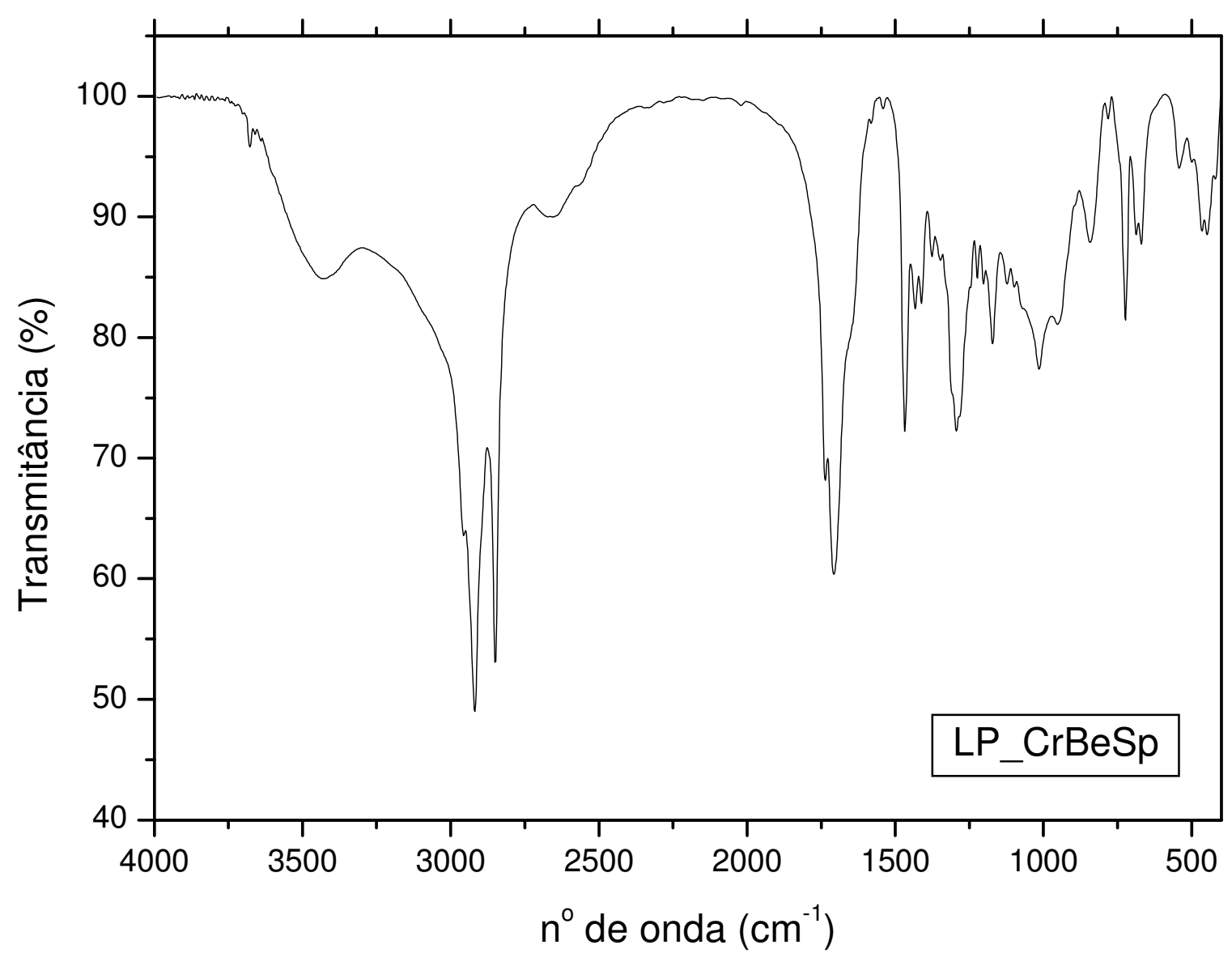

Figura 73 - Espectro de absorção de infravermelho da amostra LP_CRBESP. 
A Figura 74 apresenta o espectro no infravermelho da amostra de cera deteriorada da personagem Lampião (LP_CRDT). O espectro mostra uma banda de absorção larga na região entre 3600 e $3200 \mathrm{~cm}^{-1}, 3432 \mathrm{~cm}^{-1}$ que corresponde a ligação O-H, mas também pode ser devido ao estiramento da ligação N-H; mostra as bandas correspondentes ao estiramento da ligação C-H, 2919 e $2849 \mathrm{~cm}^{-1}$; a banda referente à carbolina do éster em $1736 \mathrm{~cm}^{-1}$ (estiramento da ligação $\mathrm{C}=\mathrm{O}$ ) diminui em intensidade em relação àquele referente à carbonila do ácido (estiramento da ligação $\mathrm{C}=\mathrm{O}$ ) $1711 \mathrm{~cm}^{-1}$. Observa-se as bandas de absorção em 1630 $\mathrm{cm}^{-1}$ (dobramento da ligação O-H); 1432 e $1412 \mathrm{~cm}^{-1}$ (dobramento da ligação C-H); 1377, 1296, 1172 e $953 \mathrm{~cm}^{-1}$ (estiramento da ligação C-O) e $723 \mathrm{~cm}^{-1}$ (torção da ligação C-H).

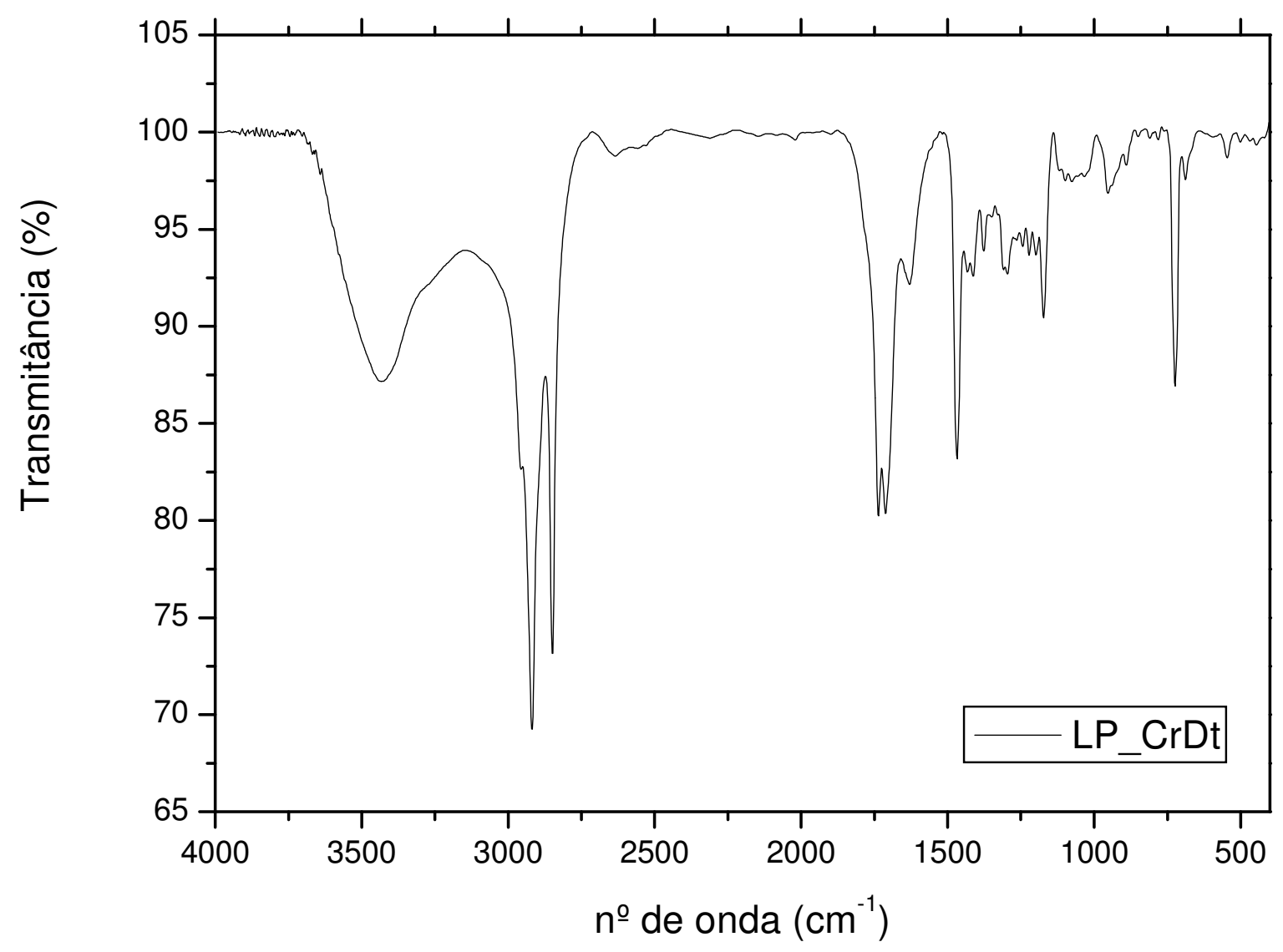

Figura 74 - Espectro de absorção no infravermelho da amostra LP_CRDT. 
A Figura 75 apresenta a sobreposição dos espectros no infravermelho das amostras de cera em bom estado da superfície e cera deteriorada da personagem Lampião (LP_CRDT e LP_CRBESP). Da mesma forma que ocorre com a personagem Afonso Pena, as principais diferenças entre os dois espectros são as intensidades relativas das bandas de absorção referentes à vibração do grupo carbonila do ácido e do éster. Na cera em bom estado a banda da carbonila do ácido é de maior intensidade do que aquela da carbonila do éster. Já na cera deteriorada esta relação se inverte. Indicando, que deve haver maior quantidade de ácido antes da deterioração.

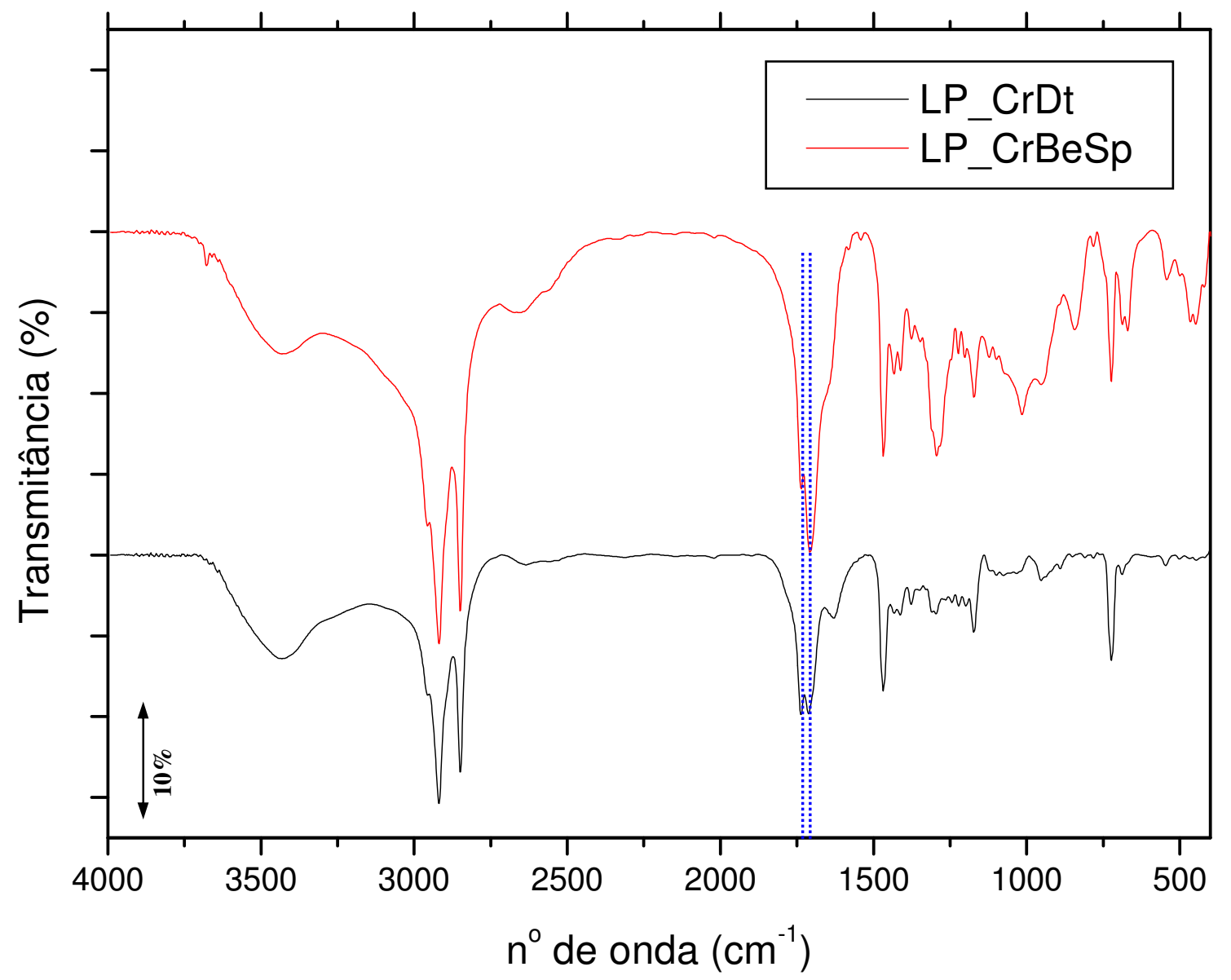

Figura 75 - Sobreposição dos espectros de absorção no infravermelho das amostras LP_CRBESP e LP_CRDT. 
Sabe-se que a intensidade da banda de absorção no infravermelho é correspondente à quantidade do grupo funcional presente no composto. A absorção é igual ao negativo do logaritmo da transmitância, como mostra a equação 8.

$$
\text { Abs }=-\log \mathrm{T}
$$

No espectro na região do infravermelho da amostra LP_CRBESP a banda de absorção correspondente à carbonila do ácido é $1708 \mathrm{~cm}^{-1}$ e o valor da transmitância (T) é 0,75 , a banda correspondente à carbonila do éster está em $1736 \mathrm{~cm}^{-1}$ e o valor da transmitância (T) é 0,82 . Já no espectro da amostra LP_CRDT as duas bandas correspondentes à carbonila do ácido $\left(1711 \mathrm{~cm}^{-1}\right)$ e à carbonila do éster $\left(1736 \mathrm{~cm}^{-1}\right)$ tem mesma intensidade, 0,82. Comparando-se a razão entre os logaritmos negativos das duas bandas de carbonila da amostra LP_CRBESP com a razão entre os logaritmos negativos das duas bandas de carbonila da amostra LP_CRDT, verifica-se que na cera em bom estado a razão ácido/éster é 1,45 , enquanto que na cera deteriorada é 1 . Sendo assim, pode-se sugerir que existe aproximadamente $45 \%$ mais ácido na cera em bom estado do que na cera deteriorada.

Cálculo da absorbância das bandas correspondentes às carbonilas do ácido e do éster na amostra LP_CRBESP

$\mathrm{T}_{1708}=0,75$

$\mathrm{Abs}_{\text {ácido }}=-\log \mathrm{T}=-\log 0,75=0,1250$

$\mathrm{T}_{1736}=0,82$

Abséster $=-\log \mathrm{T}=-\log 0,82=0,0861$

Abs $_{\text {ácido }} \div \mathrm{A}_{\text {éster }}=0,1250 \div 0,0861=1,45$
Cálculo da absorbância das bandas correspondentes às carbonilas do ácido e do éster na amostra LP_CRDT

$\mathrm{T}_{1711}=0,82$

$\mathrm{Abs}_{\text {ácido }}=-\log \mathrm{T}=-\log 0,82=0,0861$

$\mathrm{T}_{1736}=0,82$

$\mathrm{Abs}_{\text {éster }}=-\log \mathrm{T}=-\log 0,82=0,0861$

Absácido $_{\text {ás }} \mathrm{A}_{\text {éster }}=0,0861 \div 0,0861=1$ 
A Figura 76 apresenta o espectro no infravermelho da amostra de cera do miolo (não deteriorada) da personagem Lampião (LP_CRML). O espectro não tem nenhuma banda de absorção significativa na região entre 3600 e $3200 \mathrm{~cm}^{-1}$; mostra as bandas correspondentes ao estiramento da ligação C-H, 2918 e $2849 \mathrm{~cm}^{-1}$; a banda referente à carbolina do éster (estiramento da ligação $\mathrm{C}=\mathrm{O}$ ) $1736 \mathrm{~cm}^{-1}$, e à carbonila do ácido (estiramento da ligação $\mathrm{C}=\mathrm{O}) 1703 \mathrm{~cm}^{-1}$; 1467, 1432, 1412 e $1308 \mathrm{~cm}^{-1}$ (dobramento da ligação C-H); 1296, 1121, 1000 e $939 \mathrm{~cm}^{-1}$ (estiramento da ligação C-O); e $723 \mathrm{~cm}^{-1}$ (torção da ligação C-H).

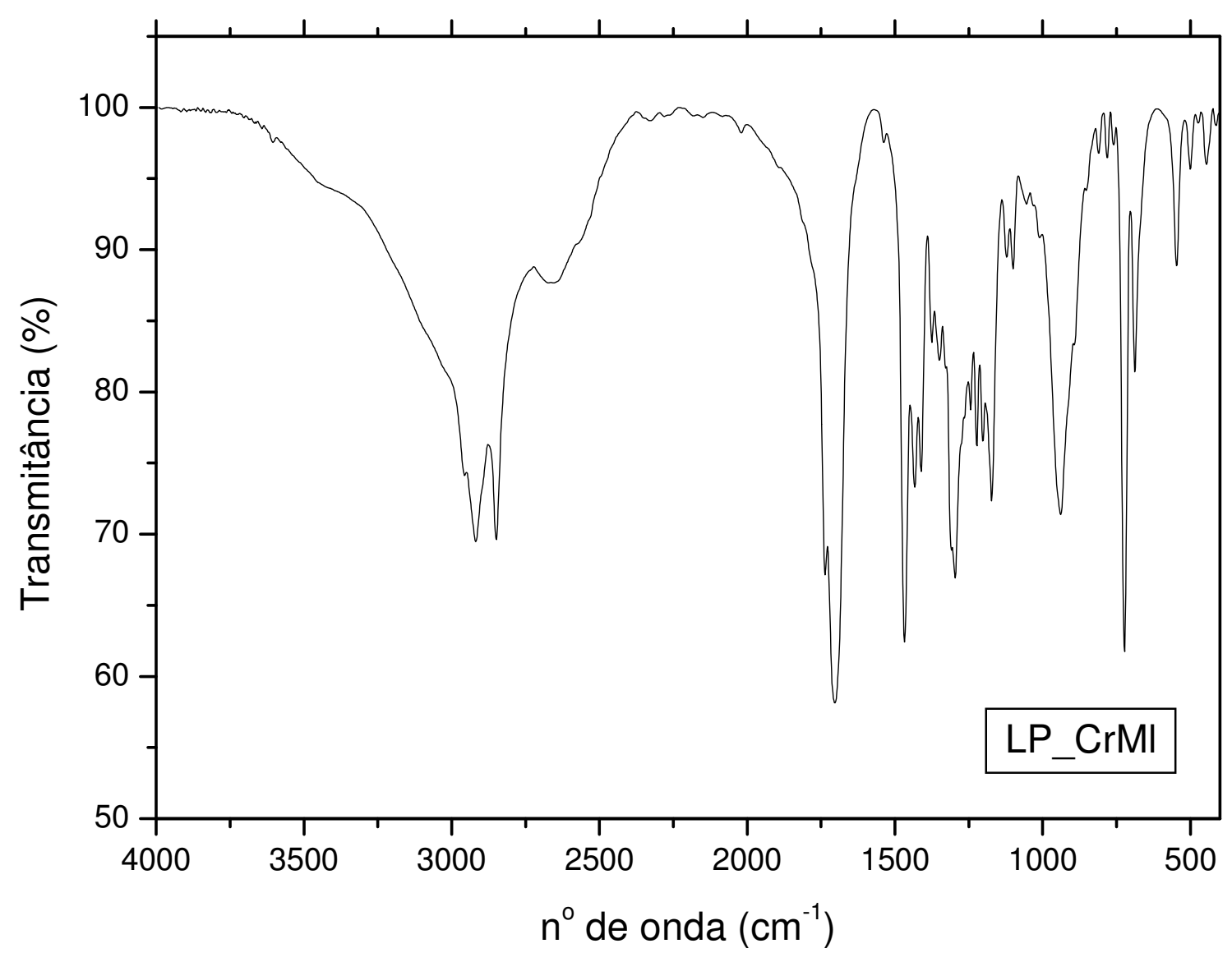

Figura 76 - Espectro de absorção no infravermelho da amostra LP_CRML. 
A Figura 77 apresenta o espectro no infravermelho da amostra de cera interna da personagem Lampião (LP_CRIT). O espectro mostra um ombro de banda larga da região entre 3600 e 3200 $\mathrm{cm}^{-1}, 3387 \mathrm{~cm}^{-1}$ que corresponde ao estiramento da ligação $\mathrm{O}-\mathrm{H}$, mas também pode ser devido ao estiramento da ligação N-H; mostra as bandas de absorção correspondentes ao estiramento da ligação C-H, 2955, 2919 e 2849 $\mathrm{cm}^{-1}$; a banda referente à carbolina do éster (estiramento da ligação $\mathrm{C}=\mathrm{O}$ ) $1736 \mathrm{~cm}^{-1}$, e aquela referente à carbonila do ácido (estiramento da ligação $\mathrm{C}=\mathrm{O}) 1705 \mathrm{~cm}^{-1}$; 1468, 1433 e $1412 \mathrm{~cm}^{-1}$ (dobramento da ligação C-H); 1310, 1296, 1172 e $938 \mathrm{~cm}^{-1}$ (estiramento da ligação C-O) e $723 \mathrm{~cm}^{-1}$ (torção da ligação C-H). Da mesma forma que foi observado para a personagem AP, não há alterações significativas na parte do miolo (exceto na camada imediatamente abaixo da superfície na região da testa) e na parte interna da escultura da personagem LP, decorrentes do processo de deterioração.

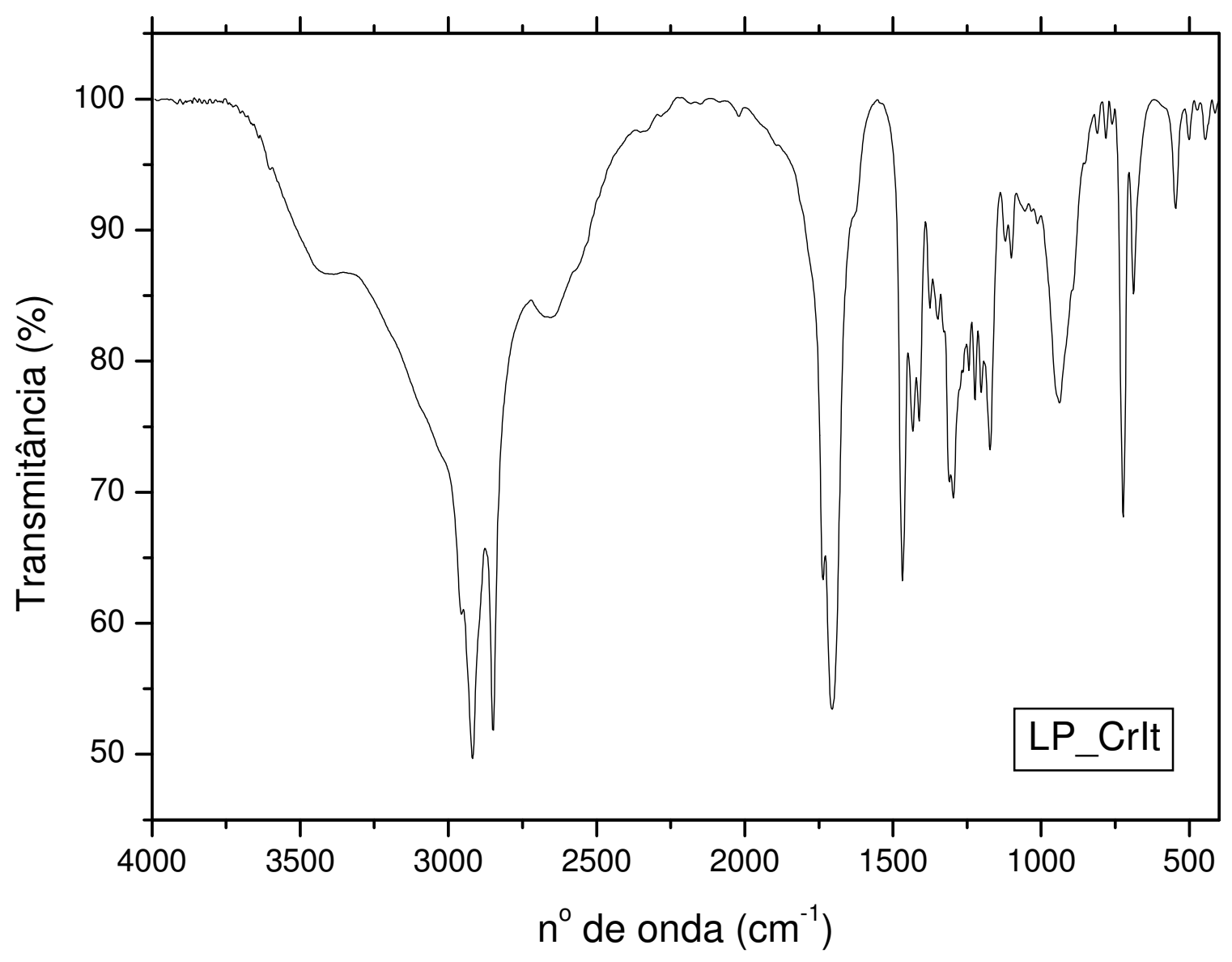

Figura 77 - Espectro de absorção no infravermelho da amostra LP_CRIT. 
A Figura 78 apresenta o espectro no infravermelho da amostra de cera deteriorada restaurada com calor da personagem Lampião (LP_CRDTRC). O espectro mostra a banda de absorção larga na região entre 3600 e $3200 \mathrm{~cm}^{-1}, 3428 \mathrm{~cm}^{-1}$ que corresponde ao estiramento da ligação $\mathrm{O}-\mathrm{H}$, mas também pode ser devido ao estiramento da ligação $\mathrm{N}-\mathrm{H}$; mostra as bandas correspondentes ao estiramento da ligação C-H, 2919 e $2849 \mathrm{~cm}^{-1}$; a banda referente à carbonila do éster (estiramento da ligação $\mathrm{C}=\mathrm{O}$ ) diminui de intensidade, $1736 \mathrm{~cm}^{-1}$, em relação àquela referente à carbonila do ácido (estiramento da ligação $\mathrm{C}=\mathrm{O}$ ) $1708 \mathrm{~cm}^{-1}$. Observa-se as bandas em: $1633 \mathrm{~cm}^{-1}$ (dobramento da ligação O-H); 1433 e $1412 \mathrm{~cm}^{-1}$ (dobramento da ligação C-H); 1376, 1296, 1172 e 938 cm$^{-1}$ (estiramento da ligação C-O) e $723 \mathrm{~cm}^{-1}$ (torção da ligação C-H).

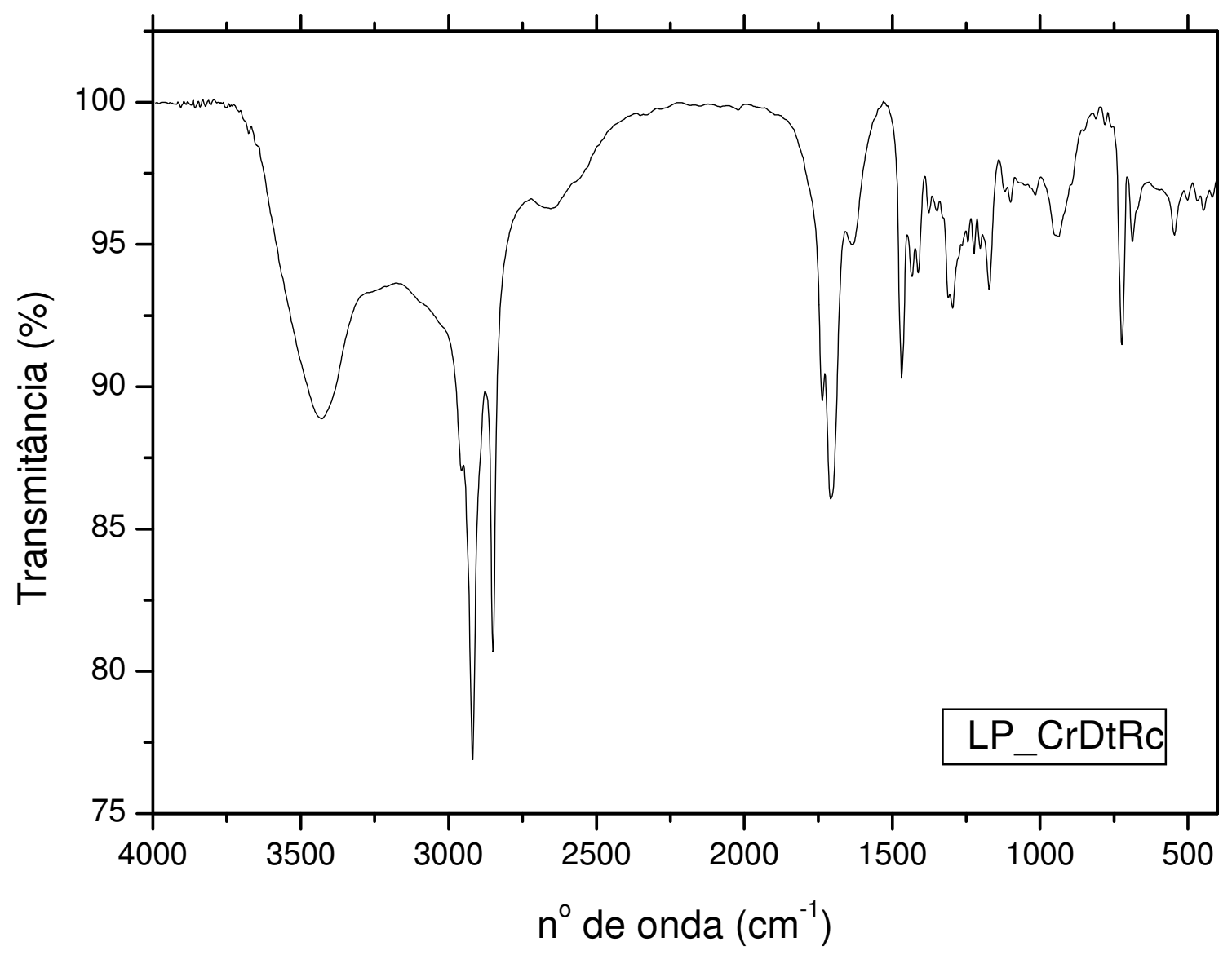

Figura 78 - Espectro de absorção no infravermelho da amostra LP_CRDTRC. 
Da mesma forma como foi feito para as amostras da personagem AP, pode-se comparar e visualizar melhor os espectros no infravermelho das três amostras de cera não deteriorada através da sobreposição dos mesmos conforme ilustrado na Figura 79.

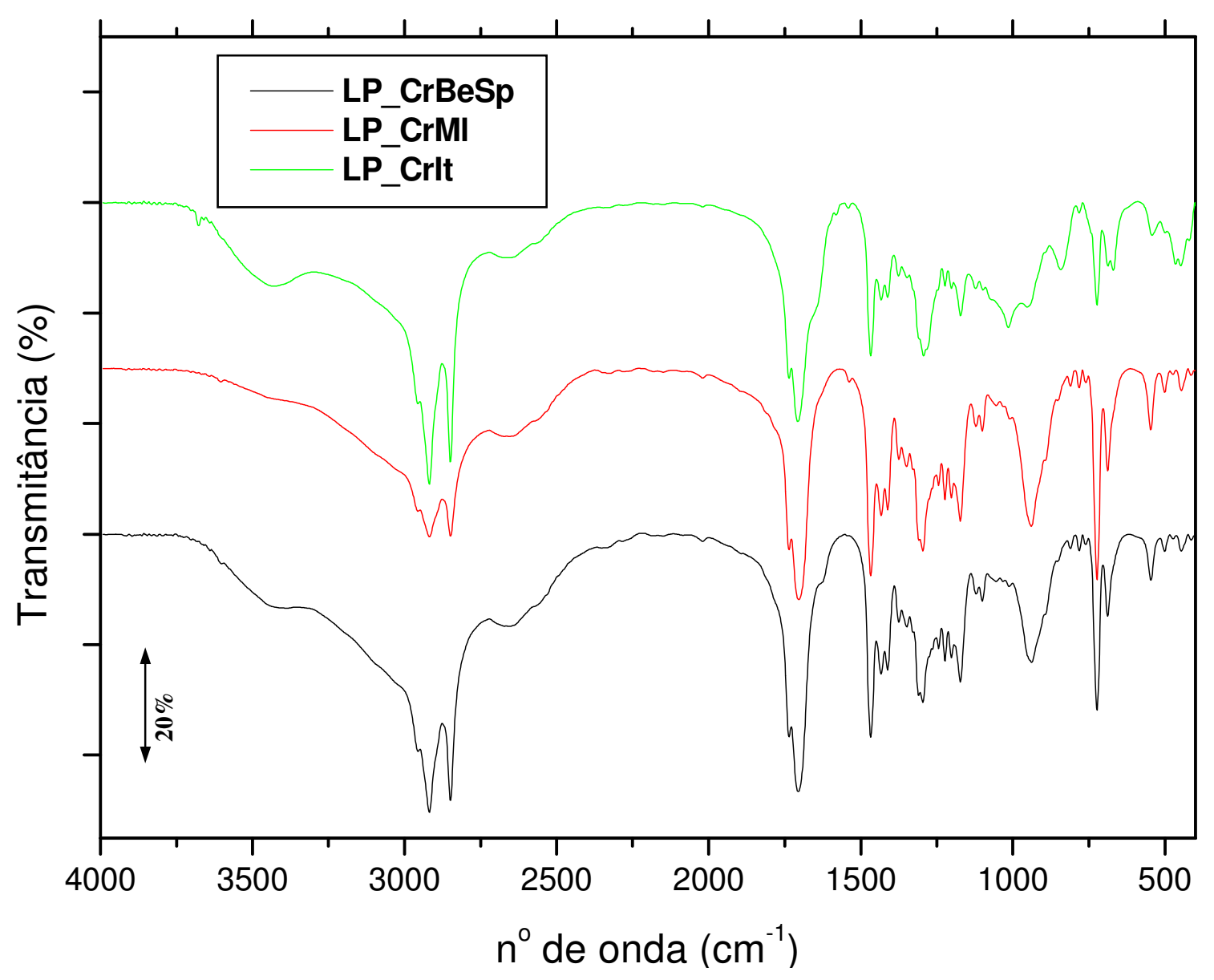

Figura 79 - Sobreposição dos espectros de absorção no infravermelho das amostras LP_CRBESP, LP_CRML e LP_CRIT. 
A Figura 80 apresenta a sobreposição dos espectros no infravermelho das amostras de cera deteriorada e de cera deteriorada restaurada com calor da personagem Lampião. Da mesma forma que ocorreu na personagem Afonso Pena, na amostra de cera deteriorada observa-se que as bandas de absorção na região de 1700 a $1740 \mathrm{~cm}^{-1}$ referentes à carbonila do éster e do ácido apresentam a mesma intensidade, diferentemente da cera em bom estado da superfície. $\mathrm{Na}$ amostra de cera deteriorada restaurada com calor verifica-se uma relação entre as intensidades das bandas das carbonilas do éster e do ácido semelhante àquela da cera em bom estado, ou seja, a banda de absorção do ácido tem maior intensidade do que aquela do éster. Uma hipótese, como já foi dito, seria que no tratamento térmico ocorreu a homogeneização da cera e a proporção ácido/éster aproximou-se daquela da cera original em bom estado.

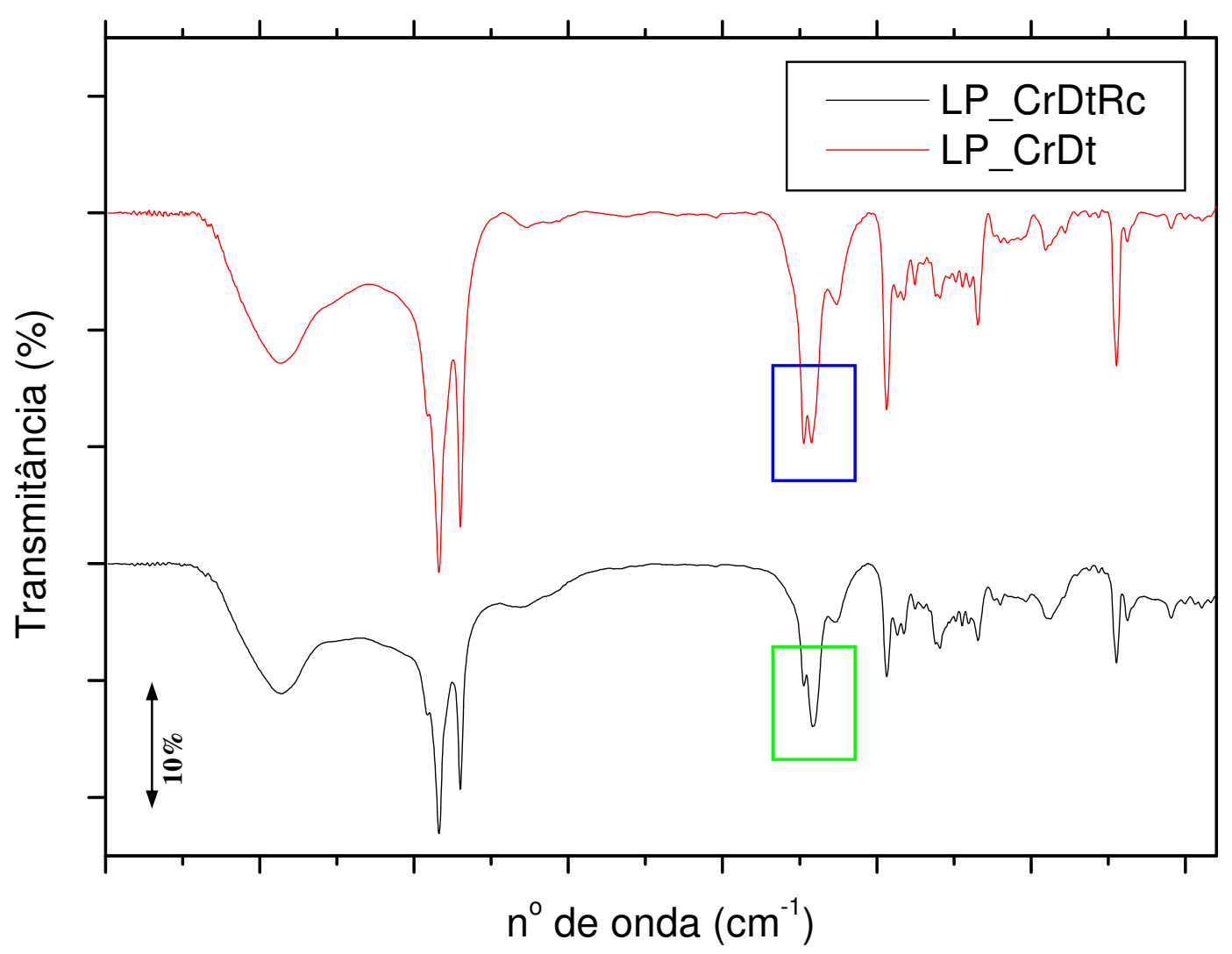

Figura 80 - Sobreposição dos espectros no infravermelho das amostras LP_CRDT e LP_CRDTRC. 
A Figura 81 apresenta a sobreposição dos espectros no infravermelho das amostras de cera deteriorada da personagem Afonso Pena e de cera deteriorada da personagem Lampião. Em ambos os espectros, as bandas referentes às carbonilas dos ésteres diminuíram em relação àqueles referentes às carbonilas dos ácidos. Na amostra LP_CRDT as duas bandas de absorção ficam com a mesma intensidade, como indica o quadrado azul sobre o respectivo espectro na Figura 81. Na amostra AP_CRDT não é possível distinguir entre uma banda e outra, como também indica o quadrado verde na Figura 81. Observa-se, portanto, comportamento semelhante na alteração da relação ácido/éster nas duas amostras de cera deteriorada.

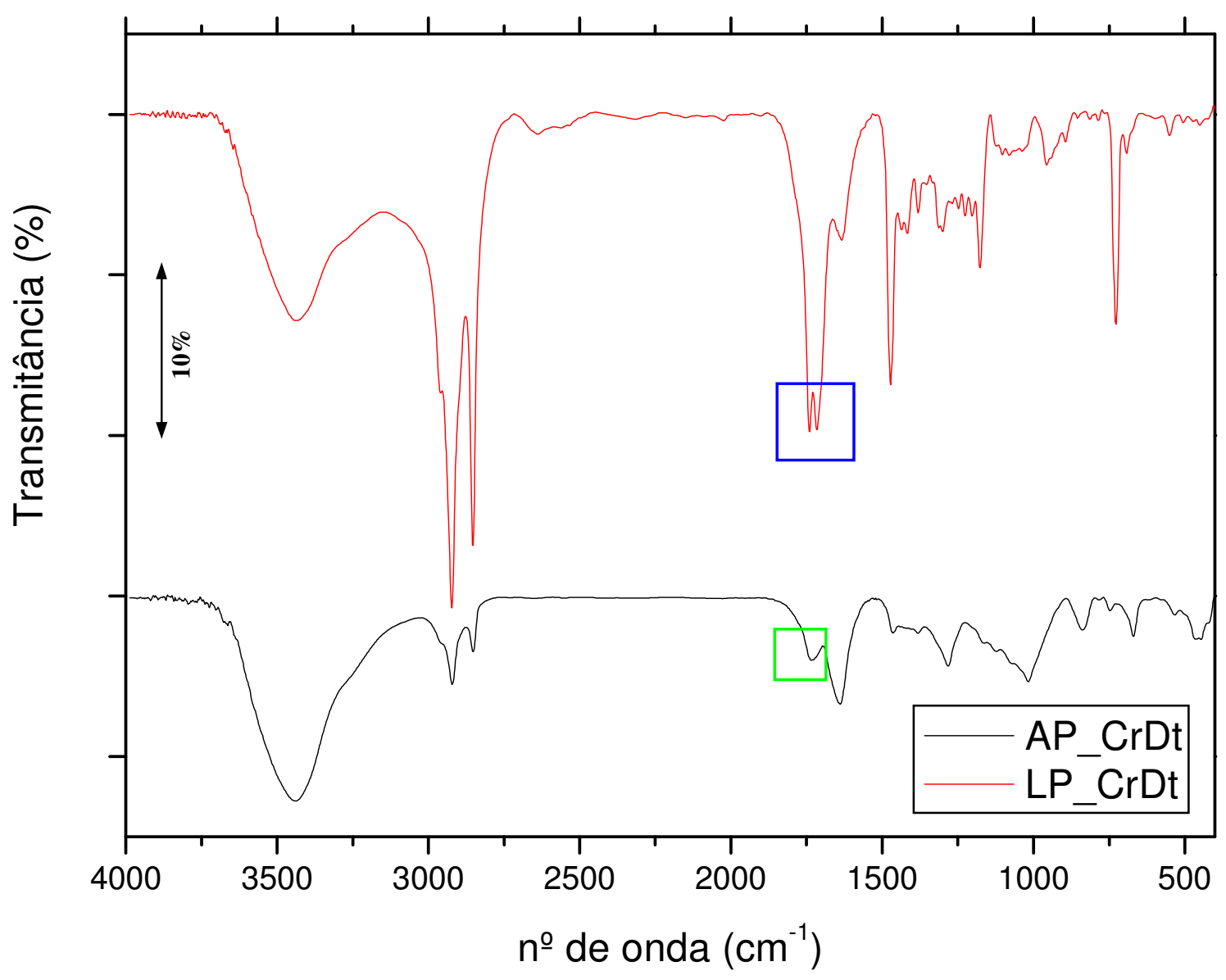

Figura 81 - Sobreposição dos espectros no infravermelho das amostras AP_CRDT e LP_CRDT. 


\subsubsection{ANÁLISE ELEMENTAR (AE)}

A Tabela 9 resume as porcentagens de carbono, hidrogênio e nitrogênio encontradas nas amostras retiradas de obras de arte.

Tabela 9 - Resultados de análise elementar das amostras retiradas de obras de arte.

\begin{tabular}{l|c|c|c}
\hline AMOSTRA & $\% \mathrm{C}$ & $\% \mathrm{H}$ & $\% \mathrm{~N}$ \\
\hline AP-CRDT & 55,28 & 7,95 & 2,03 \\
\hline AP-CRBESP & 53,86 & 7,99 & 2,16 \\
\hline AP_CRDTRC & 48,56 & 7,30 & 1,34 \\
\hline AP-CRML & 76,63 & 12,48 & 1,86 \\
\hline AP-CRIT & 76,58 & 12,48 & 1,24 \\
\hline LP-CRDT & 75,02 & 12,09 & 0,67 \\
\hline LP-CRBESP & 50,70 & 7,30 & 2,42 \\
\hline LP_CRDTRC & 67,53 & 11,22 & 0,57 \\
\hline LP-CRML & 78,11 & 13,04 & 0,23 \\
\hline LP-CRIT & 73,13 & 12,34 & 0,03 \\
\hline
\end{tabular}

As porcentagens de $\mathrm{C}, \mathrm{H}$ e $\mathrm{N}$ da superfície são diferentes daquelas do miolo e do interior porque na superfície existe uma porcentagem de até $30 \%$ de material inorgânico (conforme observado na análise térmica), principalmente devido à presença de pigmentos. Pode-se notar que a porcentagem de C na superfície é de 50\%, tanto para a personagem LP, como para a personagem AP para amostras deterioradas ou intactas. Já as amostras do miolo e da parte interna têm em torno de $70 \%$ de C. Esta afirmação vale para todas as amostras exceto a LP_CRDT que é de superfície mas apresenta porcentagem de C característica do miolo ou da parte interna. Isto ocorreu, pois o dano nesta superfície foi mais profundo e a coleta da amostra avançou no miolo. A porcentagem de $\mathrm{H}$ segue o mesmo perfil. Já a porcentagem de $\mathrm{N}$ é mais complexa de ser analisada, pois os pigmentos presentes na superfície podem conter este elemento. É importante enfatizar que através da restauração com aplicação de calor, se observa a recuperação dos valores das porcentagens de $\mathrm{C}$ e $\mathrm{H}$ característicos da superfície. 


\subsubsection{Microscopia ELETRÔNICA DE VARREDURA COM ANALISAdOR DE DISPERSÃo DE ENERGIA DE RAIOS X (MEV-EDS)}

Para entender o mecanismo de alteração de composição química relacionado com a deterioração optou-se por utilizar técnicas de caracterização de superfície. O MEV/EDS é uma técnica muito útil neste caso, pois além da visualização da micro morfologia pode-se obter a análise elementar da superfície observada.

As Figuras 82 a 84 ilustram fotografias com microscópio eletrônico de varredura de uma região da cera em bom estado da superfície da cabeça da personagem Afonso Pena (AP_CRBESP), a primeira com aumento de 500 vezes e as duas outras com aumentos de 2000 vezes.

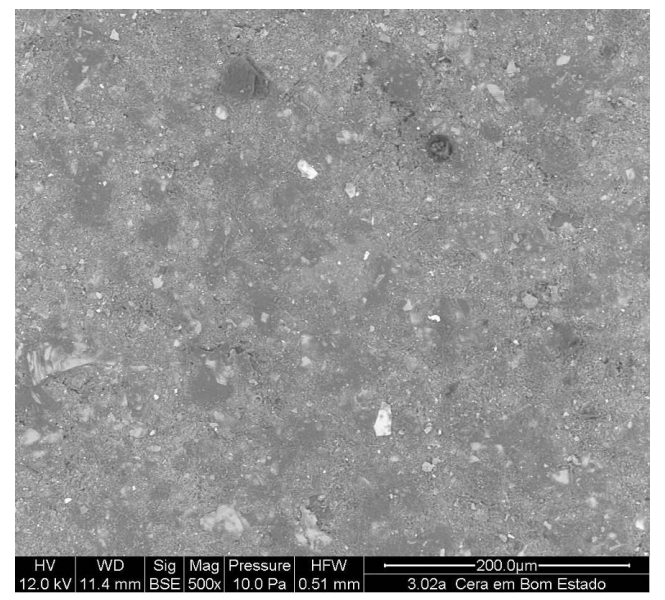

Figura 82 - Fotografia com MEV/EDS da amostra AP_CRBESP, com aumento de 500 vezes.

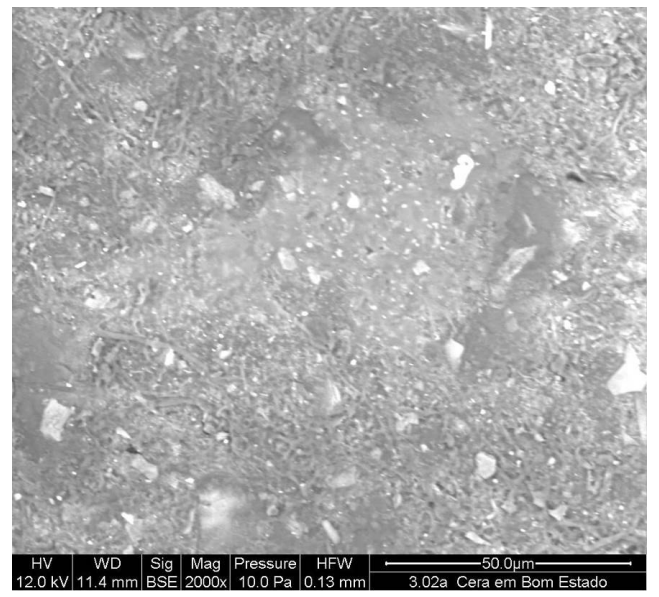

Figura 83 - Fotografia com MEV/EDS da amostra AP_CRBESP, com aumento de 2000 vezes.

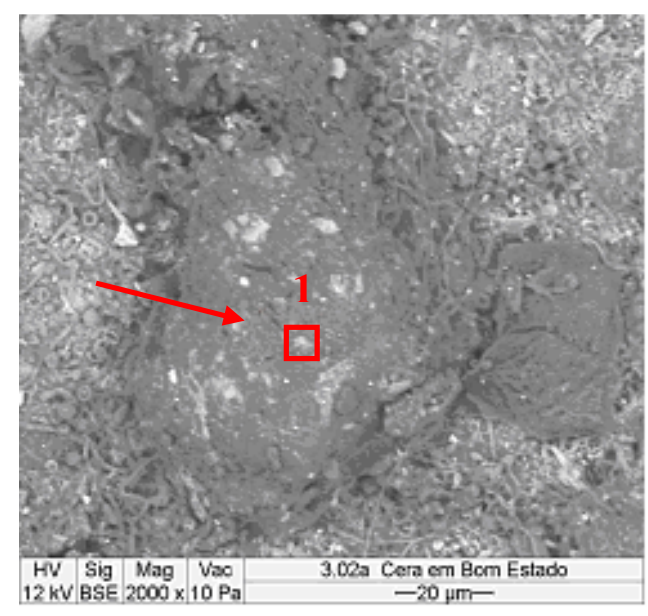

Figura 84 - Fotografia com MEV/EDS da amostra AP_CRBESP, com aumento de 2000 vezes, indicando uma região menor que engloba uma partícula, chamada de região 1 . 
A Figura 85 é um espectro de dispersão de energia de raios $X$ da área ilustrada da Figura 84 e a Figura 86 corresponde à ampliação da área delimitada pelo retângulo vermelho na Figura 85 , para permitir uma melhor visualização dos picos de menor intensidade.

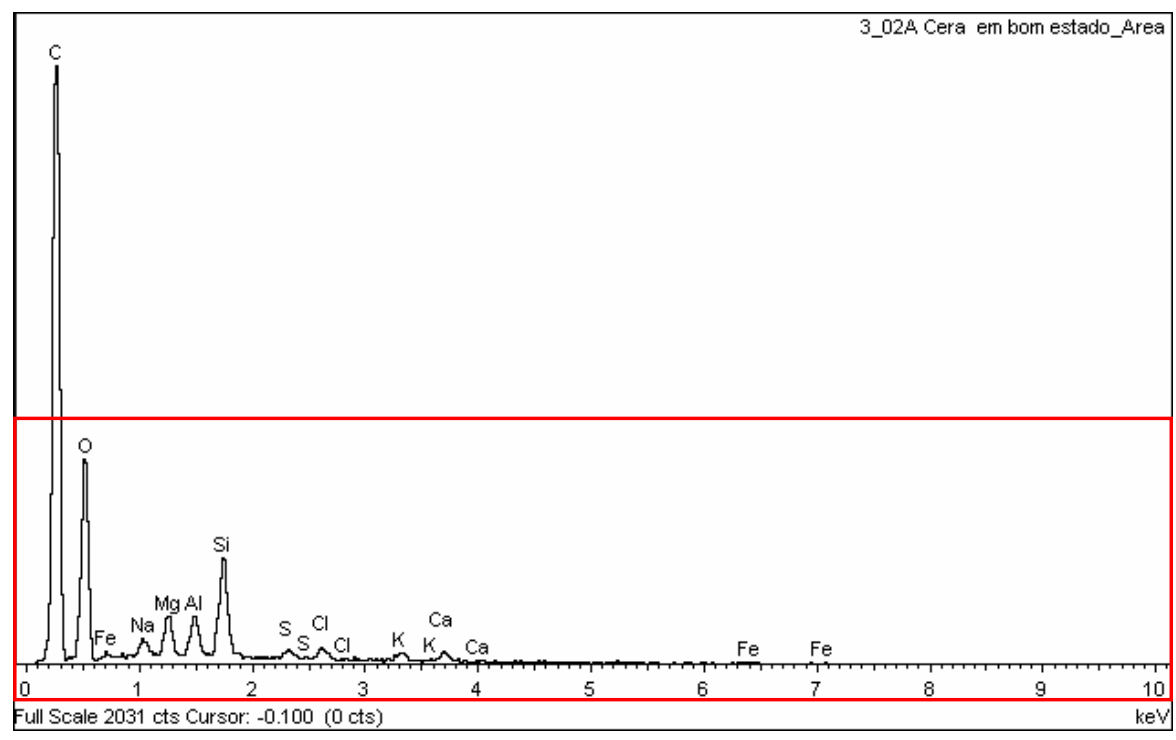

Figura 85 - Espectro de dispersão de energia de raios $X$ da região ilustrada na Figura 84.

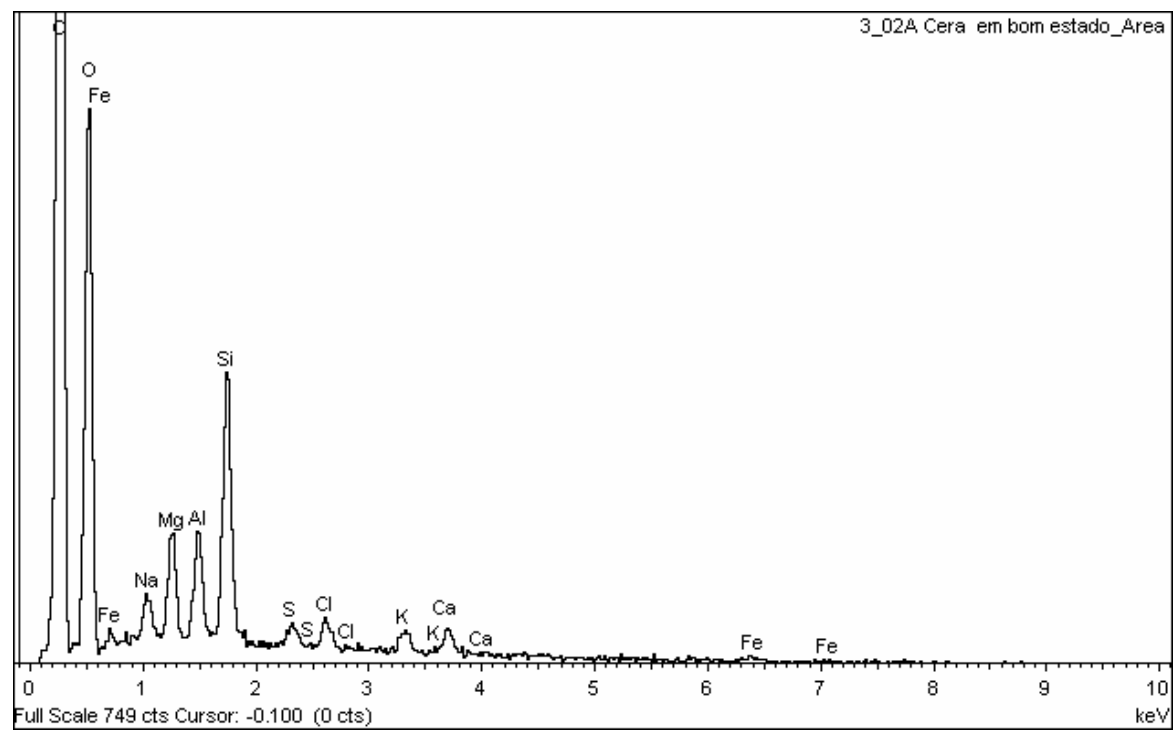

Figura 86 - Detalhe ampliado do espectro de dispersão de energia de raios $\mathrm{X}$ da região ilustrado na Figura 85. 
A Figura 87 é um espectro de dispersão de energia de raios $\mathrm{X}$ da região 1, a qual contém uma partícula, assinalada na Figura 84 e a Figura 88, corresponde à ampliação da área delimitada pelo retângulo vermelho na Figura 87, para permitir uma melhor visualização dos picos de menor intensidade.

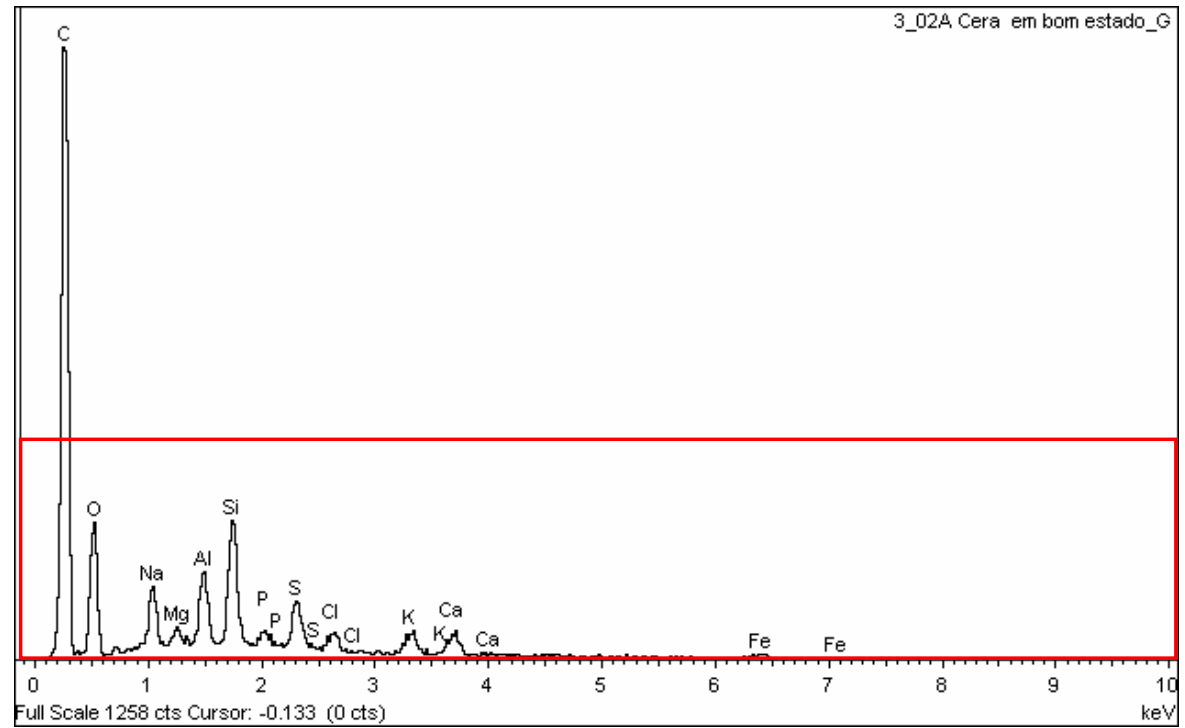

Figura 87 - Espectro de dispersão de energia de raios $\mathrm{X}$ da região 1 demarcada na Figura 84.

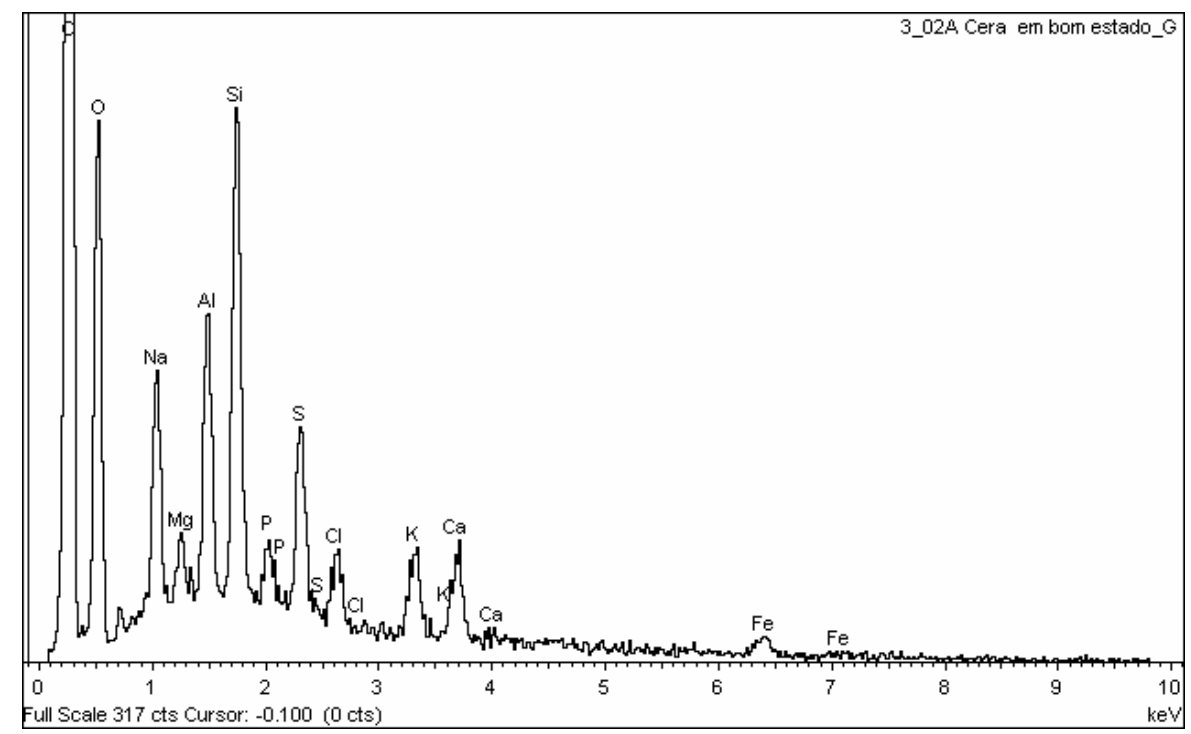

Figura 88 - Detalhe ampliado do espectro de dispersão de energia de raios $\mathrm{X}$ da região 1 demarcada na Figura 84. 
As Tabelas 10 e 11 apresentam as porcentagens em massa dos elementos encontrados nos espectros apresentados nas Figuras 85 e 87 respectivamente.

Tabela 10 - Porcentagem em massa dos elementos encontrados no espectro de área da Figura 85.

\begin{tabular}{c|c}
\hline ELEMENTO & \% MASSA \\
\hline $\mathrm{C}$ & 51,34 \\
\hline $\mathrm{O}$ & 37,46 \\
\hline $\mathrm{Na}$ & 0,71 \\
\hline $\mathrm{Mg}$ & 1,52 \\
\hline $\mathrm{Al}$ & 1,43 \\
\hline $\mathrm{Si}$ & 4,04 \\
\hline $\mathrm{S}$ & 0,40 \\
\hline $\mathrm{Cl}$ & 0,70 \\
\hline $\mathrm{Ca}$ & 1,04 \\
\hline $\mathrm{K}$ & 0,74 \\
\hline $\mathrm{Fe}$ & 0,63 \\
\hline TOTAL & 100,00 \\
\hline
\end{tabular}

Tabela 11 - Porcentagem em massa dos elementos encontrados no espectro de área da Figura 87.

\begin{tabular}{c|c}
\hline ELEMENTO & \% MASSA \\
\hline $\mathrm{C}$ & 55,34 \\
\hline $\mathrm{O}$ & 25,02 \\
\hline $\mathrm{Na}$ & 2,14 \\
\hline $\mathrm{Mg}$ & 0,47 \\
\hline $\mathrm{Al}$ & 2,34 \\
\hline $\mathrm{Si}$ & 4,61 \\
\hline $\mathrm{Cl}$ & 1,04 \\
\hline $\mathrm{S}$ & 2,50 \\
\hline $\mathrm{Ca}$ & 2,06 \\
\hline $\mathrm{K}$ & 1,76 \\
\hline $\mathrm{Fe}$ & 2,00 \\
\hline TOTAL & 100,00
\end{tabular}

As fotografias feitas com microscópio eletrônico permitiram visualizar a presença de partículas dispersas na superfície das esculturas. Estas partículas correspondem aos pigmentos e/ou cargas adicionados na mistura de cera-resina. A composição elementar da região demarcada na Figura 84 obtida através do espectro de dispersão de energia de raios $\mathrm{X}$ mostrado na Figura 85 nos dá informações importantes sobre a possível natureza dos pigmentos e cargas. A porcentagem de carbono encontrada nesta área é da mesma ordem de grandeza daquela encontrada na análise elementar apresentada na Tabela 9.

Os elementos encontrados na superfície das esculturas, pelas técnicas utilizadas neste trabalho, são: H, N, C, O, Na, Mg, Al, Si, S, K, Ca, Ti e Fe.

Através da comparação das porcentagens relativas de elementos encontrados em vários pontos medidos na superfície em bom estado da cabeça da personagem Afonso Pena, notamos que há uma variação na presença e na quantidade desses elementos devido à variação de cor da escultura, e, portanto, a multiplicidade de pigmentos. 
A Figura 89 ilustra uma fotografia com microscópio eletrônico de varredura de uma região da cera deteriorada da superfície da cabeça da personagem Afonso Pena (AP_CRDT), com aumento de 2000 vezes. Nesta região é possível visualizar uma partícula de aproximadamente $20 \mu \mathrm{m}$ de largura por $40 \mu \mathrm{m}$ de altura. A Tabela 12 lista os elementos encontrados no espectro de área da partícula demarcado pela região vermelha na Figura 89.

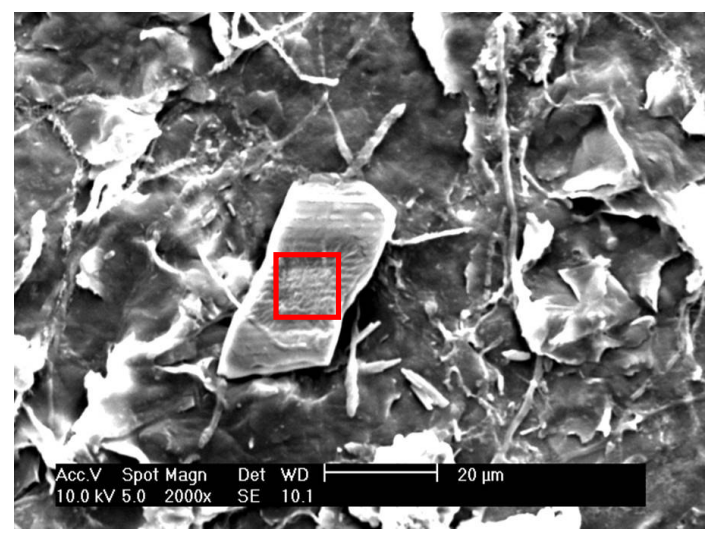

Figura 89 - Fotografia com MEV/EDS da amostra AP_CRDT, com aumento de 2000 vezes.
Tabela 12 - Porcentagem em massa dos elementos encontrados no espectro de área da partícula demarcado pela região vermelha na Figura 89.

\begin{tabular}{c|c}
\hline ELEMENTO & \% MASSA \\
\hline $\mathrm{C}$ & 14,99 \\
\hline $\mathrm{O}$ & 24,77 \\
\hline $\mathrm{Na}$ & 0,63 \\
\hline $\mathrm{Mg}$ & 0,23 \\
\hline $\mathrm{Al}$ & 0,13 \\
\hline $\mathrm{Si}$ & 0,72 \\
\hline $\mathrm{S}$ & 0,34 \\
\hline $\mathrm{K}$ & 58,54 \\
\hline TOTAL & 100,00 \\
\hline \multicolumn{2}{|c}{}
\end{tabular}

Pelo formato da partícula e por sua composição elementar pode-se dizer que é uma partícula de pigmento. Não foi possível determinar a cor do pigmento, pois ele está numa região de cera deteriorada, que se apresenta esbranquiçada. Porém pela alta quantidade de potássio em relação aos outros elementos e pela presença dos elementos $\mathrm{Al}, \mathrm{Mg}$ e $\mathrm{Si}$, pode-se indicar o pigmento terra verde $\left(\mathrm{K}\left[\left(\mathrm{Al}, \mathrm{Fe}^{\mathrm{III}}\right),\left(\mathrm{Fe}^{\mathrm{II}}, \mathrm{Mg}\right)\right]\left(\mathrm{AlSi}_{3}, \mathrm{Si}_{4}\right) \mathrm{O}_{10}(\mathrm{OH})_{2}\right)$. 
As Figuras 90 a 92 ilustram fotografias com microscópio eletrônico de varredura acoplado a um analisador de dispersão de energia, de uma região da cera do miolo da cabeça da personagem Afonso Pena (AP_CRML), com aumentos de 500, 2000 e 8000 vezes, respectivamente.

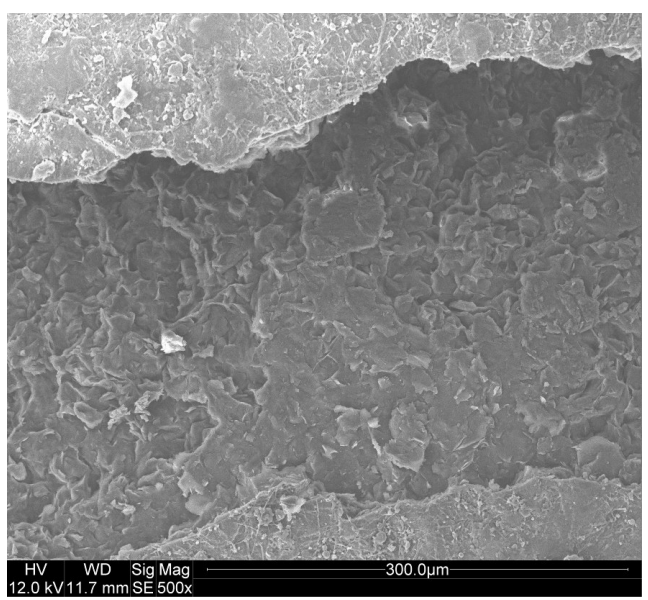

Figura 90 - Fotografia com MEV/EDS da amostra AP_CRML, com aumento de 500 vezes.

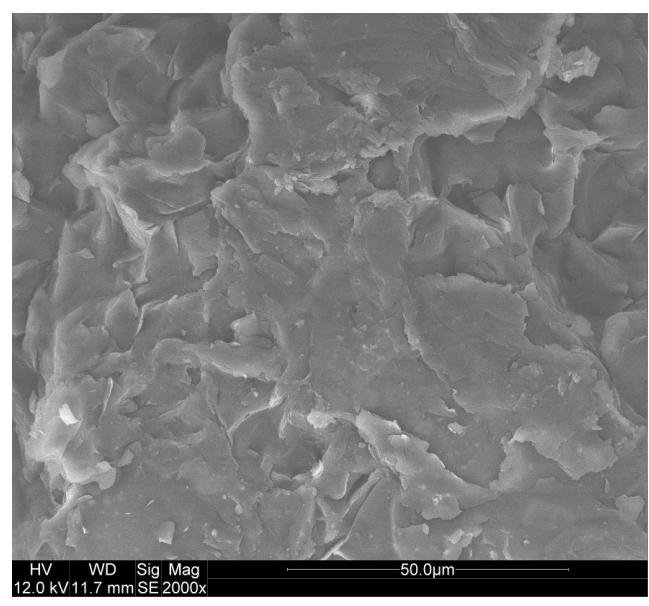

Figura 91 - Fotografia com MEV/EDS da amostra AP_CRML, com aumento de 2000 vezes.

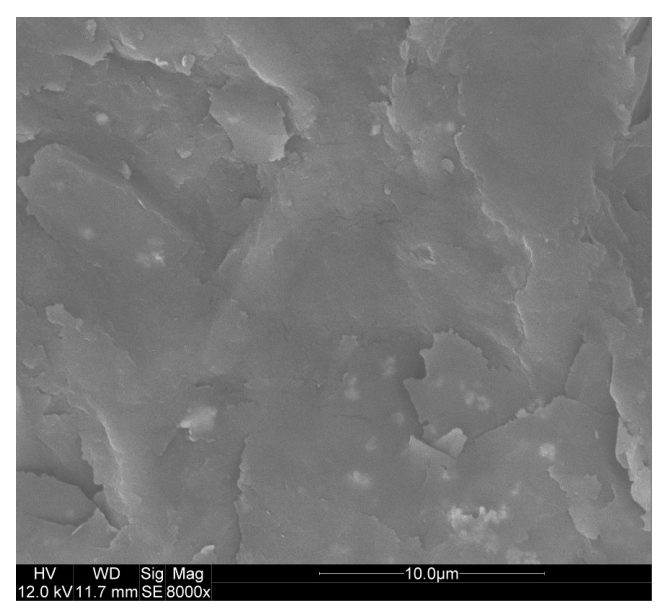

Figura 92 - Fotografia com MEV/EDS da amostra AP_CRML, com aumento de 8000 vezes. 


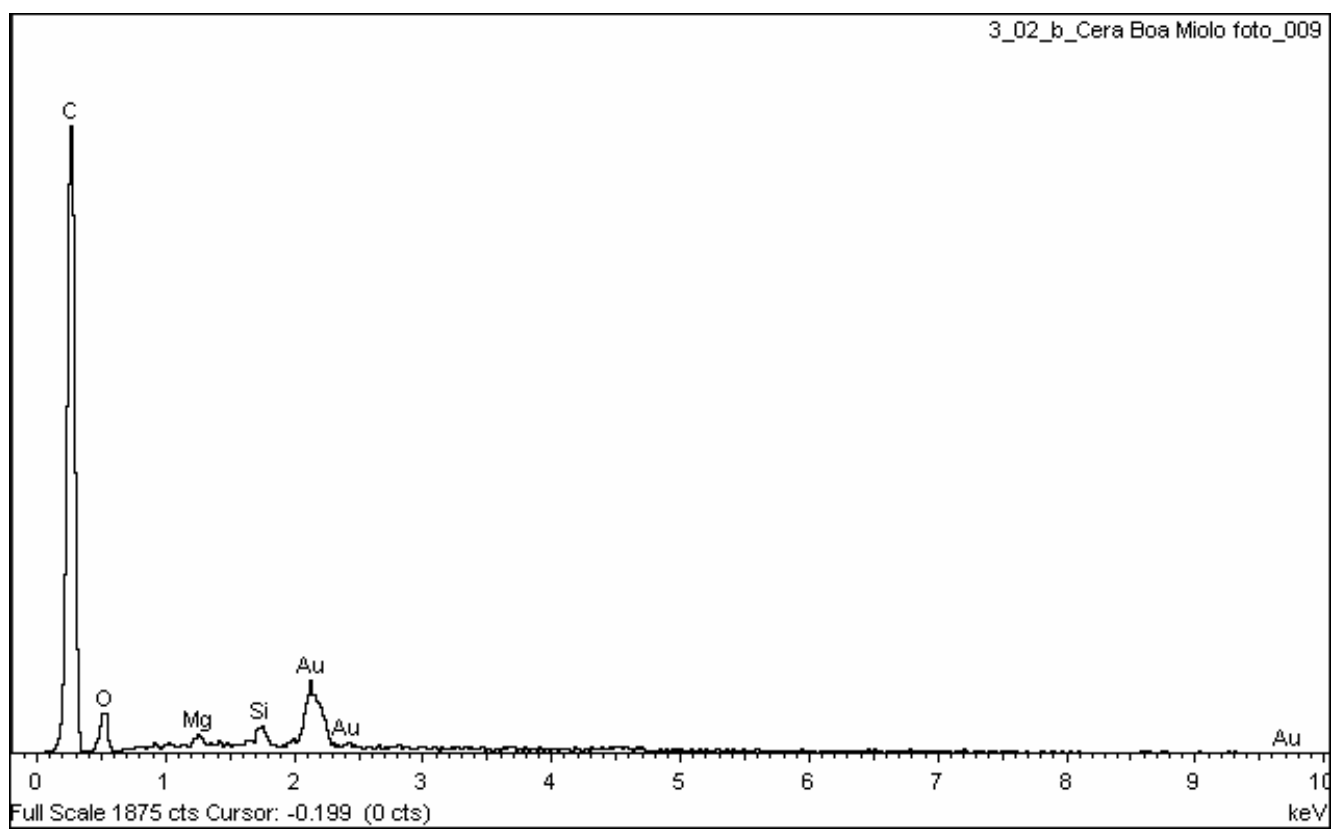

Figura 93 - Espectro de dispersão de energia de raios X da região ilustrada na Figura 92.

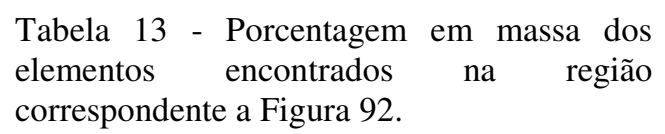

\begin{tabular}{c|c}
\hline ELEMENTO & \% MASSA \\
\hline $\mathrm{C}$ & 80,46 \\
\hline $\mathrm{O}$ & 18,17 \\
\hline $\mathrm{Mg}$ & 0,43 \\
\hline $\mathrm{Si}$ & 0,93 \\
\hline TOTAL & 100,00 \\
\hline
\end{tabular}

A Figura 93 apresenta um espectro de dispersão de energia de raios $X$ da região ilustrada na Figura 92, enquanto que a Tabela 13 apresenta a porcentagem em massa dos elementos encontrados.

Comparando-se o espectro apresentado na Figura 93 com aquele apresentado na Figura 85 pode-se notar a diferença de composição entre a cera da superfície e a cera do miolo das esculturas. A quantidade de material inorgânico encontrado na superfície da cera, sem considerar o oxigênio que está presente tanto na composição das ceras como na composição de alguns pigmentos, varia entre 10 e $30 \%$ aproximadamente, enquanto que no miolo, encontramos somente traços de material inorgânico, 1,36\%, provavelmente devido à 
contaminação do material. Este resultado foi também observado nos dados de análise térmica e é o esperado segundo os dados documentais, ou a "receita" dos artistas.

As Figuras 94 a 97 ilustram fotografias com microscópio eletrônico de varredura acoplado à um analisador de dispersão de energia, de uma região da cera deteriorada da cabeça da personagem Afonso Pena (AP_CRDT), com aumentos de 2000, 25000, 8000 e 60000 vezes respectivamente.

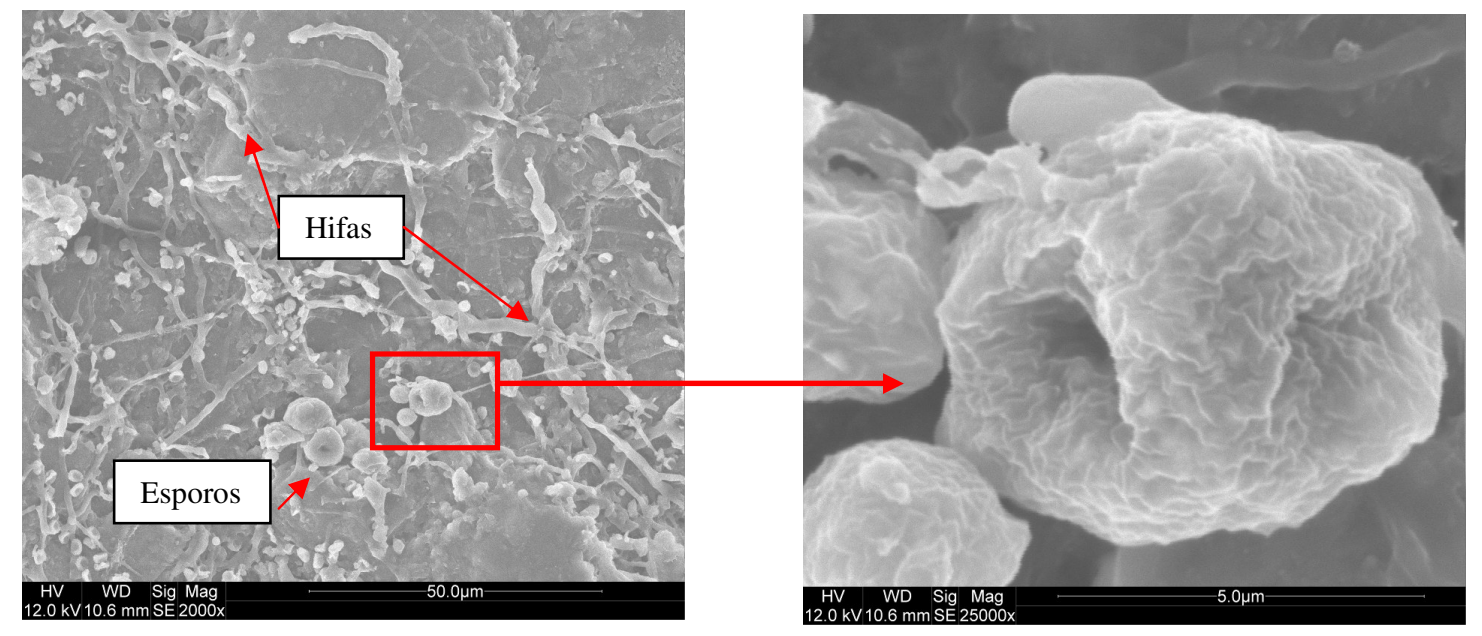

Figura 94 - Fotografia com MEV/EDS da amostra AP_CRDT, com aumento de 2000 vezes, apontando as hifas e os esporos dos fungos.

Figura 95 - Fotografia com MEV/EDS da amostra AP_CRDT, com aumento de 25000 vezes. Esporo.

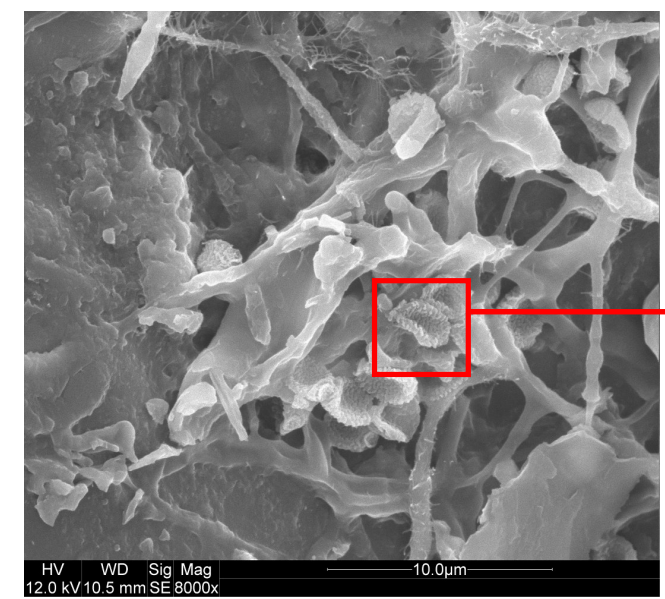

Figura 96 - Fotografia com MEV/EDS da amostra AP_CRDT, com aumento de 8000 vezes.

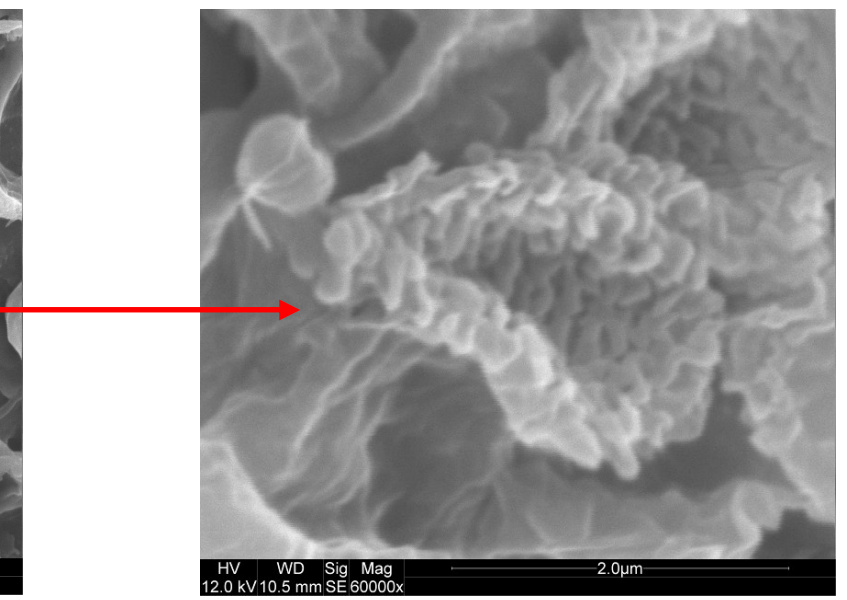

Figura 97 - Fotografia com MEV/EDS da amostra AP_CRDT, com aumento de 60000 vezes. Esporo. 
A figura 98 é um espectro de dispersão de energia de raios $\mathrm{X}$ da região ilustrada na Figura 96 e a Tabela 14 apresenta a porcentagem em massa dos elementos encontrados na região correspondente a Figura 96.

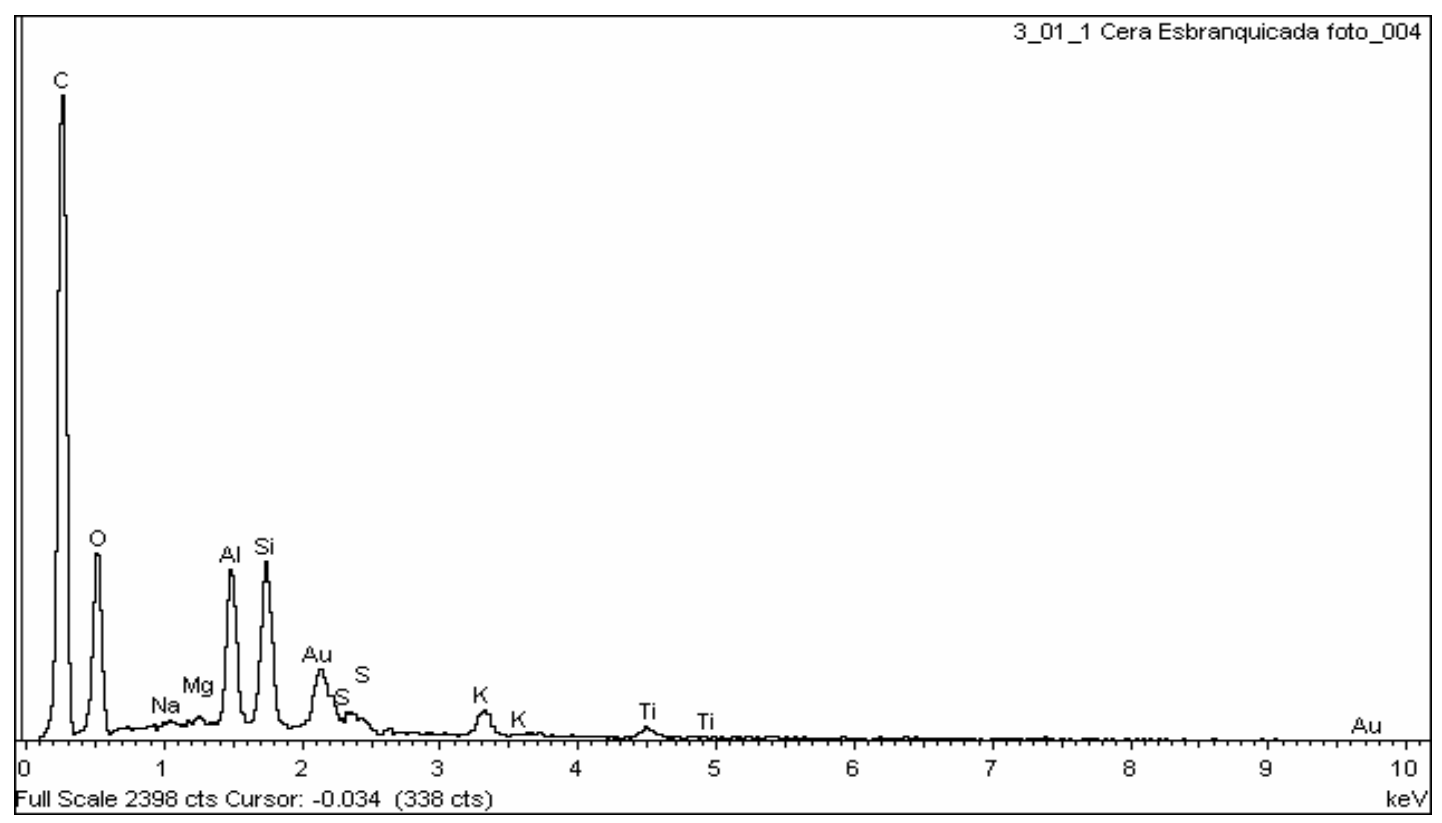

Figura 98 - Espectro de dispersão de energia de raios X da região ilustrada na Figura 96.

Tabela 14 - Porcentagem em massa dos elementos encontrados na região correspondente a Figura 96.

\begin{tabular}{c|c}
\hline ELEMENTO & \% MASSA \\
\hline $\mathrm{C}$ & 57,26 \\
\hline $\mathrm{O}$ & 32,83 \\
\hline $\mathrm{Na}$ & 0,16 \\
\hline $\mathrm{Mg}$ & 0,15 \\
\hline $\mathrm{Al}$ & 3,20 \\
\hline $\mathrm{Si}$ & 3,95 \\
\hline $\mathrm{S}$ & 0,34 \\
\hline $\mathrm{K}$ & 1,33 \\
\hline $\mathrm{Ti}$ & 0,78 \\
\hline TOTAL & 100,00 \\
\hline
\end{tabular}


A partir dos resultados obtidos com MEV/EDS não foi possível constatar alterações significativas na composição média das ceras da superfície em bom estado e da superfície deteriorada, exceto no caso da amostra LP_CRDT, onde, como já foi mencionado, a deterioração avançou para o miolo da obra.

Por outro lado, esta técnica foi decisiva na identificação do agente causador dos danos. Nas Figuras 94 a 97 pode-se ver claramente a presença de microorganismos na superfície da cera deteriorada sugerindo que a mudança no aspecto da superfície de cera se deve aos fungos. Tanto pela sua presença como pela alteração físico-química que eles causaram ao substrato.

As esculturas se encontram numa região com alta umidade relativa do ar e grande variação de temperatura. Devido às condições climáticas da região a água condensa sobre a superfície das esculturas propiciando o crescimento de fungos anemófilos, que se propagam através do ar. Estes se fixam na superfície danificando-a. Os microorganismos penetraram na superfície da cera, através de partes de sua estrutura chamadas hifas, para poder usá-la como substrato metabólico, como pode ser visualizado nas Figuras 94 e 96. Na Figura 94 é possível identificar as hifas e os esporos dos fungos. As Figuras 95 e 97 ilustram esporos com aumentos de 25000 e 60000 vezes, respectivamente.

As Figuras 56 e 60 ilustram curvas TG/DTG e DSC de amostras de ceras da superfície deteriorada e em bom estado retiradas das personagens de cera. As curvas TG/DTG evidenciam pequenas perdas de massa $(0,78 \%$ e $1,69 \%)$ no intervalo entre 20 e $130^{\circ} \mathrm{C}$ aproximadamente as quais são devidas à eliminação de água de umidade e, provavelmente à eliminação de microorganismos.

A cera é uma emulsão composta por hidrocarbonetos, ácidos graxos, ésteres, álcoois, etc, conforme apresentado na Tabela 2. O espectro no infravermelho característico das ceras de abelhas mostra as bandas referentes às carbonilas dos ácidos e dos ésteres com uma certa relação de intensidade entre eles (1700 - $1740 \mathrm{~cm}^{-1}$ ) (Figura 48). Na cera deteriorada esta relação está alterada indicando que houve uma diminuição na quantidade de ácidos em relação aos ésteres (Figura 67 e Figura 75). Isto ocorre principalmente porque os ácidos graxos presentes na cera são utilizados como alimento pelos fungos (GUTARRA, CASTILHO \& FREIRE, 2003). A mudança na morfologia estrutural da superfície provoca uma modificação na reflexão da luz incidente. Quando a luz incide sobre uma superfície parte dela é absorvida e parte é refletida, dependendo da estrutura química desta superfície. O que chamamos de cor é a sensação causada nos sensores dos olhos através da luz refletida pela matéria. Porém numa superfície da mesma cor a sensação pode ser alterada pela forma como a luz é refletida por ela, a qual é também determinada por sua textura. Numa superfície lisa a 
luz é refletida em uma única direção, podendo chegar até a uma reflexão especular, enquanto que em uma superfície rugosa ela é refletida em varias direções. Essa diferença é a responsável pela sensação de brilho ou opacidade. A superfície da cera em bom estado tem um aspecto próprio com certo brilho, como pode ser visto nas Figuras 3, 4 e 34, este aspecto foi modificado pela alteração na morfologia da superfície da cera, ocasionada pela quebra da emulsão. O simples aquecimento da superfície recuperou o aspecto original, pois houve uma homogeneização da cera, como pode ser visto na Figura 85.

As Figuras 99 e 100 ilustram fotografias com microscópio eletrônico de varredura acoplado à um analisador de dispersão de energia, de uma região da cera deteriorada da cabeça da personagem Afonso Pena restaurada com calor (AP_CRDTRC), com aumentos de 16000 e 8000 vezes respectivamente.

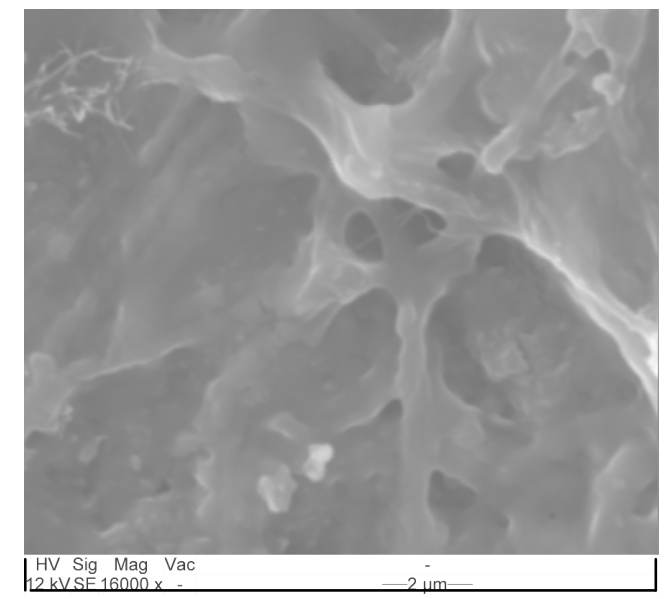

Figura 99 - Fotografia com MEV/EDS da amostra AP_CRDTRC, com aumento de 16000 vezes.

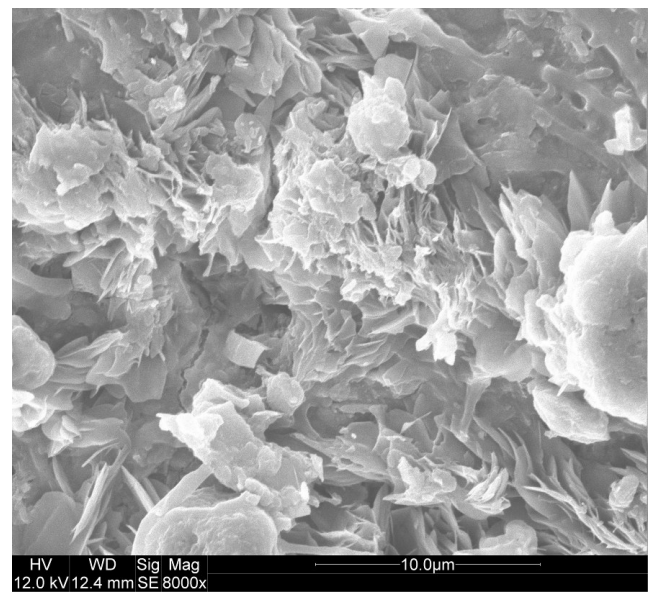

Figura 100 - Fotografia com MEV/EDS da amostra AP_CRDTRC, com aumento de 8000 vezes.

A Figura 101 representa o espectro de dispersão de energia de raios X da Figura 99, enquanto que a Tabela 15 resume os elementos encontrados neste espectro. 


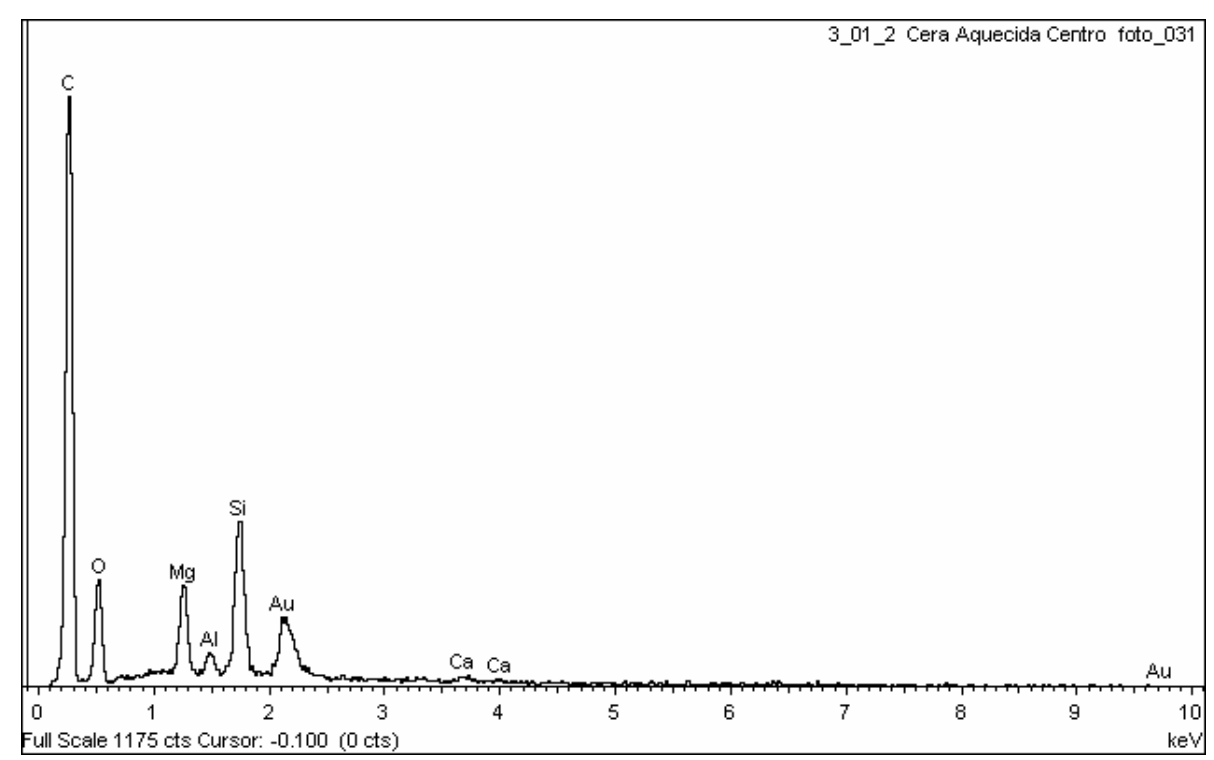

Figura 101 - Espectro de dispersão de energia de raios X da Figura 99.

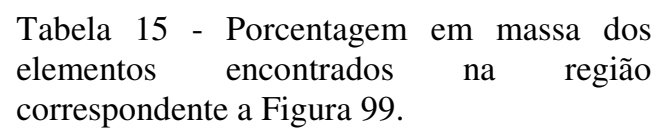

\begin{tabular}{c|c}
\hline ELEMENTO & \% MASSA \\
\hline $\mathrm{C}$ & 66,37 \\
\hline $\mathrm{O}$ & 25,55 \\
\hline $\mathrm{Mg}$ & 2,46 \\
\hline $\mathrm{Al}$ & 0,61 \\
\hline $\mathrm{Si}$ & 4,62 \\
\hline $\mathrm{Ca}$ & 0,38 \\
\hline TOTAL & 100,00 \\
\hline
\end{tabular}

Na Figura 99 pôde-se constatar que o aquecimento utilizado na restauração incorporou os fungos na mistura de ceras, resinas e pigmentos.

Na Figura 100, verificou-se uma alteração na estrutura da cera. A superfície ficou laminada. É provável que isto se deva ao calor aplicado na restauração da obra, porém no escopo deste trabalho não foi possível precisar o motivo.

Através das análises realizadas não foi encontrado nenhum material diferente de ceras e resina damar sobre a superfície das esculturas que pudesse indicar algum tipo de ligante utilizado em tintas aplicadas sobre a superfície. Provavelmente a coloração foi feita com a aplicação de pigmentos dispersos em cera diluída, ou seja: a própria cera foi utilizada como ligante da tinta de acabamento.

A Figura 102 ilustra fotografia com MEV/EDS, de uma região da cera deteriorada da cabeça da personagem Lampião (LP_CRDT), com aumentos de 159. 


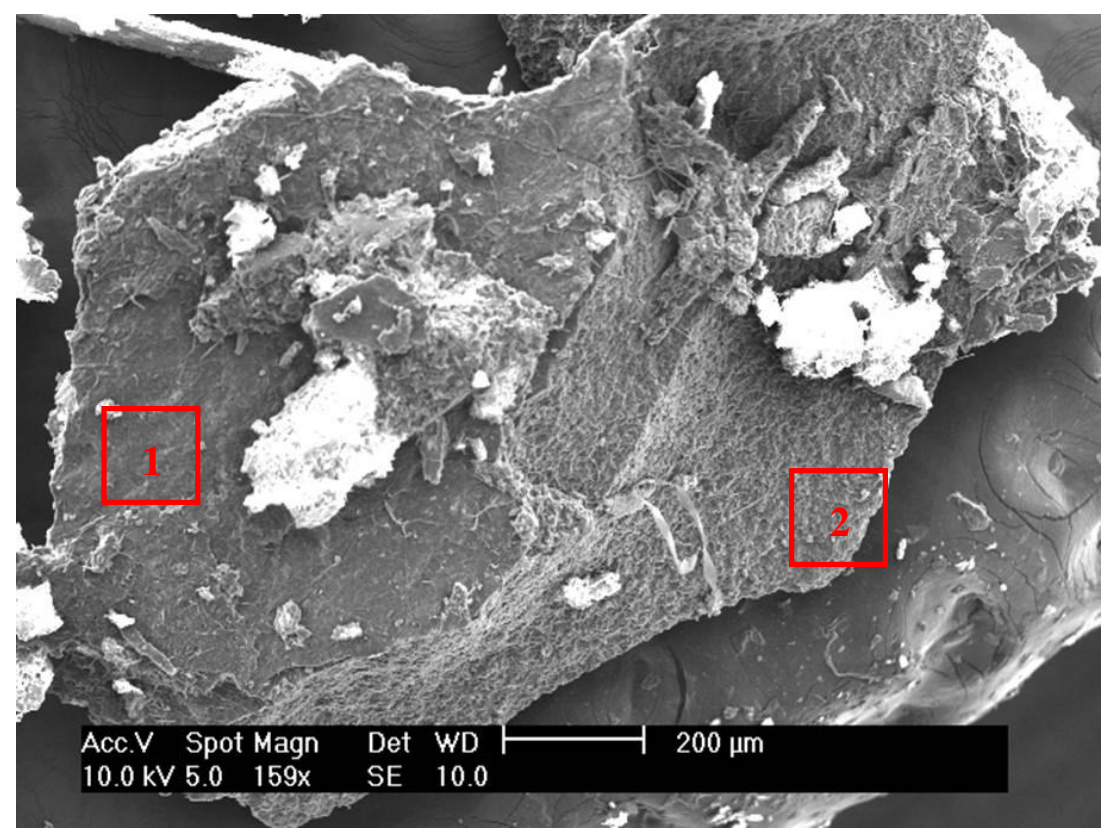

Figura 102 - Fotografia com MEV/EDS da amostra LP_CRDT, com aumento de 159 vezes.

Tabela 16 - Porcentagem em massa dos elementos encontrados na região 1 da Figura 102.

\begin{tabular}{c|c}
\hline ELEMENTO & \% MASSA \\
\hline $\mathrm{C}$ & 80,50 \\
\hline O & 19,50 \\
\hline TotAL & 100,00 \\
\hline
\end{tabular}

Tabela 17 - Porcentagem em massa dos elementos encontrados na região 2 da Figura 102.

\begin{tabular}{c|c}
\hline ELEMENTO & \% MASSA \\
\hline $\mathrm{C}$ & 82,66 \\
\hline $\mathrm{O}$ & 17,34 \\
\hline TOTAL & 100,00 \\
\hline
\end{tabular}

As Tabelas 16 e 17 apresentam os elementos encontrados em duas regiões distintas da Figura 102, região 1 e 2 , respectivemente.

Conforme já mencionado mais de uma vez, só foram encontrados carbono e oxigênio nesta amostra porque a coleta pegou parte do miolo, também deteriorado, devido à extensão do problema. 


\section{CONSIDERAÇõES FINAIS}

Neste trabalho de caracterização físico-química e analítica de materiais de esculturas de cera do Museu Alpino foi possível fazer as seguintes considerações.

Na caracterização de materiais de obras de arte feitas de cera foi necessário a utilização e associação de diferentes técnicas. Sempre que possível, as técnicas devem ser não destrutivas ou não invasivas. Caso contrário os experimentos devem ser realizados com quantidades de amostras na faixa de miligramas. Por outro lado, deve-se considerar que o trabalho de investigação científica (de obras de arte) nunca prescinde da investigação histórica, cultural, etc.

Não foi possível quantificar os diferentes tipos de cera pelas técnicas utilizadas. Porém, foi possível identificar a presença de cera de abelhas, cera de carnaúba, diferenciar amostras quanto ao teor de materiais inorgânicos e orgânicos, etc.

A alteração na aparência da cera das esculturas do Museu Alpino foi devido a fatores físicos e químicos causados pela presença de microorganismos heterótrofos, os quais usam a cera como substrato, se alimentando dos ácidos graxos presentes na mistura. Visto que a cera é uma emulsão, a diminuição dos ácidos graxos provoca uma quebra nessa emulsão modificando a micro estrutura e ocasionando perda mecânica da superfície, conseqüentemente, resultando na aparência esbranquiçada.

O simples aquecimento superficial da região esbranquiçada permitiu recuperar a aparência original porque ocorre a homogeneização da cera sem nenhuma degradação em conseqüência do procedimento adotado. $\mathrm{O}$ tratamento térmico foi realizado próximo à temperatura de fusão das ceras, fato evidenciado pelo comportamento térmico por análise térmica das possíveis matérias primas empregadas na confecção da obra.

As obras de arte, inseridas no nosso ecossistema estão sujeitas a degradações físicas químicas

e biológicas. As alterações naturais de temperatura e umidade, assim como a própria atmosfera do planeta dão origem a problemas de deterioração físico-química. As alterações de umidade e temperatura provocam movimentações nas substâncias que compõem as obras causando problemas estruturais e/ou agindo como catalisadores de reações entre os elementos que compõe a obra. A atmosfera do planeta composta entre outras coisas por oxigênio e contaminada por materiais oriundos da poluição reage com a superfície da obra danificando-a. Além disso, as obra de arte estão sujeitas à degradação biológica. Conforme explicado na Figura 5 (CANEVA, NUGARI, SALVADORI, 1991), do ponto de vista de energia, a cadeia alimentar, da qual elas fazem parte, dá origem a uma pirâmide ecológica e em cada estágio há 
uma dispersão de energia seguida da lei termodinâmica de aumento de entropia. Da mesma forma os materiais, do ponto de vista de físico-químico tendem a se converter para o estado de menor energia.

Por estas razões a conservação de materiais (ou de bens culturais) por um tempo infinito é impossível, porque a matéria tende a se reverter para o seu estado original, para uma estrutura mais simples e mais estável.

É importante considerar uma estratégia de preservação de esculturas de cera, assim como de todos os bens culturais que se quiser conservar. Para tanto é necessário antes de tudo, o controle ambiental do local onde se encontram as obras. O ideal para preservação de obras de arte seria um ambiente com um micro-clima com atmosfera anoxia e controle de umidade e temperatura.

Os microorganismos estão presentes no ar e se depositam sobre qualquer superfície, mas só se desenvolvem em condições de umidade e temperatura adequadas sobre substrato metabolizável. Não é adequado aplicar produtos antimicrobianos de efeito residual sobre as obras de arte já que estes podem também reagir com os componentes da obra.

Portanto, dentro da estratégia de conservação de bens culturais, a política de preservação por meio da utilização de atmosferas controladas é muito importante. 


\section{Perspectivas}

O universo de conservação e restauração de bens culturais é muito rico e ainda pouco estudado. No Brasil a investigação científica de obras de arte começou a ser feita há cerca de 15 ou 20 anos. A profissão ainda não é reconhecida e o primeiro curso confirmado de formação no nível de graduação será em 2008, na Universidade Federal de Minas Gerais. Ao mesmo tempo temos um vasto patrimônio que está se deteriorando, portanto, todo e qualquer estudo científico que contribua com o conhecimento dos materiais e técnicas utilizados pelos artistas assim como os processos de interação da obra com o meio ambiente e seus processos de degradação será de grande importância.

Do ponto de vista de continuação deste trabalho, já estão sendo estudados os pigmentos utilizados pelos artistas nas esculturas de cera do Museu Alpino através do método de indução de partículas por emissão de raios X (PIXE), no Laboratório de Materiais e Feixes Iônicos (LAMFI) no Instituto de Física da Universidade de São Paulo (IF/USP). Será interessante no futuro estudar o fenômeno de laminação da cera que ocorre depois da restauração. Também é importante a realização de um estudo de diferentes possibilidades de pinturas translúcidas (para dar a sensação de pele) que podem ser utilizadas nas esculturas de cera e sua interação com o suporte (cera) - adesão, etc.

É possível listar uma infinidade de perguntas à espera de respostas, mas o que sempre é fascinante é entender o que ocorre na interface obra/ar. Pesquisar as superfícies e a melhor forma de conservá-las, seja, limpando (removendo materiais adsorvidos, produtos de oxidação, etc.), seja, protegendo, com vernizes apropriados ou atmosferas controladas e/ou modificadas. 


\section{REFERÊNCIAS BIBLIOGRÁFICAS}

ASTM E1582-04 Standard practice for calibration of temperature scale for thermogravimetry, 2004.

AIRES-BARROS, L. Os monumentos e a doença da pedra. Fundação Calouste Gulbenkian, 1991. Acessado em setembro de 2007. Disponível em $<$ http://zircon.dcsa.fct.unl.pt/dspace/handle/123456789/169>

AZZAROLI, M. L., Storia della specola, in Atti de I Congresso Internazionale, La ceroplastia nella scienza e nell arte. Firenze: Leo S. Olschki Editore, 1975. Vol. XX-1. p.1-21.

BISSON, C.S., DYE, W.B. U. S. Patent, 1936. 2, p. 37-111.

BURMESTER, A. Investigation of paint media by differential scanning calorimetry (DSC), in Studies in Conservation, May, 1992. Vol. 37, N. 2. p. 73-81.

CANEVA, G., NUGARI, M., SALVADORI, O. Biology in the conservation of works of art. Rome, ICCROM, 1991. 182 p.

CASSAR, M., ROBINS, G.V., FLETTON, R.A., ALSTIN, A. Organic components in historical non-metallic seals identified using ${ }^{13}$ C-NMR spectroscopy, in Nature, 1983. 303, p. 238-239.

CASTRO, K., PÉRZ-ALONSO, M., RODRIGUEZ-LASO, M., FERNADEZ, L.A., MADARIAGA, J.M., On-line FT-Raman and dispersive Raman spectra database of artists' materials (e-VISART database), Anal Bioanal Chem., 2005. 382, p.248-258.

CHU, W.K., MAYER, J.W., NICOLET, M.A., Backscattering spectrometry, New York, Academic Press, 1978. 
CLYDESDALE, A., Beeswax: A survey of the literature on its properties and behavior, SSCR Journal, 1994. 5(2), p. 9.

COATES, J., Interpretation of infrared spectra: A practical approach, Encyclopedia of Analytical Chemistry, 2000. p. 10815-10837.

COLOMBINI, M.P., BONADUCE, I., Characterization of beeswax in works of art by gas chromatography-mass spectrometry and pyrolysis-gas chromatography-mass spectrometry procedures, in Journal of Chromatography A, 2004. 1028, p. 297-306.

DERRICK, M. R., STULIK, D., LANDRY, J.M., Infrared spectroscopy in conservation science, Los Angeles: J Paul Getty Trust Ed., 1999. 235p.

DOELEN, G. A., Molecular studies of fresh and aged triterpenoid varnishes, Amsterdam: Molart. 2002. 178p.

DUARTE, L. C., JUCHEM, P. L., PUlZI, G. M., BRUM, T. M. M., CHODUR, N., LICCARDO, A., FISCHER, A. C., ACAUAN, R. B., Aplicações de microscopia eletrônica de varredura (MEV) e sistema de energia dispersiva (EDS) no estudo de gemas: exemplos brasileiros, Porto Alegre, Pesquisas em Geociências, 2003. 30(2): p. 3-15.

EDWARDS, H. G. M., FARWELL, D. W., DAFFNER, L., Fourier-transform Raman spectroscopic study of natural waxes and resins, Spectrochimica Acta Part A: Molecular and Biomolecular Spectroscopy, 1996. Vol. 52, issue 12, p. 1639-1648.

FELLER, R. L., STOLOW, N., JONES, E. H., On picture varnishes and their solvents, National Gallery of Art, Washington, 1985. 260 p.

FERRETTI, M., Scientific investigation of works of art, Rome, Italy: ICCROM, 1993. 81p.

GATACRE, E. V., FRASER, J., Madame Tussaud's methods, in La ceroplastia nella scienza e nell arte. Firenze: Leo S. Olschki Editore, 1975. Vol. XX (2), p. 639-648. 
GIOLITO, I., IONASHIRO,M., A nomenclatura em análise térmica, parte II, in Cerâmica, 1988. p. 26.

GIOLITO, I., Revista de química industrial, 1988. 12, p. 663.

GRISWOLD, J., The history, preservation and conservation of wax artifacts in Mac Seminar, Art Conservation Program, Queens University.1992.

GUERINO, A. C., CRUZ-LANDIM, C., Ocorrência e morfologia de glândulas tegumentares no abdome de algumas abelhas (Hymenoptera: Apidae): um estudo comparado in Neotropical Entomology. Rio Claro: UNESP. 2003. 32 - 2. p. 261-267.

GUTARRA, M. L. E., CASTILHO, L.R, FREIRE, M.G., Seleção de fungos produtores de lipase por fermentação no estado sólido, Dissertação de mestrado, Rio de Janeiro, Brasil: Departamento de Bioquímica, IQ/UFRJ, 2003.

HAINES, P.J., Thermal methods of analysis principles, applications and problems. Glasgow, Blackie Academic \& Professional, 1995.

HINSCH, K.D., GULKER, G. , HELMERS, H. , Checkup for aging artwork - optical tools to monitor mechanical behavior, in Optics and lasers engineering. 2007. 45, p. 578-588.

HOOYDONK, G., Analysis with micro-Raman spectroscopy of natural organic binding media and varnishes used in art in Analytical Chimica Acta, 2000. 407, p. 261-274.

IONASHIRO,M., GIOLITO, I., Nomenclatura, padrões e apresentação dos resultados em análise térmica. , in Cerâmica, 1980. 17, p. 26.

JIMÉNEZ, J. J., BERnAL, J. L., NOZAL, M. J., TORIBIO, L., MARTIN, M. T., Physicochemical parameters for the characterization of pure beeswax and detectation of adulterations in European Journal Lipid Science Technology, 2005. 107, p. 158-166. 
JIMÉNEZ, J. J., BERNAL, J.L., BERNAL, J., NOZAL,M.J., MARTIN,M.T., Sample preparation methods for beeswax characterization by gas chromatography with flame ionization detection in Journal of chromatography A, 2006. Vol. 1129, Issue 1-2, p. 262-272. JOHANSSON, S.A.E., CAMPBELL, J.L. PIXE, A novel technique for elemental analysis. John Wiley and Sons. 1988.

KAMEDA, T., Molecular structure of crude beeswax studied by solid-state 13C NMR in Journal of Insect Science, 2004. p. 4-29.

KAUFMANN, V., Restoration of an $18^{\text {th }}$ century half life-size anatomical figure modeled in beeswax, in The Conservator 1988. 12, p. 25-30.

KAWANO, Y., Espectroscopia vibracional de absorção no infravermelho, in Técnicas de caracterização de polímeros, Artliber Editora, 2007. p. 17-39.

KIMPE, K., Jacobs, P., A., WAELKENS, M., Mass spectrometric methods prove the use of beeswax and ruminant fat in late Roman cooking pots in Journal of Chromatography A, 2002. Vol. 968, p. 151-160.

KNUUTIEN, U., NORRMAN, A., The Analysis of waxes by differential scanning calorimetry and Fourier transform infrared spectroscopy in Conservation without limits, Helsinki, Finland, XV Congress of IIC-Nordic Group, August, 2000. p. 23-26.

LARSON, L. J., SHIN, K. K., ZINK, J. I., Photoluminescence spectroscopy of natural resins and organic binding media of paintings in JAIC, 1991. p. 89-104.

MACHADO, L.D.B., MATOS, J.R., Análise térmica diferencial e calorimetria exploratória diferencial in Técnicas de caracterização de polímeros, Artliber Editora, 2004. p. 229-261.

MASSCHELEIN-KLEINER, L., Ancient binding media varnishes and adhesives, Rome, ICCROM, 1995. 110p. 
MATOS, J.R., MACHADO, L.D.B., Análise térmica - termogravimetria in Técnicas de caracterização de polímeros, Artliber Editora, 2004. p. 209-228.

McNAUGHTIN, J.L., MORTIMER, C.T., Differential scanning calorimetry. Noewalk, s.d. The Perkin-Elmer Corporation, 1975. [extraído de IRS; Physical chemistry, série 2, vol. 10, Butterwords , London, 1975.]

MILLS, J.S., WHITE, R., The organic chemistry of museum objects, second ed., Butterworths, Heinemann, 1994. 206p.

MIYANO, M.H., MOURA, M.F.V., SIQUEIRA, L., LUIZ, J.M., MATOS, J.R., Ilustração da influência da razão de aquecimento nos resultados de termogravimetria, in Química nova, 2000. Vol. 23 n $^{0} 1$, p. 113.

MIYANO, M.H., NARIMATSU, L.E.S., WANDERMUREN,M.N, MATOS, J.R., Resultados de análise elementar associados à termogravimetria, in anais da Associação Br. De Química, 1996. Vol. 45 nº 4, p. 185-190.

MONCRIEFF, A., WEAVER, G., Cleaning - Conservation science teaching series, Museums \& galleries commission, London, 1987. 128p.

MURRELL, J. V., Some aspects of the conservation of wax models in Studies in Conservation , 1971. 16, p. 95-109.

NEWEY, C., BOFF, R., DANIELS, V., PASCOE, M., TENNENT, N., Adhesives \& coatings - Conservation science teaching series, Museums \& galleries commission, London, 1987. 135p.

ODLYHA, M., The applications of thermoanalytical techniques to the preservation of art and archaeological objects in Handbook of thermal analysis and calorimetry 2, BROWN, M., Department of Chemistry, Rhodes University, South Africa GALLAGHER, P., Department of Chemistry and Materials Science \& Engineering, The Ohio State University, 
USA.,2003.942p.

Preface of especial edition of thermal analysis in the conservation of works of art, Thermochimica Acta, 365. 2000. p. ix-x.

Investigation of the binding media of paintings by thermoanalytical and spectroscopic techniques, Thermochimica Acta, 1995. Vol.269 - 270, 705 - 727, p. ix-x.

OLIVEIRA, F.F., Contribuição da análise térmica no desenvolvimento de formulações de batons. Dissertação de Mestrado. IQ/USP - 2002.

PAN, A., CHIUSSI,S., SERRA, J., GONZÁLEZ, P., LÉON, B., Calibration of Raman spectroscopy at $1064 \mathbf{~ n m}$ for beeswax quantification, Applied Spectroscopy, 2007. Vol. 61, Issue 111. p. 1259-1264.

POGGESI, M., A coleção de figuras em cera do Museu La Specola in Enyclopaedia Anatômica: Museo La Specola Florence, Colônia, Taschen. 2006. p. 46-63.

REED, S. J. B. Electron microprobe analysis and scanning electron microscopy in geology, New York, Cambridge University Press. 1996. 201 p.

REGERT, M. , LANGlOIS, J., LAVAL, E. , LÊ-HO, A.S., PAGÉS-CAMAGNA, S., Elucidation of molecular and elementary composition of organic and inorganic substances involved in 19th century wax sculptures using an integrated analytical approach, in Analytica Chimica Acta, 2006. 577, p. 140-152.

REGERT, M., LANGLOIS, J., COLINART, S., Characterization of works of art by gas chromatography procedures in Journal of Chromatography A, 2005. 1091, p. 124-136.

RIZZO, M. M., MACHADO, L. D. B., BORRELY, S. I., SAMPA, M. H. O., RELA, P. R.,FARAH, J.P.S., SCHUMACHER, R. I., Effects of gamma rays on a restored painting 
from the XVII ${ }^{\text {th }}$ century in Radiation Physics and Chemistry, Avignon, France, Pergamon Press, 2002. 63, p. 259-262.

RIZZO, M. M., “Acompanhamento por Equipamento Portátil de EDXRF de Procedimento de Restauro para Remoção de Sais Insolúveis sobre Pinturas Murais” in Um olhar contemporâneo sobre a preservação do patrimônio cultural material. Rio de Janeiro, MHN - Museu Histórico Nacional, 2008. No prelo.

Como se dá o trabalho interdisciplinar in III Revista da APCR - Associação Paulista de Conservadores e Restauradores de Bens Culturais. São Paulo. 2005. Vol.III, p. 2628.

SEBELIEN, J., Uber die Zusammensetzung eines alten von der Wikingerzeit herruhrenden norwegischen Bienenwachses aus dem Osebergschiffe in Z. Angew. Chem. 1913, Vol. 26, p. 689-692.

SILVERSTEIN, R. M., BASSLER, G. C., MORRIL, T. C., Identificação espectrométrica dos compostos orgânicos, Editora Guanabara Koogan S.A, 1991. 490 p.

SITWELL, C., STANIFORTH, S., Studies in the history of painting restoration, Archetype Publications, London, England, 1996. 180p.

THOMSON, G., The museum environment, London: Butterwoths \& Co Ltd., second edition, 1986. 293p.

TOWNSEND, J., H., Thermo microscopy applied to painting materials from the late 18th and 19th centuries in Thermochimica Acta, 2000. Vol. 365, Issue 1-2, p. 79-84.

TULlOCH, A. P., Beeswax - composition and analysis, Praire Regional Laboratoty, National Research Council of Canada, Saskatoon, Saskatchewan, Canada , 1980.

TURI, E.A., Thermal characterization of polymeric materials, Academic Press, San Diego, 1997. 
TURNER, W. R., BROWN, D. S., HARRISON, D. V., Properties of paraffin waxes, in Industrial and Engineering Chemistry, 1955. Vol. 47 nº 6, p. 1219-1225.

VANDENABEELE, P., WEHLING, B., MOENS, L., EDWARDS, H., DE REU, M., VAN HOOYDONK, G., Analysis with micro-Raman spectroscopy of natural organic binding media and varnishes used in art in Analytica Chimica Acta, 2000. 407, p. 261-274.

VANSElL, G. H., BISSON, C. S., Plant Quarentine, U. S. Dept. Agr., Bur. Entomol. 1940. E - 485 .

VOORHEES, K. J., BEVERLY, M. B., KAY, P. T., Principal component analysis of the pyrolisis-mass spectra from African, Africanized hybrid, and European beeswax, Journal of Analytical and Applied Chemistry, 1995. Vol.34, Issue 2, p. 251-263.

WATH, A. H., The chemistry and technology of waxes, Reinhold Publishing Corporation, New York USA, 1947. 519 p.

WEAVER, G., ASHELEY-SMITH, J., JOY, A., STANIFORTH, S., BARKER, A., An introduction to materials - Conservation science teaching series, Museums \& galleries commission, London, 1987. 112 p.

WENDLANDT, W.W., Thermal analysis, Jonh Wiley \& Sons, Inc, New York, 1986. 